\title{
Alocação de Recursos em uma Arquitetura Óptica Cloud-Fog RAN para o Suporte da Internet 5G
}

\author{
Rodrigo Izidoro Tinini
}

TESE APRESENTADA

$\mathrm{AO}$

Instituto DE MATEMÁticA E EstatísticA

DA

UNIVERSIDADE DE SÃo PAULO

PARA

OBTENÇÃO DO TÍTULO

$\mathrm{DE}$

DOUTOR EM CIÊNCIAS

\author{
Programa: Doutorado em Ciência da Computação \\ Orientador: Prof. Dr. Daniel Macêdo Batista \\ Coorientador: Prof. Dr. Gustavo Bittencourt Figueiredo
}

Durante o desenvolvimento deste trabalho o autor recebeu auxílio financeiro da CAPES e da Hewlett Packard Enterprise - HPE

São Paulo, agosto de 2019 


\section{Alocação de Recursos em uma Arquitetura Óptica Cloud-Fog RAN para o Suporte da Internet 5G}

Esta versão da tese contém as correções e alterações sugeridas pela Comissão Julgadora durante a defesa da versão original do trabalho, realizada em 21/08/2019. Uma cópia da versão original está disponível no Instituto de Matemática e Estatística da Universidade de São Paulo.

Comissão Julgadora:

- Prof. Dr. Daniel Macêdo Batista - IME-USP

- Prof. Dr. Alfredo Goldman Vel Lejbman - IME-USP

- Prof. Dr. Edmundo Roberto Mauro Madeira - Unicamp

- Prof. Dr. Gustavo Souza Pavani - UFABC

- Prof. Dr. Carlos Alberto Kamienski - UFABC 


\title{
FICHA CATALOGRÁFICA
}

\author{
Tinini, Rodrigo Izidoro \\ T587 Alocação de recursos em uma arquitetura óptica cloud-fog RAN para o suporte da \\ Internet 5G / Rodrigo Izidoro Tinini; orientador Daniel Macêdo Batista; coorientador \\ Gustavo Bittencourt Figueiredo. -- São Paulo, 2019. \\ $148 \mathrm{f}$.
}

Tese (Doutorado) - Programa de Pós-Graduação em Ciência da Computação, Universidade de São Paulo.

1. Redes ópticas. 2. Redes 5G. 3. Fronthaul óptico. 4. Computação em nuvem. 5. Computação em névoa. I. Batista, Daniel Macêdo, orient. II. Figueiredo, Gustavo Bittencourt, coorient. III. Universidade de São Paulo. IV. Título.

Elaborada pelo Serviço de Informação e Biblioteca Carlos Benjamin de Lyra do IME-USP, pela bibliotecária Eliana Mara Martins Ramalho CRB-8/4819 


\section{A onipresença e a onipotência de Deus Salmo 139}

Senhor, tu me sondaste, e me conheces.

Tu conheces o meu assentar e o meu levantar: de longe entendes o meu pensamento.

Cercas o meu andar, e o meu deitar; e conheces todos os meus caminhos.

Sem que haja uma palavra na minha língua, eis que, ó Senhor, tudo conheces.

Tu me cercaste em volta; e puseste sobre mim a tua mão.

Tal ciência é para mim maravilhosíssima; tão alta que não a posso atingir.

Para onde me irei do teu Espírito, ou para onde fugirei da tua face?

Se subir ao céu, tu aí estás; se fizer no Seol a minha cama, eis que tu ali estás também.

Se tomar as asas da alva, se habitar as extremidades do mar.

Até ali a tua mão me guiará e a tua destra me susterá.

Se disser: De certo que as trevas me encobrirão; então a noite será luz à roda de mim.

Nem ainda as trevas me escondem de ti: mas a noite resplandece como o dia; as trevas e a luz são para ti a mesma coisa.

Pois possuíste os meus rins; entreteceste-me no ventre da minha mãe.

Eu te louvarei, porque de um modo terrível, e tão maravilhoso fui formado; maravilhosas são as tuas obras, e a minha alma o sabe muito bem.

Os meus ossos não te foram encobertos, quando no oculto fui formado, e entretecido como nas profundezas da terra.

Os teus olhos viram o meu corpo ainda informe, e no teu livro todas estas coisas foram escritas; as quais iam sendo dia-a-dia formadas, quando nem ainda uma delas havia.

E quão preciosos me são, ó Deus, os teus pensamentos! Quão grandes são as somas deles!

Se as contasse, seriam em maior número do que a areia: quando acordo ainda estou contigo.

Ó Deus! tu matarás de certo o ímpio: apartaivos portanto de mim, homens de sangue.

Pois falam malvadamente contra ti; e os teus inimigos tomam o teu nome em vão.

Não aborreço eu, ó Senhor, aqueles que te aborrecem, e não me aflijo por causa dos que se levantam contra ti?

Aborreço-os com ódio completo: tenho-os por inimigos.

Sonda-me, ó Deus, e conhece o meu coração: prova-me, e conhece os meus pensamentos.

E vê se há em mim algum caminho mau, e guia-me pelo caminho eterno. 


\section{Agradecimentos}

Então, após 4 longos anos, esta Tese está concluída. Confesso que esta era a seção da Tese que eu mais ansiava por escrever, pois aqui iria agradecer a todos que me ajudaram a concluir este trabalho que representa a maior jornada até então tomada por mim.

Primeiramente, agradeço a Deus, criador de todas as coisas, e a Seu santo Filho Jesus Cristo por terem me amado e me concedido tão sublime sorte nesta terra. Por toda a força, condição e ânimo durante a execução deste trabalho, por todas as promessas cumpridas e por todo o bem que eu pude desfrutar durante o meu doutorado.

Aos meus pais, Josias e Vânia, pelo amor incondicional, pelo apoio sempre presente e por sempre me incentivarem e acreditarem no meu sonho. Como escrevi nos agradecimentos da minha dissertação de mestrado, novamente aqui o digo: este trabalho não é meu, é de vocês. Vocês são o maior amor da minha vida e eu sempre irei amá-los. Não há palavras para agradecer a vocês, por todo o sacrifício durante a nossa vida, por todo o amor, por todas as dificuldades que passamos juntos... A vocês eu dedico este trabalho, a vocês eu dedico o maior trabalho que fiz até hoje! Amo vocês e sempre irei amar!

À minha irmã Sarah, por todo o amor e claro, por você existir e ser minha irmã. Amo você e você é um presente de Deus à nossa família.

Aos meus avós, paternos e maternos, por todo o amor e por toda boa criação. Em especial ao meu avô José Izidoro, que descansou de seu combate durante o desenvolvimento desta pesquisa. Por todo amor, por todo incentivo ao estudo, a uma vida honesta, por nos ensinar o amor e a paciência de Deus. Ah, por todas as enciclopédias que o senhor comprou quando eu ainda nem era nascido, mas que despertaram em mim a curiosidade pela ciência quando eu ficava olhando curioso as fotos do espaço e desenhos de constelações! Eu te amo, te amo e sempre te amarei por todos os dias da minha vida. Como eu gostaria que o senhor estivesse aqui, Vô, para ver onde os seus sonhos chegaram! O senhor foi o melhor Vô que alguém poderia ter e eu sou a pessoa mais rica deste Universo por ter sido seu neto. Eu te amo e sempre te amarei, e quando nos encontrarmos novamente, irei te abraçar tão forte e te direi que te amo!

À Esther, o grande amor da minha vida. Por todo o amor e apoio recebido durante esta pesquisa, por me ouvir nos meus momentos de ansiedade e desespero e por sempre fortalecer a minha fé com boas palavras, por sempre acreditar em mim. A época em que nos conhecemos foi especial na minha pesquisa e principalmente na minha vida! Eu te amo e espero que você ainda veja eu colher muitos frutos a partir deste doutorado. Também agradeço aos seus pais, sua irmã e toda a sua família por todo o carinho e por terem me recebido com tanto amor. Amo vocês!

Ao meu primo Eliézer, por todas as partidas de Rainbow Six Siege jogadas nestes anos e que foram cruciais para aliviar a tensão durante o doutorado!

Aos meus tios, tias, primos e primas, por todo o amor e boa companhia durante toda a minha 
vida.

Ao meu pequeno amigo Toby, que infelizmente me deixou durante este trabalho. Foi uma alegria ter você como nosso amigo e desfrutar do seu vigor e felicidade durante todos os anos em que esteve nos alegrando com seu amor puro e sincero! Você nos fez muito feliz!

Ao meu pequeno amigo Buzz, por sempre morder o meu pé quando eu chego em casa e por sempre me fazer companhia, deitado na minha cama atrás de mim enquanto eu trabalhava na pesquisa ou escrevia a Tese! Você nos faz muito feliz!

Ao meu orientador, professor Daniel Macêdo Batista, pela oportunidade concedida, por todo o ensinamento passado e por todo o apoio durante o meu doutorado. Por ter acreditado no meu tema de pesquisa e me ajudado a crescer como pesquisador, pela excelente orientação que foi crucial para o desenvolvimento deste trabalho. Eu espero ser um pesquisador como você algum dia e ser uma inspiração para meus futuros alunos, como você é para mim.

Ao meu coorientador, professor Gustavo Bittencourt Figueiredo, por todo o ensinamento passado, por sempre contribuir de forma extraordinária para as ideias que eu tive durante o doutorado, por todo o apoio nos momentos de ansiedade que tive, por ter sido um amigo durante o meu doutorado. Espero que possamos colher muitos frutos ainda e escrever muitos bons artigos que tragam ideias e resultados incríveis! Eu também espero ser um pesquisador como você algum dia e também ser uma inspiração como você é para mim.

Ao professor Marco Dimas Gubitoso, por todas as ótimas conversas que tínhamos sobre filmes, jogos e livros durante o período em que fui seu monitor.

Aos professores Massimo Tornatore e Biswanath Mukherjee pela parceria na minha pesquisa e pelas extraordinárias contribuições ao meu trabalho e às minhas publicações.

Aos professores Alfredo Goldman, Edmundo Madeira, Gustavo Pavani e Carlos Kamienski pela participação na minha banca e por todos os comentários que ajudaram a melhorar esta Tese.

A todos os funcionários do IME, por sempre me atenderem com atenção e cordialidade durante o doutorado.

A todos os professores e alunos do grupo de Sistemas, por todas as frutíferas reuniões e por todos os comentários que vieram a ajudar no desenvolvimento da minha pesquisa.

Agradeço à Coordenação de Aperfeiçoamento de Pessoal de Nível Superior (CAPES), à Hewlett Packard Enterprise (HPE) e ao INCT da Internet do Futuro para Cidades Inteligentes financiado por CNPq proc. 465446/2014-0, CAPES - Auxílio 001, FAPESP proc. 14/50937-1 e FAPESP proc. 15/24485-9 pelo auxílio financeiro recebido durante o desenvolvimento deste trabalho.

Por fim, a todos os professores e pesquisadores citados aqui e que me inspiram na carreira acadêmica, dedico a seguinte frase de Isaac Newton: "Se enxerguei mais longe, foi porque me apoiei sobre os ombros de gigantes!" 
"E eu, João, vi a santa cidade, a nova Jerusalém, que de Deus descia do céu, adereçada como uma esposa ataviada para o seu marido. E ouvi uma grande voz do céu, que dizia: Eis aqui o tabernáculo de Deus com os homens, pois com eles habitará, e eles serão seu povo, e o mesmo Deus estará com eles, e será o seu Deus. E Deus limpará de seus olhos toda a lágrima, e não haverá mais morte, nem pranto, nem clamor, nem dor; porque já as primeiras coisas são passadas." 


\section{Resumo}

TININI, R. I. Alocação de Recursos em uma Arquitetura Óptica Cloud-Fog RAN para o Suporte da Internet 5G. 2019. 148 f. Tese de Doutorado - Instituto de Matemática e Estatística, Universidade de São Paulo, São Paulo, 2019.

A futura Internet $5 \mathrm{G}$ vem demandando novos esforços dos operadores de telecomunicações por conta do grande tráfego esperado em tal rede. Arquiteturas de redes de acesso a rádio (Radio Access Networks (RAN)) baseadas em computação em nuvem (Cloud Radio Access Networks (CRAN)) já vêm sendo utilizadas para lidar com a grande cobertura demandada por essas redes ao mesmo tempo em que busca-se uma operação energeticamente eficiente, centralizando o processamento de sinais de banda-base em uma nuvem. Entretanto, a centralização do processamento de banda-base na arquitetura CRAN pode levar a sobrecargas em seus recursos de processamento, chamados de Unidades de Banda-Base (BaseBand Units (BBUs)), e na rede de transporte óptica, chamada de fronthaul, responsável por interconectar as antenas remotas da rede (Remote Radio Heads (RRHs)) à nuvem, degradando dessa forma as rígidas restrições de latência esperadas em redes $5 \mathrm{G}$ e levando até mesmo ao bloqueio de requisições por falta de recursos computacionais ou de rede.

Esta Tese introduz uma nova arquitetura de rede chamada de Cloud-Fog RAN (CF-RAN) que busca estender as capacidades da CRAN por meio dos paradigmas de computação em névoa, para prover processamento local de banda-base, e de Virtualização de Funções de Rede (Network Functions Virtualization (NFV)), para realizar a ativação e desativação dinâmica das funções de processamento locais.

Formulações baseadas em Programação Linear Inteira (Integer Linear Programming (ILP)) e heurísticas baseadas em teoria dos grafos e relaxações lineares são propostas para realizar a alocação dos recursos de rede e processamento da CF-RAN. A eficácia dos algoritmos propostos foram verificados por meio de execuções das formulações ILP e de simulações. Os resultados mostraram que a arquitetura CF-RAN é capaz de aumentar a cobertura de atendimento de uma rede $5 \mathrm{G}$ em comparação à CRAN, além de prover eficiência energética, baixa latência e otimizar a utilização tanto dos recursos de rede como de processamento.

Palavras-chave: Redes Ópticas, Redes 5G, Fronthaul Óptico, Computação em Nuvem, Computação em Névoa, CRAN, CF-RAN. 


\section{Abstract}

TININI, R. I. Resource Allocation in a Cloud-Fog RAN Optical Architecture on the Support of 5G Internet. 2019. 148 f. Ph.D. Dissertation - Instituto de Matemática e Estatística, Universidade de São Paulo, São Paulo, 2019.

The forthcoming $5 \mathrm{G}$ Internet has been demanding new efforts from telecommunication operators due to the intense traffic expected in this network. Radio Access Architectures - (RAN) based in cloud computing (Cloud Radio Access Networks - CRAN) has been adopted to deal with the increasingly coverage demanded by these networks, while a energy-efficient operation is achieved by the centralization of baseband processing signals in a cloud. However, the centralization of baseband processing in CRAN may lead to overloads in its processing resources, called BaseBand Units (BBUs), and in the transport network, known as the fronthaul, responsible for interconnecting the network Remote Radio Heads (RRHs) to the cloud, degrading the strict latencies restrictions expected in $5 \mathrm{G}$ networks and even leading to blocking of requisitions due to lack of processing and network resources.

This dissertation introduce a new network architecture called Cloud-Fog RAN (CF-RAN) that extends the capacities of CRAN by the paradigms of fog computing, to promote local baseband processing, and Network Functions Virtualization (NFV), to perform a dynamic activation and deactivation of local processing functions.

Integer Linear Programming (ILP) formulations and heuristics based on graph theory and linear relaxations are proposed to perform the allocation of network and processing resources in CF-RAN. The efficiency of the proposed algorithms was evaluated by executions of the ILP formulation and simulations. Results showed that CF-RAN can increase the network coverage of a $5 \mathrm{G}$ network in comparison to CRAN, besides providing energy efficiency, low latency and optimizing the usage of network and processing resources.

Keywords: Optical Networks, 5G Networks, Optical Fronthaul, Cloud Computing, Fog Computing, CRAN, CF-RAN. 


\section{Sumário}

Lista de Acrônimos $\quad$ xiii

Lista de Figuras $\quad$ xvii

Lista de Tabelas $\quad$ xxi

1 Introdução $\quad 1$

1.1 Motivação . . . . . . . . . . . . . . . . . . . . . . . . . 4 4

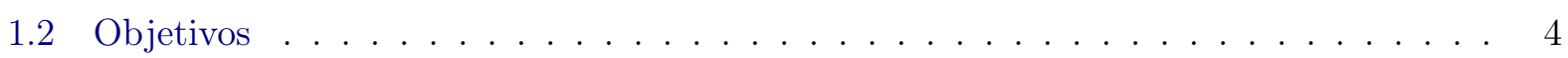

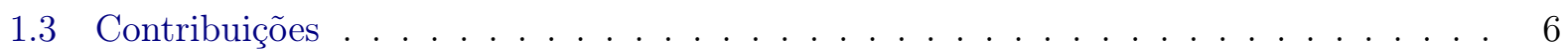

1.4 Organização da Tese . . . . . . . . . . . . . . . . . . . 6

1.5 Publicações realizadas e prêmios recebidos durante o desenvolvimento da Tese . . . . 7

2 Trabalhos Relacionados $\quad 9$

3 Conceitos Básicos $\quad 15$

3.1 Redes Ópticas Passivas . . . . . . . . . . . . . . . . . . . . . . . . 15

3.1.1 Principais componentes de uma Passive Optical Network (PON) . . . . . . 17

3.1.2 Tecnologias atuais e tecnologias futuras para as PONs . . . . . . . . . . 18

3.1 .3 Redes NG-PON e TWDM-PON . . . . . . . . . . . . . . . . . . . . . . 19

3.1.4 Virtualização das Redes Ópticas Passivas - VPON . . . . . . . . . . . . . . . 20

3.2 Cloud Radio Access Network - CRAN . . . . . . . . . . . . . . . . . . 20

4 Arquitetura Cloud-Fog RAN $\quad 23$

4.1 Organização geral da arquitetura CF-RAN . . . . . . . . . . . . . . . . . . 23

4.2 Arquitetura do fronthaul TWDM-PON . . . . . . . . . . . . . . . . . . . . 24

4.2 .1 Arquitetura dos nós de processamento . . . . . . . . . . . . . . . . . 27

4.3 Alocação de vBBUs e dimensionamento de comprimentos de onda e formação de VPONs energeticamente eficiente . . . . . . . . . . . . . . . . 28

4.4 Modelo de avaliação de desempenho . . . . . . . . . . . . . . . . . . . . . 31

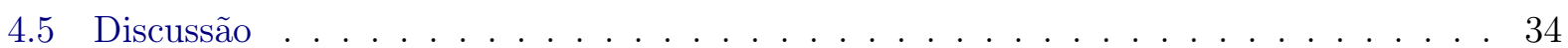

5 Formulação de Programação Linear Inteira (ILP) para Solução dos Problemas de Alocação de vBBUs e Formação de VPONs $\quad 35$

5.1 Formulação do problema . . . . . . . . . . . . . . . . . . . . . . 35

5.2 Formulação ILP . . . . . . . . . . . . . . . . . . . . . . . . . . 36 
6 Heurística Baseada em Teoria dos Grafos $\quad 41$

6.1 Definição do grafo direcionado que representa a arquitetura CF-RAN . . . . . . . . . 41

6.1.1 Heurística para o dimensionamento de comprimento de onda para tráfego

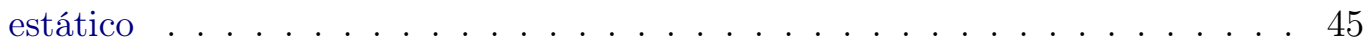

6.1.2 Heurísticas para o dimensionamento de comprimento de onda em cenários de tráfego dinâmico . . . . . . . . . . . . . . . . . . . . . 47

7 Avaliação da Formulação ILP e Heurísticas Baseadas em Teoria dos Grafos 49

7.1 Avaliação do dimensionamento dos comprimentos de onda . . . . . . . . . . . . . . 49

7.2 Alocação de vBBUs e criação de VPONs . . . . . . . . . . . . . . . . . . 55

$7.2 .1 \quad$ Discussão . . . . . . . . . . . . . . . . . . . . . . . . . . . 59

7.3 Avaliação das heurísticas em cenários de tráfego dinâmico . . . . . . . . . . . . . 60

7.3 .1 Discussão . . . . . . . . . . . . . . . . . . . . . . . 67

8 Impacto da Migração de vBBUs e Reconfiguração de VPONs $\quad 69$

8.1 Mecanismo de ativação da migração de carga de trabalho . . . . . . . . . . . . . . 72

8.2 Formulação ILP para a migração de vBBUs e reconfiguração das VPONs . . . . . . . 73

8.2 .1 Variáveis de entrada . . . . . . . . . . . . . . . . . . . 73

8.2 .2 Variáveis de decisão . . . . . . . . . . . . . . . . . . . . . . 73

8.2 .3 Função objetivo . . . . . . . . . . . . . . . . . . . . . . . . . . . . 74

8.2 .4 Restrições . . . . . . . . . . . . . . . . . . . . . . . . 74

8.3 Relaxação da formulação ILP para migração de cargas de trabalho . . . . . . . . . 78

9 Avaliação da Migração de vBBUs e Reconfiguração de VPONs $\quad 87$

9.1 Resultados acerca da formulação ILP para migração de tráfego . . . . . . . . . . . 87

9.1 .1 Discussão . . . . . . . . . . . . . . . . . . . . . . . 95

10 Avaliação da Relaxação da Formulação ILP $\quad 97$

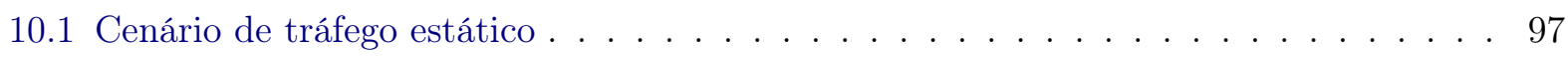

10.1 .1 Discussão . . . . . . . . . . . . . . . . . . . . . . . 103

10.2 Cenário de tráfego dinâmico . . . . . . . . . . . . . . . . . . . 104

10.2 .1 Discussão . . . . . . . . . . . . . . . . . . . . . . . . . . 113

11 Conclusões $\quad 115$

11.1 Trabalhos futuros . . . . . . . . . . . . . . . . . 116

Referências Bibliográficas $\quad 119$ 


\section{Lista de Acrônimos}

3GPP 3rd Generation Partnership Project

A-PON Asynchronous Transfer Mode Passive Optical Network

ADSL Assymetrical Digital Subscriber Line

AG-VF Aggregation Groups VPON Formation

ATM Asynchronous Transfer Mode

B-PON Broadband Passive Optical Network

BBU BaseBand Unit

CAPEX Capital Expenditure

CF-FL Cloud First-Fog Least

CF-RAN Cloud/Fog Radio Access Network

CO Central Office

CoMP Coordinated Multipoint

CPRI Common Public Radio Interface

CRAN Cloud Radio Access Network

CWDM Coarse Wavelength Division Multiplexing

DBA Dynamic Bandwidth Allocation

DRAN Distributed Radio Access Network

DWDM Dense Wavelength Division Multiplexing

EPON Ethernet Passive Optical Network

FgF Fog-First

FRAN Fog Radio Access Network

FSAN Full Service Access Network

FTTB Fiber to the Building 
FTTC Fiber to the Curb

FTTH Fiber to the Home

FTTx Fiber to the $\mathrm{x}$

GPON Gigabit Passive Optical Network

H-CRAN Heterogeneous Cloud Radio Access Network

HARQ Hybrid Automatic Repeat Request

HFC Hybrid Fiber Coax

IEEE Institute of Electrical and Electronics Engineers

ILP Integer Linear Programming

IoT Internet of Things

LC Line Card

LL Least Loaded

LM Live Migration

LTE Long-Term Evolution

ML Most Loaded

MIMO Multiple Input - Multiple Output

NFV Network Function Virtualization

NG-PON Next-Generation Passive Optical Network

OLT Optical Line Terminal

ONU Optical Network Unit

OPEX Operational Expenditure

PON Passive Optical Network

QoS Quality of Service

RAM Random Access Memory

RAN Radio Access Network

RRH Remote Radio Head

RWA Routing and Wavelength Assignment

TDM Time Division Multiplexing

TWDM-PON Time and Wavelength Division Multiplexing Passive Optical Network 
vBBU Virtualized BaseBand Unit

VDU Virtual Digital Unit

VPF Virtualized Processing Functions

VPON Virtualized Passive Optical Network

WDM Wavelength Division Multiplexing 


\section{Lista de Figuras}

1.1 Evolução das arquiteturas de redes móveis . . . . . . . . . . . . . . . . . . . . 2

1.2 Arquitetura CRAN . . . . . . . . . . . . . . . . . . . 3

3.1 Exemplo de uma rede WDM com diferentes comprimentos de onda (Lambdas) sendo transmitidos na mesma fibra óptica . . . . . . . . . . . . . . . . . . 16

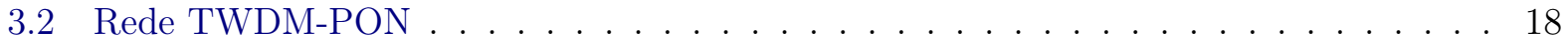

4.1 Panorama geral da arquitetura CF-RAN . . . . . . . . . . . . . . . . 24

4.2 As duas opções de conexão dos RRHs às ONUs . . . . . . . . . . . . . . . . . . . 25

4.3 Detalhes dos nós de processamento . . . . . . . . . . . . . . . . . . 26

4.4 Colisão de comprimentos de onda no fronthaul da arquitetura CF-RAN . . . . . . 30

6.1 Grafo direcionado representando a arquitetura CF-RAN como uma rede de fluxo . . 43

7.1 Consumo de energia e quantidade de RRHs atendidos (capacidade da nuvem $=30 \mathrm{e}$

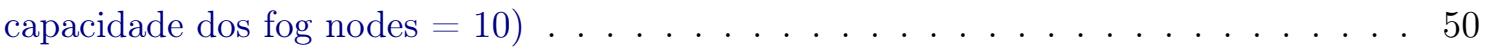

7.2 Quantidade de VPONs (capacidade da nuvem $=30$ e capacidade dos fog nodes $=10) 50$

7.3 Quantidade de nós ativos (capacidade da nuvem $=30$ e capacidade dos fog nodes $=$

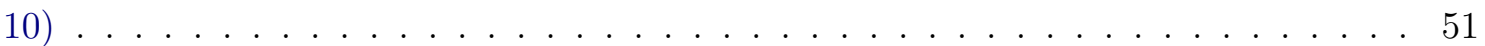

7.4 Consumo de energia e quantidade de RRHs atendidos (capacidade da nuvem $=10 \mathrm{e}$

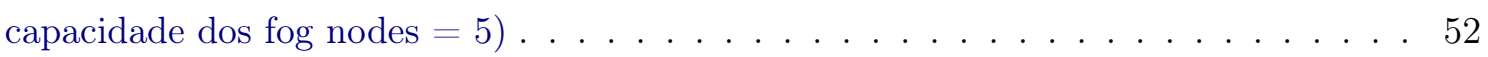

7.5 Quantidade de VPONs (capacidade da nuvem $=10$ e capacidade dos fog nodes $=5$ ) 53

7.6 Quantidade de nós ativos (capacidade da nuvem $=10$ e capacidade dos fog nodes $=5$ ) 53

7.7 Densidade de VPONs por nós ativos para o cenário de maior capacidade de processamento na nuvem . . . . . . . . . . . . . . . . . . . . . 5 54

7.8 Consumo de energia para maiores e menores capacidades de processamento _ . . . . 55

7.9 Crescimento do tempo de execução . . . . . . . . . . . . . . . . . . . . . 56

7.10 Consumo de energia para diferentes quantidades de RRHs e considerando grupos de agregação de 4 RRHs para a política AG-VF . . . . . . . . . . . . . . . 56

7.11 Comparação do consumo de energia entre a formulação ILP e a heurística CF-FL para diferentes escalas da CF-RAN . . . . . . . . . . . . . . . . . 57

7.12 Comparação dos tempos de execução entre a formulação ILP e a heurística CF-FL para diferentes escalas da CF-RAN . . . . . . . . . . . . . . . . . 58

7.13 Tempos de execução da heurística CF-FL para diferentes escalas da CF-RAN . . . . 59

7.14 Trade off entre consumo de energia e latência mínima média para a transmissão de

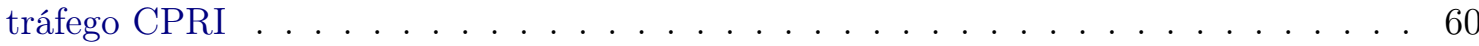


7.15 Padrão diário de tráfego . . . . . . . . . . . . . . . . . . . . . . 61

7.16 Consumo de energia das heurísticas da CF-RAN e CRAN . . . . . . . . . . . 61

7.17 Probabilidade de bloqueio para as heurísticas da CF-RAN e CRAN . . . . . . . . . 62

7.18 Latência média de propagação . . . . . . . . . . . . . . . . . . . 63

7.19 Trade off entre latência e consumo de energia para a heurística Fog First . . . . . . . 64

7.20 Trade off entre latência e consumo de energia para a heurística Most Loaded . . . . . 64

7.21 Trade off entre latência e consumo de energia para a heurística Least Loaded . . . . 65

7.22 Trade off entre latência e probabilidade de bloqueio para a heurística Fog First . . . 66

7.23 Trade off entre latência e probabilidade de bloqueio para a heurística Most Loaded . 66

7.24 Trade off entre latência e probabilidade de bloqueio para a heurística Least Loaded . 67

8.1 Desbalanceamento de cargas de trabalho entre as VDUs 1 e 2, além da presença de mais VPONs do que o necessário para as transmissões a essas VDUs . . . . . . . . . 69

8.2 a) Nós de processamento desbalanceados antes da migração de vBBUs b) Nós de processamento balanceados após a migração de vBBUs . . . . . . . . . . . . . 70

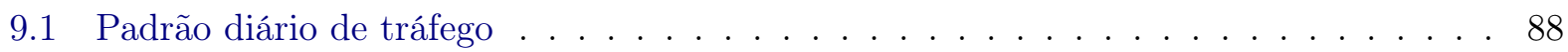

9.2 Consumo de energia quando a comutação entre VDUs é minimizada . . . . . . . . . 88

9.3 Consumo de energia quando a criação de VPONs é minimizada . . . . . . . . . . . . 89

9.4 Probabilidade de bloqueio quando a comutação entre VDUs é minimizada . . . . . . 90

9.5 Probabilidade de bloqueio quando a criação de VPONs é minimizada . . . . . . . . . 90

9.6 Desperdício da largura de banda quando a comutação entre VDUs é minimizada . 91

9.7 Desperdício da largura de banda quando a criação de VPONs é minimizada . . . . . 91

9.8 Média de migrações de vBBUs para a nuvem quando a comutação entre VDUs é minimizada . . . . . . . . . . . . . . . . . . . . 92

9.9 Média de migrações de vBBUs para a nuvem quando a criação de VPONs é minimizada 93

9.10 Tempo médio de interrupção de serviço quando a comutação entre VDUs é minimizada 93

9.11 Tempo médio de interrupção de serviço quando a criação de VPONs é minimizada 94

9.12 Probabilidade do serviço ser interrompido quando a comutação entre VDUs é minimizada . . . . . . . . . . . . . . . . . . 94

9.13 Probabilidade do serviço ser interrompido quando a criação de VPONs é minimizada 95

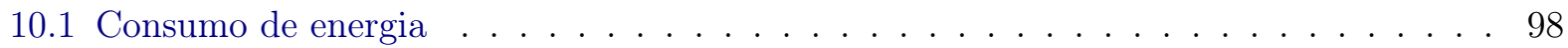

10.2 Probabilidade de bloqueio . . . . . . . . . . . . . . . . . . . . 99

10.3 Quantidade de fluxos CPRI redirecionados entre VDUs . . . . . . . . . . . . . . . 99

10.4 Taxa de desperdício de largura de banda . . . . . . . . . . . . . . . 100

10.5 Taxa de desperdício da capacidade de processamento . . . . . . . . . . . . . . 101

10.6 Quantidade de nós de processamento ativados . . . . . . . . . . . . . . . . 101

10.7 Quantidade de VPONs ativadas . . . . . . . . . . . . . . . . . . . 102

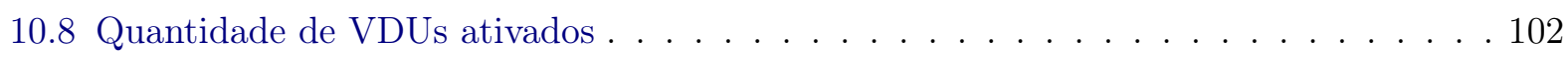

10.9 Tempo de execução . . . . . . . . . . . . . . . . . . . . . . . . 103

10.10Tempo de execução da política minVPON e relaxações . . . . . . . . . . . . . . . . 104

10.11Tempo de execução das relaxações . . . . . . . . . . . . . . . . . . . 104 
10.12Consumo de energia das relaxações e ILP no cenário dinâmico, política minRedir e heurística relaxada relaxedMinRedir . . . . . . . . . . . . . . . . . 105

10.13Consumo de energia das relaxações e ILP no cenário dinâmico, política minVPON e heurística relaxada relaxedMinVPON . . . . . . . . . . . . . . . 106

10.14Probabilidade de bloqueio das relaxações e ILP no cenário dinâmico, política minRedir106 10.15Probabilidade de bloqueio das relaxações e ILP no cenário dinâmico, política minVPON107 10.16Quantidade de migrações das relaxações e ILP no cenário dinâmico, política minRedir108 10.17Quantidade de migrações das relaxações e ILP no cenário dinâmico, política minVPON108 10.18Tempo médio de interrupção de serviços das vBBUs das relaxações e ILP no cenário dinâmico, política minRedir ． . . . . . . . . . . . . . . . . 109

10.19Tempo médio de interrupção de serviços das vBBUs das relaxações e ILP no cenário dinâmico, política minVPON ． . . . . . . . . . . . . . . . . 109

10.20Probabilidade de interrupção de serviços das vBBUs das relaxações e ILP no cenário dinâmico, política minRedir, em escala logarítmica ～. . . . . . . . . . . . . 110

10.21Probabilidade de interrupção de serviços das vBBUs das relaxações e ILP no cenário dinâmico, política minVPON, em escala logarítmica . . . . . . . . . . . . . 110

10.22Desperdício de largura de banda das relaxações e ILP no cenário dinâmico, política minRedir . . . . . . . . . . . . . . . . . . . . . . 111

10.23Desperdício de largura de banda das relaxações e ILP no cenário dinâmico, política $\operatorname{minVPON} \ldots \ldots \ldots \ldots \ldots \ldots$

10.24Tempos de execução das relaxações e ILP no cenário dinâmico, política minRedir . 112 10.25Tempos de execução das relaxações e ILP no cenário dinâmico, política minVPON . 113 


\section{Lista de Tabelas}

2.1 Comparação com os trabalhos relacionados . . . . . . . . . . . . . . . . 13

4.1 Latência do processamento de banda-base . . . . . . . . . . . . . . . . . . . . 27

4.2 Custo energético dos elementos da CF-RAN . . . . . . . . . . . . . . . 32

10.1 Quantidade de RRHs, nós de processamento e comprimentos de onda . . . . . . . . . 97 
xxii LISTA DE TABELAS 


\section{Capítulo 1}

\section{Introdução}

As primeiras redes de acesso a rádio - Radio Access Network (RAN), ou redes celulares, foram propostas há cerca de 40 anos, com o objetivo de proporcionar cobertura abrangente aos usuários e lidar com a mobilidade dos recursos conectados a elas $\left[\mathrm{PLJ}^{+} 14 \mathrm{a}\right]$.

Como ilustrado na Figura 1.1, tais redes são formadas por estações base, ou células, equipadas com antenas, que recebem e transmitem sinais de equipamentos móveis, e unidades de processamento de banda-base, chamadas de BaseBand Unit (BBU) [NYW15], que realizam o processamento dos sinais de rádio recebidos dos equipamentos dos usuários. Como mostrado na Figura 1.1, na presente quarta geração de redes celulares, o processamento de banda-base pode ser realizado de forma centralizada em uma única célula da rede ou de forma colaborativa por diversas células da rede, enquanto que nas gerações anteriores, o processamento dos dados agregados em uma célula era realizado localmente, em BBUs que eram instaladas juntamente com as antenas, a chamada arquitetura Distributed Radio Access Network (DRAN) (Redes de Acesso a Rádio Distribuídas).

A capacidade de prover processamento colaborativo entre as células da rede possibilita que uma rede móvel seja capaz de implementar poderosas técnicas de mitigação de interferência e diminuição da queda de serviço em decorrência da mobilidade dos usuário móveis.

Em relação à mitigação de interferência, ela se dá por meio da técnica Coordinated Multipoint (CoMP) $\left[\mathrm{IDM}^{+} 11\right]$, definida para uso em sistemas Long-Term Evolution (LTE)-Advanced pelo grupo de padronização 3rd Generation Partnership Project (3GPP) [rGPPG13], onde os sinais de interferência recebidos por usuários presentes na borda das células são transformados em sinais úteis que são transmitidos conjuntamente pelas antenas que geram a interferência. O CoMP envolve a sinalização entre células que geram interferência com o objetivo de informar o estado dos seus canais de rádio e coordenar uma transmissão ao usuário afetado. Quanto à diminuição da queda de serviço quando um usuário atravessa diversas células da rede, técnicas de Handover [TJ91] são utilizadas para delegar o processamento de banda-base dos sinais de um usuário de uma célula para outra.

Entretanto, as arquiteturas e tecnologias das RANs atuais não serão capazes de atender às demandas de tráfego móvel da quinta geração de Internet móvel, a chamada rede 5G [HRTA14] [rGPPG19], onde espera-se que a demanda de tráfego cresça de forma exponencial anualmente [WZHW15] em decorrência dos emergentes cenários de Internet of Things (IoT) [AIM10] e Cidades Inteligentes $\left[\mathrm{CNW}^{+} 12\right]$, onde centenas, ou até mesmo milhares de dispositivos móveis, tais como celulares, sensores e carros inteligentes gerarão demandas de processamento de banda-base para as células da rede gerando um tráfego aproximadamente 1000 vezes maior do que o experimentado em 2010 [Cis].

Além disso, as técnicas de CoMP, Handover e as aplicações de IoT e cidades inteligentes de- 
mandam baixas latências em relação ao seu processamento. Note que, ao aumentar a quantidade de elementos demandando processamento de banda-base na BBU de uma célula, mais difícil será para manter a latência de tais processamentos em baixos níveis, ao passo que as BBUs tenderão a ficar cada vez mais estressadas.

Como uma forma de atender ao crescente número de elementos móveis na rede, a densificação das antenas e elementos de processamento nas células dessas redes foi proposta para aumentar a abrangência na cobertura aos usuários, por meio da utilização de HetNets [PLW $\left.{ }^{+} 11\right]$, porém quanto mais densa for uma célula, maior será seu consumo energético, pois a instalação de HetNets também implica a instalação de uma infraestrutura de alimentação e refrigeração dedicada ao seu funcionamento. Além disso, ao densificar as células, aumenta-se a probabilidade de usuários experimentando interferência e demandando maiores usos do CoMP.

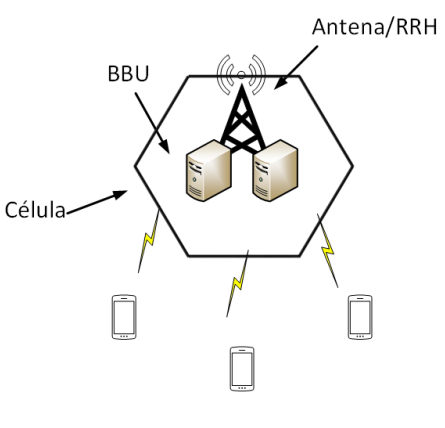

$1 G, 2 G$ e $3 G$

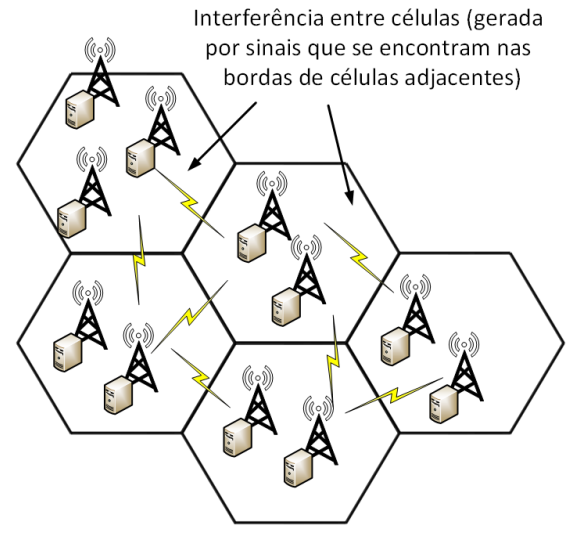

$4 G$

Figura 1.1: Evolução das arquiteturas de redes móveis

Para atender a densificação dos elementos móveis da rede mas diminuindo o consumo de energia, a utilização de uma arquitetura de computação em nuvem operando em conjunto com as células, chamada de Cloud Radio Access Network (CRAN) [WZHW15] (Figura 1.2), foi proposta para diminuir o consumo geral da rede móvel.

$\mathrm{Na}$ arquitetura CRAN, as BBUs são separadas das antenas receptoras/transmissoras de sinais e centralizadas em uma nuvem, conforme visto na Figura 1.2. Nas células da rede, permanecem apenas antenas de baixo consumo energético chamadas de Remote Radio Head (RRH) responsáveis por realizarem processamentos simples de sinais de rádio, como amplificação, conversão analógica/digital e processamento de rádio frequência. A comunicação entre os RRHs e a nuvem de BBUs é realizada por uma rede de transporte óptica chamada de fronthaul [TA15] [ATM17].

Essa arquitetura de rede é capaz de diminuir os custos capitais (Capital Expenditure (CAPEX)) e operacionais (Operational Expenditure (OPEX)) relacionados à implantação e manutenção de células na rede, centralizando todos os recursos computacionais em um único local e assim diminuindo gastos de locação de sites, de consumo de energia elétrica e de equipamentos de refrigeração, pois o consumo elétrico ao se manter diversas BBUs em um único local é menor do que se forem mantidas distribuídas $\left[\mathrm{MBC}^{+} 16\right]$, já que utiliza-se apenas uma única infraestrutura de alimentação elétrica e refrigeração para mantê-las.

Além disso, a CRAN é capaz de aumentar a eficiência espectral das antenas da rede, pois ao centralizar o processamento de banda-base, a latência de sinalização do CoMP torna-se muito 


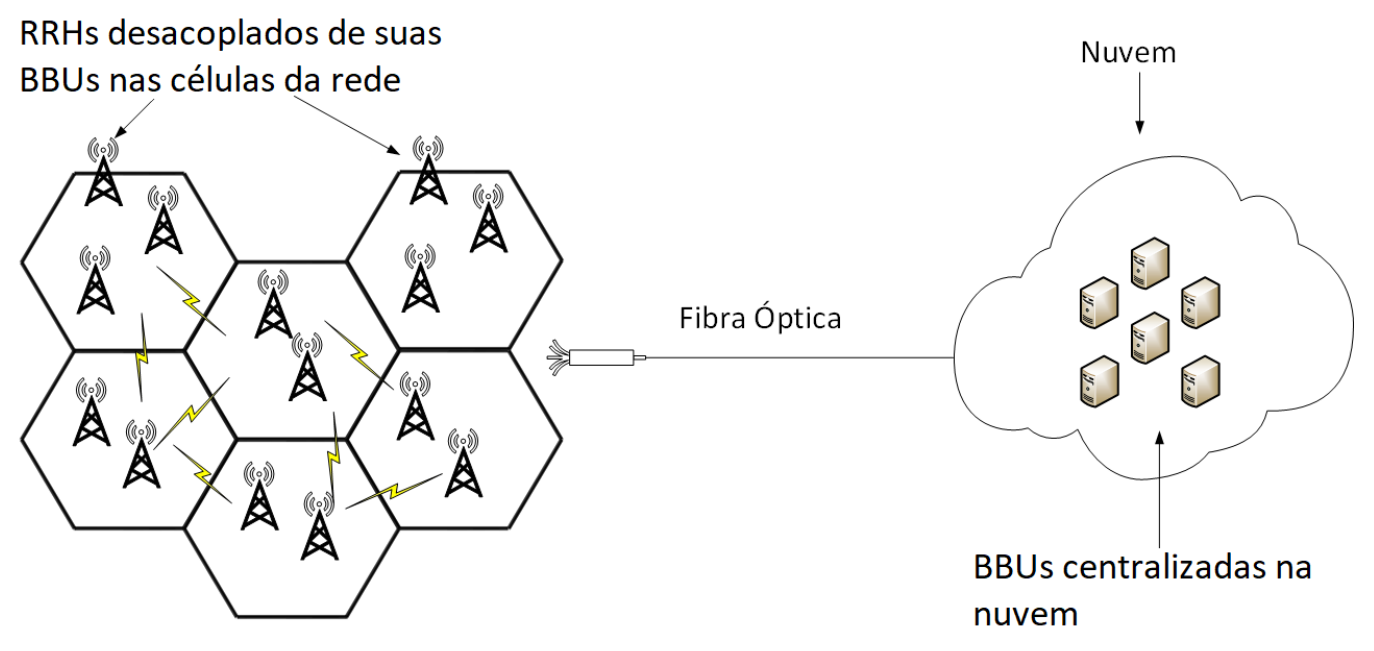

CRAN

Figura 1.2: Arquitetura CRAN

baixa, aumentando assim o seu desempenho ao coordenar os RRHs de forma centralizada ao invés da sinalização distribuída [IDM+11, XLA13].

Em relação à implantação do fronthaul, a CRAN utiliza redes ópticas [RSS09] para sua implantação e a transmissão dos dados é realizada sob o padrão Common Public Radio Interface (CPRI) [DlOHLA16] [CPR], que é responsável por digitalizar os sinais de rádio das antenas e transmiti-los pelo fronthaul.

O padrão CPRI especifica que a comunicação entre os RRHs e a nuvem deve atender a rígidas restrições de tempo em decorrência do protocolo Hybrid Automatic Repeat Request (HARQ) [LSPS09], que controla a sincronização e retransmissão de quadros entre os usuários móveis e os RRHs.

O CPRI também especifica diferentes opções de linhas de transmissão para os RRHs em função de sua configuração Multiple Input - Multiple Output (MIMO) [LHS03]. Assim, cada RRH é capaz de gerar taxas de dados de $614,4 \mathrm{Mbps}$ até $24,3 \mathrm{Gbps}$ e, futuramente, utilizando-se de canais de rádio de maior capacidade espectral, esta demanda irá ultrapassar facilmente os 100Gbps por RRH [DlOHLA16].

Para que as altas demandas de banda e latência sejam atendidas no fronthaul da arquitetura CRAN, a utilização de Redes Ópticas Passivas (PONs) com Divisão na Multiplexação por Tempo e Comprimento de Onda, ou Time and Wavelength Division Multiplexing Passive Optical Network (TWDM-PON) [LZE $\left.{ }^{+} 12\right]$, é proposta pela comunidade de redes ópticas para a implantação do fronthaul. As redes TWDM-PON oferecem altas taxas de transmissão síncronas (ou seja, tanto no sentido uplink quanto no sentido downlink), além de prover baixas latências de propagação no fronthaul por conta da ausência de elementos ativos ao longo da extensão das fibras ópticas. Além disso, redes TWDM-PON introduzem a capacidade de virtualização da própria PON por meio do compartilhamento de um único comprimento de onda (o próprio canal de transmissão óptico) entre diversos usuários da rede que dividem suas transmissões no domínio do tempo, criando assim uma PON exclusiva a um grupo de transmissores chamada de Virtualized Passive Optical Network (VPON). 


\subsection{Motivação}

Apesar da arquitetura CRAN reduzir o consumo energético e aumentar a eficiência espectral da rede, tanto o fronthaul quanto seus recursos computacionais possuem capacidades limitadas. O processamento centralizado de banda-base pode trazer problemas quanto a escalabilidade dos recursos computacionais da nuvem. A sobrecarga dos recursos computacionais da nuvem irá aumentar a latência total de transmissão dos quadros CPRI, o que poderá eventualmente diminuir a qualidade de serviço (Quality of Service (QoS)) provida aos usuários de uma rede 5G [FWM $\left.{ }^{+} 16\right]$ [MBT $\left.{ }^{+} 17\right]$. Além disso, o crescimento dos RRHs em uma rede ou dos próprios sinais de banda-base agregados em cada RRH em função de suas configurações MIMO [FT07] poderá exceder a quantidade de banda disponível no fronthaul.

Tanto a capacidade do fronthaul quanto da nuvem são fatores limitantes à cobertura total da rede CRAN. Se a demanda da rede crescer de tal forma que o fronthaul ou os processadores da nuvem tenham suas capacidades esgotadas, as requisições de transmissão de tráfego CPRI serão bloqueadas e alguns ou muitos usuários não conseguirão acessar os serviços de uma rede $5 \mathrm{G}$.

Esses cenários de aumento na latência ou bloqueio de serviços tornam-se muito mais críticos quando pensamos em aplicações com severas restrições de latência, como uma aplicação de veículos autônomos ou cirurgias remotas. O não atendimento a essas aplicações pode gerar sérias consequências à vida humana.

Os cenários atuais e as previsões acerca das redes $5 \mathrm{G}$ trazem em frente a necessidade de uma nova arquitetura que seja capaz de superar as limitações impostas pela arquitetura CRAN.

\subsection{Objetivos}

Esta Tese tem como objetivo principal a proposta de uma nova arquitetura de redes com foco em ultrapassar as limitações da arquitetura CRAN e em atender os requisitos de banda e latência de uma rede $5 \mathrm{G}$ adaptável ao crescimento de suas demandas.

É proposta uma arquitetura de redes $5 \mathrm{G}$ chamada de Cloud/Fog Radio Access Network (CF-RAN). A arquitetura CF-RAN é uma arquitetura que busca expandir as capacidades de transmissão do fronthaul e processamento da nuvem em relação às arquiteturas CRAN. Por meio do paradigma de computação em névoa, ou fog computing [BMZA12], a CF-RAN expande a capacidade de processamento da rede com a instalação de nós de processamento locais aos usuários, referidos nesta Tese como fog nodes. Os fog nodes são nós de processamento que replicam os serviços da nuvem, entretanto, com capacidade de processamento reduzida. Como eles são instalados mais próximos dos RRHs, além de expandirem a capacidade geral de processamento da rede, são capazes de prover menor latência, em relação à nuvem, para as aplicações que eventualmente serão processadas neles. Apesar de aumentar a capacidade de processamento da rede, a utilização indiscriminada de fog nodes pode aumentar consideravelmente o consumo energético de uma rede. Além disso, a instalação dos fog nodes faz com que a rede móvel tenha uma arquitetura similar a uma DRAN. Entretanto, a CF-RAN difere-se da arquitetura DRAN pois nesta cada estação-base possui uma BBU instalada, ao passo que na CF-RAN um único fog node pode servir a múltiplos RRHs.

Para que o aumento da capacidade de processamento seja balanceado com o consumo energético, a arquitetura CF-RAN baseia-se na virtualização do processamento de banda-base, por meio da utilização do paradigma de Virtualização das Funções de Rede, ou Network Function Virtu- 
alization (NFV) [HSMA14], onde os processamentos realizados por equipamentos de rede podem ser realizados em máquinas virtuais instanciadas em servidores dedicados. Por meio de NFV, o processamento das BBUs é realizado em elementos chamados de Unidades Digitais Virtuais, ou Virtual Digital Unit (VDU). Uma VDU é um container [Ber14] de funções virtualizadas de rede, onde o processamento de uma BBU é virtualizado em uma BBU virtual, ou Virtualized BaseBand Unit (vBBU).

Considerando um processamento virtualizado dos sinais de banda-base, o paradigma de NFV permite que tanto as VDUs quanto as vBBUs sejam ativadas ou desativadas dinamicamente em função da demanda de tráfego da rede 5G. Dessa forma, o consumo energético pode ser balanceado, pois os fog nodes podem ser ativados apenas quando houver a necessidade, por exemplo por conta do esgotamento do fronthaul ou da nuvem. Nessa arquitetura, mecanismos de ativação das vBBUs precisam ser propostos para garantir o atendimento a determinada demanda da rede além de um bom balanceamento entre a cobertura da rede e o consumo de energia. O problema da decisão de ativação de vBBUs frente à demanda da rede é chamado de problema de alocação de vBBUs, ou $v B B U s$ Placement. A ativação dinâmica das funções de processamento é outro ponto diferencial em relação à arquitetura DRAN, pois nesta as BBUs de cada estação-base estão sempre ativas durante a operação da rede.

Em relação ao fronthaul da arquitetura CF-RAN, ele é expandido para prover a comunicação dos RRHs tanto para os fog nodes quanto para a nuvem. Entretanto, neste novo cenário os comprimentos de onda disponíveis na rede TWDM-PON não podem mais ser utilizados apenas para a criação de VPONs que transmitem para a nuvem. Os comprimentos de onda devem ser devidamente dimensionados entre a nuvem e os fog nodes, de forma que uma única VPON só possa ser utilizada para transmitir para um único nó de processamento; do contrário, se o mesmo comprimento de onda for utilizado para transmissões em diferentes nós, pode ocorrer a colisão dos canais ópticos. Essa restrição na utilização das VPONs torna necessária a proposta de algoritmos eficientes para o dimensionamento dos comprimentos de onda da rede para transmissão nos diferentes nós de processamento atendidos pelo fronthaul. Este problema é introduzido nesta Tese e é chamado de problema de dimensionamento de comprimento de onda e formação de VPONs.

Assim, além da proposta da arquitetura CF-RAN, esta tese propõe algoritmos ótimos e heurísticas eficientes para o tratamento conjunto dos problemas de alocação de vBBUs e de dimensionamento de comprimento de onda e formação de VPONs. Em suas naturezas, tanto o problema de alocação de vBBUs quanto o problema de dimensionamento de comprimento de onda e formação de VPONs são problemas de alocação de recursos em uma rede.

Adicionalmente, em uma rede móvel há muita flutuação na demanda de tráfego [ $\left.\mathrm{PLL}^{+} 11\right]$, em decorrência da mobilidade de seus usuários, fazendo necessário que reconfigurações das vBBUs e VPONs ativadas sejam realizadas para que o menor consumo de energia, e um uso eficiente dos recursos computacionais e de rede, sejam obtidos. Soluções baseadas em formulações de Programação Linear Inteira (Integer Linear Programming (ILP)) são comumente utilizadas para a obtenção de soluções ótimas em problemas de alocação de recursos [WTT ${ }^{+}$16] [MTM07] [JMT07]. Entretanto, soluções baseadas em ILP possuem complexidade computacional elevada por serem do tipo NP-Completo [DC02] [FWM $\left.{ }^{+} 16\right]$ e seus tempos de convergência no cálculo de uma solução ótima não escalam eficientemente em função do crescimento do tamanho da entrada do problema. Por outro lado, formulações ILP são eficientes para obter soluções ótimas em cenários considerados 
pequenos e podem ser utilizadas para a definição de heurísticas eficientes que buscam emular seu comportamento em cenários maiores.

Além das contribuições já introduzidas, esta Tese também apresenta duas formulações ILP e um conjunto de heurísticas para o tratamento dos problemas supracitados. A primeira formulação considera a alocação conjunta de vBBUs e criação de VPONs em cenários de tráfego estático. Nos cenários de tráfego dinâmico, onde requisições de transmissão de tráfego CPRI chegam e saem da rede, um modelo baseado em grafos [FXDF12] e heurísticas são propostos para realizar a alocação e desativação dinâmica tanto de vBBUs quanto de VPONs. A segunda formulação ILP é uma extensão da formulação anterior e tem o objetivo de realizar a reconfiguração dinâmica dos elementos da rede por meio de um balanceamento de carga que busca desativar VDUs e VPONs quando a distribuição de carga na rede estiver desbalanceada. Em extensão a esta formulação, para sua aplicação em cenários de larga escala, heurísticas baseadas na relaxação da formulação ILP [BdFMG08] são propostas.

Por fim, um modelo de avaliação de desempenho também é proposto nesse trabalho, para avaliar o desempenho da arquitetura, formulações ILP e heurísticas propostas.

\subsection{Contribuições}

As contribuições desta Tese são as seguintes:

- A proposta de uma arquitetura híbrida CF-RAN capaz de aumentar a cobertura de arquiteturas CRAN.

- Um modelo de avaliação de desempenho da arquitetura CF-RAN

- A proposta de uma formulação ILP para o tratamento dos problemas de alocação de vBBUs e de dimensionamento de comprimento de onda e formação de VPONs em cenários estáticos de pequena escala.

- A proposta de um modelo e heurísticas baseados em teoria dos grafos para o tratamento dos problemas de alocação de vBBUs e de dimensionamento de comprimento de onda e formação de VPONs em cenários dinâmicos de larga escala.

- A proposta de uma formulação ILP para a reconfiguração dos elementos ativos na CF-RAN baseada na redistribuição das cargas de trabalho tanto da rede quanto dos processadores com vistas à redução do consumo energético e utilização eficiente dos recursos disponíveis.

- A proposta de heurísticas baseadas na relaxação da formulação ILP de reconfiguração dos elementos da rede para a solução desse problema em cenários de larga escala.

\subsection{Organização da Tese}

Esta Tese está organizada nos seguintes capítulos:

Capítulo 2, que introduz uma discussão acerca dos trabalhos relacionados.

Capítulo 3, que apresenta conceitos básicos das PONs e da tecnologia TWDM-PON e da arquite- 
tura CRAN.

Capítulo 4, que apresenta a arquitetura CF-RAN, seus detalhes operacionais, os problemas de alocação de vBBUs, dimensionamento de comprimento de onda, formação de VPONs e um modelo de avaliação de desempenho da arquitetura.

Capítulo 5, que introduz a primeira formulação ILP desenvolvida para o tratamento dos problemas de alocação de vBBUs e formação de VPONs supracitados em cenários de tráfego estático e pequena escala.

Capítulo 6, onde heurísticas baseadas em teoria dos grafos são propostas para solucionar os problemas de alocação de vBBUs e dimensionamento de comprimento de onda e formação de VPONs em cenários estáticos e dinâmicos de larga escala.

Capítulo 7, que apresenta os resultados obtidos com a formulação ILP e as heurísticas baseadas em teoria dos grafos.

Capítulo 8, em que uma nova formulação ILP e heurísticas baseadas na relaxação linear dessa formulação são propostas para a migração de vBBUs entre fog nodes e nuvem e a reconfiguração de VPONs na arquitetura CF-RAN.

Capítulo 9, onde os resultados obtidos com a formulação ILP para migração de vBBUs e reconfiguração de VPONs são apresentados.

Capítulo 10, onde os resultados obtidos pelas heurísticas baseadas na relaxação linear da formulação ILP são apresentados.

Capítulo 11, que apresenta a conclusão da pesquisa realizada nesta Tese, além de discutir trabalhos futuros relacionados aos temas aqui abordados.

\subsection{Publicações realizadas e prêmios recebidos durante o desenvol- vimento da Tese}

Os resultados alcançados nesta Tese geraram as seguintes publicações, diretamente ligadas à Tese:

- [TFB19] Tinini, R. I., Figueiredo, G. B., \& Batista, D. M. . (2019, September). A Batch Scheduling Algorithm for VPON Reconfiguration and BBU Migration in Hybrid Cloud-Fog RAN. In IEEE NCA 2019-2019 IEEE International Symposium on Network Computing and Applications (pp. 1-8). IEEE.

- $\left[\mathrm{TBF}^{+}{ }^{19 a}\right.$ ] Tinini, R. I., Batista, D. M., Figueiredo, G. B., Tornatore, M., \& Mukherjee, B. (2019, December). Energy-Efficient BaseBand Processing via vBBU Migration in Virtualized Cloud-Fog RAN. In GLOBECOM 2019-2019 IEEE Global Communications Conference (pp. 1-6). IEEE.

- $\left[\mathrm{TBF}^{+}\right.$19b] Tinini, R. I., Batista, D. M., Figueiredo, G. B., Tornatore, M., \& Mukherjee, B. (2019). Low-Latency and Energy-Efficient BBU Placement and VPON Formation in Virtualized Cloud-Fog RAN. Journal of Optical Communications and Networking, 11(4), B37-B48. 
- [TBF18] Tinini, R. I., Batista, D. M., \& Figueiredo, G. B. (2018, June). Energy-efficient VPON formation and wavelength dimensioning in cloud-fog RAN over TWDM-PON. In 2018 IEEE Symposium on Computers and Communications (ISCC) (pp. 521-526). IEEE.

- $\left[\mathrm{TRB}^{+}\right.$17] Tinini, R. I., Reis, L. C., Batista, D. M., Figueiredo, G. B., Tornatore, M., \& Mukherjee, B. (2017, December). Optimal placement of virtualized BBU processing in hybrid cloud-fog RAN over TWDM-PON. In GLOBECOM 2017-2017 IEEE Global Communications Conference (pp. 1-6). IEEE.

A publicação Energy-efficient VPON formation and wavelength dimensioning in Cloud-Fog RAN over TWDM-PON [TBF18] recebeu o prêmio Microsoft/IEEE Best Student Paper durante a conferência internacional IEEE ISCC'18.

Um artigo intitulado 5GPy: A SimPy-based Simulator for 5G Hybrid Cloud-Fog RAN Architectures, descrevendo um simulador desenvolvido para apoiar as pesquisas realizadas nesta Tese e o modelo de avaliação de desempenho apresentado no Capítulo 4, está na primeira rodada de revisões de uma edição especial do periódico Simulation Modelling Practice and Theory, intitulada Modeling and Simulation of Fog Computing, após um retorno de minor revision.

Indiretamente ligados a esta Tese, os seguintes artigos foram publicados:

- [dSTFB19] dos Santos, M. R. P., Tinini, R. I., Figueiredo, G. B. \& Batista, D. M (2019, November). Data Analysis and Energy Consumption Prediction in a Cloud-Fog RAN Environment. In 2019 11th IEEE Latin-American Conference on Communications (LATINCOM) (pp. 1-6). IEEE.

- $\left[\mathrm{RDA}^{+}\right.$18] Riva, M., Donâncio, H., Almeida, F. R., Figueiredo, G. B., Tinini, R. I., Cesar Jr, R. M., \& Batista, D. M. (2018, May). An Elastic Optical Network-based Architecture for the 5G Fronthaul. In Anais do XXXVI Simpósio Brasileiro de Redes de Computadores e Sistemas Distribuídos. SBC.

Em [dSTFB19], um algoritmo de Machine Learning foi utilizado para prever o consumo energético da arquitetura CF-RAN. Em [RDA $\left.{ }^{+} 18\right]$, a tecnologia de redes ópticas elásticas passivas foi inicialmente explorada no suporte do fronthaul de arquiteturas CRAN. 


\section{Capítulo 2}

\section{Trabalhos Relacionados}

A utilização de redes ópticas no suporte de arquiteturas de redes a rádio tem despertado o interesse da comunidade científica por conta de três aspectos cruciais para o desenvolvimento e evolução das redes 5G: o consumo de energia, a alta demanda por banda e a baixa latência que será requisitada por futuras aplicações que farão uso de uma rede $5 \mathrm{G}$, como aplicações de veículos autônomos e operações realizadas remotamente por médicos. Além desses aspectos, outros problemas operacionais de redes móveis também tem sido endereçados por pesquisadores da área, como mitigação de interferência entre estações-base e diminuição da interrupção de serviços quando da ocorrência de handovers entre as estações-base. Os trabalhos recentes que propuseram soluções para os problemas supracitados basearam-se principalmente nas alocações eficientes de recursos de processamento e de rede para garantir o desempenho esperado das redes.

Em [CTP14], os autores propuseram o desacoplamento das BBUs de uma DRAN por meio de um esquema de multi-camadas de hospedagem de BBUs em uma arquitetura CRAN, onde as BBUs desacopladas dos RRHs poderiam ser distribuídas em múltiplos Central Office (CO)s, ou escritórios centrais, espalhados em áreas rurais ou urbanas ou completamente centralizados em uma nuvem. Nesse trabalho, os RRHs e os pontos da rede que implantavam a hospedagem de BBUs foram interconectados por uma topologia de múltiplos anéis, ou ring and spur, sob uma rede óptica ativa multiplexada por divisão do comprimento de onda (Wavelength Division Multiplexing $(\mathrm{WDM}))$. Diferentes níveis de agregação das BBUs nos COs foram avaliados e uma formulação de ILP para solucionar o problema de Roteamento e Alocação de Comprimento de Onda (Routing and Wavelength Assignment (RWA)) nessa arquitetura CRAN foi proposta. Os resultados mostraram que quão maior for a agregação de BBUs em um único ponto da rede, maior é a economia de energia, confirmando a hipótese de que a centralização das BBUs é capaz de otimizar o consumo de energia em redes 5G com maior densidade de antenas. Entretanto, a utilização da rede WDM ativa pode aumentar as latências da rede por conta do processamento realizado em nós intermediários para comutação dos comprimentos de onda. Além disso, a virtualização das BBUs e a cooperação em conjunto da nuvem e outros COs da rede não foi explorada, o que pode ser um fator limitador para a cobertura total da rede.

A mitigação de interferência por meio da utilização de redes ópticas em uma arquitetura CRAN foi proposta pelos autores em $\left[\mathrm{FWM}^{+} 16\right]$. Nesse trabalho, a utilização de técnicas de coordenação multi-ponto, ou CoMP, foi proposta para orquestrar transmissões a usuários móveis utilizando-se de sinais de interferência. No CoMP, RRHs que geram interferência a um usuário móvel que reside na borda da estação-base de algum desses RRHs realizam sinalizações entre si com o objetivo 
de informarem uns aos outros o estado de utilização dos seus canais de transmissão para que um canal em comum seja utilizado por esses RRHs para iniciar transmissões ao usuário em questão. Utilizando-se de uma rede TWDM-PON, a latência dessa sinalização pode ser drasticamente diminuída. Além disso, por meio da criação e estabelecimento ótimo de VPONs e máquinas virtuais em uma nuvem, RRHs que devem transmitir a um mesmo usuário podem ser agrupados no mesmo canal de transmissão e máquina virtual, diminuindo-se ainda mais a latência para a sinalização do estado dos canais. Entretanto, apesar da centralização da sinalização do CoMP reduzir significantemente a latência, os resultados mostraram que a longo prazo as máquinas virtuais que suportam o processamento do CoMP tendem a ficar muito carregadas e a latência tende a crescer. Como apenas um nó de processamento é utilizado, duas possíveis alternativas surgem para diminuir a latência crescente. A primeira é realocar o processamento dos RRHs em outras máquinas virtuais presentes no mesmo nó, entretanto, para que isso seja possível é necessário que haja capacidade computacional para a instanciação de novas máquinas virtuais. De toda forma, essa solução pode não funcionar a longo prazo, pois essas novas máquinas virtuais podem vir a tornar-se carregadas e o problema voltar a acontecer. Uma segunda alternativa é a utilização de nós de processamento adicionais para o processamento do CoMP. Assim, quando a nuvem torna-se estressada computacionalmente, novos RRHs que demandam processamento do CoMP são alocados em nós de processamento adicionais. Essa segunda proposta pode trazer mais vantagens ainda em relação ao desempenho do CoMP, pois a eficiência espectral das transmissões que essa técnica orquestra é uma função da latência tomada para o início das transmissões, que no caso de nós de processamento adicionais, pode ser reduzida ainda mais se esses nós forem implantados mais próximos dos RRHs.

No estudo realizado em [WWC $\left.{ }^{+} 16\right]$, a utilização de VPONs contribuiu para a diminuição da latência durante o processo de tratamento de handovers em uma arquitetura CRAN. Semelhantemente ao trabalho realizado em $\left[\mathrm{FWM}^{+} 16\right]$ para a diminuição da latência do CoMP, neste trabalho a latência para delegação do controle do processamento de sinais de banda-base de usuários que se locomoviam entre diferentes estações-base pode ser diminuída por uma alocação eficiente de BBUs virtualizadas referentes às estações-base próximas entre si na extensão da rede móvel. Além disso, um algoritmo de predição de movimentação dos equipamentos móveis foi proposto para aumentar a eficiência da alocação das BBUs virtuais de modo que os dados dos RRHs envolvidos em um procedimento de handover fossem transmitidos em uma mesma VPON e processados em uma mesma máquina virtual diretamente ligada a essa VPON. Os resultados mostraram que essa alocação eficiente dos RRHs nas VPONs e nas máquinas virtuais pode otimizar a vazão das estações-base durante procedimentos de handover.

A utilização de uma rede óptica elástica para implantação do fronthaul foi proposta pelos autores do estudo realizado em $\left[\mathrm{VCA}^{+} 17\right]$. Nesse trabalho, uma grade de frequências flexível é utilizada para prover alocação de frequências ópticas em granularidades muito menores do que redes WDM tradicionais, aumentando dessa forma a utilização da banda disponível frente às demandas de banda de uma rede móvel. Os resultados mostraram que por meio da alocação flexível de frequências ópticas, o consumo energético da rede pôde ser consideravelmente reduzido frente a alocações tradicionais de largura de banda, por conta da alocação proposta ser melhor adaptada às flutuações de tráfego CPRI durante um dia de operação da rede móvel.

Apesar da centralização do processamento de banda-base na arquitetura CRAN trazer reduções do consumo energético em relação a arquiteturas anteriores, essa centralização impõe uma carga de 
trabalho muito alta no fronthaul e, com o avanço da tecnologia, a demanda por banda no fronthaul pode chegar à ordem dos Tbps. Para contornar esse problema, a descentralização do processamento de banda-base começou a ser considerada pela comunidade científica. Essa nova proposta veio de duas formas. A primeira é o particionamento do processamento dos sinais de banda-base [All18], que define até oito opções de particionamento das funções de processamento de banda-base entre a nuvem e algum dispositivo de processamento presente na borda da rede. A segunda é a utilização cooperativa entre a nuvem e nós de processamento auxiliares que somente são ativados quando a nuvem ou o fronthaul experimentam cargas de trabalho muito altas que podem degradar a latência na rede ou até mesmo bloquear requisições.

Como forma de otimizar a utilização do fronthaul, além de aumentar a eficiência espectral da rede, uma arquitetura de RAN heterogênea, chamada de Heterogeneous Cloud Radio Access Network (H-CRAN) foi proposta em [PLJ $\left.{ }^{+} 14 \mathrm{~b}\right]$. Nessa arquitetura, os benefícios da arquitetura CRAN são combinados com as capacidades de processamento das estações-base. Assim, a nuvem poderia ser utilizada apenas para o processamento de banda-base enquanto o processamento das estações-base poderia ser utilizado para atender a serviços orientados aos usuários, como serviços de telefonia, por exemplo. Entretanto, os autores dessa proposta não exploraram a possibilidade de uma distribuição dinâmica do processamento entre a nuvem e os recursos computacionais presentes nas estações-base de forma a balancear o consumo de energia e a distribuição do processamento entre os diversos recursos computacionais disponíveis.

Nesse contexto, os autores do estudo realizado em $\left[\mathrm{LZG}^{+} 15\right]$ propuseram o particionamento do processamento dos sinais de banda-base entre a nuvem e recursos computacionais presentes nas estações-base. Nesse trabalho, a rede e o particionamento do processamento de banda-base foram modelados como um grafo e a distribuição do processamento foi executado por meio de um algoritmo genético executado sobre a rede abstraída em um grafo. Foi constatado que o particionamento do processamento de fato reduz a carga do fronthaul, como esperado, mas ao custo de um aumento no consumo de energia.

Os autores em [WAC17] propuseram uma arquitetura baseada na H-CRAN chamada de HybridCRAN, ou CRAN híbrida, operando sob uma rede TWDM-PON. Essa arquitetura propõe a implantação de nós de processamento remotos mais próximos dos RRHs de forma que o processamento de banda-base possa ser particionado entre a nuvem e os nós remotos. A distribuição ótima do processamento de banda-base entre a nuvem e os nós remotos foi formulada como um problema de programação de restrições. Nessa formulação, diferentes opções de particionamento do processamento eram escolhidas e alocadas na rede de acordo com a carga de trabalho tanto do fronthaul quanto da nuvem. Como esperado, os resultados mostraram que a carga do fronthaul pode ser aliviada por meio do particionamento do processamento ao custo do aumento do consumo energético. Entretanto, nesse trabalho os autores não apresentaram a influência que a utilização de nós adicionais de processamento exerce sobre a latência da rede. A partir do momento em que novos nós de processamento são adicionados na rede, a alocação da largura de banda necessária para a realização de transmissões até esses nós torna-se um problema que precisa ser resolvido na operação da rede. Assim, um ponto crucial que foi negligenciado nesse trabalho foi que a capacidade da rede TWDM-PON utilizada para suportar as transmissões tanto para a nuvem quanto para os nós remotos não foi dimensionada, de forma que todos os comprimentos de onda disponíveis nessa rede deveriam ser otimamente distribuídos entre todos os nós de processamento para que as 
transmissões e o particionamento do processamento fosse realizado de forma mais realista, provendo também resultados mais realistas.

A utilização de nós de processamento adicionais na rede para o suporte de acesso a conteúdos em cache por meio de computação em névoa é proposta por meio da arquitetura Fog Radio Access Network (FRAN) [ZQC $\left.{ }^{+} 17\right]$. Na arquitetura FRAN, o processamento dos sinais de banda-base pode ser realizado tanto na nuvem quanto de forma distribuída em fog nodes, além do cache ser realizado em diferentes equipamentos que residem na borda da rede, tais como pontos de acesso ou até mesmo equipamentos móveis. Nessa arquitetura, o objetivo é maximizar a utilização dos equipamentos presentes na borda da rede para que a carga do fronthaul seja sempre minimizada. Nesse contexto, no trabalho realizado em $\left[\mathrm{CJC}^{+} 18\right]$, o paradigma de computação em névoa foi utilizado para realizar cache colaborativo dos conteúdos mais acessados por meio dos RRHs de uma rede móvel. Um algoritmo de clusterização baseado em teoria dos grafos e formulação ILP foi proposto pelos autores para coordenar o off-loading e acesso desses conteúdos aos RRHs da rede. Os resultados desse estudo apresentaram reduções nos tempos de acesso a conteúdos armazenados em cache nos fog nodes da rede.

Outro problema muito importante a ser tratado durante a operação de uma rede $5 \mathrm{G}$ é a migração de cargas de trabalho por conta da flutuação de tráfego experimentada em redes móveis. No contexto desta Tese, a migração de cargas de trabalho se faz necessária em dois aspectos: Primeiro, as cargas de processamento podem ser migradas de fog nodes para a nuvem se a demanda da rede é reduzida. Segundo, as cargas das VPONs podem ser migradas entre VPONs de forma a utilizar de forma mais eficiente a banda disponível na rede e até mesmo desativar VPONs com o objetivo de poupar a energia consumida por receptores ópticos. No contexto de migração de cargas de trabalho, alguns trabalhos recentes têm abordado este problema.

Os autores do estudo realizado em [WLLM14] propuseram a reconfiguração de VPONs em função de mudanças no tráfego com o objetivo de reduzir o consumo de energia. Entretanto, nesse trabalho essa reconfiguração das VPONs foi realizada em uma rede com apenas um nó de processamento como destino final das transmissões de todas as VPONs. Assim, a migração das cargas de trabalho ocorria apenas entre as VPONs destinadas ao mesmo nó de processamento.

Um mecanismo de balanceamento de carga na arquitetura CRAN foi proposto pelos autores em [TM17] para a redução da latência de aplicações de cenários de IoT. Para definir a migração das cargas de trabalho entre as BBUs da rede, os autores utilizaram como métrica o menor tempo de espera de processamento nas BBUs. Os resultados mostraram que quando as cargas de trabalho são reorganizadas nas BBUs considerando essa métrica, a latência geral de processamento pode ser reduzida.

O balanceamento de carga durante o acesso a conteúdos hospedados tanto em uma nuvem quanto em cache em fog nodes foi proposto pelos autores em [CSK16]. Nesse trabalho, os autores consideraram duas redes de transporte distintas conectando as estações-base da rede à nuvem ou aos fog nodes. A proposta desse trabalho baseia-se na priorização do acesso a conteúdos hospedados na nuvem, assim, o algoritmo proposto pelos autores baseia-se em priorizar o balanceamento das cargas de trabalho da rede de transporte que conecta-se à nuvem. Os fog nodes são acessados apenas quando a rede de transporte da nuvem encontra-se muito congestionada de forma que mesmo um balanceamento das suas cargas de trabalho não seja suficiente para aliviar sua demanda. Além do mais, para que os acessos aos conteúdos sejam feitos da forma mais eficiente possível, um algoritmo 
de clusterização foi proposto para orquestrar transmissões de diversos RRHs cujos usuários móveis a eles conectados demandam conteúdos semelhantes. A clusterização das transmissões requisitantes de conteúdos mostrou-se eficiente na redução do consumo de energia e o balanceamento das cargas de trabalho da rede de transporte da nuvem foi capaz de otimizar a métrica de QoS da rede.

Em suma, a Tabela 2.1 apresenta as contribuições desta Tese em comparação com os trabalhos que foram discutidos nesta seção.

Tabela 2.1: Comparação com os trabalhos relacionados

\begin{tabular}{|l|c|c|c|c|c|}
\hline Trabalho & Virtualização & Fog Computing & NFV & TWDM-PON & Migração \\
\hline Cui et al. 2018 & & $\mathrm{X}$ & $\mathrm{X}$ & & \\
\hline Wang et al., 2017 & $\mathrm{X}$ & $\mathrm{X}$ & & $\mathrm{X}$ & \\
\hline Velasco et al., 2017 & & & & & $\mathrm{X}$ \\
\hline Tsai et al., 2017 & & & & & $\mathrm{X}$ \\
\hline Chen et al., 2016 & & $\mathrm{X}$ & & $\mathrm{X}$ & \\
\hline Figueiredo et al., 2016 & $\mathrm{X}$ & & & $\mathrm{X}$ & \\
\hline Wang et al., 2016 & $\mathrm{X}$ & $\mathrm{X}$ & & $\mathrm{X}$ & $\mathrm{X}$ \\
\hline Liu et al., 2015 & & & & & \\
\hline Wang et al., 2014 & $\mathrm{X}$ & & & $\mathrm{X}$ & \\
\hline Carapellese et al., 2014 & & $\mathrm{X}$ & & $\mathrm{X}$ \\
\hline Peng et al., 2014 & & $\mathrm{X}$ & $\mathrm{X}$ & $\mathrm{X}$ \\
\hline Esta Tese & & & & \\
\hline
\end{tabular}

Assim, considerando os trabalhos apresentados, essa Tese avança o estado-da-arte ao prover uma cooperação dinâmica entre a nuvem e os fog nodes da arquitetura CF-RAN por meio da ativação e desativação dinâmica dos recursos de processamento e de rede, além da migração de cargas de trabalho dos recursos de processamento e de rede entre a nuvem e fog nodes. Além disso, nossas contribuições visam dimensionar também de forma eficiente os comprimentos de onda disponíveis na rede TWDM-PON entre a nuvem e os fog nodes da rede, de forma que as limitações de capacidade da rede de transporte sejam consideradas para uma maior fidedignidade dos resultados e comportamentos apresentados.

Em comparação com as outras arquiteturas propostas para suporte das redes $5 \mathrm{G}$, como a H-CRAN e FRAN, a arquitetura CF-RAN distingue-se nos seguintes pontos: Em comparação com a arquitetura H-CRAN, a CF-RAN propõe a utilização de nós de processamento locais, os fog nodes, dedicados a receber o processamento de múltiplos RRHs, ao passo que na arquitetura H-CRAN é considerado que as funções locais de processamento sejam implementadas dentro de recursos de processamento presentes na própria célula da rede que hospeda um RRH. Além disso, como já citado, o objetivo operacional da CF-RAN é buscar o balanceamento entre a nuvem e o processamento local por meio de ativações dinâmicas dos recursos de processamento locais. Em comparação com a arquitetura FRAN, a CF-RAN não busca maximizar a utilização dos fog nodes, pois seu objetivo principal é a diminuição do consumo energético por meio da utilização prioritária da nuvem. Nesse contexto, a utilização dos fog nodes é eventual, com o objetivo de aliviar a carga tanto no fronthaul quanto na nuvem. Entretanto, nesta Tese nós também avaliamos o impacto que a maximização da utilização dos fog nodes tem sobre a maximização da utilização da nuvem e os trade offs que surgem nesses casos. 


\section{Capítulo 3}

\section{Conceitos Básicos}

Este capítulo define os conceitos necessários para a compreensão das contribuições que serão detalhadas nos capítulos seguintes. São definidos vários conceitos relacionados com o funcionamento das PONs e da arquitetura CRAN.

\subsection{Redes Ópticas Passivas}

Essa seção busca introduzir as características da redes ópticas e a necessidade de sua utilização nas redes $5 \mathrm{G}$.

Redes ópticas [Muk97]s são redes de computadores onde os dados são transmitidos por meio de feixes de luz propagados através de uma fibra óptica. A fibra óptica é um guia de onda constituído de um núcleo, uma casca e uma capa. Tanto o núcleo quanto a casca constituem o próprio guia de onda e são fabricados com sílica. A capa, utilizada para melhorar as características mecânicas da fibra, é feita de plástico. A transmissão dos dados em uma fibra óptica ocorre por meio da reflexão da luz de uma ponta à outra do núcleo da fibra, além da casca também transmitir parte da energia dos sinais transmitidos, reduzindo dessa forma a perda de potência dos sinais [RSS09].

As redes ópticas são caracterizadas por proverem baixas latências de propagação dos dados e alta capacidade de largura de banda. A baixa latência provem do tempo de propagação da luz no núcleo da fibra, que é de aproximadamente $200 \mathrm{mil} \mathrm{km}$ por segundo, considerando um trecho de propagação sem a presença de nós intermediários na rede. A alta capacidade de largura de banda em redes ópticas provem da tecnologia WDM [Muk00]. Em redes WDM, os dados de um usuário da rede são modulados em porções da frequência óptica chamadas de comprimentos de onda. Em tais redes, múltiplos comprimentos de onda podem ser transmitidos simultaneamente na mesma fibra, sem que haja colisão dos dados modulados em diferentes comprimentos de onda. Este processo é ilustrado na Figura 3.1. Assim, múltiplos comprimentos de onda constituem diferentes canais de transmissão que partilham a mesma fibra óptica para suas propagações.

A tecnologia WDM pode ser dividida em duas categorias, as redes Coarse Wavelength Division Multiplexing (CWDM) [Woo05] e Dense Wavelength Division Multiplexing (DWDM) [EM00]. O que difere essas tecnologias é a quantidade de comprimentos de onda que podem ser multiplexados na mesma fibra. A quantidade de comprimentos de onda utilizados em cada uma dessas tecnologias é definido por um conjunto de frequências e o espaçamento espectral entre cada uma delas. A lista de frequências disponível em cada uma dessas redes são organizadas em uma lista de frequência chamada de grid (grade). Um grid de comprimentos de onda provê uma lista dos mesmos unifor- 


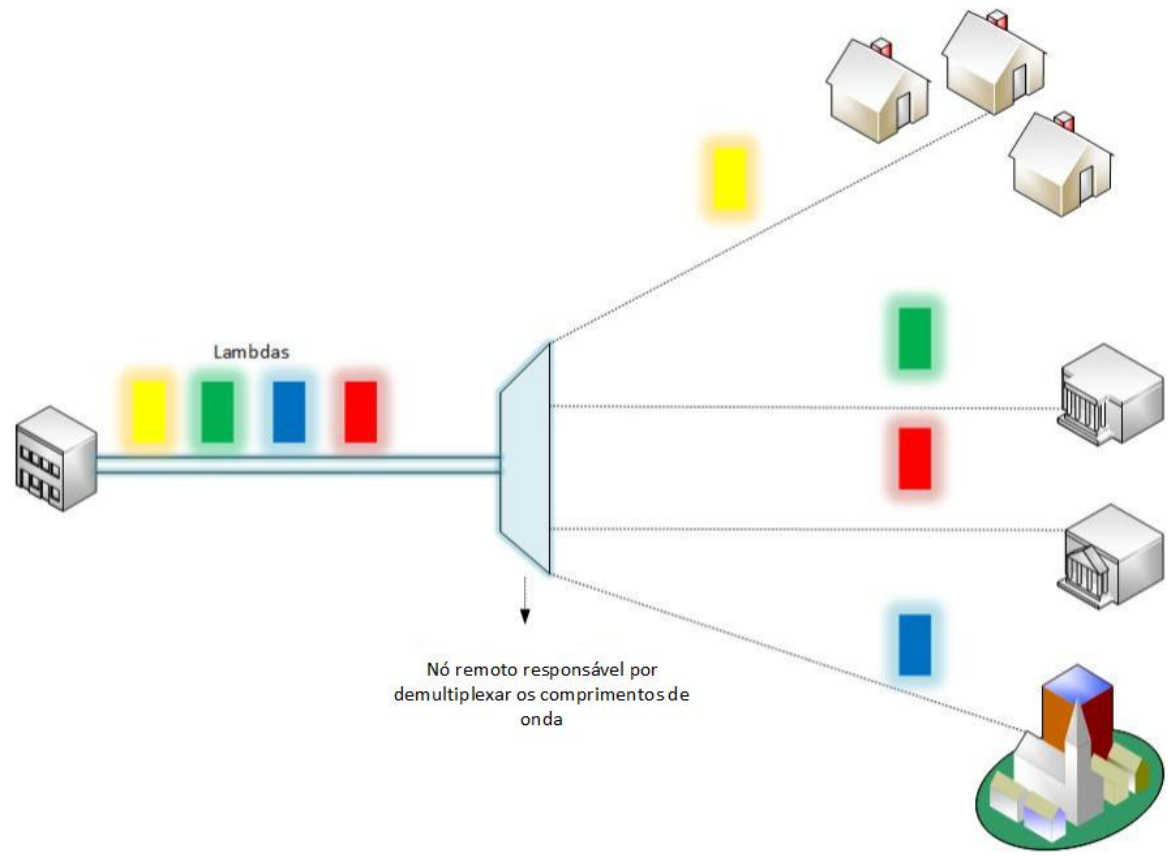

Figura 3.1: Exemplo de uma rede WDM com diferentes comprimentos de onda (Lambdas) sendo transmitidos na mesma fibra óptica

memente espaçados entre si.

O espaçamento dos comprimentos de onda em uma rede CWDM é de $2500 \mathrm{GHz}$, ou 20nm. Já em uma rede DWDM, o espaçamento é muito menor, sendo de 100, 50 ou $25 \mathrm{GHz}$, provendo dessa forma muito mais comprimentos de onda do que uma rede CWDM. Nesse contexto, a utilização de 300 comprimentos de onda em redes DWDM já foi demonstrada [FB05].

As redes ópticas também podem ser aplicadas para atenderem a três tipos diferentes de redes: As redes de longa distância [SM07], as redes metropolitanas [GPC02] e as redes de acesso [KSG $\left.{ }^{+} 07\right]$. Redes de longa distância são redes que buscam prover conexões entre áreas muito distantes entre si, como por exemplo, provedores presentes em estados diferentes ou até mesmo em continentes diferentes. Já em redes metropolitanas, os enlaces da rede óptica são utilizados para interconectarem nós de uma rede dentro da área de uma cidade ou regiões metropolitanas, como por exemplo, um conjunto de servidores em uma cidade. As redes de acesso ópticas, por fim, são utilizadas para prover a conexão entre os usuários finais e algum provedor de serviços.

Em relação ao atendimento ao usuário final (que no contexto deste trabalho é considerado como sendo o próprio RRH) por meio das redes de acesso, a crescente demanda por banda tem feito com que as tecnologias atuais de redes de acesso não ópticas, como Assymetrical Digital Subscriber Line (ADSL) [Gor00] que opera sobre enlaces de cobre ou Hybrid Fiber Coax (HFC) [Way98] que introduz uma utilização híbrida de fibras ópticas e pares metálicos, não sejam capazes de prover a banda necessária para as redes 5G. Em tais tecnologias, as taxas de transmissão alcançadas são por volta de $25 \mathrm{Mbps}$ e $38 \mathrm{Mbps}$, uma capacidade muito aquém do que é esperado para as transmissões de tráfego CPRI. Assim, a utilização de rede composta apenas de fibras ópticas para a entrega dos dados ao usuário final, ou Fiber to the x (FTTx) [Kei06], é uma forte candidata em relação às tecnologias de acesso atuais. A tecnologia FTTx é uma categoria geral que descreve as vertentes que utilizam redes ópticas como redes de acesso aos usuários finais, podendo ser dividida nas seguintes vertentes: Fiber to the Home (FTTH) $\left[\mathrm{P}^{+} 08\right]$, que considera a entrega a usuário domésticos, Fiber 
to the Building (FTTB) [LBG08], que considera a entrega dos dados a empresas, por exemplo, e Fiber to the Curb (FTTC) [SS91], onde a fibra da rede de acesso chega até um poste e do poste os sinais são entregues aos usuários, comerciais ou domésticos.

A tecnologia de redes ópticas proposta para implantação das redes FTTx é a tecnologia de redes ópticas passivas, ou PON [Kra05]. As PONs são caracterizadas por proverem altas taxas de transmissão de dados, baixos custos de operação e latência, em decorrência da não existência de equipamentos ativos entre os usuários da rede. Por conta da baixa latência provida por essas redes, ela é a candidata mais considerada pela comunidade óptica para a implantação do fronthaul em arquiteturas CRAN e na proposta arquitetura CF-RAN.

\subsubsection{Principais componentes de uma PON}

Uma PON é formada por um terminal de linha óptica, ou Optical Line Terminal (OLT), um conjunto de unidades de redes ópticas, ou Optical Network Unit (ONU)s e splitters, ou divisores, ópticos. O OLT é um equipamento instalado em um ponto de agregação dos dados transmitidos por diversos usuários finais de uma PON, como, por exemplo, o escritório de uma provedora de internet. Assim, o local de instalação do OLT é comumente chamado de CO. As ONUs, por sua vez, são instaladas no usuário.

As ONUs são responsáveis por realizar a transmissão dos dados gerados pelos usuários em sinais ópticos ou receber os dados transmitidos pela PON. Cada ONU transmite em um comprimento de onda, que por sua vez é definido e concedido para uma transmissão pela OLT. Dessa forma, a OLT pode ser vista como o orquestrador das transmissões das ONUs, gerenciando os comprimentos de onda da rede e cedendo-os às ONUs.

Além de gerenciar e definir os comprimentos de onda de cada ONU, o OLT é responsável por receber os sinais ópticos advindos de diferentes usuários de uma PON e encaminhá-los ao seu próximo destino e transmitir dados para as ONUs nos diferentes comprimentos de onda cedidos à elas. Os sinais que o OLT recebe são demultiplexados e encaminhados para transceptores ópticos chamados de Line Card (LC)s. Um LC é responsável por receber e encaminhar sinais em uma frequência específica de um comprimento de onda. Note que a quantidade de LCs presentes em um OLT é igual à quantidade de comprimentos de onda gerenciados por ele.

O splitter óptico é um elemento passivo instalado entre as ONUs e o OLT, e este é responsável por multiplexar os diferentes comprimentos de onda de fibras individuais, chamadas de fibras de distribuição, de múltiplas ONUs em direção ao OLT no sentido de uplink. No sentido de downlink, ele é responsável por dividir os sinais advindos do OLT por uma fibra de alimentação para todas as ONUs da rede. Note que o splitter é um elemento passivo e, assim, ele não realiza nenhuma filtragem dos comprimentos de onda recebidos por ele no sentido downlink, de forma que todas as ONUs recebem todos os comprimentos de onda enviados pelo OLT. Os comprimentos de onda são filtrados pelas ONUs para que o usuário receba os dados esperados de sua transmissão.

A Figura 3.2 ilustra um exemplo de uma PON e seus elementos organizados em um topologia ponto-multiponto, que é a topologia mais utilizada na implantação de PONs. Note que os únicos elementos ativos na rede são as ONUs e o OLT. 


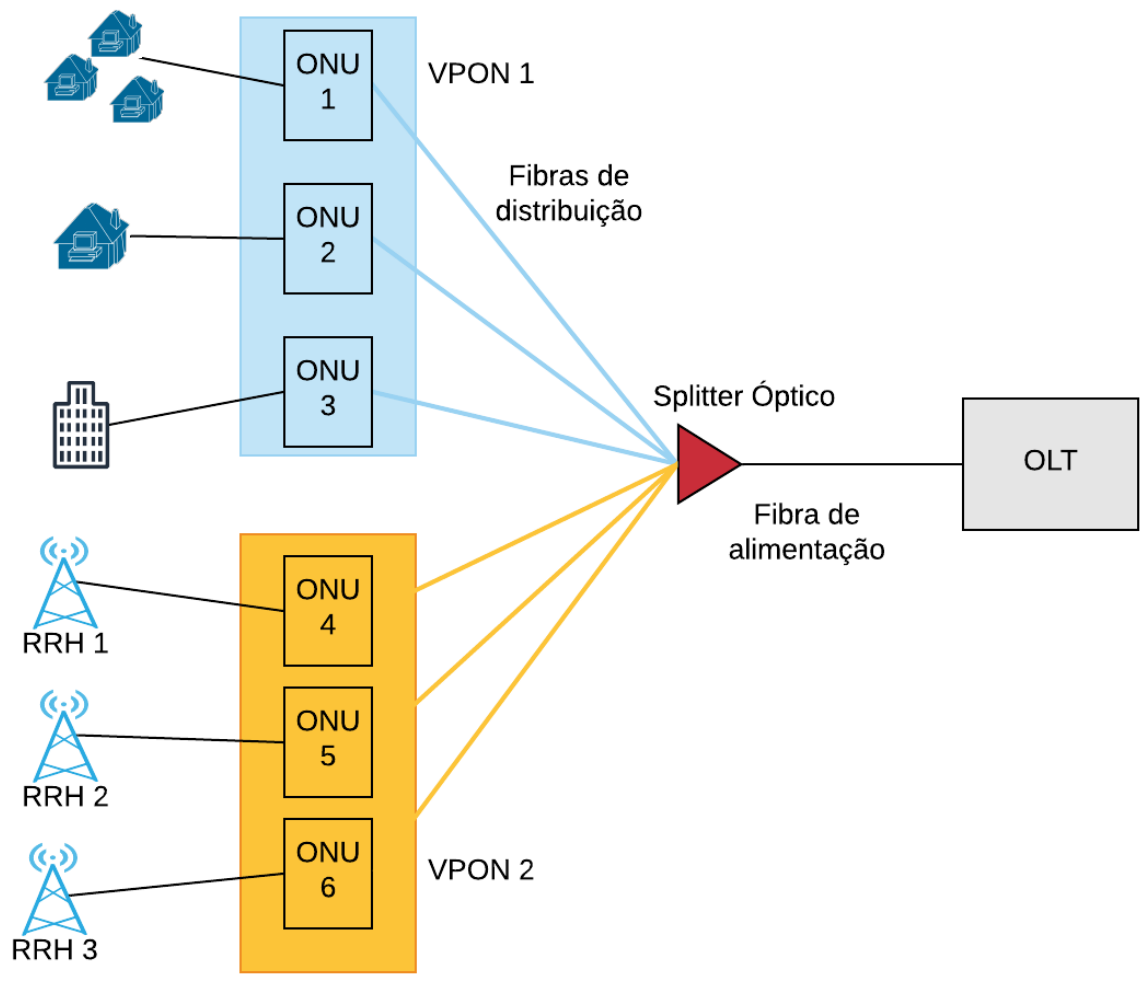

Figura 3.2: Rede TWDM-PON

\subsubsection{Tecnologias atuais e tecnologias futuras para as PONs}

A definição das PONs teve início na década de 90, pelo Full Service Access Network (FSAN), que é um grupo formado por operadoras de telecomunicação responsável pela padronização das PONs.

A primeira PON utilizava o protocolo Asynchronous Transfer Mode (ATM) [Kal02] para a sinalização em camada 2, definindo assim a primeira tecnologia de PON conhecida como Asynchronous Transfer Mode Passive Optical Network (A-PON) [XYH02]. A A-PON possuía capacidade de transmissão de 155Mbps (baixo para os padrões atuais mas significativo para a época) e, com o objetivo de aumentar a capacidade dessa rede para que uma gama maior de serviços de telecomunicação pudesse ser atendida, o grupo FSAN iniciou a definição de um padrão para uma PON de acesso a banda larga, nascendo assim a tecnologia Broadband Passive Optical Network (B-PON) [EIY01] em 1998 sob o padrão ITU-T G.983.x. Entretanto, a B-PON ainda utilizava a transmissão de quadros ATM e, para que houvesse compatibilidade com redes ethernet, em 2001 o Institute of Electrical and Electronics Engineers (IEEE) realizou a integração de dispositivos ethernet com uma PON por meio da tecnologia Ethernet Passive Optical Network (EPON) [KP02]. A EPON é capaz de prover taxas de transmissão síncronas de aproximadamente 1,25Gbps e possui capacidade de atender de 16 a 32 usuários por splitter óptico. Por sua vez, o FSAN realizou a padronização de uma nova tecnologia de PON, chamada de Gigabit Passive Optical Network (GPON) [CSI07] com taxas de transmissão maiores que a EPON e com suporte a encapsulamento ethernet e ATM na camada 2, além de um encapsulamento proprietário para serviços de voz.

Em relação à EPON, as redes GPON são capazes de prover aproximadamente 2, 5Gbps de capacidade de transmissão no sentido downstream e 1,25Gbps de capacidade no sentido upstream. 
Em relação à cobertura dos usuários, redes GPON são capazes de atender de 32 a 64 ONUs em um splitter óptico.

Atualmente, as tecnologias EPON e GPON são predominantes na utilização das PONs no mundo todo e são as escolhas naturais para implantação de cenários FTTx. Entretanto, mesmo com suas altas capacidades de transmissão, sua evolução é necessária em frente ao crescimento da demanda de banda atualmente, e que será ainda maior nos cenários de redes 5G. Essa crescente demanda de banda tem levado a definição de uma futura geração de PONs chamada de Next-Generation Passive Optical Network (NG-PON) $\left[\mathrm{KBC}^{+} 09\right]$.

\subsubsection{Redes NG-PON e TWDM-PON}

A próxima evolução das PONs é chamada de NG-PON. A proposta da NG-PON é idealizada pelos grupos FSAN, IEEE e ITU SG-15 e baseia-se em uma evolução das redes GPON, caracterizando-se pelos seguintes pontos:

- Aumento significativo das taxas de transmissão, provendo até 500Gbps

- Aumento da cobertura das ONUs provendo uma cobertura mínima de 254 ONUs até uma cobertura máxima de 1024 ONUs conectadas por splitter óptico

- Aumento na extensão das fibras em relação a redes GPON

- Baixos custos capitais e operacionais e compatibilidade com redes GPON

A evolução para redes NG-PON deve considerar uma completa evolução das tecnologias atuais de PONs, entretanto, tal evolução deve garantir que os usuários das GPONs atuais coexistam com as futuras NG-PON. Dessa forma, a evolução rumo às redes NG-PON foi dividida em duas etapas, as redes NG-PON1 e NG-PON2 [EMPP09].

As redes NG-PON1 são referidas como uma evolução a curto prazo e que seja coexistente com as PONs atuais. Nessas redes, equipamentos já utilizados poderiam receber atualizações que os fizessem operar com comprimentos de onda adicionais e de maior capacidade sem afetar as GPONs já utilizadas. Já as redes NG-PON2 representam uma evolução a longo prazo sem dependência ou compromisso com as PONs existentes.

O esforços atuais rumo ao desenvolvimento das redes NG-PON2 baseiam-se em taxas de transmissão de 10Gbps e síncronas em relação às transmissões de uplink e downlink. Além disso, espera-se que tais redes sejam flexíveis em relação à alocação de banda aos usuários.

Uma tecnologia que vem sendo fortemente considerada para a realização da NG-PON é a tecnologia TWDM-PON [LZE $\left.{ }^{+} 12\right]$. Nessa tecnologia, as transmissões dos usuários podem ser multiplexadas tanto no domínio da frequência quanto no domínio do tempo, ao passo que múltiplas ONUs podem partilhar o mesmo comprimento de onda mas dividindo suas transmissões em fatias de tempo controladas pelo OLT. Cada comprimento de onda em uma rede TWDM-PON tem uma capacidade de transmissão de 10Gbps. Outra característica das redes TWDM-PON é a instalação de lasers reajustáveis nas ONUs. A presença de lasers reajustáveis nas ONUs faz possível que cada ONU possa ser configurada em qualquer comprimento de onda disponível pelo OLT e, dependendo do estado da rede, as ONUs também podem ser reconfiguradas para outros comprimentos de onda.

A capacidade de configuração dinâmica dos comprimentos de onda em cada ONU torna possível a 
possibilidade de balanceamento de carga nos comprimentos de onda, de tal forma que, se a demanda de rede cai em algum momento, as ONUs são reconfiguradas para utilizarem a menor quantidade possível de comprimentos de onda e assim balancear a utilização da banda disponível da rede. Ainda em relação à capacidade de configuração dinâmica das ONUs, as redes TWDM-PON introduzem a capacidade de virtualização das PONs em redes ópticas passivas virtualizadas, ou VPONs.

\subsubsection{Virtualização das Redes Ópticas Passivas - VPON}

Uma VPON é uma rede óptica passiva que é configurada para uso exclusivo de uma ou mais ONUs pelo OLT. Como o OLT possui a capacidade de dinamicamente configurar os comprimentos de onda das ONUs, e a rede TWDM-PON permite que várias ONUs compartilhem o mesmo comprimento de onda por meio da multiplexação por divisão no tempo (Time Division Multiplexing (TDM) [TEK88]), as ONUs partilhando de um mesmo comprimento de onda podem ser enxergados como uma PON exclusiva na rede.

Assim, uma VPON consiste na alocação de um comprimento de onda exclusivo para um grupo de ONUs transmitindo ao OLT. Por meio de uma VPON, cada ONU consegue transmitir na taxa de 10Gbps e as VPONs também podem ser formadas para atender a requisitos específicos de uma rede. Por exemplo, uma VPON pode ser formada para atender os usuários de uma aplicação específica, como usuários domésticos ou usuários de redes móveis, como no caso de redes $5 \mathrm{G}$.

A Figura 3.2 ilustra um cenário onde duas VPONs foram criadas para atender a diferentes perfis de usuários da rede. Note que as ONUs 1, 2 e 3 foram configuradas para transmitirem os dados de áreas domésticas e comerciais, utilizando o comprimento de onda azul, formando assim a VPON 1. Por outro lado, as ONUs 4, 5 e 6 são conectadas aos RRHs que servem a uma rede móvel. Por meio da configuração dessas ONUs para transmitirem utilizando o comprimento de onda amarelo, a VPON 2 foi formada para exclusivamente transmitir os sinais de banda-base que são gerados em uma rede móvel.

Por conta da alta capacidade de banda e a dinamicidade na atribuição da mesma aos usuários oferecida por meio da criação de VPONs, a tecnologia TWDM-PON foi considerada a tecnologia de redes ópticas mais promissora para a implantação do fronthaul das redes CRAN.

Assim, além das altas taxas de transmissão e da dinamicidade na atribuição dos comprimentos de onda às ONUs, a ausência de elementos ativos ao longo da extensão das fibras de uma TWDM-PON contribui para a diminuição da latência de propagação, tendo em vista que durante a propagação de um sinal não haverá a computação de latências decorrentes de processamento em nós intermediários, o que é algo decisivo na escolha dessa tecnologia para a implantação do fronthaul de arquiteturas como a CRAN e a arquitetura proposta nesse trabalho.

Por fim, a ausência de elementos ativos contribui para uma redução nos custos energéticos dessa rede, tornando-a uma opção interessante em termos de OPEX.

\subsection{Cloud Radio Access Network - CRAN}

As arquiteturas de redes móveis CRAN surgiram como uma evolução das tradicionais arquiteturas DRAN. Nas arquiteturas DRAN, o atendimento a uma região específica de usuários em uma rede móvel era realizado por uma célula da rede, onde uma antena era responsável por receber e transmitir os sinais de banda-base originados ou destinados a equipamentos de usuários móveis. 
Um sinal de banda-base é um sinal de rádio de baixa frequência que não sofreu nenhuma modulação no dispositivo que o gerou. Esse sinal, entretanto, ao ser recebido pela antena é processado em uma série de funções das camadas 1 e 2 antes que os seus dados sejam encaminhados para as camadas superiores e as requisições de aplicações dos clientes possam ser atendidas. Essa série de processamentos efetuados no sinal de banda-base é chamada de processamento de banda-base.

Para realizar o processamento de banda-base, cada célula da rede era equipada com um dispositivo chamado de Unidade de Banda-Base, ou BBU. As BBUs são hardwares dedicados ao processamento das funções de banda-base. Após o processamento de banda-base ser realizado, os dados das camadas superiores são encaminhados a um roteador de borda da rede por uma interface de transporte chamada de backhaul. Após serem recebidos no roteador de borda, os dados são encaminhados para algum destino da rede para que os processamentos das camadas superiores possam ser realizados.

A utilização de arquiteturas DRAN se deu até a presente quarta geração de Internet móvel (4G), entretanto, essa arquitetura não é energeticamente eficiente pois cada célula da rede demanda uma infraestrutura de alimentação e refrigeração para a manutenção das BBUs. Em cenários de aumento da cobertura da rede móvel, o crescimento de uma DRAN demandará a instalação de cada vez mais infraestruturas de alimentação e refrigeração para novas células criadas na rede.

Essa necessidade por aumentar a cobertura da rede mas sem o crescimento do consumo energético levou à proposta de uma nova arquitetura que fosse capaz de diminuir o consumo da rede ao passo que novas células pudessem ser instaladas. Assim, a arquitetura CRAN nasceu da ideia de desacoplar as BBUs das células da rede com vistas em centralizá-las em uma nuvem.

As células da rede agora são equipadas com antenas de baixo consumo energético utilizadas apenas para realizar algumas funções mais simples de processamento de banda-base, tais como amplificação, conversão analógica/digital e processamento de rádio frequência. O restante das funções de processamento é realizado de forma remota na nuvem. Por isso, tais antenas são chamadas de RRHs. Como todas as BBUs estão centralizadas na nuvem, apenas uma única infraestrutura de alimentação e refrigeração é utilizada para manter suas operações, reduzindo assim os custos capitais e operacionais da rede.

A desacoplação das BBUs também levou à necessidade de uma rede de transporte, o fronthaul, para conectar as células da rede e a nuvem. Entretanto, como já supracitado no capítulo introdutório desta Tese, a centralização do processamento de banda-base pode esgotar tanto a capacidade do fronthaul quanto da nuvem, levando até mesmo a interrupções dos serviços da rede, o que justifica nossa proposta de uma arquitetura que visa expandir as capacidades da CRAN ao mesmo tempo que opera de uma forma energeticamente eficiente. 


\section{Capítulo 4}

\section{Arquitetura Cloud-Fog RAN}

Neste capítulo a arquitetura CF-RAN será apresentada. Primeiramente, serão discutidos os detalhes da rede utilizada no fronthaul para conectar os RRHs e os nós de processamento. Após isso, serão apresentadas a arquitetura dos nós de processamento e a operação geral da arquitetura CF-RAN. O conteúdo deste Capítulo foi publicado em [TRB $\left.{ }^{+} 17\right]$, [TBF18] e [TBF ${ }^{+}$19b].

\subsection{Organização geral da arquitetura CF-RAN}

O objetivo da arquitetura CF-RAN é de aumentar a cobertura oferecida por redes CRAN por meio do oferecimento de um ambiente híbrido entre nuvem e computação em névoa. Entretanto, sua principal premissa é o provisionamento de uma operação eficiente no que diz respeito à ativação de seus recursos de processamento e de rede.

A arquitetura CF-RAN é organizada em duas camadas de processamento, a camada de nuvem e a camada de névoa. A camada de nuvem é composta por um nó de processamento único, que é a nuvem em si. Note que neste ponto, múltiplos nós de processamento podem compor a nuvem, entretanto, neste trabalho, por questões de simplicidade, nós consideramos que a camada de nuvem é composta por apenas um nó de processamento. Uma nuvem formada por múltiplos nós de processamento iria demandar a proposta de uma rede óptica adicional utilizada apenas para a interconexão desses nós. A camada de névoa, por sua vez, é composta por múltiplos fog nodes que são instalados mais próximos dos usuários. Cada fog node é conectado a um grupo de RRHs. Cada RRH, por sua vez, é conectado há um único fog node por meio de uma fibra óptica dedicada. Neste trabalho nós assumimos que não existe uma rede de interconexão entre os fog nodes, de forma que não há a possibilidade de comunicação entre eles sem utilizar a nuvem. Entretanto, a presença de uma rede de interconexão dos fog nodes é um tema futuro de pesquisa decorrente deste trabalho.

Assim, a arquitetura CF-RAN é composta por RRHs presentes nas células da rede, fog nodes e uma nuvem, responsáveis por prover o processamento de banda-base virtualizado e um fronthaul implantado sob uma rede TWDM-PON que conecta os RRHs tanto às camadas de nuvem e névoa.

No contexto de operação eficiente da CF-RAN, este trabalho considera uma operação eficiente como aquela em que a minimização do consumo de energia, dentre outras métricas de desempenho, é priorizada. Assim, a utilização da nuvem é priorizada sobre os fog nodes. Os fog nodes, por sua vez, são recursos auxiliares que são dinamicamente ativados conforme os recursos de processamento ou de rede da nuvem são esgotados. Além disso, o particionamento das funções de processamento não é considerado neste trabalho, de forma que o processamento de banda-base de cada RRH é realizado 
inteiramente ou na nuvem ou em um fog node. Por fim, a Figura 4.1 apresenta um panorama geral da arquitetura e organização da CF-RAN.

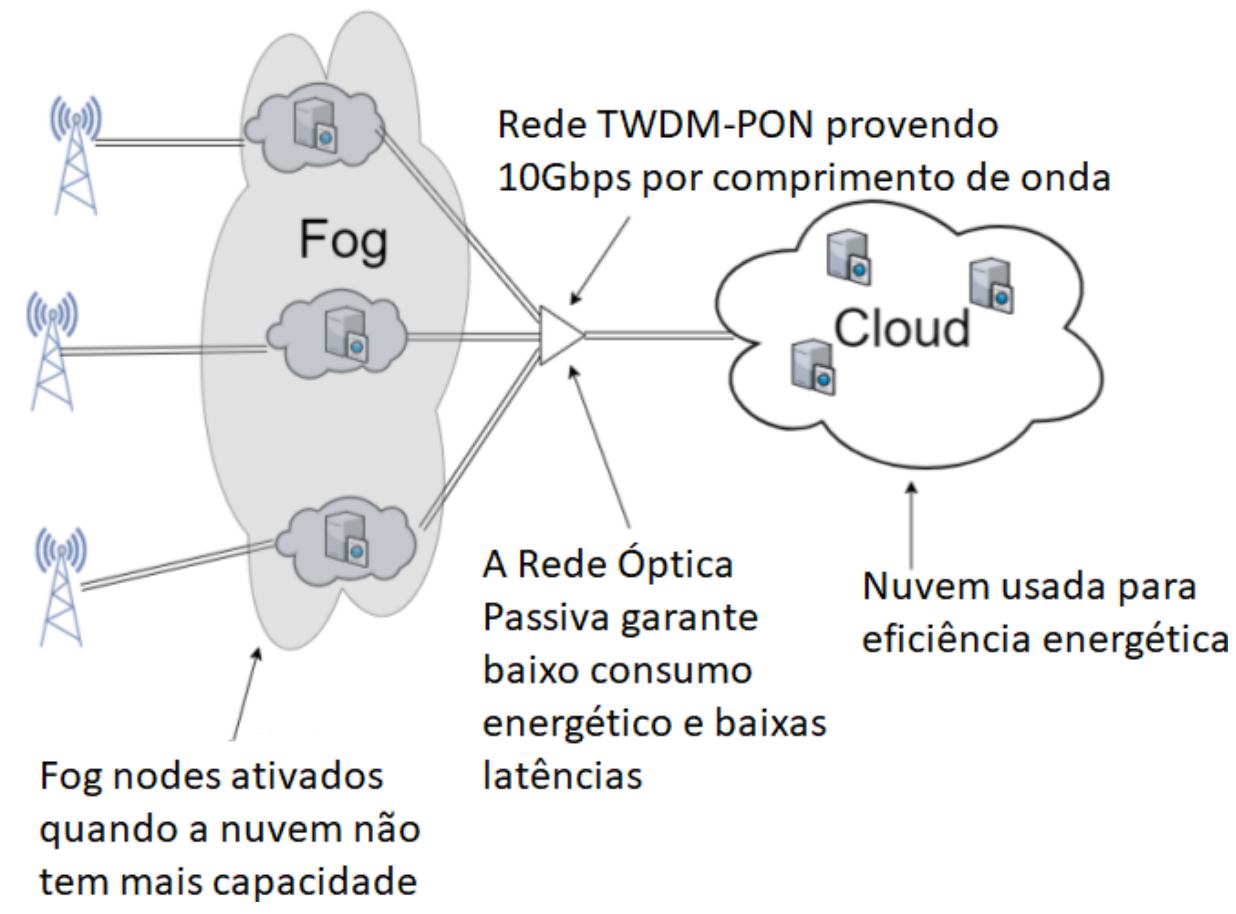

Figura 4.1: Panorama geral da arquitetura $C F-R A N$

Em relação ao fronthaul, múltiplos enlaces de fibra óptica são utilizados para prover a conexão necessária entre todos os elementos da rede. Os detalhes acerca da arquitetura do fronthaul são apresentados na próxima seção.

\subsection{Arquitetura do fronthaul TWDM-PON}

Cada RRH da rede é conectado por uma fibra óptica dedicada a uma unidade de rede óptica (ONU). As ONUs são responsáveis por transmitirem os dados dos RRHs conectados a ela em um comprimento de onda específico. Na arquitetura CF-RAN, cada ONU pode ser conectada a um ou múltiplos RRHs. Assim, é uma escolha do operador conectar um RRH em uma ONU single-port ou vários RRHs em uma ONU multi-port.

Nesse trabalho, uma ONU multi-port será referida como um grupo de agregação (GA). A Figura 4.2 a) mostra RRHs sendo conectados a ONUs single-port e a Figura 4.2 b) mostra uma ONU multi-port sendo usada para realizar a conexão de múltiplos RRHs.

A utilização de ONUs single-port irá aumentar a quantidade de ONUs instaladas na rede em comparação com a agregação de múltiplos RRHs em uma única ONU. Entretanto, se ONUs multiports forem usadas, o tráfego CPRI requerido em cada ONU irá aumentar. Nós iremos considerar esses dois esquemas de conexões RRHs-ONUs para explorar diferentes opções de consumo de energia na arquitetura CF-RAN.

O comprimento de onda que cada ONU deve usar é decidido por um terminal de linha óptica (OLT), que reside no lado do receptor e é responsável por configurar cada ONU para transmitir em um comprimento de onda disponível. Na arquitetura CF-RAN, cada nó de processamento é equipado com uma OLT. 


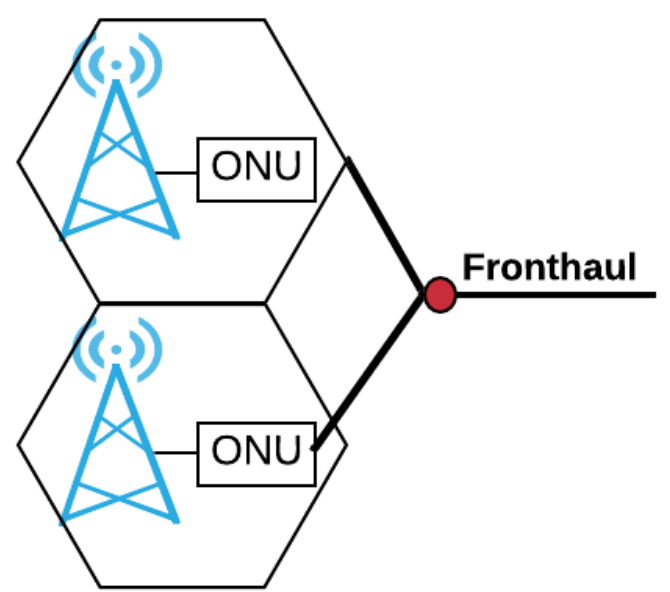

a) RRHs conectados em ONUs single-port

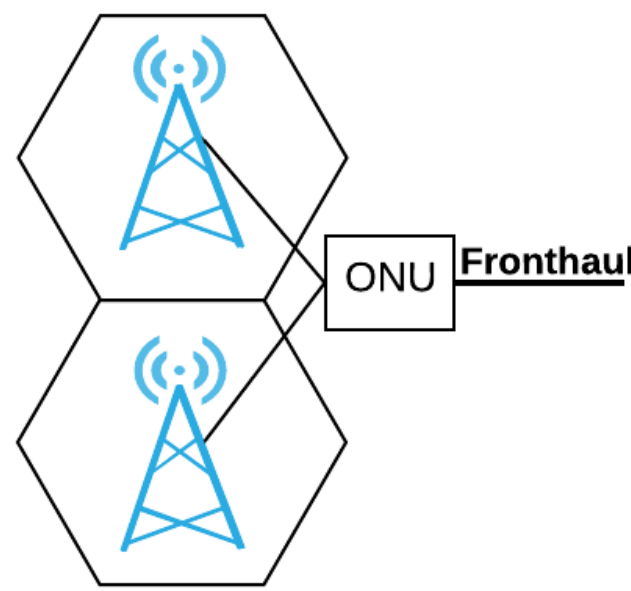

b) RRHs conectados em ONUs multi-port

Figura 4.2: As duas opções de conexão dos RRHs às ONUs

Nós assumimos que cada ONU é equipada com lasers reconfiguráveis que podem ser configurados para transmitirem em qualquer um dos comprimentos de onda disponíveis na rede. Assim, cada ONU pode utilizar qualquer comprimento de onda para realizar suas transmissões.

Como visto na Figura 4.1, cada ONU é conectada a um fog node e à nuvem. Para permitir que os dados transmitidos na TWDM-PON possam ser recebidos tanto na nuvem quanto nos fog nodes, a topologia apresenta três níveis de multiplexação.

No primeiro nível de multiplexação, múltiplas ONUs são conectados a um splitter óptico interno a um fog node. Esse splitter interno é responsável por direcionar o tráfego à OLT do fog node ou a uma fibra de distribuição que encaminha seus sinais rumo à nuvem. Essa conexão é ilustrada na Figura 4.3, onde dois splitters ópticos internos aos fog nodes 1 e 2 encaminham tráfego CPRI tanto para os OLTs dos fog nodes quanto para o splitter nível 2.

No segundo nível de multiplexação, um splitter óptico de nível 1 é utilizado para multiplexar o tráfego de múltiplas fibras de distribuição em uma fibra de alimentação. Por fim, conectado à nuvem há um splitter óptico de nível 2, responsável por multiplexar o tráfego de diferentes fibras de alimentação e encaminhar os comprimentos de onda para a OLT da nuvem.

Como a CF-RAN opera sob o protocolo CPRI para prover a transmissão dos dados pelo fronthaul, a arquitetura aqui proposta deve operar sob as restrições de latência impostas pelo CPRI.

\section{Latência Máxima do Fronthaul}

Durante a transmissão e processamento de tráfego CPRI, o fronthaul deve prover uma latência de ida e volta entre os RRHs e as vBBUs que não exceda a latência máxima de 3 ms requerida pelo protocolo HARQ [WTT $\left.{ }^{+} 16\right]$.

O protocolo HARQ é utilizado para sincronizar a transmissão e solicitar retransmissão de quadros entre os RRHs e os equipamentos de usuários [LSPS09]. O HARQ impõe que os equipamentos de usuários devem receber mensagens $A C K / N A C K$ de suas vBBUs dentro do intervalo da transmissão de três sub-quadros após a transmissão de dados para o RRH. Se o equipamento do usuário 


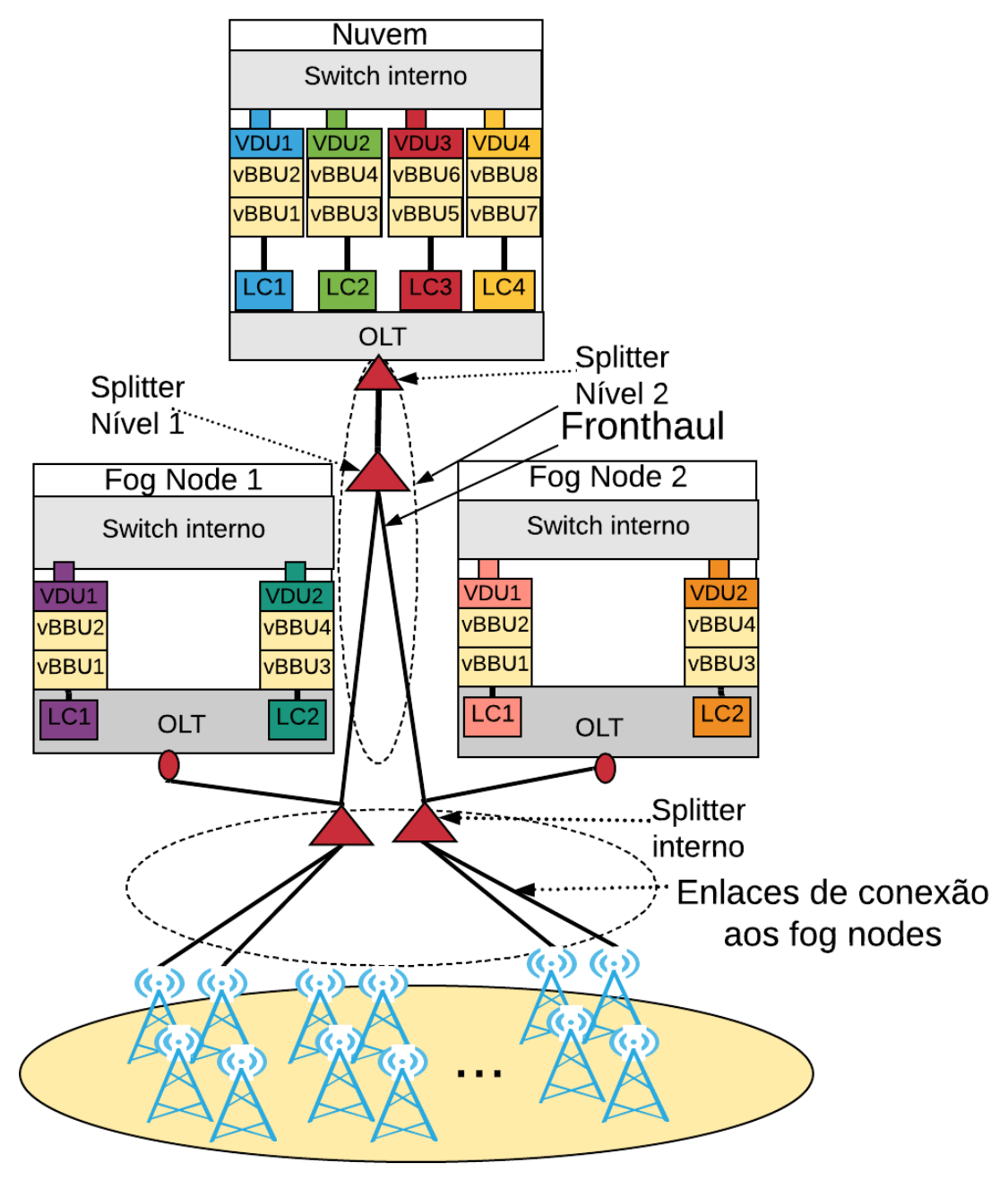

Figura 4.3: Detalhes dos nós de processamento

não recebe nenhuma mensagem $A C K / N A C K$ nesse intervalo, eles irão retransmitir os dados para o RRH. Note que, se essa latência não for atendida, a transmissão entre equipamentos e RRHs será dessincronizada.

O limite de $3 \mathrm{~ms}$ vem dos valores de latência das funções de processamento apresentadas na Tabela 4.1, que compõem o processamento de banda-base até a operação do HARQ.

A latência de processamento dos sinais de radiofrequência no RRH, tanto no uplink (UL) (quando os sinais são recebidos dos equipamentos de usuários) quanto no downlink (DL) (quando o $\mathrm{RRH}$ transmite os quadros para os equipamentos de usuários) somam uma latência total de $\sim 40 \mu \mathrm{s}$. A latência de processamento de cada quadro CPRI é de $\sim 10 \mu \mathrm{s}$, considerando o encapsulamento e desencapsulamento dos quadros CPRI nos RRHs e vBBUs, respectivamente. Finalmente, o tempo de processamento que cada quadro CPRI toma em sua vBBU é de $\sim 2700 \mu$ s.

Somando-se essas latências, o tempo total de processamento de banda-base de cada quadro CPRI é de $40 \mu \mathrm{s}+10 \mu \mathrm{s}+2700 \mu \mathrm{s}=2750 \mu \mathrm{s}$, e a latência máxima introduzida pela transmissão desses quadros no fronthaul é de no máximo $250 \mu$ s [Net15]. 
Tabela 4.1: Latência do processamento de banda-base

\begin{tabular}{|l|l|}
\hline Latência de processamento de radiofrequência dos RRHs em UL/DL & $\sim 40 \mu \mathrm{s}$ \\
\hline Latência de processamento dos quadros CPRI (RRH + BBU) & $\sim 10 \mu \mathrm{s}$ \\
\hline Latência de processamento na BBU (UL/DL PHY +MAC) & $\sim 2700 \mu \mathrm{s}$ \\
\hline
\end{tabular}

\subsubsection{Arquitetura dos nós de processamento}

A Figura 4.3 mostra a arquitetura dos nós de processamento utilizados para o provisionamento de processamento virtualizado do tráfego CPRI. Tanto o nó de nuvem quanto os fog nodes possuem as mesmas arquiteturas e funções, diferenciando-se apenas em suas capacidades de processamento.

Para que seja possível receber o tráfego advindo do fronthaul, cada OLT nos nós de processamento é equipada com um conjunto de transceptores ópticos chamados de LC. Os LCs operam na frequência de um comprimento de onda exclusivo e são responsáveis tanto por receber tráfego CPRI de transmissões uplink quanto por realizarem transmissões downlink rumo às ONUs. Nesse sentido, quando múltiplas ONUs são configuradas no mesmo comprimento de onda, um VPON é criado e o LC ressonante na frequência do VPON é o elemento responsável por receber seus sinais ópticos e os encaminhar para o processamento de banda-base.

Nesse contexto, cada LC é exclusivamente conectado a um container de processamento virtualizado de banda-base chamado de VDU. Cada VDU é responsável pela instanciação de funções de processamento virtualizadas, ou Virtualized Processing Functions (VPF)s que provêm controle na rede. Entre essas funções de controle, o processamento de banda-base é virtualizado em VPFs específicas chamadas de vBBUs, que são as próprias BBUs virtualizadas.

Assim, o tráfego recebido em um LC é encaminhado para a sua VDU para que seja processado nas vBBUs ali instanciadas.

Cada VDU tem uma capacidade limitada de processamento, o que é um fator limitador para a quantidade de vBBUs que podem ser instanciadas nela. Como cada VPON pode realizar o transporte de uma carga de tráfego CPRI que exceda a capacidade de vBBUs da VDU associada ao VPON, um cenário de redirecionamento de tráfego entre VDUs é necessário.

Nesse caso, cada nó de processamento é equipado com um switch interno responsável por comutar, ou redirecionar quadros CPRI entre VDUs.

No caso de todo o tráfego CPRI recebido em um VPON ser maior que a capacidade da VDU associada ao seu LC, esse switch é utilizado para transmitir o tráfego excedente recebido na LC para uma VDU auxiliar. Note que, nesse caso, a utilização do switch irá implicar em consumo adicional de energia e em latências adicionais também, decorrentes da comutação dos CPRI para VDUs auxiliares.

Tanto as VDUs quanto as vBBUs são elementos virtualizados que podem ser ativados e desativados conforme a necessidade da rede. Da mesma forma, como as VPONs são criadas mediante a configuração dinâmica de um conjunto de ONUs em um comprimento de onda, elas também podem ser tanto criadas, modificadas (retirada de uma ONU de umVPON) ou desativadas dinamicamente.

Por conta disso, a operação da CF-RAN é baseada na ativação e desativação dinâmica desses recursos, de tal maneira que eles sejam ativados e desativados conforme a demanda da rede para que o melhor desempenho seja obtido na rede. Assim, no próximo capítulo nós apresentamos o problema de alocação de recursos de processamento e de rede para o suporte do processamento de banda-base. 
Assim, para cada carga CPRI ingressante na rede, a quantidade necessária de VDUs e vBBUs deve ser ativada para suprir a demanda de processamento. Além disso, deve-se decidir se esses elementos serão ativadas na nuvem ou nos fog nodes. Por fim, após a alocação das vBBUs ser decidida, a quantidade necessária de VPONs deve ser criada no fronthaul para realizar as transmissões nos nós de processamento que foram ativados para receber a carga CPRI a ser processada.

A próxima seção irá apresentar a definição dos problemas de alocação de vBBUs e de dimensionamento de comprimento de onda e formação de VPONs.

\subsection{Alocação de vBBUs e dimensionamento de comprimentos de onda e formação de VPONs energeticamente eficiente}

Cada RRH ativo na rede móvel irá gerar uma porção de tráfego CPRI que deve ser transmitida até a camada de névoa ou de nuvem para ser processada. Nós iremos nos referir neste trabalho a uma porção de tráfego CPRI gerada por um RRH como uma requisição CPRI.

Durante a operação da rede, para cada RRH gerando requisições CPRI deve ser descoberto um nó de processamento com disponibilidade computacional suficiente para receber e processar essa requisição. Isso implica na descoberta de um nó de processamento cujas VDUs possuam capacidade para que uma nova vBBU seja instanciada para o processamento dessas requisições.

A descoberta de um nó de processamento apto para receber o processamento de uma requisição CPRI pode considerar diferentes métricas com vistas na otimização de diferentes métricas de operação da rede. Por exemplo, como os fog nodes são instalados mais próximos dos RRHs, se for priorizada o processamento de requisições CPRI em fog nodes, os RRHs que usarem esses nós de processamento para execução de suas requisições CPRI irão oferecer um serviço de menor latência para os usuários de suas áreas de cobertura. Por outro lado, se buscar-se otimizar o consumo de energia da rede, prioriza-se a utilização da nuvem sobre os fog nodes para a execução do processamento de banda-base. Entretanto, note que a escolha da métrica de desempenho para a descoberta de um nó de processamento pode causar o surgimento de trade offs na rede.

Conforme o exemplo dado, caso a diminuição da latência seja priorizada, mais fog nodes poderão ser ativados na rede, ultrapassando em muito o consumo energético eficiente que o uso priorizado da nuvem poderia gerar. Por outro lado, caso a utilização da nuvem seja priorizada, a latência total de processamento de banda-base pode ser aumentada pois a nuvem encontra-se mais distante dos RRHs.

Nesta Tese, nós buscamos balancear a operação da rede em termos de suas métricas de desempenho. Entretanto, o principal objetivo dos algoritmos que serão propostos será a diminuição do consumo de energia. Assim, nossas propostas irão priorizar a utilização da nuvem para evitar que um uso indiscriminado dos fog nodes possa ocorrer.

Durante a operação da rede, os RRHs podem ser ativados ou desativados em função da presença ou ausência de equipamentos móveis em suas áreas de cobertura. Assim, para cada RRH que tornase ativo na rede, é verificado na nuvem se existe alguma VDU ativa para a instanciação de uma vBBU para receber o tráfego desse RRH. Caso não haja nenhuma VDU ativa, seguindo o paradigma de NFV, uma nova VDU é ativada e uma vBBU é instanciada para receber a requisição CPRI. Caso já existam VDUs ativas, uma delas, com capacidade suficiente para a instanciação de novas vBBUs deve ser escolhida para o processamento da requisição. Para aumentar a eficiência energética da 
rede, buscar-se-á a instanciação de vBBUs primeiramente esgotando-se a capacidade das VDUs já ativas antes que novas VDUs sejam ativadas, em um comportamento first-fit.

Após a VDU ser escolhida, a vBBU será instanciada. Note que, caso não haja disponibilidade computacional na nuvem, isto é, todas as VDUs estão ativas e não têm capacidade para a instanciação de novas vBBUs, os fog nodes serão ativados para a instanciação de novas VDUs e vBBUs. Nesse contexto, a capacidade computacional dos fog nodes é aproveitada da mesma forma que a capacidade das VDUs: primeiramente esgota-se toda a capacidade computacional de um fog node antes da ativação de novos fog nodes, fazendo com que os fog nodes sejam ativadas um a um na rede. Quanto à escolha das VDUs dentro dos próprios fog nodes, a mesma estratégia first-fit utilizada para a instanciação de novas vBBUs na nuvem também é utilizada.

Como já supracitado, além da alocação de uma VDU e vBBU em um nó de processamento, é necessário que os requisitos de banda de cada requisição CPRI sejam atendidos para que o tráfego da requisição possa ser transmitido entre um RRH e sua vBBU pelo fronthaul. Assim, além da alocação dos recursos de processamento, faz-se necessário que um canal de transmissão no fronthaul TWDM-PON seja alocado para a transmissão da requisição.

O fronthaul TWDM-PON opera utilizando-se do conceito de virtualização da PON, ou, VPON para realizar a transmissão das requisições CPRI. Como supracitado, uma VPON é capaz de agregar o tráfego de múltiplos RRHs e multiplexá-los no domínio do tempo. Em relação à utilização das VPONs para suporte do tráfego gerado na rede, para os diversos RRHs que transmitem a um nó de processamento, um comprimento de onda disponível na rede é reservado para esses RRHs e suas ONUs são configuradas para transmitirem nessa frequência específica, formando assim a VPON. A escolha de um comprimento de onda para atender a grupos de RRHs é chamada de problema de formação de VPONs. No contexto da arquitetura CRAN, o problema de formação de VPONs basicamente trata da escolha de um comprimento de onda que tenha capacidade para receber um ou mais RRHs com o objetivo de transmitirem seus sinais rumo a um LC presente na OLT da nuvem. Note que nesse cenário, todas VPONs formadas na rede transmitirão para a nuvem.

Entretanto, no contexto da arquitetura CF-RAN, diferentemente da arquitetura CRAN, não existe apenas um nó de processamento, que é a nuvem, mas sim um conjunto de nós de processamento que podem receber o tráfego advindo de uma ou mais VPONs. A presença de mais nós de processamento que podem receber o tráfego de uma VPON é um fator complicador para a formação das VPONs, pois, se um comprimento de onda for utilizado para transmitir o tráfego de duas ou mais VPONs em múltiplos nós de processamento, os sinais de VPONs destinados a nós diferentes, mas com seus dados modulados no mesmo comprimento de onda, poderão colidir na rede.

Assim, o problema de formação de VPONs na arquitetura CF-RAN deve procurar evitar a ocorrência de colisões nos enlaces do fronthaul. Isso pode ser feito limitando cada comprimento de onda a ser utilizado para a criação de uma VPON em um nó de processamento exclusivo. Em outras palavras, os comprimentos de onda devem ser dimensionados e exclusivamente alocados a cada nó de processamento de forma que cada VPON seja roteado a um único destino na rede, evitando que VPONs de mesma frequência se cruzem no fronthaul e gerem colisão dos sinais ópticos. Note que, além da colisão dos sinais ópticos no fronthaul, caso duas ou mais VPONs de mesma frequência transmitam a nós de processamento diferentes, por conta da operação passiva da rede, os sinais de todas as VPONs serão encaminhados para todos os LCs da rede pelos splitters ópticos, fazendo com que sinais destinados a um nó de processamento específico sejam recebidos nos LCs de outro 


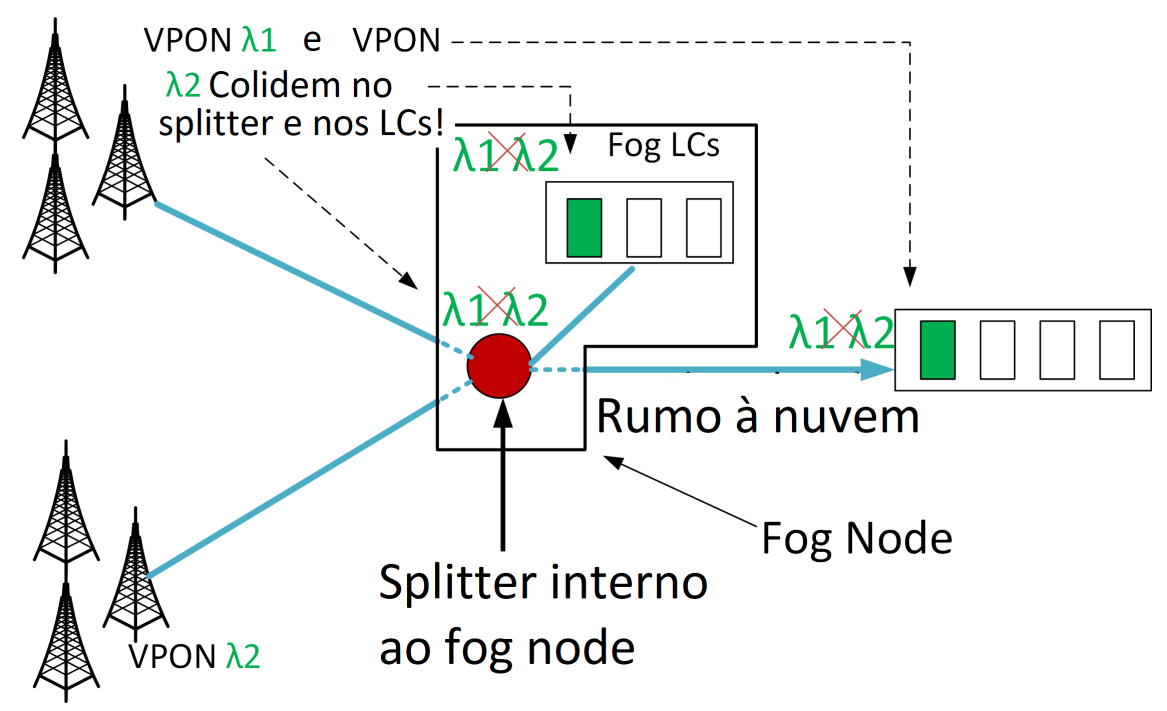

Figura 4.4: Colisão de comprimentos de onda no fronthaul da arquitetura $C F-R A N$

nó, causando um transtorno a este nó que irá receber esses dados incorretos e deverá realizar a leitura do cabeçalho CPRI antes de descartá-los, o que pode gerar ainda mais consumo energético e atrasos por conta desse processamento adicional. Note que, apesar da rede TWDM-PON controlar a ocorrência de colisões no domínio do tempo por meio de um algoritmo de Dynamic Bandwidth Allocation (DBA), esse controle é utilizado para controlar o fluxo de dados de cada VPON, e não o fluxo de dados de diferentes VPONs em meio a diferentes nós de processamento. Logo, faz-se necessário que as VPONs sejam eficientemente dimensionadas entre os nós de processamento da rede para evitar colisões.

A ocorrência de colisão nos enlaces da rede ou recebimento de sinais das VPONs em nós errados é ilustrado na Figura 4.4. Nessa Figura existe uma nuvem e um fog node e as VPONs 1 e 2 foram criadas utilizando-se do comprimento de onda verde, para transmissão para a nuvem e para o fog node. Note que, como os sinais das duas VPONs serão transmitidos rumo ao splitter óptico, isso gera uma colisão entre eles ao serem multiplexados na fibra de distribuição que está conectada nesse splitter, além dos sinais colididos serem encaminhados para ambos os nós de processamento, gerando também a entrega de dados corruptos aos LCs de ambos os nós.

Como supracitado no Capítulo 3, a formação de uma VPON compreende a alocação de um comprimento de onda que será recebido em um LC em algum nó de processamento. Os LCs são elementos ativos da rede que consomem energia para a realização da demultiplexação dos sinais ópticos recebidos e encaminhamento dos mesmos para as VDUs. Logo, a quantidade de VPONs criados na rede irá demandar a ativação de uma mesma quantidade de LCs nos nós de processamento. Assim, para que o consumo de energia da rede possa ser sempre otimizado, busca-se a minimização das VPONs ativas na rede, o que faz necessário que os comprimentos de onda sejam dimensionados de forma energeticamente eficiente nos nós de processamento da rede. Em outras palavras, busca-se diminuir a quantidade de VPONs ativas para o suporte de uma determinada demanda de tráfego com vistas na minimização do consumo energético proveniente da ativação das LCs.

É importante ressaltar que, a capacidade de banda do fronthaul estará dividida entre a capacidade total de transmissão destinada à nuvem e aos fog nodes. A capacidade total de transmissão destinada à nuvem é dada em função da quantidade de comprimentos de onda alocados à ela, e semelhantemente, a capacidade de transmissão de cada fog node é dada em função da quantidade 
dos comprimentos de onda alocados a cada um deles. Note que, como os comprimentos de onda são recursos limitados, eles devem ser eficientemente dimensionados entre os nós de processamento. Se um operador reservar todos os comprimentos de onda para transmissões rumo à nuvem, não haverá comprimentos de onda disponíveis para transmitir aos fog nodes quando estes forem ativados. Da mesma forma, se todos os comprimentos de onda são reservados aos fog nodes, não haverá comprimentos de onda para transmitir à nuvem quando a capacidade dos fog nodes for exaurida.

Ainda no contexto do dimensionamento dos comprimentos de onda entre os nós de processamento, pode ocorrer o caso da capacidade de transmissão da nuvem ser exaurida antes mesmo de sua capacidade de processamento. Isso pode ocorrer devido à configuração MIMO de cada RRH, que, a depender do crescimento da demanda da rede, pode aumentar o tráfego CPRI gerado em cada RRH de tal forma que um VPON não seja capaz de suportar seu tráfego, mesmo que seu nó de processamento tenha capacidade para suportar o processamento de requisições CPRI advindas de RRHs com configurações MIMO gerando menor tráfego. Nesse caso, caso haja esse esgotamento da banda da nuvem, os fog nodes também serão ativados para receber esse tráfego excedente.

Por fim, a alocação e formação eficiente tanto das vBBUs quanto das VPONs irá impactar o desempenho da rede. Por conta disso, será apresentado na próxima seção um modelo de avaliação de desempenho da arquitetura CF-RAN.

\subsection{Modelo de avaliação de desempenho}

Como a arquitetura CF-RAN baseia-se fortemente na cooperação entre nuvem e névoa, faz-se necessário que um modelo de avaliação de desempenho seja utilizado para capturar as vantagens, desvantagens e nuances dessa cooperação. Por natureza, a nuvem e a névoa compartilham similaridades em relação às suas habilidades computacionais, mas, por outro lado, sua cooperação pode levar a comportamentos opostos na rede. Por exemplo, a nuvem implementa uma natureza centralizada de processamento ao passo que a névoa implementa uma natureza distribuída de processamento, o que pode levar ao surgimento de trade offs durante a operação da rede $5 \mathrm{G}$.

Por conta disso, é necessário que, durante a operação da rede ou durante a avaliação de novos protocolos, o comportamento de diferentes métricas de desempenho seja capturado para que todas as nuances advindas da cooperação entre nuvem e névoa sejam identificadas.

Assim, nessa seção nós iremos apresentar um conjunto de métricas de desempenho identificadas durante o desenvolvimento deste trabalho e modelos matemáticos para sua avaliação.

A principais métricas identificadas nesta Tese para avaliação de desempenho da arquitetura CF-RAN foram as seguintes: Consumo energético, latência do fronthaul, latência da comutação entre VDUs, probabilidade de bloqueio, taxa de desperdício de banda e taxa de utilização das VDUs. A seguir essas métricas são descritas.

\section{Consumo energético}

O consumo energético da rede é proveniente do consumo energético de todos elementos ativos da rede, seja de processamento ou de transmissão. Entretanto, note que só consideraremos para avaliação de desempenho os elementos que são dinamicamente ativados ou desativados na rede, tais como os nós de processamento, as VDUs, vBBUs, o switch interno dos nós e as LCs utilizadas para recebimento do tráfego das VPONs.

Assim, o consumo de energia pode ser modelado conforme a equação a seguir 


$$
C_{n e t w o r k}=\left(\sum_{n=1}^{N} x_{n} . C_{n}\right)+\left(\sum_{w=1}^{W} \sum_{n=1}^{N} z_{w n} . C_{l c}\right)+\left(\sum_{n=1}^{N} e_{n} . C_{e}\right)
$$

onde $x_{n}$ é um conjunto de variáveis binárias representando cada nó $n$ ativo durante a operação da rede, $C_{n}$ é o custo energético em watts de cada nó de processamento $n, z_{w n}$ é um conjunto de variáveis binárias representando cada VPON $w$ criada para transmitir tráfego ao nó de processamento $n, C_{l c}$ é o custo em watts de cada LC ativa na rede, $e_{n}$ é o conjunto de binários que representam os switches $e$ ativados em cada nó $n$ para realizar a comutação entre VDUs e $C_{e}$ é o custo em watts da ativação de cada switch. Entretanto, note que que se a formulação de algum algoritmo considerar mais ou menos elementos em sua execução, a equação de consumo de energia será modificada com a adição ou exclusão desses possíveis elementos.

Por fim, em relação ao consumo energético, a Tabela 4.2 apresenta os valores considerados em nossos algoritmos [WTT $\left.{ }^{+} 16\right]$ [WAC17] para suas execuções e nas análises dos resultados. Tanto a nuvem quanto cada fog node possuem um valor fixo de consumo energético, dado em função de sua infraestrutura e de seu poder computacional. Além desse consumo fixo, há um consumo variável que é dado em função das VDUs, vBBUs e LCs que são instanciadas, tanto na nuvem quanto nos fog nodes.

Tabela 4.2: Custo energético dos elementos da CF-RAN

\section{Elemento}

Nó DRAN

Consumo base da nuvem

Consumo base de um fog node

Consumo de uma VDU na nuvem e nos fog nodes

Consumo de uma vBBU

Consumo de um LC

Consumo de um OLT

Consumo de um switch interno

Custo
600 watts
600 watts
300 watts
100,50 watts
20 watts
5 watts
100 watts
15 watts

\section{Latência do fronthaul}

Conforme supracitado, a latência máxima permitida no fronthaul é de apenas $250 \mu$ s para realizar uma transmissão de ida e volta entre os RRHs e suas vBBUs.

Como o fronthaul TWDM-PON da arquitetura CF-RAN não é equipado com nenhum equipamento ativo entre as ONUs e as vBBUs, a latência do fronthaul é modelada como o tempo tomado por cada sinal óptico de uma VPON para ser transmitido entre dois pontos na rede. Tal latência é então expressa como

$$
F_{\text {latency }}=2\left(D_{\text {rrh-proc }} / L_{\text {speed }}\right)
$$

onde $F_{\text {latency }}$ é a latência geral de propagação no fronthaul, $D_{r r h-p r o c}$ é a distância em km entre um RRH e o nó de processamento que hospeda sua vBBU e $L_{\text {speed }}$ é a velocidade da luz dentro do núcleo da fibra óptica, que é $\sim 2 * 10^{8} \mathrm{~m} / \mathrm{s}$, considerando uma fibra multi-modo com um núcleo de $50 \mu \mathrm{m}$ de largura. O fator de 2 é utilizado para computar o tempo de propagação considerando uma transmissão de ida e volta entre os RRHs e as vBBUs.

\section{Latência da comutação entre VDUs}


Essa métrica de latência busca capturar a operação de comutação de tráfego CPRI entre múltiplas VDUs. Por exemplo, se o tráfego CPRI transmitido em uma VPON for processado em vBBUs presentes em duas ou mais diferentes VDUs, o switch interno é ativado para comutar o tráfego entre essas VDUs. Para modelar esse comportamento, nós utilizamos variáveis binárias que representam o tráfego CPRI dos RRHs que sofreram comutação entre VDUs. Assim, a latência de comutação pode ser expressada como

$$
\sum \sum_{i=1}^{R} k_{i n}
$$

onde $k_{i n}$ é um conjunto de variáveis binárias que representam as requisições CPRI que foram comutadas entre VDUs no nó de processamento $n$.

\section{Probabilidade de bloqueio}

A métrica de probabilidade, ou taxa, de bloqueio tem o objetivo de capturar a probabilidade de bloqueio de transmissões CPRI. Na operação da arquitetura CF-RAN, o bloqueio de uma requisição CPRI ocorre quando não existe nenhuma VDU na rede capaz de instanciar uma nova vBBU ou não há nenhum comprimento de onda disponível para suportar a transmissão da requisição em uma VPON.

Essa métrica é tradicionalmente expressa como $R_{\text {lost }} / R_{\text {arrived }}$, onde $R_{\text {lost }}$ é a quantidade de requisições CPRI bloqueadas e $R_{\text {arrived }}$ é o total de requisições CPRI geradas durante a operação da rede.

\section{Desperdício de banda}

O uso eficiente dos comprimentos de onda da arquitetura CF-RAN vem por meio da transmissão de todos as requisições CPRI utilizando-se a menor quantidade de VPONs possíveis. Entretanto, levando em consideração o algoritmo utilizado para formação de VPONs, a taxa de desperdício de banda pode ser menor ou maior dado uma quantidade de requisições CPRI buscando uma VPON.

Nós definimos a taxa de desperdício de banda como

$$
1-\left(T_{\text {cpri }} / T_{\text {vpons }}\right)
$$

onde $T_{\text {cpri }}$ é o total de banda utilizada por todas as requisições CPRI sendo transmitidas na rede e $T_{v p o n s}$ é a quantidade total de banda disponível para transmissões, dada em função da quantidade de VPONs criadas.

\section{Utilização das vBBUs}

Semelhantemente à taxa de desperdício de banda, nós expressamos a taxa de utilização das VDUs como a razão entre a carga total de processamento utilizado pelas requisições CPRI e a capacidade total de processamento disponível na rede, conforme mostrado na expressão a seguir

$$
U_{v B B U}=T_{\text {processing }} / T_{V D U s}
$$

onde $T_{\text {processing }}$ é o total de requisições CPRI sendo processadas na rede e $T_{V D U s}$ é o total de VDUs ativas na rede para receber todo o processamento requisitado pelos RRHs. 


\subsection{Discussão}

Este Capítulo apresentou a arquitetura CF-RAN e os problemas de alocação de vBBUs e formação de VPONs, além de prover um modelo de avaliação de desempenho para a operação da rede. No próximo Capítulo será apresentada uma formulação baseada em ILP para a solução dos problemas apresentados neste Capítulo. 


\section{Capítulo 5}

\section{Formulação de Programação Linear Inteira (ILP) para Solução dos Problemas de Alocação de vBBUs e Formação de VPONs}

Neste Capítulo será apresentada uma formulação ILP para a solução dos problemas de alocação de vBBUs e formação de VPONs em cenários estáticos de operação onde a carga total de requisições CPRI que demandam processamento e transmissão é conhecida de antemão, não impondo à operação da rede incertezas estatísticas quanto à chegada ou saída dessas requisições da rede. O conteúdo desse Capítulo foi publicado em [TRB $\left.{ }^{+} 17\right]$ e [TBF18].

Apesar de em cenários reais o tráfego ser dinâmico e formulações ILP serem conhecidas por altos tempos de convergência das soluções, algoritmos baseados em formulações ILPs são amplamente utilizados em cenários estáticos pois são capazes de gerar soluções ótimas em problemas de dimensionamento e alocação de recursos em rede. Nesse contexto, o comportamento adotado pelas soluções baseadas em formulações ILP pode ser utilizado para o desenvolvimento de heurísticas que emulam o comportamento de ILPs e são capazes de gerarem soluções sub-ótimas, ou até mesmo ótimas, provendo tempos de convergência muito menores que as formulações ILP provêm.

Da mesma forma, nesse trabalho as soluções baseadas em ILP serão utilizadas para a proposta de heurísticas para a solução dos problemas de alocação de recursos na arquitetura CF-RAN em cenários dinâmicos e de maior escala. Uma dessas heurísticas, baseada em teoria dos grafos, será apresentada no próximo Capítulo.

Primeiramente, apresentaremos a formulação matemática do problema de alocação de vBBUs e formação de VPONs e em sequência, a formulação ILP proposta será apresentada.

\subsection{Formulação do problema}

Seja $R$ um conjunto de RRHs ativos que geram, cada um, uma requisição CPRI e demandam seu processamento em qualquer nó de processamento $n$ por meio da transmissão de qualquer comprimento de onda disponível na rede. Dado um conjunto $N$ de nós de processamento e um conjunto $W$ de comprimentos de onda disponíveis $w$, encontre um escalonamento que aloque todas as requi- 
sições de $R$ na menor quantidade possível de nós de processamento $n$ utilizando o menor número de comprimentos de onda $w$ para a formação de VPONs para transmitir as requisições.

Esse problema é uma variação do problema do empacotamento em duas dimensões ou $2 D$ bin packing [PJ93] [mJGJ96], onde cada requisição CPRI deve ser "empacotada" tanto em um nó de processamento quanto em uma VPON, respeitando os limites de capacidade de ambos. Por fim, o objetivo é minimizar a quantidade de nós de processamento e VPONs utilizados para suportar todas as requisições para que uma operação energeticamente eficiente seja alcançada.

\subsection{Formulação ILP}

A formulação ILP promove eficiência energética por meio da ativação dos recursos da rede em função do crescimento da demanda. Assim, conforme a demanda cresce, mais nós de processamento e VPONs são criados. Se a demanda da rede está baixa, recursos desnecessários permanecem desativados.

A formulação é composta das seguintes variáveis de entrada:

\section{Variáveis de Entrada}

$R$ : o conjunto de todas as requisições CPRI $i$

$N$ : o conjunto de todos os nós de processamento $n$, incluindo o nó da nuvem e os fog nodes

$W$ : conjunto de todos comprimentos de onda $w$

$F_{i n}$ : conjunto de variáveis binárias que representam a conectividade entre o $\mathrm{RRH} i$ e o fog node

$n$

$B_{i}$ : demanda de banda da requisição CPRI $i$

$B_{w}$ : capacidade do comprimento de onda $w$

$\operatorname{Proc}_{i}$ : demanda de processamento da requisição CPRI $i$

$\operatorname{Proc}_{n}$ : capacidade de processamento do nó $n$

$C=\left\{C_{1}, \ldots, C_{n}\right\}:$ conjunto dos custos energéticos de cada nó de processamento $n$

$C_{v d u}=\left\{C_{v d u}^{1}, \ldots, C_{v d u}^{n}\right\}:$ conjunto dos custos energéticos de cada VDU em cada nó $n$

$C_{l c}$ : custo energético de um LC

$B$ : um número positivo muito grande

As variáveis de decisão são as seguintes:

\section{Variáveis de Decisão}

$y_{w n}^{i}:=1$ se a requisição $i$ é processada no nó $n$ sendo transmitida pela VPON que utiliza o comprimento de onda $w, 0$ caso contrário.

$\bar{y}_{i n}:=1$ se a requisição $i$ é processada no nó $n, 0$ caso contrário. Esta é uma variável auxiliar utilizada para garantir que cada requisição $i$ só irá ser processada na nuvem ou no fog node conectado em seu RRH.

$z_{w n}:=1$ se o comprimento de onda $w$ é alocado ao nó $n$ para a criação de uma VPON, 0 caso contrário.

$x_{n}:=1$ se as funções de processamento e infraestrutura do nó $n$ são ativadas, 0 caso contrário. Essa variável é utilizada para contabilizar a quantidade de nós de processamento ativos em uma solução. 


\section{Função Objetivo}

A função objetivo 5.1

$$
\text { Minimize } \sum_{n=1}^{|N|} x_{n} \cdot C_{n}+\sum_{w=1}^{|W|} \sum_{n=1}^{|N|} z_{w n} \cdot\left(C_{l c}+C_{v d u}^{n}\right)
$$

busca minimizar a quantidade de todos os elementos ativos na rede por meio do empacotamento de quantas requisições CPRI forem possíveis no mínimo de nós de processamento e VPONs. Note que, mesmo que uma vBBU seja alocada tanto na nuvem quanto em um fog node, o custo do nó de processamento é contabilizado na função objetivo por meio do termo $\sum_{n=1}^{|N|} x_{n} * C_{n}$, onde o índice $n=1$ refere-se à ativação da nuvem e os demais índices referem-se aos fog nodes. Além disso, nós consideramos nessa formulação que a criação de VPONs implica no consumo energético de uma LC e de uma VDU. Além disso, essa formulação assume que todas as requisições CPRI são alocadas na VDU associada à sua VPON, não sendo abordado nesta formulação a comutação de tráfego entre VDUs.

\section{Restrições}

$$
\begin{aligned}
& \sum_{n=1}^{|N|} z_{w n} \leq 1 \mid \forall w \in W \\
& \sum_{w=1}^{|W|} \sum_{n=1}^{|N|} y_{w n}^{i}=1 \mid \forall i \in R \\
& \sum_{i=1}^{|R|} \sum_{n=1}^{|N|} y_{w n}^{i} . B_{i} \leq B_{w} \mid \forall w \in W \\
& \sum_{i=1}^{|R|} \sum_{w=1}^{|W|} y_{w n}^{i} . \operatorname{Proc}_{i} \leq \operatorname{Proc}_{n} \mid \forall n \in N \\
& \text { B. } x_{n} \geq \sum_{i=1}^{|R|} \sum_{w=1}^{|W|} y_{w n}^{i} \mid \forall n \in N \\
& x_{n} \leq \sum_{i=1}^{|R|} \sum_{w=1}^{|W|} y_{w n}^{i} \mid \forall n \in N \\
& B . z_{w n} \geq \sum_{i=1}^{|R|} \sum_{n=1}^{|N|} y_{w n}^{i} \mid \forall w \in W \\
& z_{w n} \leq \sum_{i=1}^{|R|} \sum_{n=1}^{|N|} y_{w n}^{i} \mid \forall w \in W \\
& B . \bar{y}_{i n} \geq \sum_{w=1}^{|W|} y_{w n}^{i} \mid \forall i, n \in R, N
\end{aligned}
$$




$$
\begin{gathered}
\bar{y}_{i n} \leq \sum_{w=1}^{|W|} y_{w n}^{i} \mid \forall i, n \in R, N \\
\bar{y}_{\text {in }} \leq F_{\text {in }} \mid \forall i, n \in R, N
\end{gathered}
$$

A restrição 5.2 garante que cada comprimento de onde só pode ser alocado a um nó de processamento para a criação de uma VPON. Essa restrição garante que a colisão entre sinais ópticos de VPONs diferentes utilizando-se de comprimentos de onda iguais nunca irá ocorrer. A restrição 5.3 implica que cada requisição CPRI só é processada e transmitida em um único nó de processamento e uma única VPON, respectivamente. A restrição 5.4 garante que a capacidade de cada VPON será respeitada e nunca serão alocados mais fluxos CPRI do que a capacidade total do comprimento de onda. Semelhantemente, a restrição 5.5 garante que a capacidade de processamento de cada nó, seja nuvem ou fog node, será respeitada. Note que essa requisição implica que não existe a possibilidade de requisições CPRI serem enfileiradas em uma VDU caso a capacidade da VDU seja exaurida. As restrições 5.6 e 5.7 contabilizam a ativação de um nó de processamento $n$ quando uma vBBU desse nó for alocada para alguma requisição. As restrições 5.8 e 5.9 reforçam a alocação de um comprimento de onda $w$ a um nó de processamento $n$ para atender a uma requisição $i$ que foi alocada para processamento no nó $n$ e para transmissão na VPON de comprimento de onda $w$. Por fim, as restrições 5.10, 5.11 e 5.12 garantem que, caso uma requisição CPRI seja alocada em um fog node, ela só poderá ser processada em um fog node que está fisicamente conectado à ela por uma fibra óptica dedicada.

Conforme foi apresentado no Capítulo 4, há duas formas de realizar a conexão entre os RRHs e as ONUs, um RRH diretamente conectado em uma ONU single-port ou múltiplos RRHs conectados em uma única ONU multi-port. Para explorar a capacidade do fronthaul TWDM-PON nesse contexto, nós consideramos as duas seguintes políticas de dimensionamento de banda para a formulação ILP:

\section{- Formação Completa de VPONs (Fully VPON Formation (Fully-VPON))}

Essa política considera que cada ONU é conectada a um único RRH e um único comprimento de onda é compartilhado por múltiplas ONUs em uma VPON. Assim, a OLT em um nó de processamento dinamicamente configura as ONUs de múltiplos RRHs para transmissões em um comprimento de onda em comum. Nesse caso, a taxa CPRI gerada por cada RRH é utilizada como a demanda de banda de uma requisição $i$.

\section{- Formação de VPONs para Grupos de Agregação (Aggregation Groups VPON Formation (AG-VF))}

Essa política considera que múltiplos RRHs são conectados em uma única ONU multi-port e um único comprimento de onda é alocado para cada grupo de agregação, fazendo com que cada grupo de agregação represente uma VPON diferente. A quantidade de RRHs em cada grupo de agregação irá definir a demanda de banda dessa ONU, e essa demanda é utilizada na formulação ILP como a demanda de banda de uma requisição $i$.

Como supracitado, algoritmos baseados em formulações ILP podem gerar as soluções ótimas em problemas de escalonamento, como os problemas aqui tratados. Entretanto, tais algoritmos são conhecidos por não escalarem bem com o tamanho da entrada do problema, o que pode levar 
a tempos muito altos de convergência para entradas muito grandes. O problema de alocação de recursos abordado neste trabalho é um problema do tipo NP-Completo [DC02] [FWM $\left.{ }^{+} 16\right]$. Assim, no próximo Capítulo será proposta uma solução heurística para a solução do problema apresentado que, além de escalar bem com o tamanho do problema, pode ser utilizado em ambientes de tráfego dinâmico. 
40 FORMULAÇÃO DE PROGRAMAÇÃO LINEAR INTEIRA (ILP) PARA SOLUÇÃO DOS PROBLEMAS DE ALOCAÇÃO DE VBBUS E FORMAÇÃO DE VPONS 


\section{Capítulo 6}

\section{Heurística Baseada em Teoria dos Grafos}

Para prover soluções ótimas ou sub-ótimas para o problema de alocação de vBBUs e formação de VPONs em cenários de larga escala e de tráfego dinâmico, faz-se necessário que soluções heurísticas sejam propostas. Neste Capítulo iremos apresentar uma solução heurística baseada em teoria dos grafos para modelar tanto a operação da CF-RAN quanto para realizar a alocação de seus recursos. O conteúdo desse Capítulo foi publicado em $\left[\mathrm{TBF}^{+} 19 \mathrm{~b}\right]$.

Nessa solução a ser proposta, um grafo direcionado é utilizado para modelar a arquitetura CF-RAN como uma rede de fluxo. Em uma rede de fluxo, um grafo direcionado pode receber um fluxo de um nó origem e tem o objetivo de direcionar este fluxo, passando por um ou mais arestas e vértices do grafo, rumo a um vértice de destino. Nesse cenário, cada aresta do grafo possui uma capacidade que determina a quantidade máxima de fluxo que pode atravessá-la e um custo atribuído à passagem de fluxo por essa aresta.

Neste trabalho, a arquitetura CF-RAN é modelada como um grafo desse tipo, onde os vértices do grafo direcionado representam os RRHs e os nós de processamento da rede e as arestas que conectam cada vértice representam os enlaces do fronthaul TWDM-PON. O problema de alocação de vBBUs e VPONs é modelado como um problema de fluxo máximo a custo mínimo, onde o objetivo é injetar a maior quantidade de fluxo entre dois vértices origem e destino no grafo enquanto a soma dos custos das arestas atravessadas é minimizada. Na nossa modelagem, um fluxo injetado no grafo representa uma requisição CPRI que deve ser transmitida entre um vértice de RRH e um vértice de nó de processamento, atravessando-se várias arestas e vértices através do grafo.

\subsection{Definição do grafo direcionado que representa a arquitetura CF-RAN}

Seja $G=(V, E)$ um grafo direcionado, onde $V(G)$ representa o conjunto de vértices de $G$ e $E(G)$ o conjunto de arestas de $G$. Cada aresta e possui um atributo de capacidade do fluxo permitido e um custo de sua utilização. Dados $e=(u, v)$, nós definimos um fluxo partindo de $u$ até $v$ por uma aresta incidente de $u$ em $v$ com capacidade maior que 0. Seja $R$ o conjunto dos RRHs $i$ presentes na rede; $F \in V$ o conjunto de fog nodes $f$ e $F_{\text {bridge }} \in V$ um conjunto de vértices intermediários $f b$ chamados de fog bridges responsáveis por realizar a interconexão de múltiplos RRHs em um único fog node. Um vértice $C \in V$ representa o nó de processamento da nuvem e o vértice $B \in V$ é um vértice intermediário utilizado para implementar um enlace entre os RRHs e a nuvem. Por fim, 
um vértice $S \in V$ é um vértice destino incidente em cada $i \in R$ responsável por realizar a injeção de fluxo CPRI em cada RRH e o vértice $D \in V$ é responsável por receber todo os fluxos CPRI transmitidos através da rede de fluxo. As variáveis $f_{\text {capacity }}$ e $c_{\text {capacity }}$ representam as capacidades de processamento dos fog nodes e da nuvem, respectivamente.

Na modelagem aqui proposta, os enlaces ópticos da rede TWDM-PON são representados pelos arcos que conectam cada RRH $i$ a um fog bridge $f b \in F_{\text {bridge }}$ e $B$. Os comprimentos de onda alocados a cada nó de processamento para a criação de VPONs nesses nós são representados pelos atributos de capacidade das arestas incidentes das fog bridges aos fog nodes $f$ e da aresta do vértice $B$ incidente em $C$. A capacidade de processamento de ambos fog nodes $f$ e da nuvem $C$ é representada pelos vértices incidentes $e$ de $f \in F$ em $D$ e $e$ de $C$ em $D$, respectivamente e o custo energético de utilização desses nós de processamento é dado pelos custos dos vértices incidentes em $D$.

A construção do grafo direcionado é dada pelos seguintes passos: Para cada vértice $i \in R$, coloque uma aresta incidente de $S$ em $i$ com custo 0 e capacidade 0 . Para cada RRH $i$ conectado a um fog node $f$, coloque uma aresta direcionada de $i$ ao fog bridge $f b \in F_{\text {bridge }}$ com custo 0 e capacidade $\infty$. Para cada $f b \in F_{b r i d g e}$, crie uma aresta direcionado de $f b$ a $f \in F$ com custo 0 e capacidade 0. Para cada $i \in R$, crie uma aresta direcionada a $B$ com custo 0 e capacidade $\infty$ e crie uma aresta direcionada de $B$ a $C$ com custo 0 e capacidade 0 . Por fim, para cada $f \in F$ crie uma aresta direcionada a $D$ com custo igual a $f_{o g} g_{\text {cost }}$ e capacidade igual a $f_{\text {capacity }}$ e crie uma aresta direcionada de $C$ a $D$ com custo 0 e capacidade igual a $c_{\text {capacity }}$.

Note que as capacidades de processamento dos fog nodes e da nuvem são dados pelas variáveis $f_{\text {capacity }}$ e $c_{\text {capacity }}$, respectivamente. O custo de cada fog node é dado pela variável $f_{o g} g_{\text {cost }}$ e, como assumimos que a nuvem sempre será priorizada para a alocação de vBBUs, o custo da aresta incidente de $C$ a $D$ será 0 , representando que a nuvem sempre estará ativada durante a operação da rede.

O grafo direcionado representando a arquitetura CF-RAN é ilustrado na Figura 6.1. Nesse exemplo, uma rede com 4 RRHs, 2 fog nodes e uma nuvem é representada. O vértice $S$ é conectado a cada aresta que representa um RRH por vértices direcionados com custo 0 e capacidade igual a 614,4, que é a opção básica de taxa de transmissão do padrão CPRI. Isso significa que cada um desses vértices pode receber fluxos CPRI de até 614,4Mbps injetados pelo vértice $S$. Os vértices RRH 1 e 2 são conectados ao vértice $F b 1$, que realiza a conexão deles com o fog node representado pelo vértice $F 1$, da mesma forma que são conectados ao vértice $B$ que os conecta ao nó de nuvem representado pelo vértice $C$. O mesmo acontece com os vértices RRH 3 e 4, que são conectados ao fog node representado pelo vértice $F 2$ como também ao vértice da nuvem. Por fim, tanto os vértices de fog nodes quanto da nuvem se conectam ao vértice $D$. Note que a capacidade da aresta incidente de $B$ em $C$ possui valor igual a $10 \mathrm{Gbps}$, o que significa que há um comprimento de onda dessa capacidade alocado à nuvem para a criação de uma VPON. Em relação às capacidades de processamento, a nuvem tem uma capacidade de 80 e os fog nodes de 16, que são os valores de capacidade presentes nas arestas que incidem em $D$.

O objetivo, então, é manter um fluxo máximo entre $S$ e $D$ atravessando cada $i$ até um nó de processamento $f \in F$ ou $C$. Na Figura 6.1, há um fluxo sendo mantido através do nó de nuvem (linhas vermelhas), o que significa que as requisições CPRI dos RRHs 1 a 4 estão sendo processadas nesse nó. Entretanto, para que o fluxo possa ser mantido entre os vértices $S$ e $D$, é necessário que 


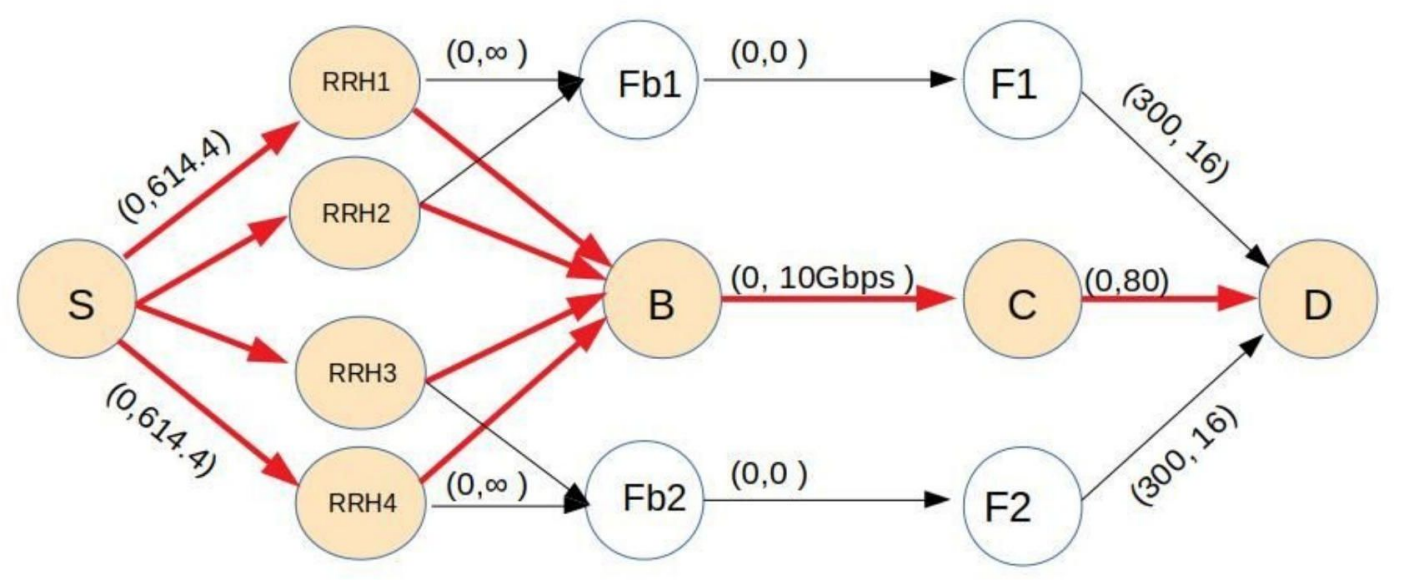

Figura 6.1: Grafo direcionado representando a arquitetura CF-RAN como uma rede de fluxo

duas operações sejam realizadas, conforme descritas a seguir.

Primeiro, em função da demanda de tráfego, uma heurística de dimensionamento de comprimentos de onda é utilizada para calcular a quantidade de banda (VPONs) a ser feita disponível nas arestas que representam o fronthaul, por meio da modificação das capacidades dessas arestas. Enquanto há comprimentos de onda disponíveis para serem alocados aos nós de processamento, as capacidades das arestas podem ser modificadas para receber a capacidade de um comprimento de onda e permitir o tráfego de uma VPON nessa aresta.

Segundo, depois que os comprimentos de onda são dimensionados na rede e o valor de capacidade das arestas que incidem nos nós de processamento é definida, um algoritmo de injeção de fluxo máximo a custo mínimo é executado para maximizar o fluxo entre os vértices $S$ e $D$ enquanto a quantidade de arestas atravessadas é minimizada (considerando a minimização da soma dos custos das arestas atravessadas).

Um algoritmo de fluxo máximo a custo mínimo é uma combinação dos algoritmos de caminho mínimo em grafos e de inserção de fluxo máximo. Em tal algoritmo, um caminho mínimo entre os vértices $S$ e $D$ é encontrado por meio da execução do algoritmo de Bellman-Ford [CLRS09] e então o algoritmo de Ford-Fulkerson [CLRS09] é executado sobre o grafo gerado pelo algoritmo de Bellman-Ford para a maximização do fluxo entre os vértices $S$ e $D$.

O algoritmo de Ford-Fulkerson consiste na inserção de fluxo máximo $f$ em um grafo direcionado $G$ e na geração de um grafo residual $G_{f}$ a partir do grafo $G$ após a inserção desse fluxo. O fluxo máximo $f$ inserido é escolhido de acordo com a menor capacidade de qualquer aresta $(u, v)$ em um dado caminho $p$ do grafo que interligue $S$ e $D$. Assim, $f(u, v)$ denomina o fluxo inserido na aresta entre os vértices $u$ e $v$.

Sendo $f(u, v)$ o fluxo na aresta $(u, v)$ e $c(u, v)$ a capacidade dessa aresta, as seguintes restrições devem ser obedecidas:

$$
\begin{gathered}
0 \leq f(u, v) \leq c(u, v) \forall(u, v) \\
\sum_{v}^{V} f(v, u)=\sum_{v}^{V} f(u, v), \forall u \in V-\{S, D\}
\end{gathered}
$$




$$
|f|=\sum_{v}^{V} f(S, v)-\sum_{v}^{V} f(v, S)
$$

Onde a restrição 6.1 garante que o fluxo $f(u, v)$ não pode ser negativo e deve ser menor ou igual à capacidade da aresta $(u, v)$. A restrição 6.2 é uma restrição de conservação de fluxo e garante que em cada vértice diferente de $S$ e $D$, a soma do fluxo ingresso é igual à soma do fluxo egresso. Por fim, a restrição 6.3 garante a maximização do fluxo $|f|$ que egressa de $S$, ou em outras palavras, o fluxo total $|f|$ é o fluxo que egressa de $S$ menos o fluxo que ingressa em $S$.

A rede residual consiste em um grafo obtido pela atualização das capacidades do grafo original após a inserção de fluxo. Se existem caminhos $p$ no grafo residual que admitem a inserção de fluxo, ou seja, sua capacidade é maior que 0 , chamamos o caminho $p$ como um caminho aumentante. Assim, iterativamente, o algoritmo de Ford-Fulkerson injeta fluxo na rede enquanto existirem caminhos aumentantes. Os caminhos aumentantes $p$ são obtidos pelo algoritmo por meio de busca em profundidade. A cada fluxo inserido em um caminho $p$ em $G_{f}$, as seguintes transformações são realizadas em $G_{f}$ :

1. Na direção do caminho $p$ que recebeu o fluxo $f$, o fluxo $f$ é subtraído das arestas pertencentes à $p$, ou seja, $c(u, v)=c(u, v)-f$. Caso $c(u, v)$ venha a tornar-se igual a 0 , ou seja, não há mais capacidade na $\operatorname{aresta}(u, v)$, a aresta $(u, v)$ é retirada de $G_{f}$.

2. Na direção oposta em cada aresta $(u, v)$ de $p$, a capacidade de $(u, v)$ é acrescida de $f$, ou seja, $c(u, v)=c(u, v)+f$. Se por ventura não existir uma aresta inversa em $(u, v)$, ela é criada. Isso é realizado para permitir a possibilidade de retirada de fluxo nessa aresta para que o fluxo em outro caminho possa ser aumentado.

Quando não existem mais caminhos aumentantes na rede, o fluxo, que consiste em um conjunto de arestas $(u, v)$, e o custo, que é a soma dos custos de cada aresta $(u, v)$ que pertencem a $p$ (que é o caminho que recebe o fluxo máximo), são retornados pelo algoritmo.

Formalmente, o algoritmo de fluxo máximo a custo mínimo é definido no Algoritmo 1:

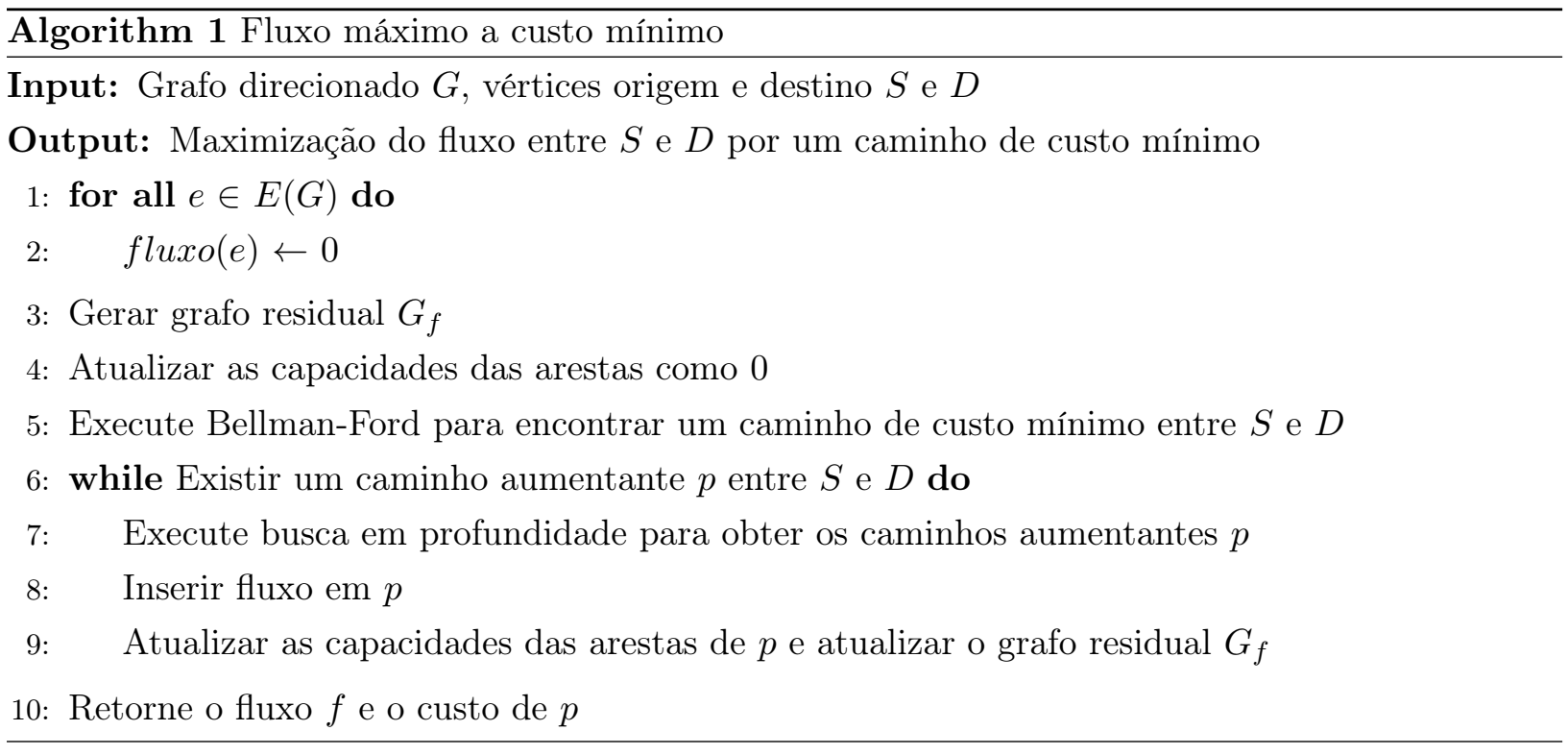

Por fim, a análise de complexidade do algoritmo 1 é realizada. A inicialização das capacidades do grafo nas linhas 1 a 4 tem um custo computacional de $O(|E|)$. A busca em profundidade para 
obtenção dos caminhos aumentantes $p$ tem custo igual a $O(|E|)$ e a execução de Ford-Fulkerson para maximização do fluxo tem custo $O\left(|E| *\left|f^{*}\right|\right)$, onde $f^{*}$ é o fluxo maximizado. Multiplicando-se e somando-se os custos, obtém-se a complexidade de $O\left(|E|+|E|^{2}+f^{*}\right)$ e retirando-se os termos de menor valor, a complexidade de $O\left(|E|^{2}\right)$ é obtida.

Esse modelo de operação da rede apenas considera a conexão de RRHs em ONUs single-port, conforme as opções de conexões entre RRHs e ONUs apresentadas no Capítulo 4. Essa decisão foi tomada por conta de que a utilização de ONUs multi-port iria aumentar o número de vértices na rede. Se apenas a conexão de um RRH por ONU é mantida, um único vértice pode ser utilizado tanto para representar o RRH quanto a ONU. Já a representação de grupos de agregação iria demandar a criação de um vértice adicional para cada grupo de RRHs conectados em uma ONU multi-port.

A solução aqui proposta tem como objetivo ser aplicada tanto em cenários estáticos como dinâmicos de tráfego. A modelagem da arquitetura CF-RAN não sofre nenhuma alteração em relação à aplicação dessa solução em qualquer um desses cenários. Entretanto, em relação ao dimensionamento dos comprimentos de onda e atualização dos valores de capacidade das arestas que representam o fronthaul, faz-se necessário que heurísticas específicas, tanto para o caso estático quanto para o dinâmico, sejam propostas.

Nas próximas seções nós apresentaremos tais heurísticas, começando com a definição de uma heurística para o caso estático.

\subsubsection{Heurística para o dimensionamento de comprimento de onda para tráfego estático}

Para determinar a quantidade de banda necessária em cada aresta incidente em nós de processamento no grafo direcionado, nós propomos nesta seção a heurística Cloud First-Fog Least (CF-FL). A heurística CF-FL é destinada apenas a ser aplicada nos casos de tráfego estático, onde uma demanda previamente conhecida e fixa de rede irá determinar uma quantidade fixa de comprimentos de onda na rede para sua transmissão.

A ideia principal dessa heurística é a alocação de comprimentos de onda para a criação de VPONs na nuvem até que toda a capacidade de processamento da nuvem seja utilizada por meio das requisições que serão transmitidas por tais VPONs e irão ativar uma ou mais vBBUs. A motivação para essa política cloud first na criação de VPONs é a priorização do uso da nuvem para a promoção de eficiência energética.

Após a capacidade de processamento da nuvem ser exaurida, os fog nodes deverão ser ativados. A heurística então calcula quantos comprimentos de onda devem ser alocados em cada fog node para suportar a demanda de transmissão CPRI que cada um irá receber. Enquanto houver comprimentos de onda disponíveis na rede, isto é, há pelo menos um comprimento de onda que não foi alocado para a criação de uma VPON na nuvem ou em qualquer fog node, a heurística CF-FL sequencialmente aloca os comprimentos de onda entre os fog nodes até que a quantidade total de banda presente em um fog node (dada em função da quantidade de comprimentos de onda alocados a ele) possa suportar as transmissões de tráfego CPRI de todos os RRHs conectados nele e que estejam ativos, isto é, gerando uma requisição CPRI. Após a quantidade total de tráfego CPRI gerada na rede, isto é, o fluxo gerado pelo vértice $S$, for menor ou igual a quantidade total de banda disponível nos enlaces da rede, isto é, o valor de capacidade nas arestas que incidem nos vértices que representam 
tanto fog nodes quanto a nuvem, o algoritmo de dimensionamento de comprimento de onda termina sua execução.

Note que, deve existir um limite para a quantidade de comprimentos de onda alocados na nuvem para criação de VPONs nesse nó de processamento. Caso esse limite não exista, por conta da priorização da nuvem em receber processamento, todos os comprimentos de onda serão alocados na nuvem e não sobrarão comprimentos de onda para a criação de VPONs nos fog nodes. Isso levará a um caso inconsistente onde a nuvem pode ter uma capacidade de transmissão superior à sua capacidade de processamento. Esse caso pode levar ao enfileiramento das requisições CPRI transmitidas por VPONs à nuvem mas que não encontram recursos computacionais para seu processamento. Note que nesse caso não há sentido que fog nodes existam na rede, pois eles nunca serão ativados e a rede se comportará exatamente como uma arquitetura CRAN. Para impedir essa extrapolação da alocação de comprimentos de onda à nuvem, nas heurísticas aqui propostas, tanto para o caso estático quanto para cenários dinâmicos, consideram a capacidade de processamento da nuvem como um fator limitador para a quantidade de comprimentos de onda a serem alocados à nuvem. Por exemplo, se a nuvem tem a capacidade de processar 32 requisições CPRI, e cada requisição CPRI possui uma taxa de transmissão de $614,4 \mathrm{Mbps}$, o limite de comprimentos de onda alocados à nuvem será restrito a 2 comprimentos de onda de capacidade de $10 \mathrm{Gbps}$.

A heurística CF-FL é formalmente descrita no Algoritmo 2. Na linha 2, a quantidade de tráfego CPRI ingressante na rede é calculada em função da quantidade de RRHs ativos que requisitam por uma VPON uma vBBU. Então, na linha 3, é verificado se as VDUs da nuvem possuem capacidade de processamento suficiente para instanciar as vBBUs que irão atender à demanda CPRI dos RRHs.

Após isso, é verificado na linha 4 se há comprimentos de onda suficientes, ou VPONs criadas, na nuvem para atender à demanda de transmissão para a nuvem. Se não há capacidade de banda suficiente alocada para a nuvem, nas linhas 5 e 6 novos comprimentos de onda são alocados à nuvem para a criação de novas VPONs até que haja capacidade de transmissão suficiente na nuvem para as transmissões das requisições que serão alocadas em vBBUs instanciadas nela.

Caso a nuvem padeça de capacidade computacional para instanciar vBBUs para todas as requisições CPRI, conforme descrito na linha 7, é então verificado se parte das requisições CPRI podem ser processadas na nuvem enquanto o resto pode ser processado em fog nodes. Se sim, novas VPONs são eventualmente criadas para transmitirem para a nuvem antes da ativação dos fog nodes (linhas 8, 9 e 10). Nesse ponto, a quantidade de tráfego CPRI residual, isto é, a quantidade de requisições CPRI que não puderam ser processadas na nuvem, é calculada na linha 12. Então, enquanto há comprimentos de onda disponíveis e enquanto o tráfego CPRI residual for maior que a soma das capacidades das arestas que incidem nos fog nodes (linha 13), nas linhas 14, 15, 16 e 17 um comprimento de onda é alocado por fog node até que a quantidade total de tráfego CPRI residual possa ser suportada pelas capacidades de transmissão dos fog nodes. A cada comprimento de onda alocado, a capacidade das arestas incidentes nos fog nodes é atualizada na linha 18.

Completando a heurística, após os comprimentos de onda serem dimensionados o algoritmo de fluxo máximo a custo mínimo é executado na linha 19 para injetar o fluxo no grafo direcionado, maximizando o fluxo entre $S$ e $D$ e atravessando a menor quantidade de arestas que incidem em vértices de nós de processamento com capacidade maior que 0 .

Algorithm 2 Heurística CF-FL para dimensionamento dos comprimentos de onda Input: Grafo direcionado $G$, conjunto de comprimentos de onda disponíveis $w \in W$, Conjunto 
de RRHs ativos $R$, largura de banda disponível para transmitir à nuvem nuvem frtBand, capacidade de processamento da nuvem $c_{\text {capacity }}$, quantidade de tráfego CPRI já alocado em uma VPON e uma vBBU allocTraffic, largura de banda total para transmitir aos fog nodes (dada em função da quantidade de comprimentos de onda alocadas aos fog nodes) fogBand Output: Alocação da requisição dos RRHs $i \in R$ em uma vBBU e uma VPON

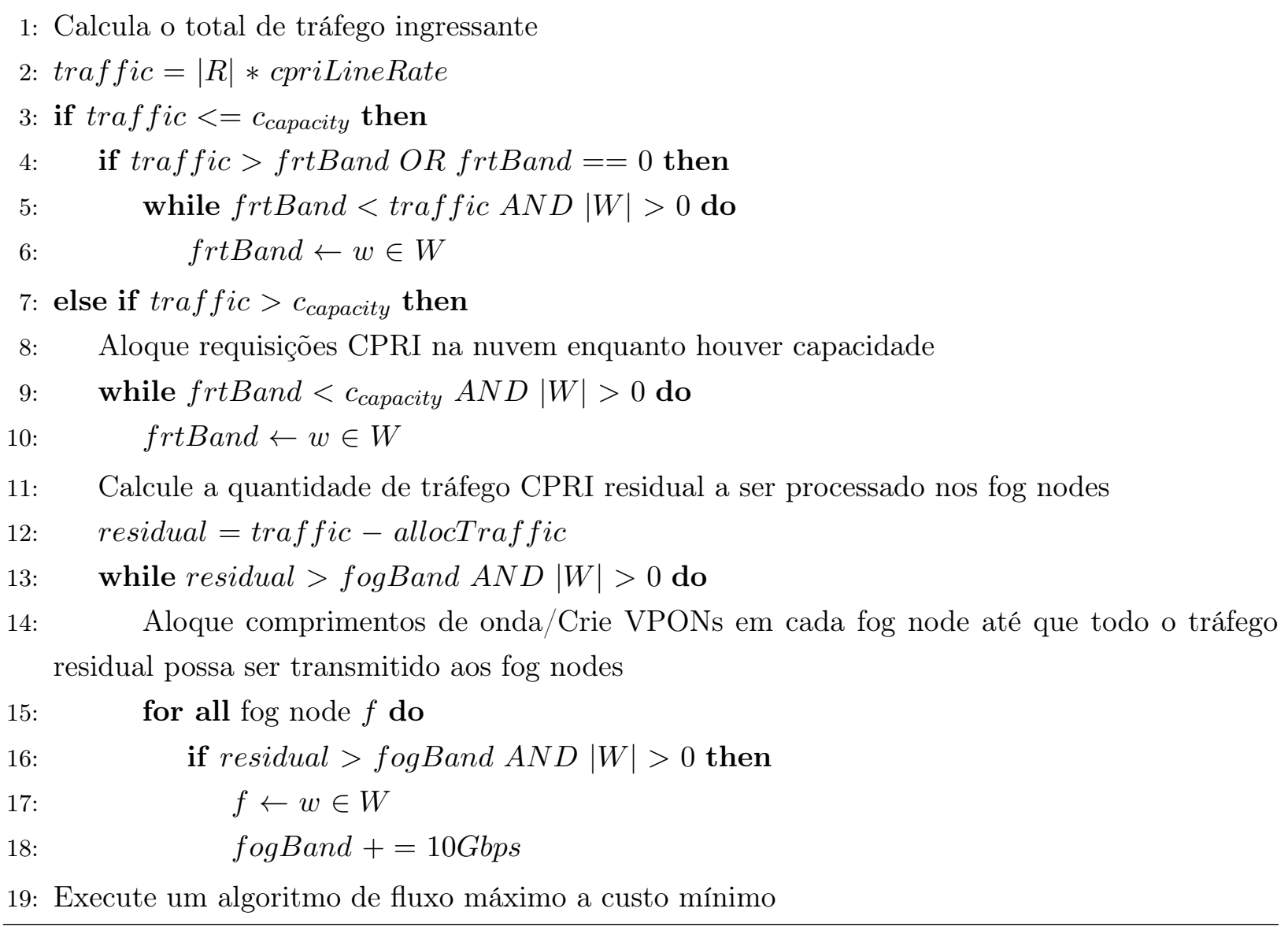

Essa heurística considera uma política de alocação uniforme dos comprimentos de onda aos fog nodes, considerando que a carga gerada pelos RRHs a cada fog node é uniforme. Entretanto, em um cenário dinâmico, pode ocorrer o caso da distribuição dos comprimentos de onda aos fog nodes não ser uniforme, pois um fog node pode possuir mais RRHs ativos do que outro fog node, gerando assim uma maior necessidade de comprimentos de onda para suporte de suas transmissões. Assim, para tratamento desse caso, nós propomos na próxima seção variações dessa heurística que são habilitadas para o dimensionamento de comprimento de onda em cenários de tráfego dinâmico onde a carga esperada em cada fog node não é uniforme.

\subsubsection{Heurísticas para o dimensionamento de comprimento de onda em cenários de tráfego dinâmico}

Em cenários dinâmicos, além da quantidade de tráfego esperada em cada fog node não ser uniforme, as requisições CPRI chegam individualmente na rede demandando uma vBBU e uma VPON. Assim, a decisão de alocação das vBBUs e VPONs torna-se única a cada requisição, e não a toda uma demanda como no caso estático. Além disso, nesse cenário as requisições permanecem consumindo os recursos da rede durante uma porção de tempo, que ao ser atingida causa a saída da requisição da rede e liberação das VPONs e vBBUs utilizadas. Quanto à saída das requisições, 
faz-se necessário também que uma heurística apropriada de dimensionamento dos comprimentos de onda também realize a desativação dinâmica dos recursos que são liberados na rede.

Assim, para tratamento do caso dinâmico, duas heurísticas são propostas nesta seção. Como não se pode prever a quantidade de tráfego esperado em cada RRH, nós propomos heurísticas que tratam dois casos extremos acerca do dimensionamento dos comprimentos de onda em tal cenário. Ambas heurísticas são destinadas a priorização do uso da nuvem, portanto, baseiam-se em uma política cloud first.

A primeira heurística, é a heurística Least Loaded (LL). A ideia dessa heurística é de, como na heurística CF-FL, alocar requisições CPRI para serem processadas na nuvem enquanto a mesma possuir capacidade de processamento e de banda. Caso a nuvem possua capacidade de processamento suficiente mas comprimentos de onda insuficientes para receber uma nova requisição, enquanto há comprimentos de onda disponíveis, um a um eles são alocados na nuvem. Quando a capacidade da nuvem é exaurida, os comprimentos de onda são alocados aos fog nodes, um de cada vez, mas seguindo uma ordem least loaded, ou menos carregados primeiro, em que a distribuição dos comprimentos de onda prioriza os fog nodes que possuem a menor quantidade de RRHs ativos conectados a eles.

A segunda heurística, chamada de Most Loaded (ML), opera de forma semelhante à heurística LL no tocante à alocação de comprimentos de onda na nuvem. Entretanto, quando a capacidade da nuvem é exaurida, os fog nodes são ordenados de forma decrescente em relação à quantidade de RRHs ativos conectados em cada um deles. Assim, os comprimentos de onda são distribuídos, um a um, em uma ordem most loaded, ou mais carregados primeiro, aos fog nodes.

Por fim, nós também propomos uma heurística para o dimensionamento de comprimentos de onda que priorize o uso dos fog nodes, ao invés da nuvem. Essa heurística é chamada de FogFirst $(\mathrm{FgF})$. A ideia por trás dessa heurística é que ela promova uma operação de menor latência em relação ao uso priorizado da nuvem. Entretanto, como é intuitivo, tal operação pode levar a um aumento no consumo de energia, pois múltiplos fog nodes podem consumir mais energia do que apenas a nuvem. A operação dessa heurística se dá da seguinte forma: Para cada requisição CPRI que ingressa na rede, primeiramente é verificado se o fog node conectado ao RRH que gerou a requisição possui capacidade de processamento e de transmissão para receber a nova requisição CPRI. Caso haja, o algoritmo de fluxo máximo a custo mínimo é executado para realizar a transmissão do fluxo da requisição até o fog node. Caso haja processamento disponível mas não haja banda, se houver comprimentos de onda disponíveis na rede, um deles é selecionado, seguindo uma política first fit, e alocado ao fog node. Caso o limite de banda alocado ao fog node tiver sido alcançado, a alocação dessa requisição no fog node é descartada e a nuvem é verificada. Se há capacidade de processamento e transmissão na nuvem, o algoritmo de fluxo máximo a custo mínimo é executado. Caso haja capacidade de processamento, mas falta banda, se há um comprimento de onda disponível, este é alocado na nuvem. O algoritmo de fluxo máximo a custo mínimo é então executado.

Em todas as heurísticas aqui propostas, caso um comprimento de onda não possa ser alocado para o atendimento de qualquer requisição CPRI ingressante na rede, a requisição é bloqueada. 


\section{Capítulo 7}

\section{Avaliação da Formulação ILP e Heurísticas Baseadas em Teoria dos Grafos}

Neste Capítulo serão apresentados os resultados referentes aos algoritmos propostos nos Capítulos 5 e 6 .

\subsection{Avaliação do dimensionamento dos comprimentos de onda}

Primeiramente, será apresentada a eficácia da formulação ILP em relação à solução do problema de dimensionamento de comprimentos de onda e formação energeticamente eficiente de VPONs. Como não há na literatura nenhum trabalho que propõe uma solução para esse problema em uma arquitetura híbrida de nuvem e névoa como a CF-RAN, nós comparamos nossa proposta com um algoritmo de dimensionamento aleatório dos comprimentos de onda, chamado aqui de Random VPON Formation. O algoritmo aleatório, basicamente aloca os comprimentos de onda nos nós da rede de forma aleatória e sem verificar se um nó já possui a quantidade de banda suficiente ou não para receber as requisições CPRI. Para explorar o poder do dimensionamento dos comprimentos de onda para formação das VPONs, nas simulações executadas para a geração dos resultados aqui apresentados foi considerada apenas a política Fully-VPON, apresentada no Capítulo 5.

O cenário simulado possui um fronthaul TWDM-PON com 10 comprimentos de onda de capacidade igual a 10Gbps. Quanto aos nós de processamento, a rede possui um total de 20 nós, sendo um desses nós a nuvem e os outros 19 fog nodes. A extensão de cada fibra óptica entre cada RRH e seu fog node é de $10 \mathrm{~km}$ e entre cada fog node e a nuvem a distância é de 10km, totalizando uma extensão de $20 \mathrm{~km}$ entre os RRHs e a nuvem, que é um valor dentro do sugerido na literatura para a manutenção da latência de propagação do fronthaul abaixo do valor máximo permitido de $250 \mu$ s.

Cada RRH gera uma requisição CPRI com taxa de transmissão igual a $614,4 \mathrm{Mbps}$, o que corresponde à opção básica de taxa CPRI. A quantidade de RRHs simulados começa na quantidade de 5 e é incrementada em 5 à cada execução.

Nós executamos a formulação ILP na ferramenta IBM ILOG CPLEX Optimization Studio V12.8.0. O computador utilizado possui um processador Intel Core I5 1.80GHz com 6GB de Random Access Memory (RAM) executando o sistema operacional Windows 10. 


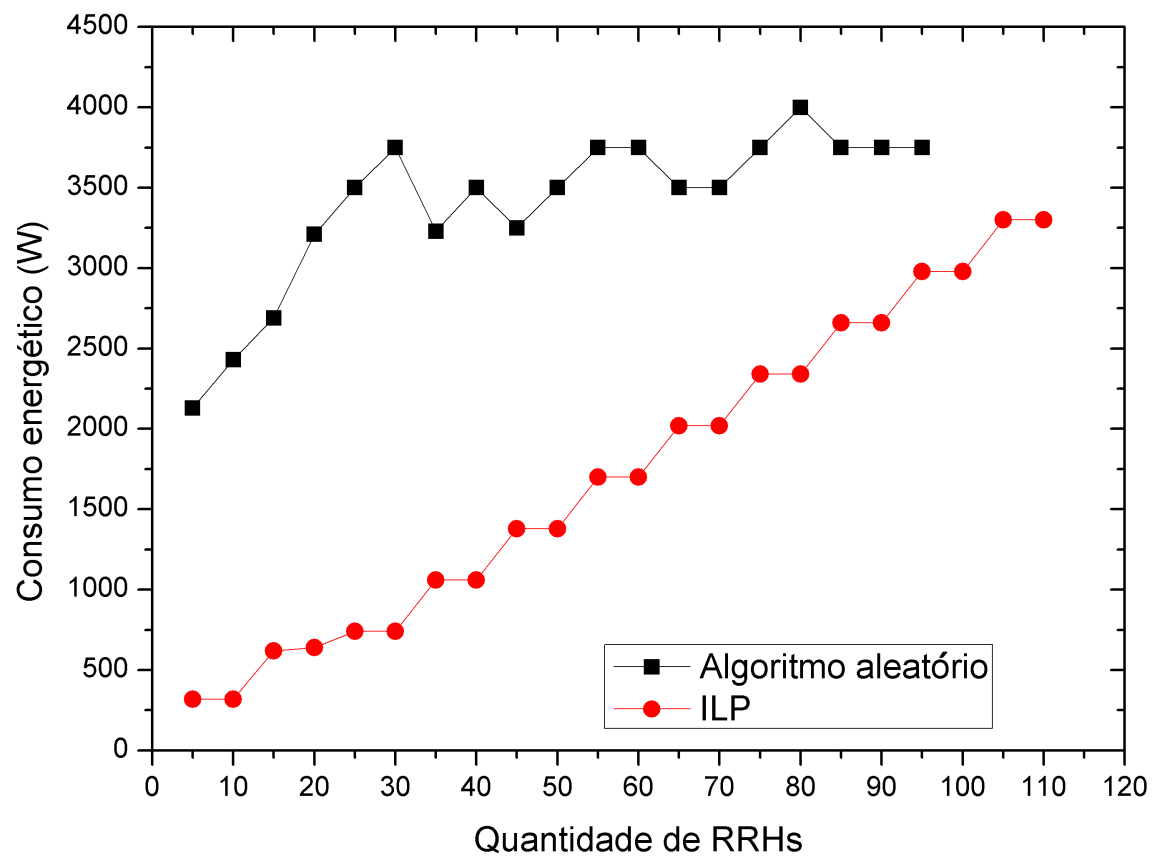

Figura 7.1: Consumo de energia e quantidade de RRHs atendidos (capacidade da nuvem = 30 e capacidade dos fog nodes $=10$ )

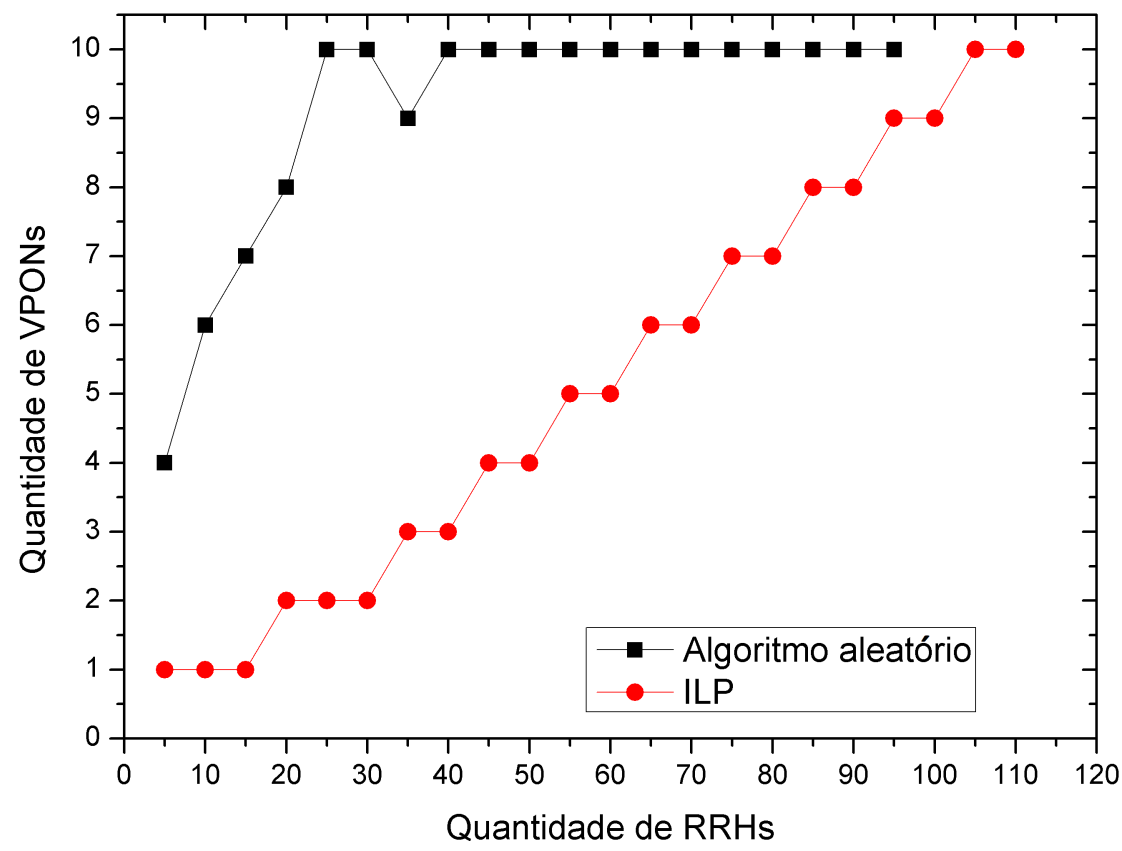

Figura 7.2: Quantidade de VPONs (capacidade da nuvem = 30 e capacidade dos fog nodes $=10$ ) 


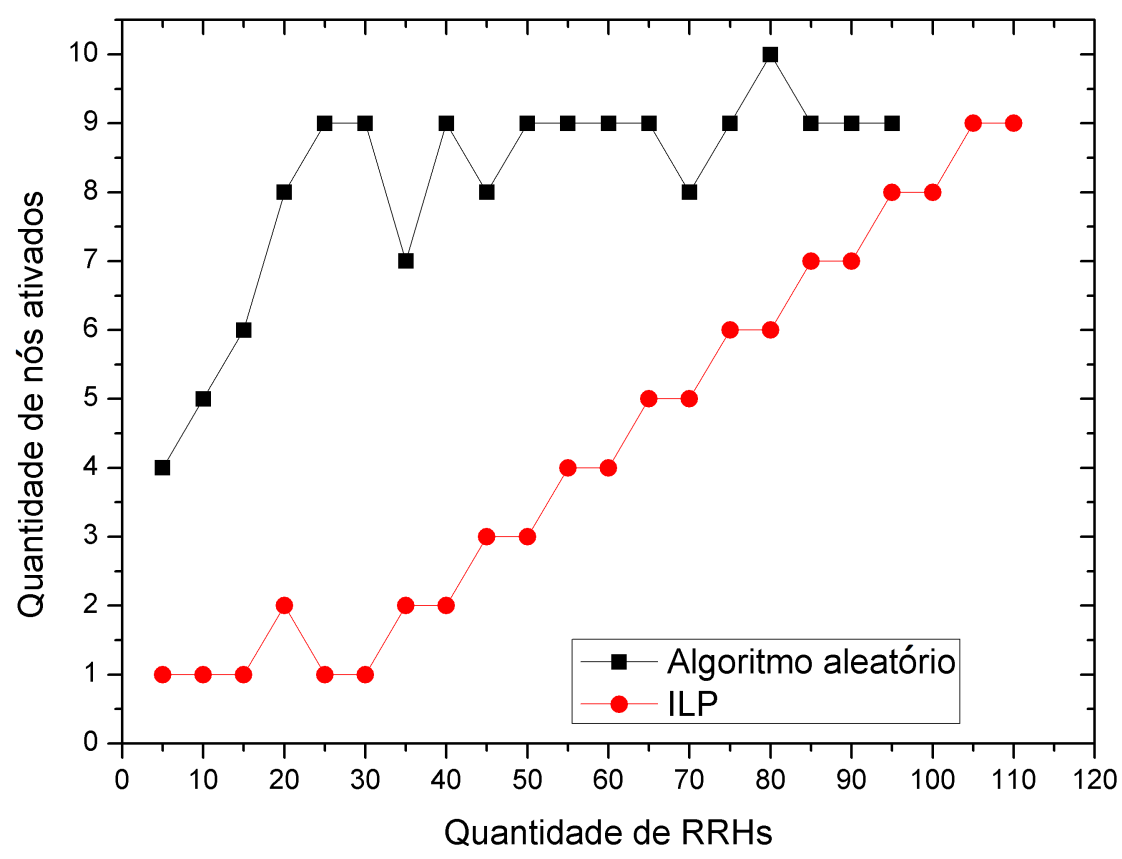

Figura 7.3: Quantidade de nós ativos (capacidade da nuvem = 30 e capacidade dos fog nodes = 10)

Primeiramente, foram avaliados o consumo de energia da rede e a quantidade máxima de RRHs atendidos na rede. Para avaliar a distribuição das VPONs e a ativação dos fog nodes, primeiramente foram considerados os valores máximos de capacidade de processamento de 30 e 10 RRHs para a nuvem e para os fog nodes, respectivamente.

A Figura 7.1 mostra que a formulação ILP proposta sempre obtém menor consumo energético, provendo reduções no consumo energético em até $80.27 \%$ em relação ao esquema aleatório. Isso ocorre porque a formulação ILP sempre irá empacotar a maior quantidade possível de RRHs em uma única VPON e alocar a maior quantidade possível de VPONs em um único nó de processamento, reduzindo assim o consumo referente à ativação de VDUs e LCs, como também do próprio nó de processamento. Esse grande desempenho energético ocorre na quantidade de 30 RRHs e pode ser explicado pelo fato de que nessa quantidade de RRHs e com a dada capacidade de processamento da nuvem, todas as VPONs são alocadas na nuvem. Assim, a formulação ILP agrega todas as requisições CPRI na menor quantidade de VPONs em um único nó. É possível observar que em quantidades maiores de RRHs (maiores que 95) o esquema aleatório não é capaz de gerar nenhuma solução. Utilizando-se da formulação ILP proposta, uma quantidade máxima de 110 RRHs pôde ser atendida na rede.

Na Figura 7.2, a quantidade de VPONs criadas é mostrada. É possível observar que a formulação ILP apenas aloca a quantidade necessária de VPONs para servir às demandas da rede. A maior diferença na quantidade de VPONs criadas em comparação com o esquema aleatório ocorre novamente na quantidade de $30 \mathrm{RRHs}$ e pode ser explicada novamente pelo fato de todas as VPONs serem criadas na nuvem nessa configuração da rede.

Agregando-se a maior quantidade possível de VPONs em um único nó de processamento, o consumo de energia apresenta valores estáveis e um crescimento linear pode ser observado conforme 


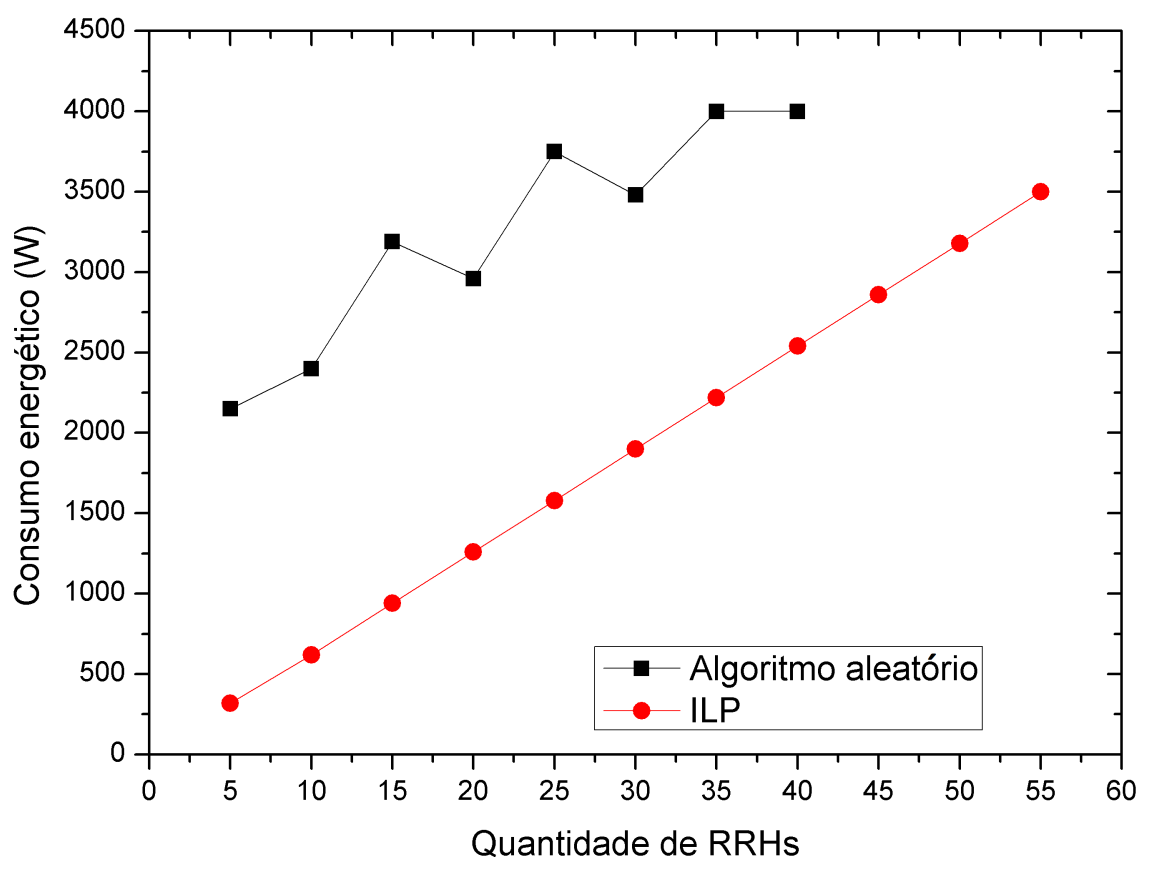

Figura 7.4: Consumo de energia e quantidade de RRHs atendidos (capacidade da nuvem $=10$ e capacidade dos fog nodes $=5$ )

cada novo nó de processamento é ativado e a maior quantidade possível de VPONs é criada nele. Esse comportamento também pode ser notado na Figura 7.3, que apresenta a quantidade de nós de processamento ativados para os dois esquemas. Novamente, quando todas as VPONs são agregadas em um único nó (30 RRHs), o melhor desempenho energético é obtido pela minimização dos nós ativos.

Conforme mostrado nas Figuras 7.1, 7.2 e 7.3, a criação de VPONs e dimensionamento dos comprimentos de onda pela formulação ILP possui melhor desempenho que o esquema aleatório e em quantidades mais elevadas de RRHs na rede o esquema aleatório não é sequer capaz de encontrar uma solução enquanto a formulação ILP continua a obter soluções ótimas. Apesar do esquema aleatório demandar muito menos tempo do que a formulação ILP para obter uma solução, conforme observado nos resultados o desempenho da formulação ILP é sempre muito superior.

Também foi avaliado o consumo energético da rede, a quantidade de VPONs criadas e nós ativados quando a capacidade de processamento dos nós é reduzida. Nessas avaliações, a capacidade de processamento da nuvem é igual a 10 e dos fog nodes é igual a 5, uma redução de 3 e 2 vezes, respectivamente.

Note que na Figura 7.4 novamente o ILP apresenta melhor desempenho que o esquema aleatório e o consumo de energia cresce constantemente em comparação com o caso da Figura 7.1. Isso é explicado em decorrência de uma ativação mais rápida dos nós de processamento por conta das capacidades de processamento dos nós terem sido diminuídas. Assim, mais nós de processamento são necessários para atender às demandas da rede. Isso também explica o fato de que com essas capacidades de processamento a quantidade de RRHs atendidos é drasticamente reduzida em comparação com a Figura 7.1. Novamente, o esquema aleatório não foi capaz de encontrar soluções 


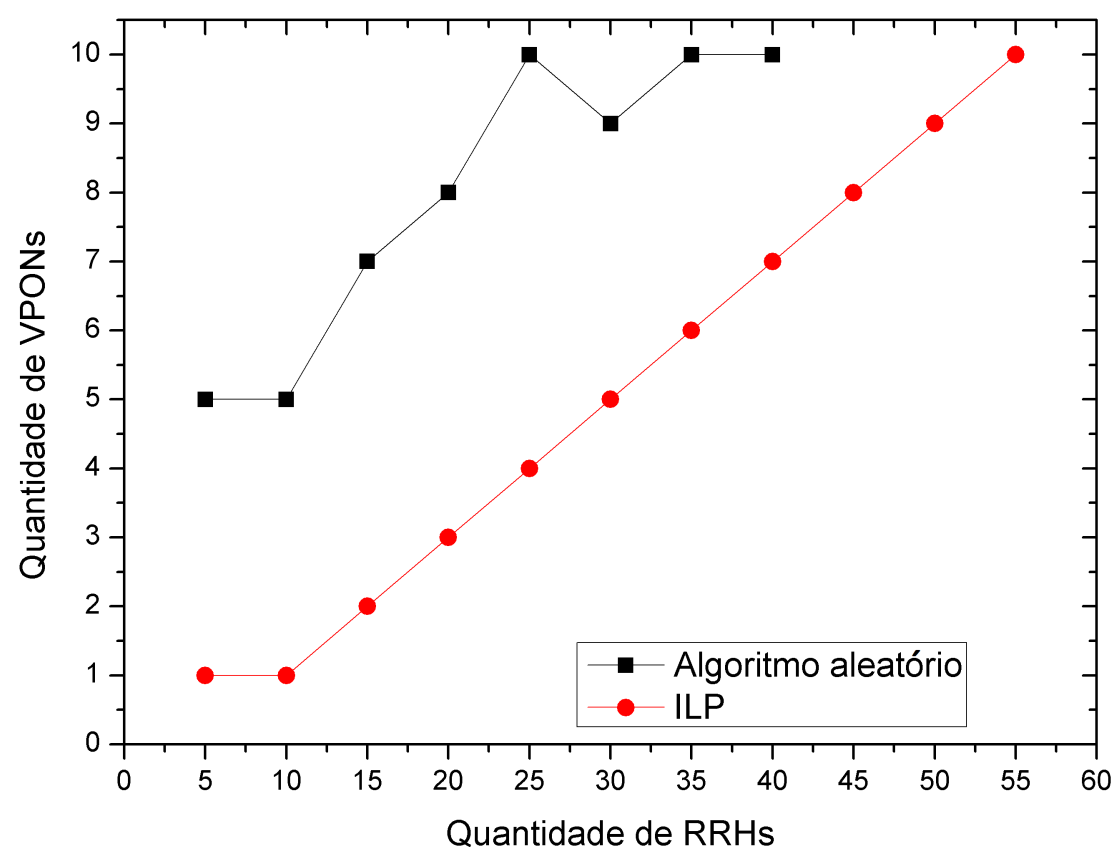

Figura 7.5: Quantidade de VPONs (capacidade da nuvem = 10 e capacidade dos fog nodes $=5$ )

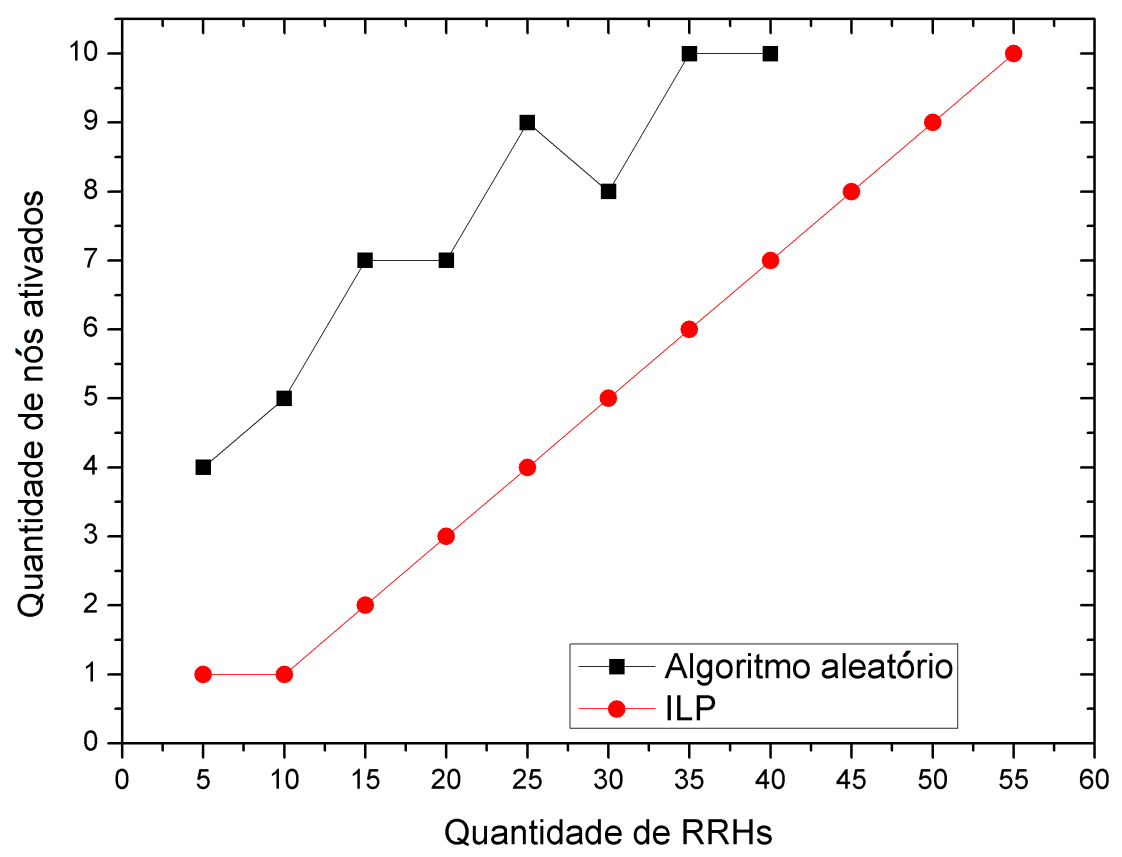

Figura 7.6: Quantidade de nós ativos (capacidade da nuvem $=10$ e capacidade dos fog nodes $=5$ ) 


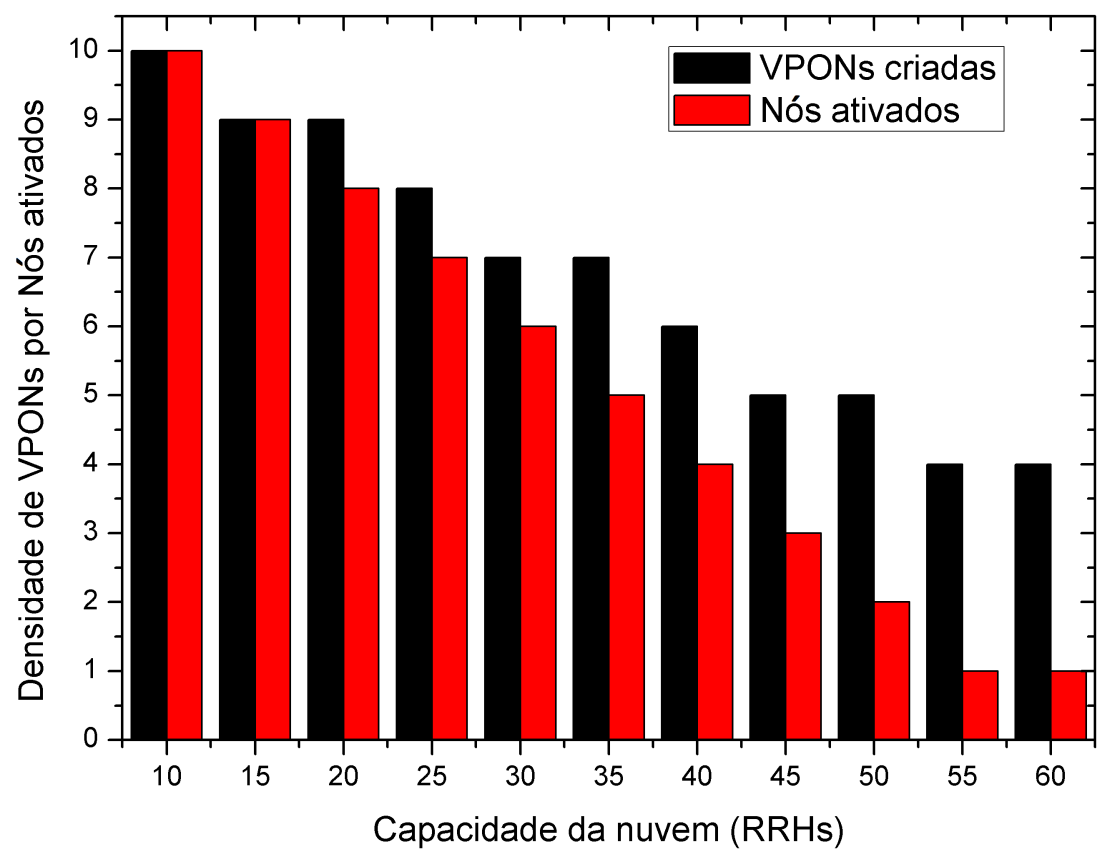

Figura 7.7: Densidade de VPONs por nós ativos para o cenário de maior capacidade de processamento na nuvem

para quantidades maiores de RRHs (maiores que 40), enquanto o ILP foi capaz de criar VPONs e dimensionar os comprimentos de onda para todas as quantidades requisitadas de RRHs.

Como também pode ser notado no crescimento das curvas do ILP nas Figuras 7.5 e 7.6 em comparação com as Figuras 7.2 e. 7.3, menos VPONs são agregadas em cada nó de processamento e os mesmos são ativados mais cedo em comparação ao caso de maiores capacidades de processamento nos nós.

Por conta da capacidade de processamento de um nó impactar a formação de VPONs, também foi avaliado qual o impacto gerado pelo aumento das capacidades de processamento na rede.

Na Figura 7.7 a capacidade de processamento dos fog nodes foi fixada em 5 RRHs e a capacidade de processamento da nuvem foi incrementada. É possível observar que nos valores mais baixos de capacidade da nuvem, a quantidade de VPONs criadas é igual ou próxima da quantidade de nós de processamento ativados, isto é, as VPONs são mais espalhadas pela rede e quase todo nó de processamento recebe uma VPON, por conta de em um cenário de capacidades mais escassas de processamento mais nós serem ativados para processar as demandas. Quando a capacidade da nuvem é aumentada, menos nós de processamento precisam ser ativadas e a densidade das VPONs aumenta, especificamente na nuvem, que é capaz de receber mais demandas e a maioria das VPONs criadas.

Na Figura 7.8, foi comparado o consumo de energia quando aumenta-se as capacidades de processamento da nuvem e dos fog nodes. Para a curva da nuvem, a capacidade de cada fog node é igual a 5 RRHs e para a curva de fog nodes, a capacidade da nuvem é fixa em 10 RRHs (assumimos que seus outros recursos computacionais estão ocupados processando outras tarefas). Para a capacidade máxima dos fog nodes nós assumimos a metade da máxima capacidade de processamento 


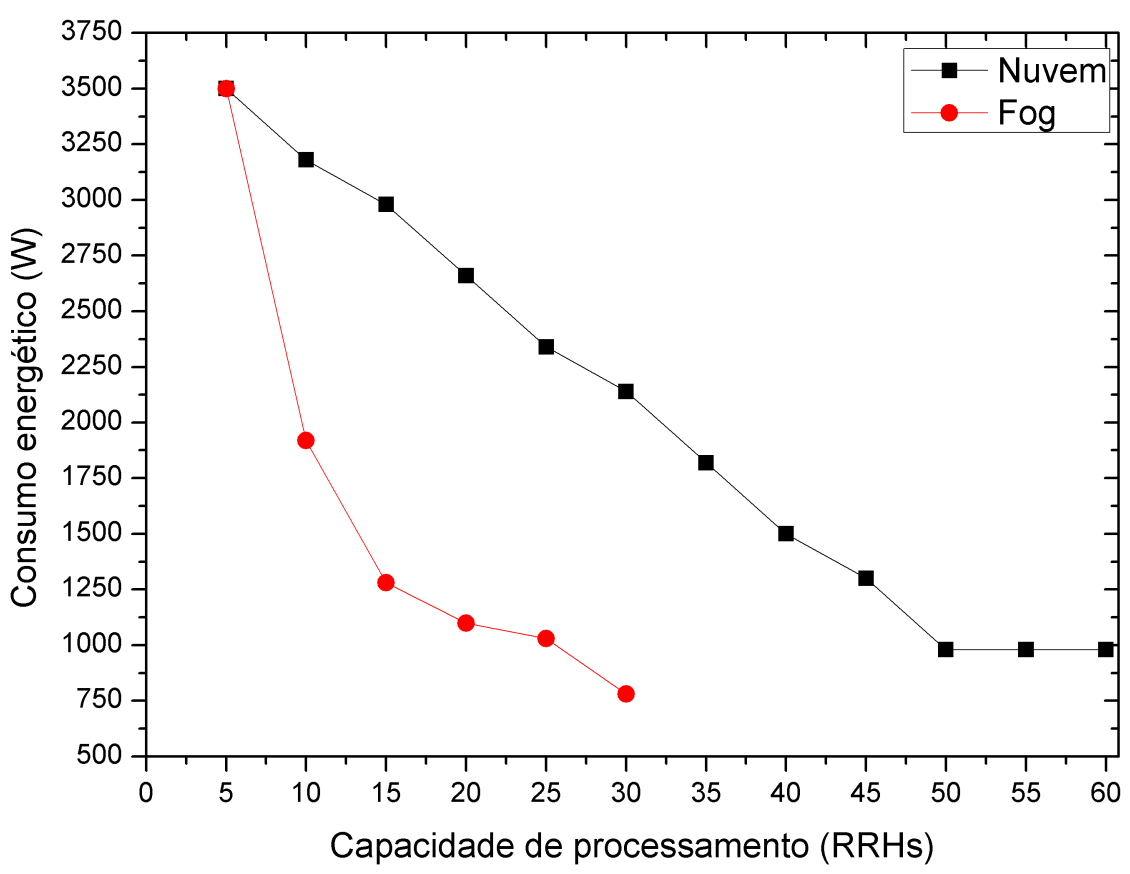

Figura 7.8: Consumo de energia para maiores e menores capacidades de processamento

da nuvem. Observe que utilizando os fog nodes um menor consumo energético é obtido quando a nuvem está mais ocupada, mas quando a nuvem possui mais capacidade de processamento, seu consumo de energia é muito próximo ao melhor consumo de energia dos fog nodes, mas com o dobro de capacidade de processamento disponível.

Por fim, na Figura 7.9 os tempos de execução da formulação ILP são exibidos. É possível observar que o tempo de execução escala em função do crescimento dos RRHs. O maior tempo de execução é de aproximadamente 4, 8 minutos.

\subsection{Alocação de vBBUs e criação de VPONs}

Nesta seção nós apresentaremos o desempenho da formulação ILP e da heurística CF-FL em relação à ativação das vBBUs e criação das VPONs em comparação com as arquiteturas DRAN e CRAN. Novamente abordaremos um cenário de tráfego estático.

Nestas simulações, a arquitetura CF-RAN é composta de 6 nós de processamento, sendo uma nuvem e 5 fog nodes. As capacidades de processamento da nuvem e dos fog nodes são de 30 e 10 RRHs, respectivamente. O fronthaul TWDM-PON é composto por 20 comprimentos de onda de capacidade de $10 \mathrm{Gbps}$ cada. Note que a rede possui mais comprimentos de onda nesse cenário para que a eficácia dos algoritmos seja testada em ambientes previstos de maior disponibilidade de banda. A extensão das fibras ópticas foi aumentada para verificar a latência de propagação obtida, sendo de $20 \mathrm{~km}$ entre os RRHs e os fog nodes e de mais $20 \mathrm{~km}$ entre os fog nodes e a nuvem, totalizando $40 \mathrm{~km}$ de extensão do fronthaul. Assim, a latência máxima para alcançar os fog nodes e a nuvem é de aproximadamente $98 \mu$ s e $196 \mu$ s, respectivamente.

Em relação às execuções da formulação ILP, nós consideramos as duas políticas de dimensio- 


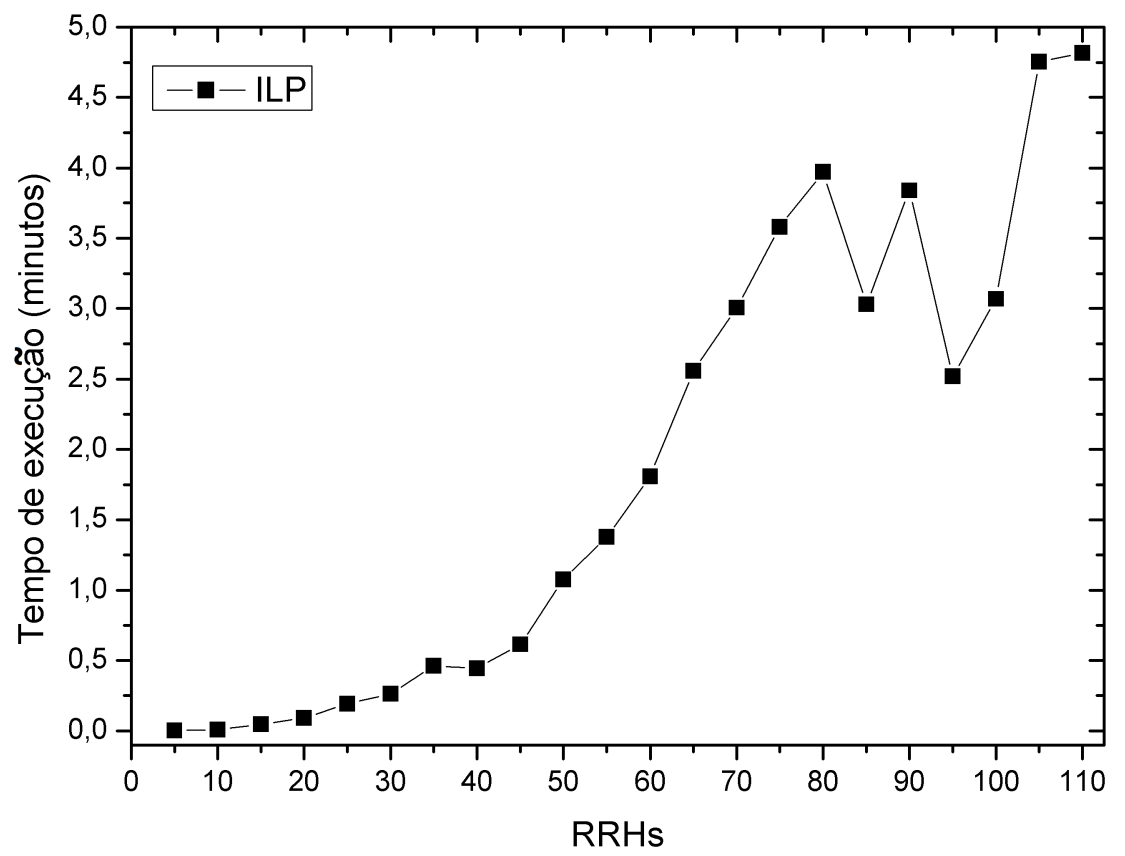

Figura 7.9: Crescimento do tempo de execução

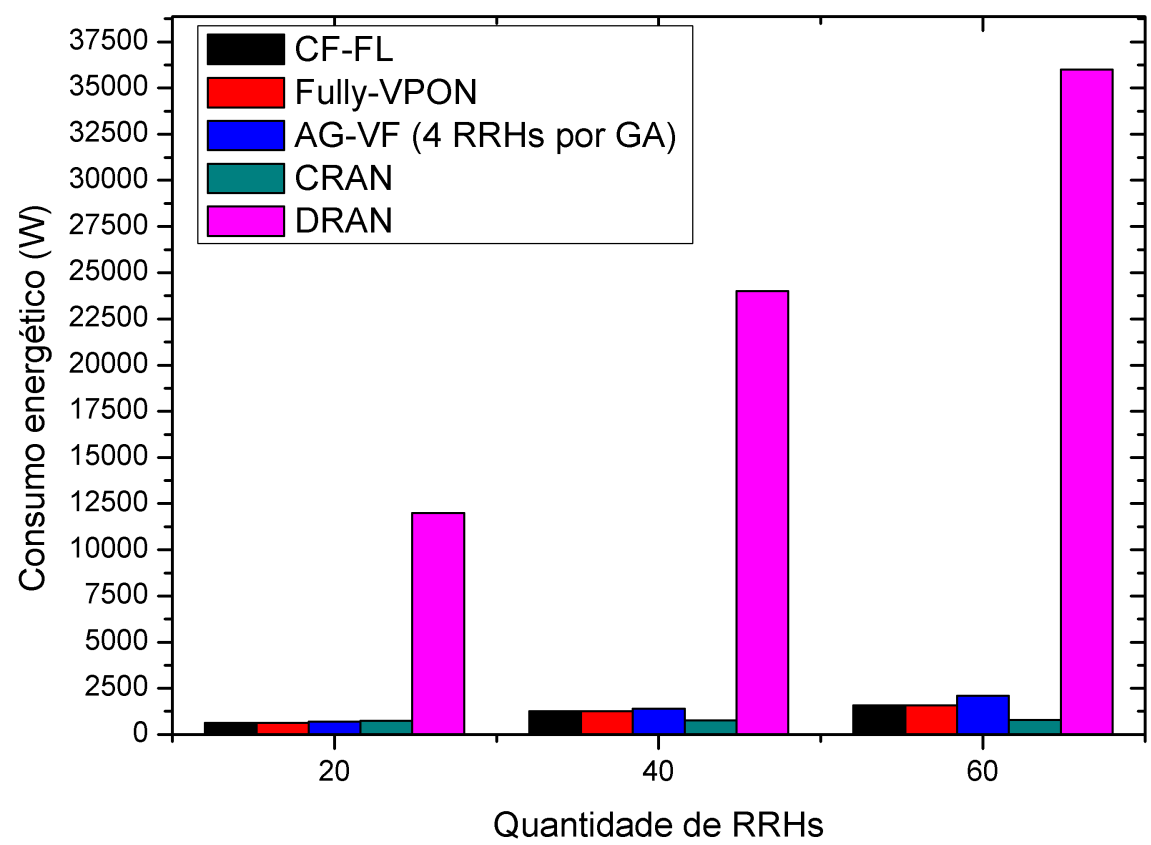

Figura 7.10: Consumo de energia para diferentes quantidades de RRHs e considerando grupos de agregação de 4 RRHs para a política $A G-V F$ 


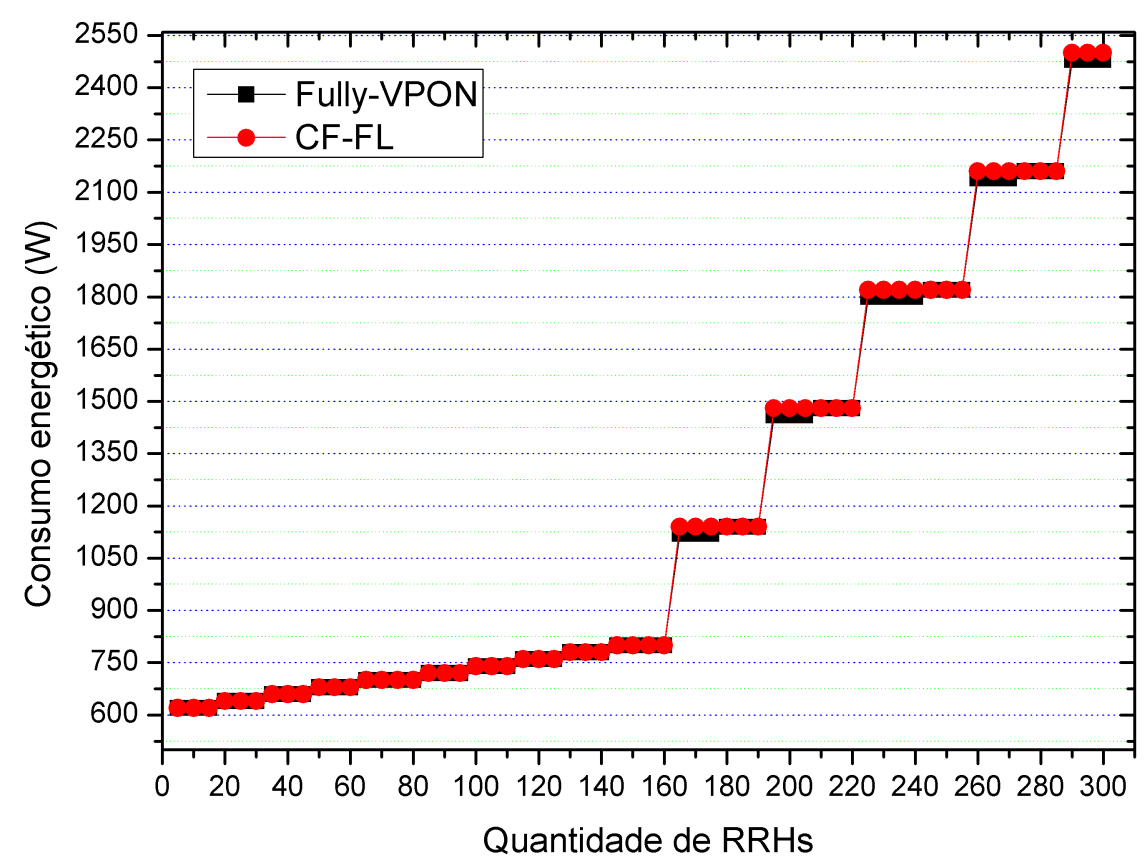

Figura 7.11: Comparação do consumo de energia entre a formulação ILP e a heurística CF-FL para diferentes escalas da CF-RAN

namento de comprimento de onda apresentadas no Capítulo 5 (Fully-VPON e Aggregation Groups VPON Formation (AG-VF)). Em relação à política AG-VF, a quantidade de RRHs conectados em uma ONU multi-port é de 4 RRHs gerando 614, $4 \mathrm{Mbps}$ cada e a quantidade de grupos de agregação presentes na rede é de 5, 10 e 15. Nessas simulações nós avaliamos o consumo de energia da rede, a latência média de propagação e o tempo de execução dos algoritmos.

A Figura 7.10 mostra o consumo de energia da arquitetura CF-RAN operando sob os algoritmos propostos em comparação com as arquiteturas DRAN e CRAN. Note que por conta da centralização e ativação dinâmica das funções de processamento, o consumo de energia da CF-RAN é notavelmente menor que o consumo da DRAN. A arquitetura CRAN também apresenta baixo consumo energético conforme a quantidade total de RRHs aumenta, mas ao custo de uma redução na cobertura da rede, como será mostrado com mais detalhes nas simulações em cenários dinâmicos. Em relação ao desempenho da arquitetura CF-RAN, o melhor de dimensionamento de banda em termos de consumo energético é obtido pela formulação ILP com a política Fully-VPON e pela heurística CF-FL. Conforme a quantidade de RRHs aumenta, e assim a quantidade de grupos de agregação, o consumo de energia da política AG-VF tem um pequeno aumento em comparação com a política Fully-VPON e a heurística CF-FL. Isso ocorre por conta da política AG-VF demandar um comprimento de onda por cada ONU, ao passo que um único comprimento de onda é utilizado por múltiplas ONUs pela política Fully-VPON e pela heurística CF-FL. Dessa forma, a minimização das VPONs criadas leva à minimização dos LCs ativados na rede. Da mesma forma, a política FullyVPON e a heurística CF-FL também utilizam a banda disponível na rede de forma mais eficiente, ao passo que o maior número possível de RRHs são transmitidos por VPON/comprimento de onda. Assim, o consumo de energia da arquitetura CF-RAN, em comparação à DRAN e utilizando-se 


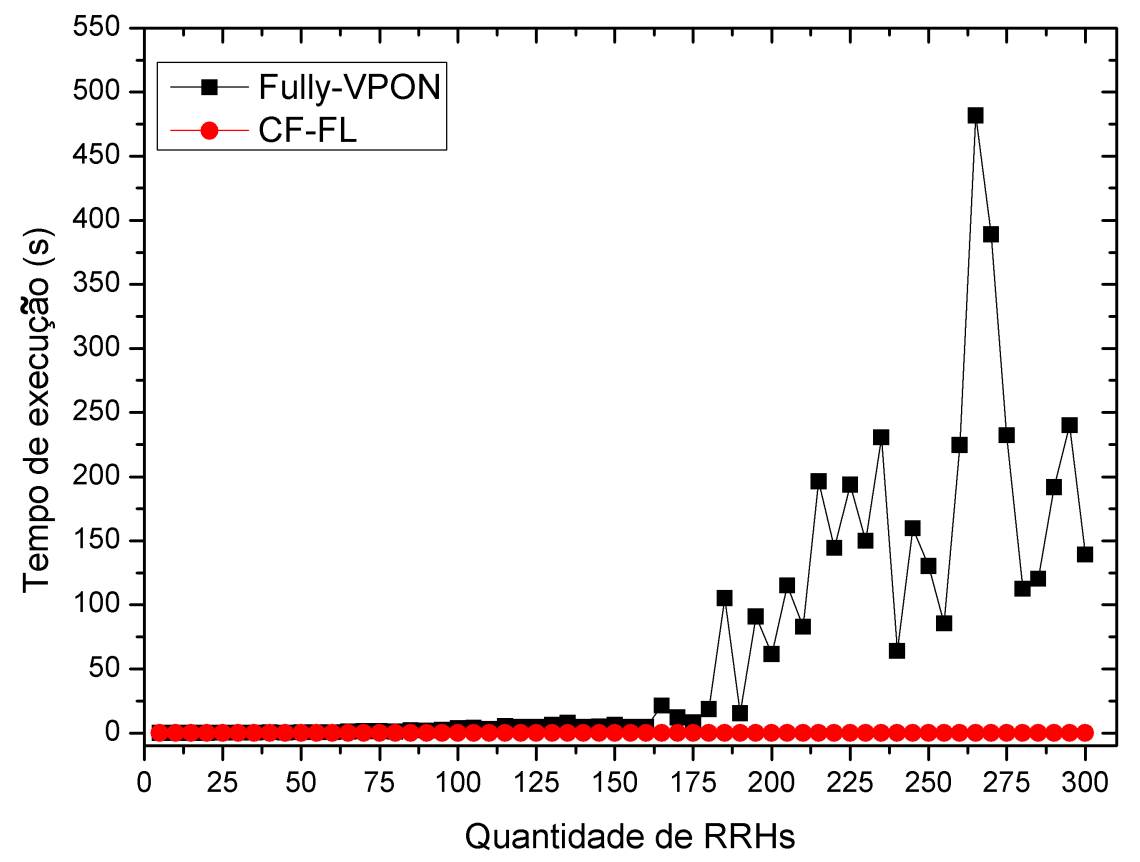

Figura 7.12: Comparação dos tempos de execução entre a formulação ILP e a heurística CF-FL para diferentes escalas da CF-RAN

da política Fully-VPON e heurística CF-FL, pode ser otimizado em até $96 \%$. Por fim, a política Fully-VPON e a heurística CF-FL possuem consumo de energia muito similares e em comparação com a política AG-VF, o consumo energético apresenta uma redução de aproximadamente $24 \%$.

Nós também comparamos a eficiência da heurística CF-FL em comparação com a formulação ILP. Como a política Fully-VPON obteve melhor desempenho que a política AG-VF, ela foi utilizada para comparação com a heurística CF-FL. Nessa comparação, nós aumentamos significantemente o tamanho e capacidade da rede para avaliar a qualidade das soluções apresentadas por ambas as soluções em cenários de larga escala, com uma quantidade mínima de 5 RRHs que cresce em 5 RRHs em cada execução até a quantidade máxima de 300 RRHs na rede. A capacidade de processamento da nuvem é de 160 RRHs e dos fog nodes é de 32 RRHs, respectivamente.

Como pode ser observado na Figura 7.11, mesmo para quantidades maiores de RRHs o desempenho da heurística CF-FL é comparável à formulação ILP, sendo possível obter as mesmas soluções ótimas para praticamente todas as quantidades de RRHs. As soluções sub-ótimas obtidas pela heurística CF-FL são capazes de aproximar as soluções ótimas em no mínimo $92 \%$ e no máximo em 99\%. Foi observado que a qualidade das soluções sub-ótimas tende a se aproximar das soluções ótimas conforme a quantidade de RRHs é incrementada. Em relação ao crescimento do consumo energético, ele tende a ser maior e apresentar saltos a partir da quantidade de 160 RRHs, justamente quando a capacidade da nuvem é exaurida e os fog nodes são ativados. Note que cada salto no consumo de energia apresentado nesse gráfico refere-se a ativação de cada fog node.

Os tempos de execução obtidos pelas soluções são apresentados na Figura 7.12. É possível observar que o tempo de execução da formulação ILP cresce em função do tamanho da entrada do problema. Entretanto, a heurística CF-FL provê um esforço computacional muito menor que 


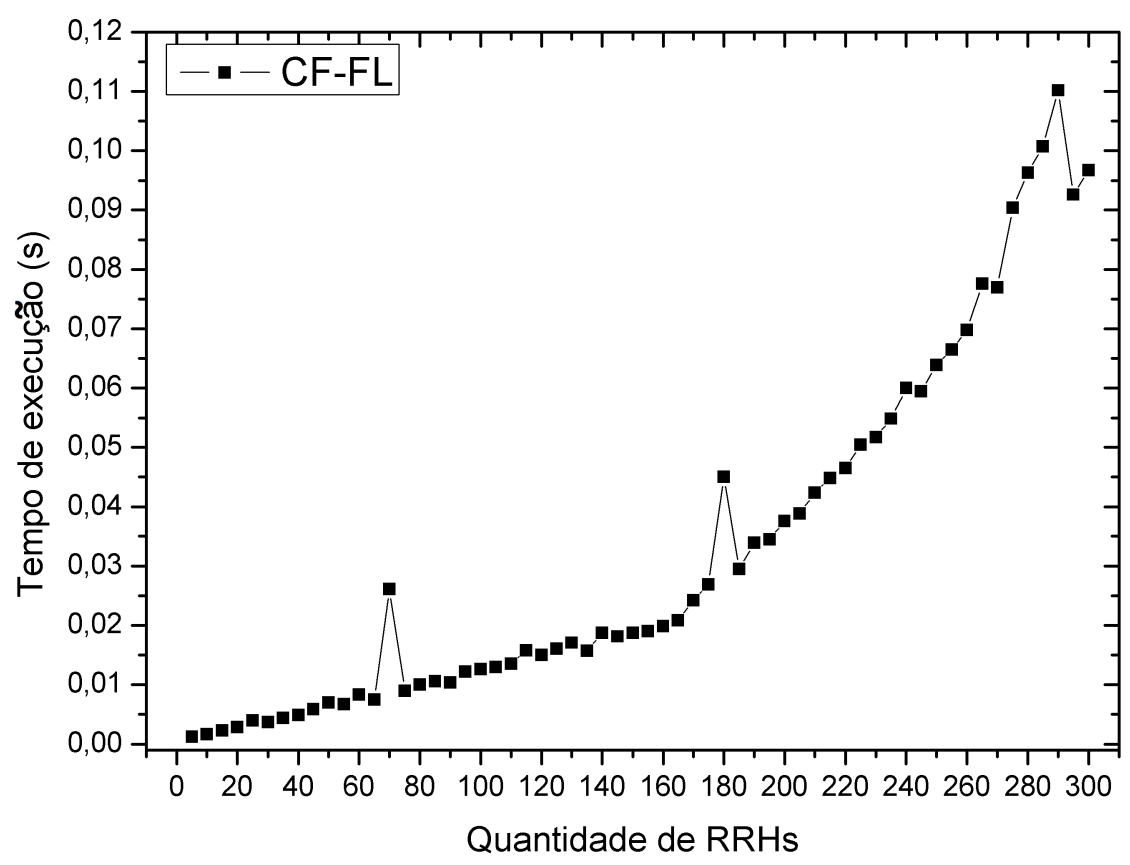

Figura 7.13: Tempos de execução da heurística CF-FL para diferentes escalas da CF-RAN

a formulação ILP, com tempos de execução na ordem de poucos milissegundos até centenas de milissegundos. Uma visão mais detalhada dos tempos de execução obtidos pela heurística CF-FL é apresentada na Figura 7.13. Note que, apesar do crescimento dos tempos de execução apresentar alguns picos, o resultado geral é a provisão de tempos de execução muito baixos pela heurística CF-FL, tornando-a uma opção viável para a solução dos problemas de alocação de vBBUs e criação de VPONs em cenários de larga escala. Por fim, na Figura 7.14 a latência média de propagação entre os RRHs e suas vBBUs é apresentada. Um trade off indireto pode ser observado entre o consumo de energia e a latência média de propagação. Quando o consumo de energia é minimizado, a latência de propagação tende a crescer pois a alocação de requisições CPRI na nuvem é priorizada nesse cenário, mas, conforme a capacidade de processamento da nuvem é exaurida, os fog nodes começam a ser ativados e as requisições passam a ser processadas localmente, o que faz com que a latência média de propagação seja diminuída por conta da distribuição do processamento em locais mais próximos dos usuários mas ao custo do aumento no consumo de energia.

\subsubsection{Discussão}

Conforme pode ser observado, a arquitetura CF-RAN traz ganhos significativos no consumo de energia em comparação a uma arquitetura DRAN tradicional, além de ser capaz de manter a latência de propagação sob os limites impostos pelo padrão CPRI. Além disso, a operação de um algoritmo eficiente para decidir a alocação das vBBUs e criação das VPONs é de suma importância na operação da arquitetura e nesse contexto foi possível obter um ótimo desempenho com a formulação ILP e a heurística CF-FL proposta, tanto na qualidade das soluções quanto no tempo de convergência, que, no caso da heurística, é capaz de ser drasticamente reduzido mas ao mesmo tempo em que a qualidade das soluções são mantidas. Entretanto, apresentou-se aqui apenas a 


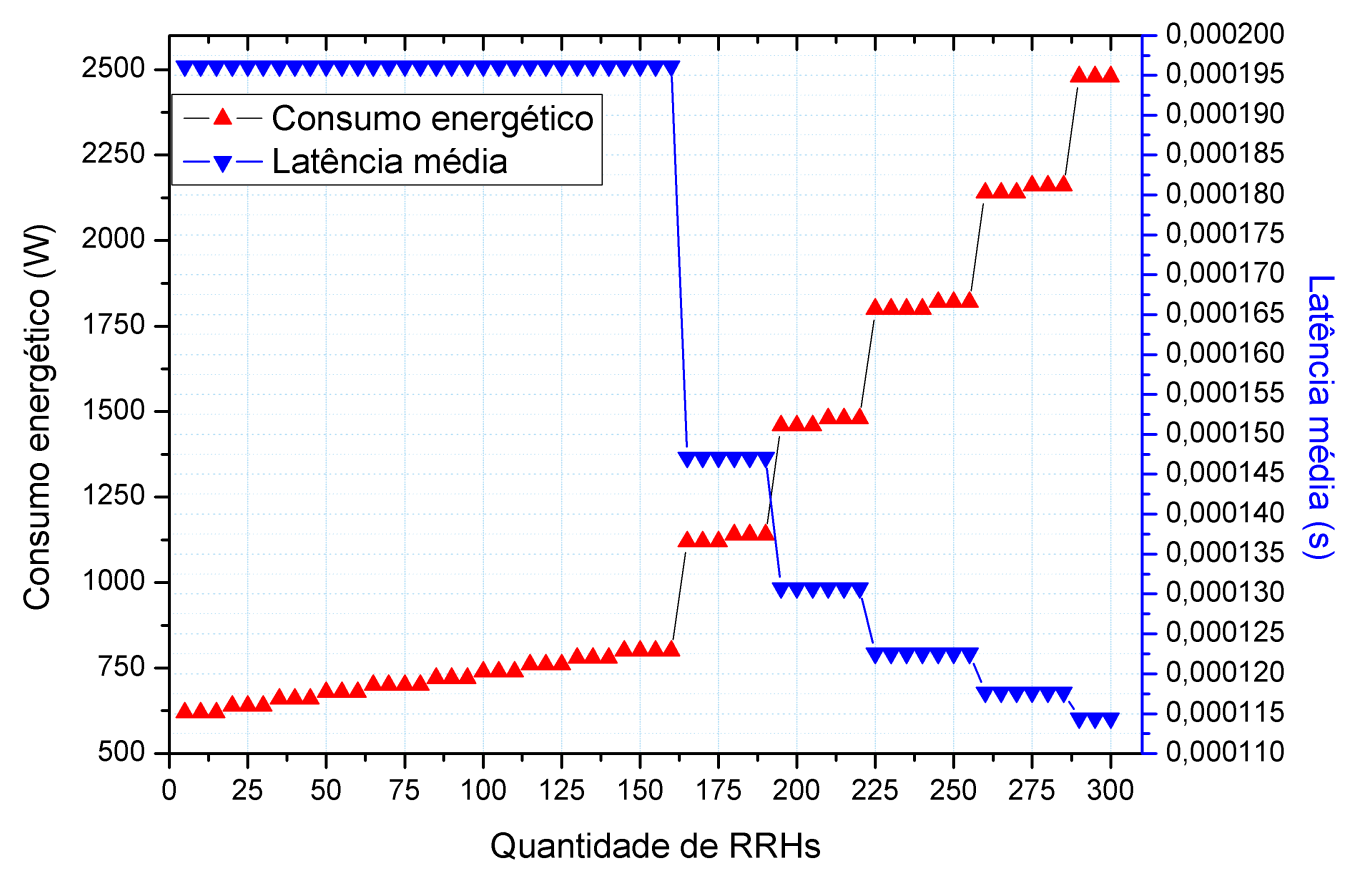

Figura 7.14: Trade off entre consumo de energia e latência mínima média para a transmissão de tráfego $C P R I$

operação da rede em ambientes de tráfego estático. Na próxima seção nós iremos avaliar o desempenho das heurísticas propostas para tratamento dos problemas de alocação de recursos frente a dinamicidade nas chegadas e saídas das requisições CPRI da rede.

\subsection{Avaliação das heurísticas em cenários de tráfego dinâmico}

Nesta seção nós iremos avaliar o desempenho das heurísticas LL, ML e FgF propostas para determinar a ativação dinâmica das vBBUs e dimensionamento dos comprimentos de onda para criação de VPONs frente a incerteza acerca da chegada e saída de requisições CPRI em um cenário de larga escala. Nas seguintes simulações nós consideramos a arquitetura CF-RAN composta por uma nuvem, 5 fog nodes, 160 RRHs e 20 comprimentos de onda com capacidade de 10Gbps no fronthaul TWDM-PON.

Cada fog node é conectado a $32 \mathrm{RRHs}$, com cada um gerando a taxa básica de tráfego CPRI (614,4Mbps). A capacidade de processamento da nuvem e dos fog nodes é de 80 e 16 RRHs, respectivamente. Para modelar o tráfego dinâmico da rede, nós utilizamos um padrão de flutuação de tráfego de uma região metropolitana durante um período de 24 horas em uma cidade da China, conforme apresentado em [ $\left.\mathrm{PLL}^{+} 11\right]$ e também utilizado pelos autores em [WTT $\left.{ }^{+} 16\right]$, conforme mostrado na Figura 7.15. Em relação à chegada das requisições CPRI dentro do padrão de tráfego, no começo da simulação todos os RRHs estão desligados. Então, eles são ativados seguindo um processo de Poisson com média igual a (e/60), onde e é a carga (em erlang) em uma dada hora de operação da rede. Após ser alocado, cada RRH permanece sendo processado e transmitido na rede durante um tempo de serviço uniformemente retirado do intervalo (0,25 hora, 1 hora), ou seja, o tempo máximo que um RRH consome recursos da rede está uniformemente distribuído entre 15 


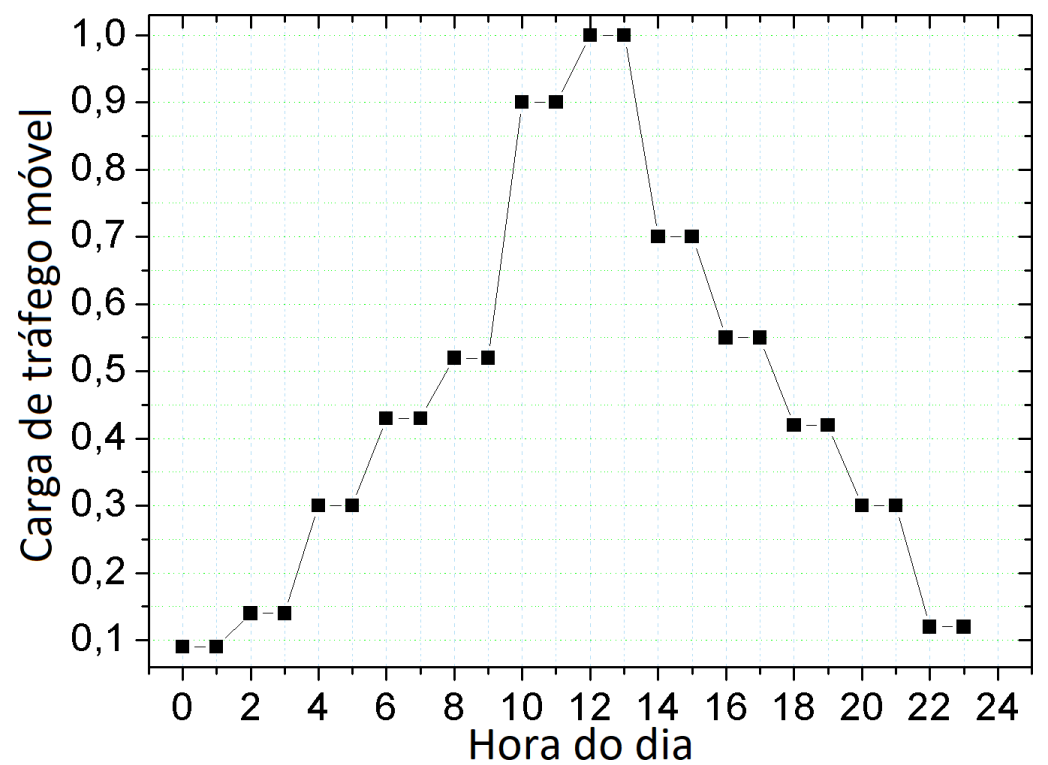

Figura 7.15: Padrão diário de tráfego

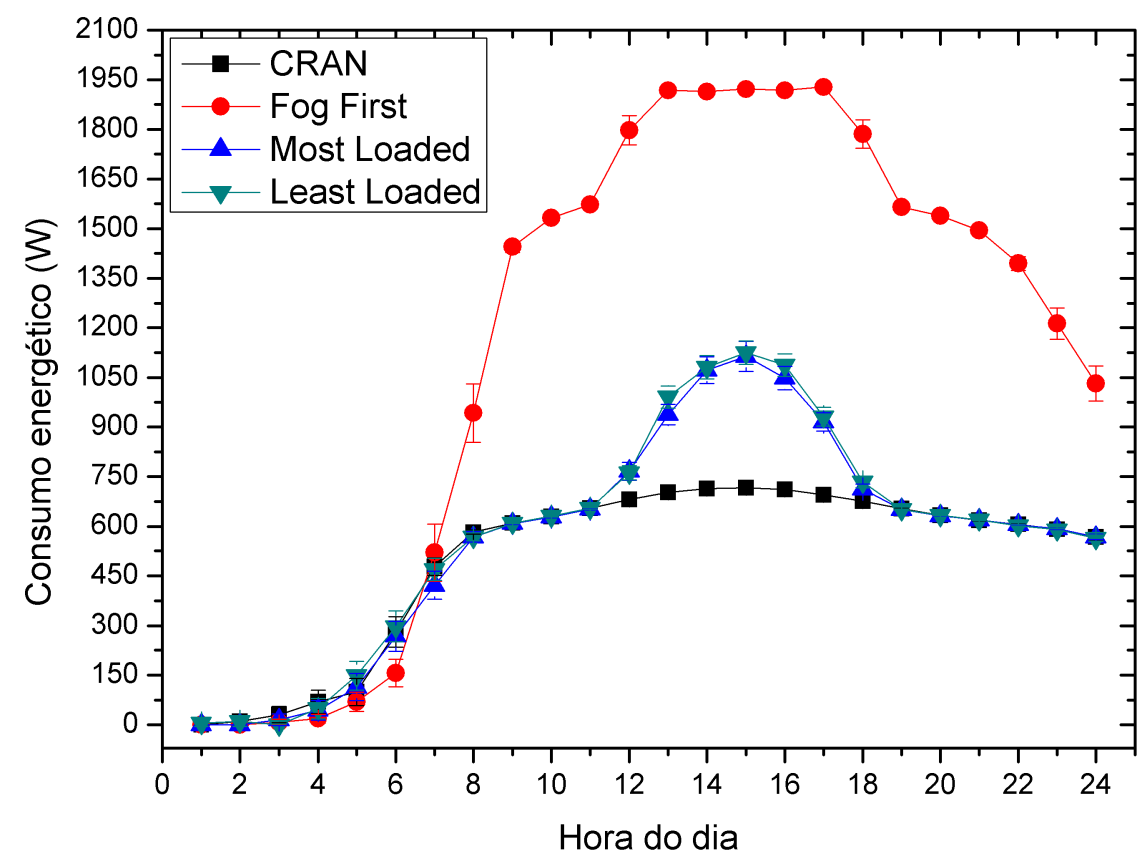

Figura 7.16: Consumo de energia das heurísticas da CF-RAN e CRAN 


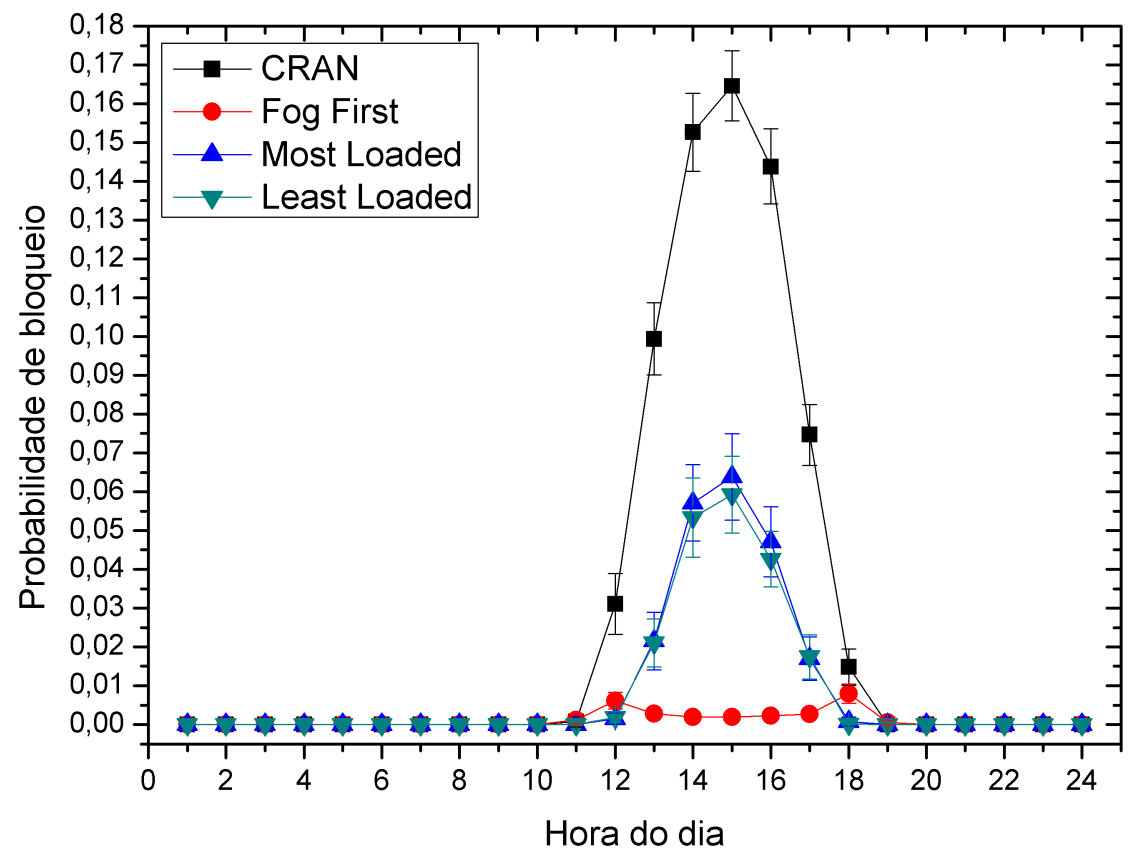

Figura 7.17: Probabilidade de bloqueio para as heurísticas da CF-RAN e CRAN

minutos e 1 hora. Os resultados apresentados mostram a média obtida de 60 execuções de cada heurística com um nível de confiança de $95 \%$.

A Figura 7.16 mostra o consumo de energia obtido por cada uma das três heurísticas de dimensionamento de comprimentos de onda em comparação com a arquitetura CRAN. É possível notar que a arquitetura CRAN possui o menor consumo de energia em comparação com a CF-RAN. Entretanto, esse baixo consumo de energia leva a altas taxas de probabilidade de bloqueio pelo fato de nenhum nó de processamento adicional ser ativado quanto a nuvem torna-se estressada por conta de uma crescente demanda da rede. Em relação às heurísticas propostas para a operação da CF-RAN, pode ser observado que o menor consumo energético também é obtido por meio da alocação prioritária das vBBUs da nuvem. Nesse contexto, ambas as heurísticas LL e ML possuem desempenho energético similar. Note que, mesmo em horas com menores erlangs (6 da manhã e meio dia), um consumo de energia relativamente alto é esperado por que mesmo quando uma pequena quantidade de RRHs está ativa, eles serão alocadas na nuvem, fazendo com que o consumo de energia da nuvem seja contabilizado nesses momentos de baixa carga de trabalho. Esse comportamento é ainda mais crítico com a heurística FgF por que múltiplos fog nodes serão ativados mesmo que a quantidade de RRHs demandando processamento seja baixa.

A Figura. 7.17 mostra a probabilidade de bloqueio para a CF-RAN e CRAN. A arquitetura CRAN apresenta a maior probabilidade de bloqueio por conta de nenhum fog node ser utilizado quando as capacidades da nuvem ou do fronthaul são esgotadas. Na operação da arquitetura CF-RAN é possível observar que a heurística $\mathrm{FgF}$ obtém a menor probabilidade de bloqueio, mas ao custo do maior consumo de energia por conta da alocação das vBBUs ser feita primeiramente nos fog nodes, conforme mostrado na Figura 7.16. Por outro lado, quando a alocação das vBBUs na nuvem é priorizada, baixas taxas de bloqueio também são obtidas, não tão baixas como no caso da 


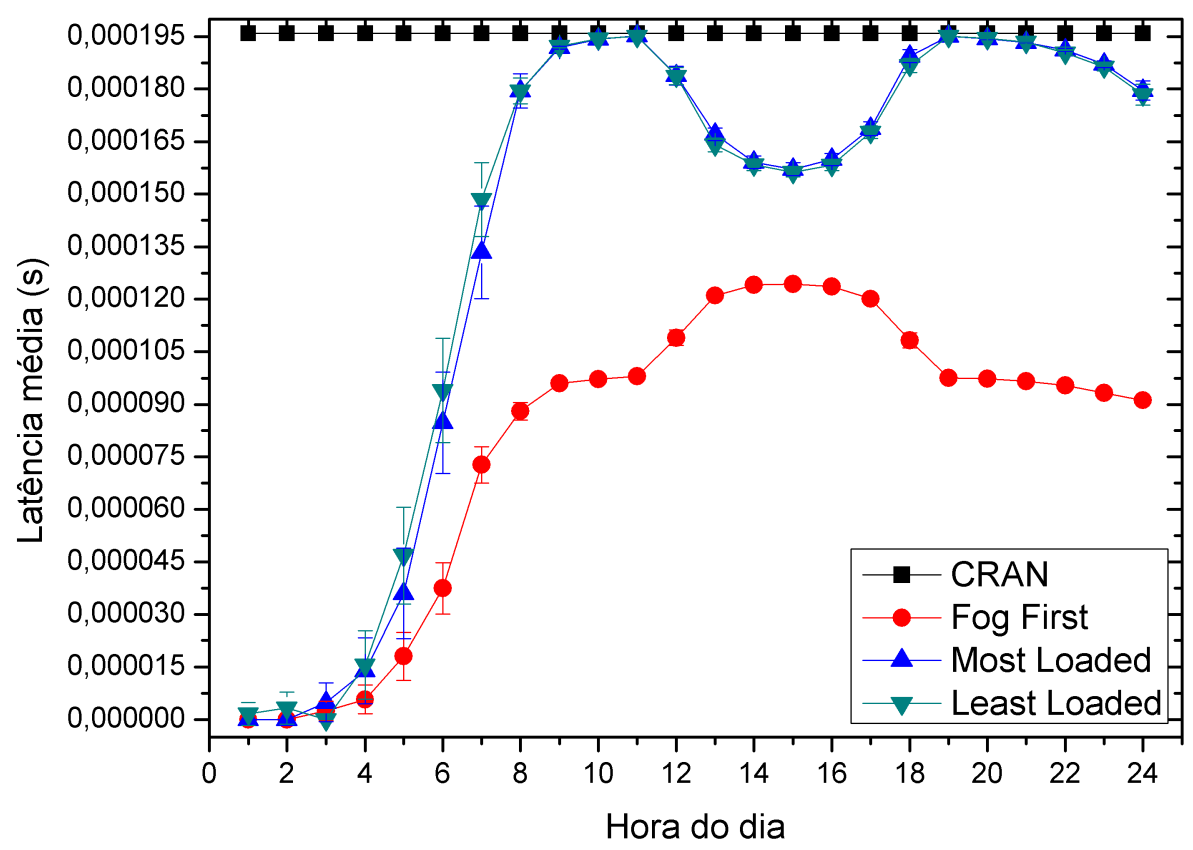

Figura 7.18: Latência média de propagação

heurística $\mathrm{FgF}$, mas ainda assim muito pequenas e com consumo energético muito menor. Também é possível observar que a heurística LL tende a produzir menor taxas de bloqueio do que a heurística ML nos horários de pico, com uma redução máxima de até $7.2 \%$.

A latência média de propagação na arquitetura CF-RAN é mostrada na Figura 7.18. Note que a CRAN sempre irá prover a maior latência de propagação em decorrência da centralização total do processamento de banda-base. Pode ser observado que a latência média provida por nossas heurísticas cresce em função da carga da rede. Por conta da ativação prioritária dos fog nodes, a heurística FgF sempre irá prover a menor latência média de propagação, provendo uma redução de até $57.3 \%$ em momentos de baixa carga de trabalho. Isso é decorrente da maior ativação de vBBUs nos fog nodes, reduzindo assim o tempo de propagação geral da rede ao passo que muitos RRHs irão experimentar a menor latência possível de propagação. Entretanto, apesar das heurísticas LL e ML possuírem maior latência de propagação que a heurística FgF, essa diferença tende a ser reduzida em até $20 \%$ nos horários de pico. Um trade off interessante pode ser observado entre a demanda da rede e a latência de propagação. Quando a utilização dos fog nodes é priorizada, a latência média de propagação tende a crescer em função da demanda da rede, entretanto, quando o uso da nuvem é priorizado, demandas mais altas da rede levam a reduções na latência média de propagação.

As Figuras 7.19, 7.20 e 7.21 mostram um trade off entre a latência média de propagação e o consumo de energia para as heurísticas propostas na arquitetura CF-RAN. É possível observar que, para a heurística $\mathrm{FgF}$, os crescimento da latência segue o consumo de energia para todos os erlangs da rede(Figura 7.19). Apesar dessa heurística produzir a menor média de latência de propagação, pode ser observado que o crescimento da latência e consumo de energia é maior para a heurística FgF em comparação com as heurísticas LL e ML. Para a heurística FgF no período entre $7: 00$ e 15 : 00, um crescimento de aproximadamente $40 \%$ e $74 \%$ na latência e consumo de energia foi 


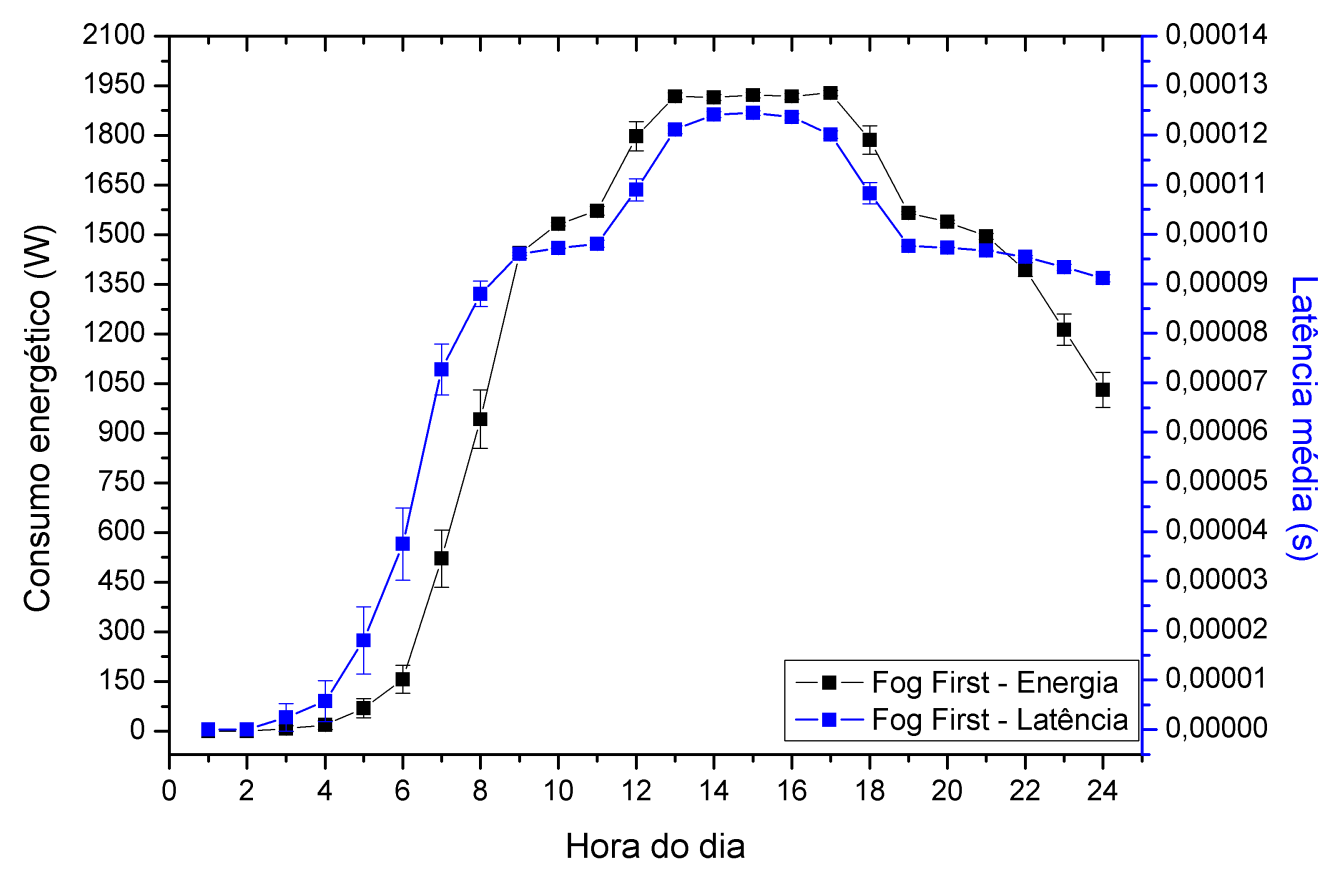

Figura 7.19: Trade off entre latência e consumo de energia para a heurística Fog First

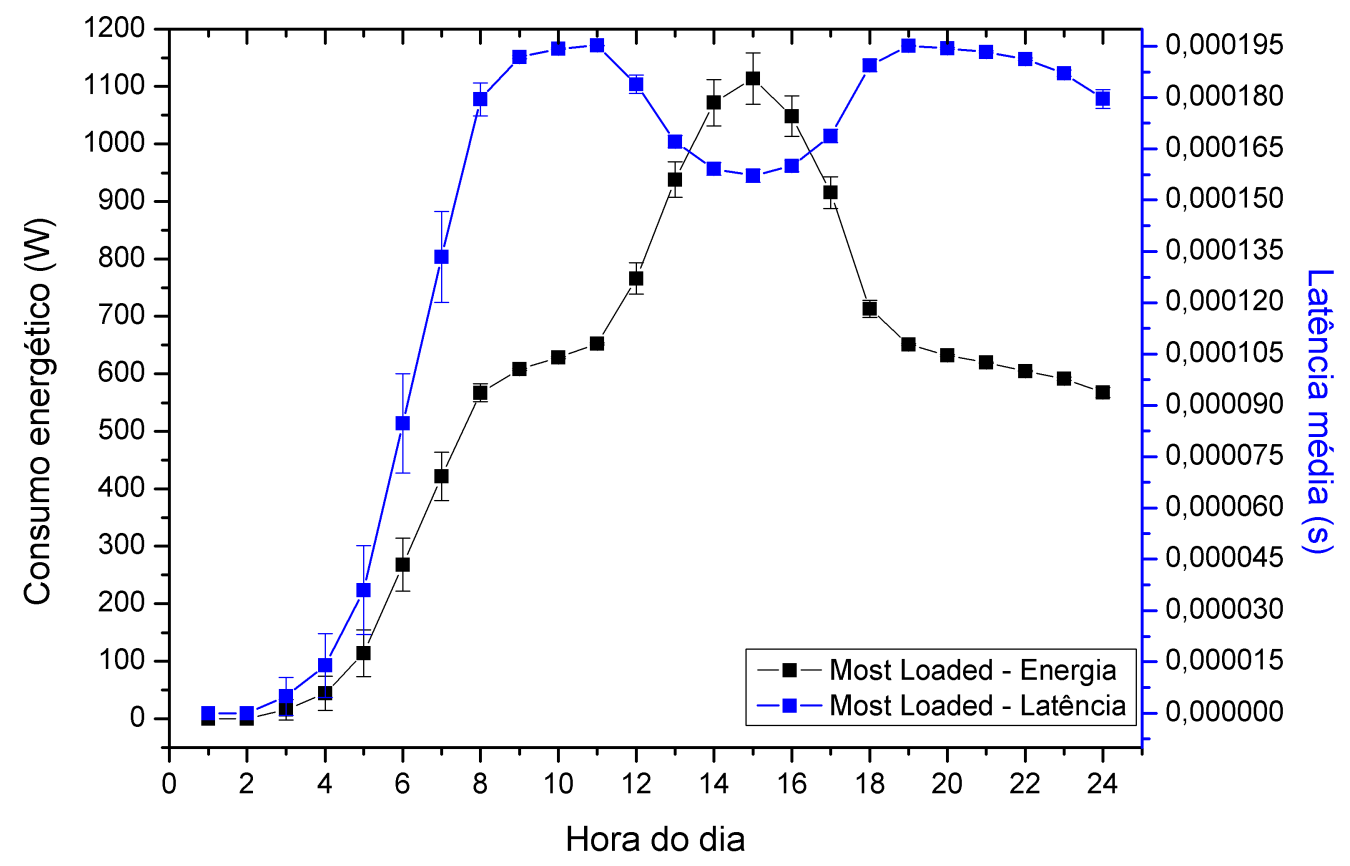

Figura 7.20: Trade off entre latência e consumo de energia para a heurística Most Loaded 


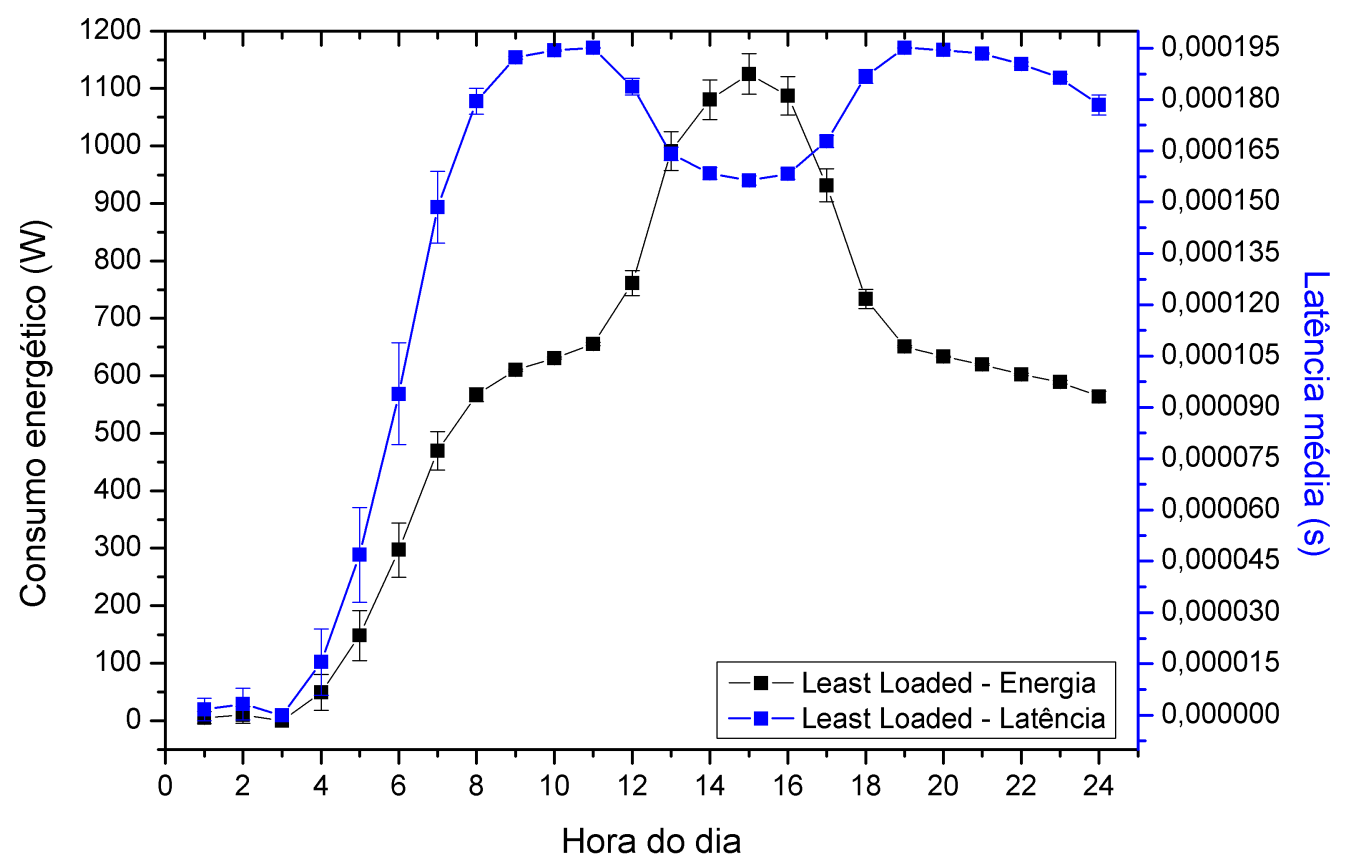

Figura 7.21: Trade off entre latência e consumo de energia para a heurística Least Loaded

observado, respectivamente. Por outro lado, há uma lacuna muito grande entre o crescimento da latência e consumo de energia para as heurísticas LL e ML.

Entre as $7: 00$ e $15: 00$, o crescimento da latência e consumo de energia é de aproximadamente $7 \%$ e $63 \%$ para a heurística ML e $7 \%$ e $59 \%$ para a heurística LL, respectivamente. Em horas de baixa carga de trabalho, uma latência maior causa baixo consumo de energia. Entretanto, em horas de cargas de trabalho maiores, por volta de $13: 00$ e $17: 00$, há um forte trade off entre a latência e consumo de energia, porque conforme mais fog nodes são ativados, a latência diminui ao custo do crescimento do consumo energético (Figuras. 7.20 e 7.21). Observe que, ao passo que a heurística FgF obtém a menor latência impondo maior gasto energético, o uso priorizado da nuvem pelas heurísticas LL e ML provêm um melhor balanceamento entre a latência média de propagação e o consumo de energia em comparação com a FgF.

Por fim, as Figuras 7.22, 7.23 e 7.24 mostram a influência da latência de propagação na probabilidade de bloqueio. Como pode ser observado para a heurística FgF (Fig. 7.22), nos horários de pico conforme a latência média cresce por volta de $15 \mu \mathrm{s}$, a probabilidade de bloqueio diminui por volta de 3 vezes. Isso ocorre porque em momentos de pico na carga de trabalho, a nuvem começa a ser utilizada pela heurística FgF e mais vBBUs podem ser admitidas na rede. Entretanto, para as heurísticas LL e ML (Figuras 7.23 e 7.24), conforme a latência e diminuída pela ativação dos fog nodes, a probabilidade de bloqueio tende a crescer, por conta de se tornar mais difícil a decisão de como dimensionar os comprimentos de onda disponíveis para todos os fog nodes que começam a ser ativados. Para as heurísticas LL e ML, quando a latência média de propagação cai em aproximadamente $40 \mu \mathrm{s}$, a probabilidade de bloqueio cresce em aproximadamente 40 and 32 vezes, respectivamente. 


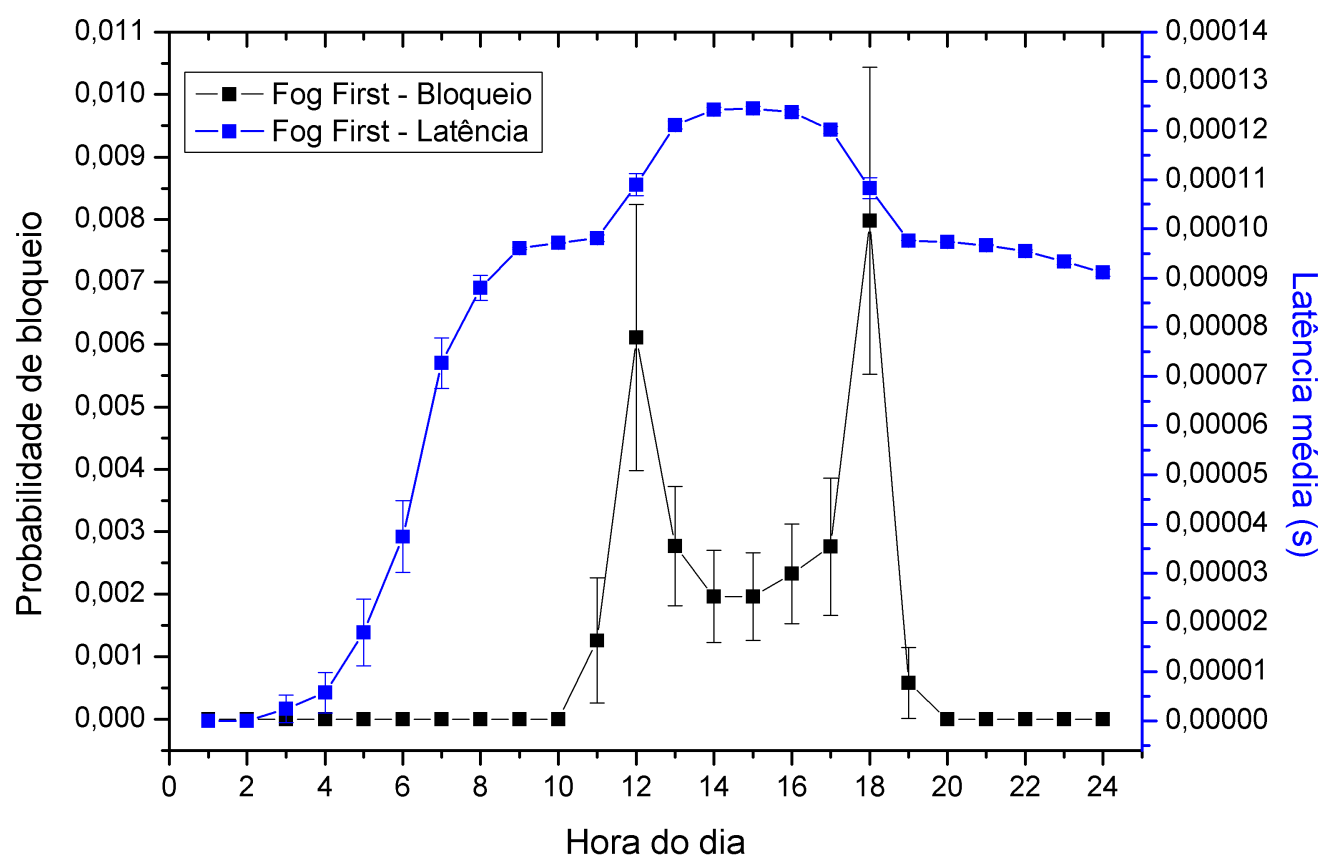

Figura 7.22: Trade off entre latência e probabilidade de bloqueio para a heurística Fog First

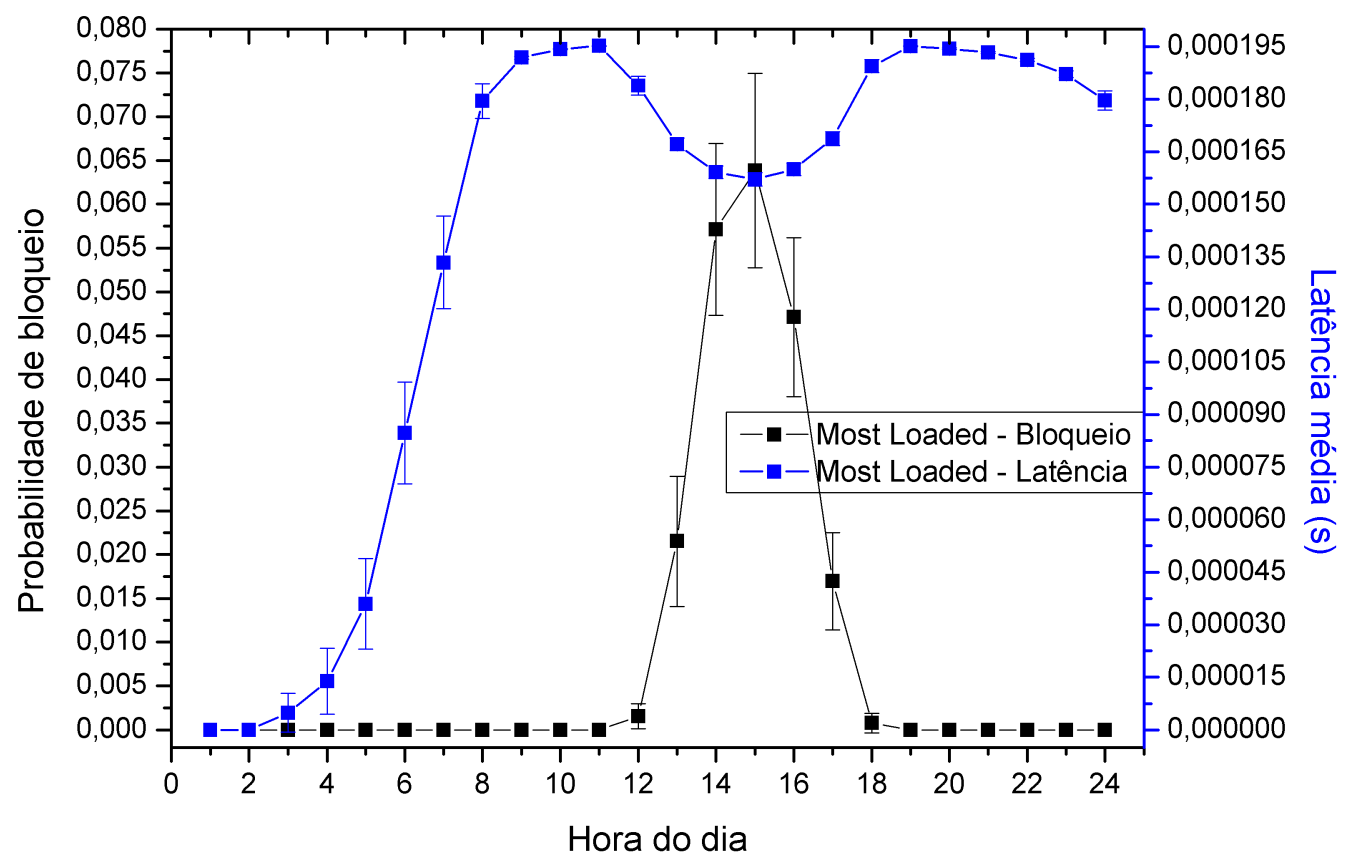

Figura 7.23: Trade off entre latência e probabilidade de bloqueio para a heurística Most Loaded 


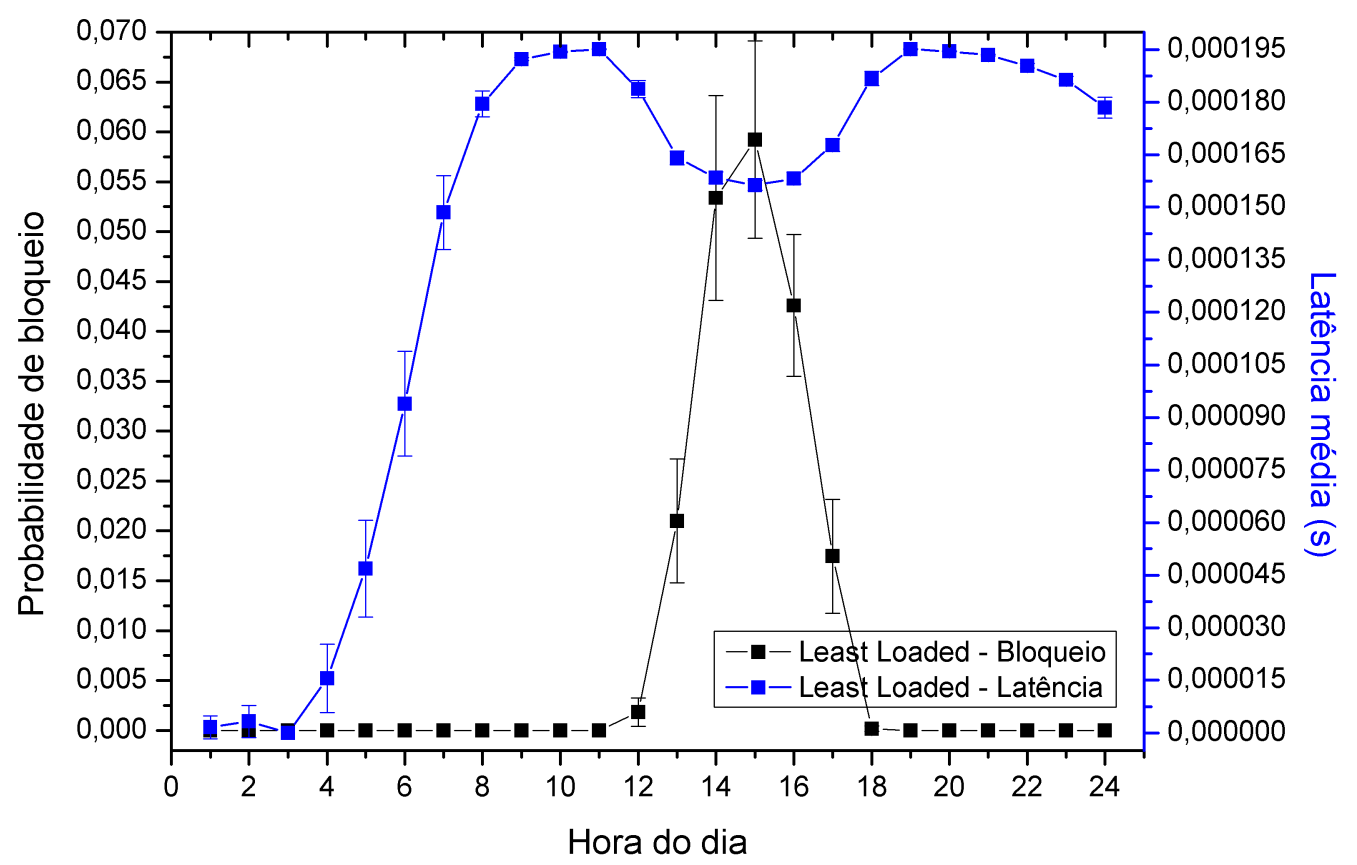

Figura 7.24: Trade off entre latência e probabilidade de bloqueio para a heurística Least Loaded

\subsubsection{Discussão}

Nesta seção as heurísticas propostas para alocação de vBBUs e criação de VPONs em cenários de tráfego dinâmico foram avaliadas. As heurísticas propostas foram capazes de manter um bom desempenho energético em cenários dinâmicos e com baixas taxas de bloqueio. Mesmo que a priorização do uso dos fog nodes traga a menor probabilidade de bloqueio, o custo de operação pode tornar-se proibitivo e mitigar as vantagens que a centralização de processamento na nuvem pode trazer. Por meio de análises de trade offs entre latência média de propagação, consumo de energia e probabilidade de bloqueio, conclui-se que a utilização priorizada da nuvem por meio das heurísticas LL e ML provê uma operação balanceada para a arquitetura CF-RAN. 


\section{Capítulo 8}

\section{Impacto da Migração de vBBUs e Reconfiguração de VPONs}

Os conceitos que serão introduzidos neste Capítulo foram publicados em [TBF ${ }^{+}$19a] e [TFB19].

$\mathrm{Na}$ arquitetura CF-RAN, o balanceamento entre consumo de energia e cobertura da rede (ou minimização da probabilidade de bloqueio) pode ser alcançado por meio da ativação dinâmica de recursos de processamento (vBBUs) e de rede (VPONs) por meio do paradigma de NFV conforme demanda a taxa de tráfego CPRI ingresso. As vantagens de se utilizar o paradigma de NFV no desempenho da rede foram mostradas no Capítulo 7.

Entretanto, os algoritmos até aqui propostos não lidam com cenários de cargas de trabalho desbalanceadas tanto nas VDUs quanto nas VPONs que podem ocorrer em decorrência das flutuações de tráfego durante a operação da rede.

No cenário de tráfego dinâmico, conforme as requisições chegam na rede e demandam uma vBBU e uma VPON, os algoritmos propostos buscam resolver um problema de escalonamento que tem as requisições como entrada e que gera como saída um escalonamento (ótimo ou sub-ótimo, como foi observado nos resultados) das requisições ingressantes nos recursos da rede. O escalonamento contempla a alocação de requisições tanto em VDUs e VPONs que foram criadas inicialmente para atender a essas requisições ou que já estavam ativadas na rede e atendiam a outras requisições.

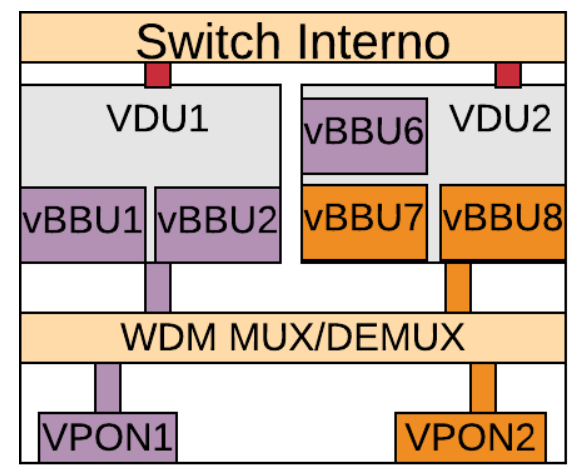

a) Antes da reconfiguração de VPONs

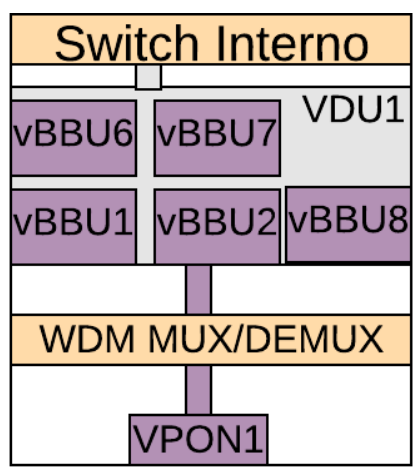

b) Após a reconfiguração de VPONs

Figura 8.1: Desbalanceamento de cargas de trabalho entre as VDUs 1 e 2 , além da presença de mais VPONs do que o necessário para as transmissões a essas VDUs

Conforme o tráfego da rede flutua $\left[\mathrm{PLL}^{+} 11\right]$, RRHs que estavam sendo processados na rede 


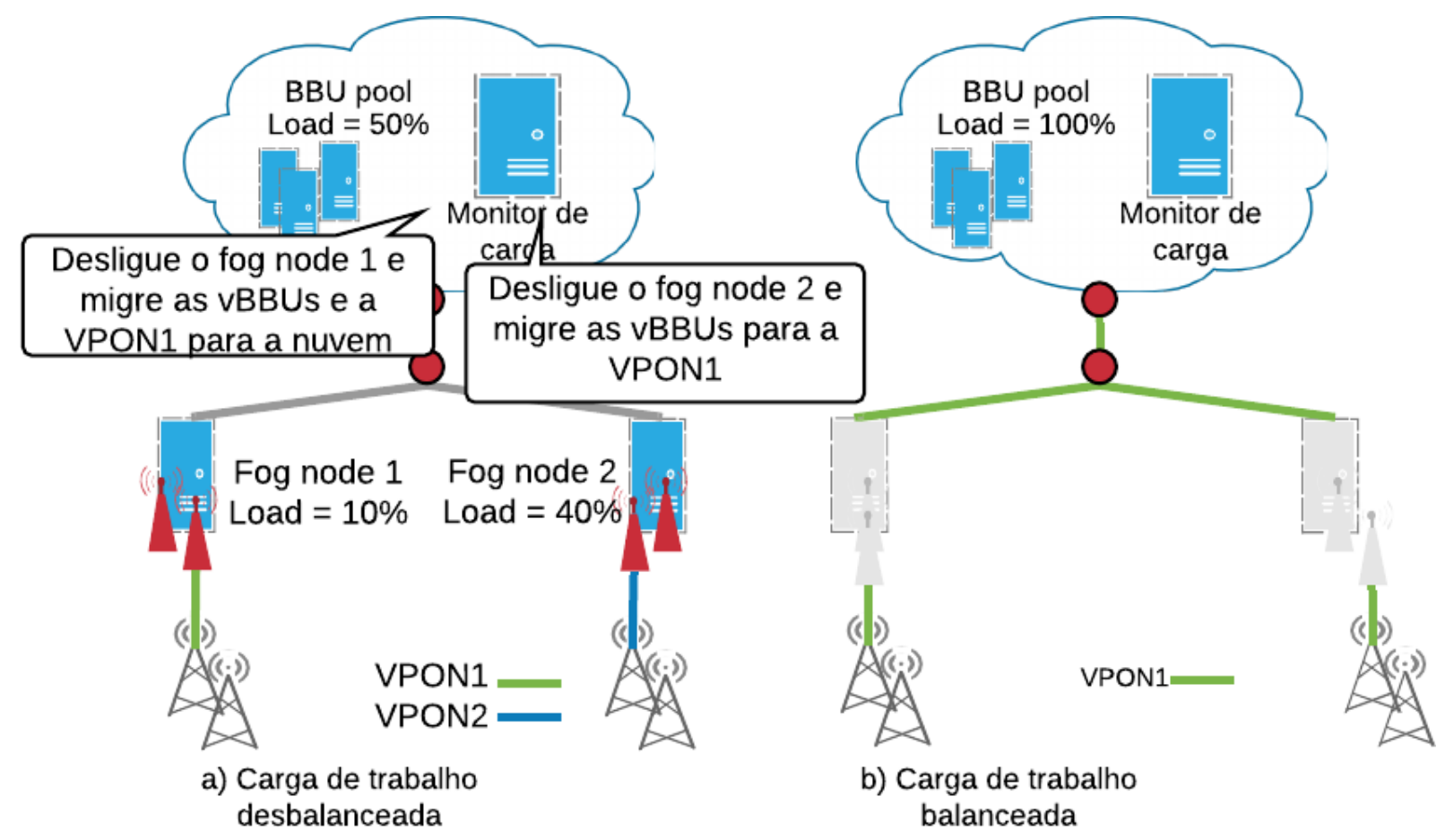

Figura 8.2: a) Nós de processamento desbalanceados antes da migração de vBBUs b) Nós de processamento balanceados após a migração de vBBUs

têm o seu processamento encerrado e são desativados. Quando um RRH é desativado, a vBBU que estava instanciada para ele em uma VDU também é desativada, diminuindo então a carga de trabalho dessa VDU. Da mesma forma, a porção de banda que ele utilizava em sua VPON também é liberada, diminuindo a quantidade de RRHs atendidos por sua VPON.

Esse comportamento pode levar a cargas de trabalho desbalanceadas entre as VDUs e entre as VPONs, pois tanto uma VDU quanto uma VPON podem estar ativadas apenas para suportar o processamento e transmissão de uma pequena parcela de RRHs. A Figura 8.1 a) ilustra um exemplo de distribuição desbalanceada das cargas de trabalho nas VDUs e VPONs de um nó de processamento qualquer. Consideremos que após diversas flutuações de tráfego e saídas de RRHs da rede, as VDUs e as VPONs apresentem as cargas de trabalho ilustradas. Consideremos também que as VDUs da Figura 8.1 têm capacidade de instanciar 10 vBBUs, e cada VPON pode realizar a transmissão de até 16 requisições CPRI. Note que não há necessidade de duas VDUs estarem ativadas, pois apenas uma delas poderia instanciar todas as vBBUs ativadas nesse nó de processamento. Da mesma forma, note que apenas uma VPON já seria capaz de suportar a transmissão de todas as requisições CPRI que são processadas nesse nó.

Nesse contexto, pode ser interessante, do ponto de vista de economia de recursos, redistribuir, ou balancear, as cargas de trabalho da rede entre as VDUs e as VPONs de forma que os recursos com baixas cargas de trabalho sejam desativados para diminuir o consumo de energia da rede. Conforme mostrado na Figura $8.1 \mathrm{~b}$ ), um procedimento de balanceamento de carga foi ativado e as vBBUs instanciadas na VDU 2 foram todas migradas para a VDU 1, da mesma forma como as ONUs dos RRHs que utilizam essas vBBUs foram reconfiguradas para transmissão na VPON 1. Por conta dessa redistribuição de carga e reconfiguração dos elementos ativos, tanto a VDU 2 quanto a VPON 2 foram desativadas e o consumo de energia pode ser otimizado frente ao cenário ilustrado na Figura 8.1 a). 
Um procedimento de redistribuição das cargas de trabalho como o que acabou de ser apresentado não traria ganhos apenas na economia de energia de um nó de processamento. Tal migração das cargas de trabalho entre VDUs poderia ocorrer entre as VDUs de diferentes nós de processamento, e não apenas entre VDUs instanciadas em um mesmo nó. Assim, não apenas VDUs podem ser desativadas para um melhor desempenho energético da rede, mas nós inteiros podem ser desativados se toda sua carga de trabalho for migrada para outro nó, contribuindo ainda mais para uma operação energeticamente eficiente na rede.

Um cenário de migração de tráfego entre nós de processamento é ilustrado na Figura 8.2. Nesse exemplo, a carga de trabalho da nuvem é suficiente para abarcar tanto a carga de trabalho do fog node 1 quanto do fog node 2. Por esse motivo, ambas cargas de trabalho são migradas para a nuvem e ambos os fog nodes são desligados. Note também que a carga das VPONs também pode ser migrada. Se uma VPON possui capacidade para suportar todo o tráfego de uma outra VPON, seria interessante usar apenas uma única VPON, e não duas para suportar esse tráfego, assim economizando a energia consumida pelos LCs ativos e até mesmo provendo uma utilização mais eficiente da largura de banda disponível na rede, evitando desperdícios desnecessários de banda. A migração de tráfego entre VPONs pode ser realizada por meio da reconfiguração das ONUs dos RRHs que transmitem em uma VPON que terá seu tráfego migrado. Além disso, a migração de tráfego de VPONs também pode contemplar a migração das próprias VPONs, que transmitem em um nó de processamento, para suportarem transmissões a outros nós de processamento. Esse exemplo é ilustrado também na Figura 8.2, onde na seção a) da figura, as VPONs 1 e 2 são utilizadas para transmissões aos fog nodes 1 e 2, respectivamente. Entretanto, como todo o tráfego foi movido para a nuvem, é necessário que as transmissões também sejam direcionadas para lá. Assim, assumese na figura que a VPON 1 possui capacidade para transmitir o tráfego da VPON 2. Assim, as ONUs dos RRHs que transmitem na VPON 2 são reconfigurados para transmitirem no comprimento de onda da VPON 1. Por fim, o comprimento de onda da VPON 1, que antes era alocado ao fog node 1, é realocado para a nuvem. Assim, a reconfiguração das ONUs e a realocação de um comprimento de onda contemplam todo o processo de migração de tráfego e reconfiguração de VPONs.

Assim, faz-se necessário que a capacidade de migração de vBBUs e reconfiguração de VPONs seja executada durante a operação da arquitetura CF-RAN para uma constante otimização de sua operação frente à liberação de uso dos recursos de processamento e rede. Para que isso seja possível, é necessário que um novo algoritmo de escalonamento da rede seja executado quando há a variação no tráfego da rede (RRHs são desligados) para que um novo escalonamento seja decidido, minimizando os recursos utilizados.

Esse novo algoritmo deve ser capaz não de apenas reconfigurar o escalonamento dos nós de processamento ativados na rede, mas também dos recursos de processamento internos em cada nó, já que a saída dos RRHs da rede irá desbalancear as VDUs ativas, e, para que o tráfego seja redistribuído entre as VDUs, conforme ilustrado na Figura 8.1, o algoritmo deve levar em consideração um escalonamento das próprias VDUs em cada nó de processamento para uma completa otimização da rede por meio da migração de tráfego.

Há também um fator complicador em relação ao escalonamento das VDUs. Conforme apresentado no Capítulo 4, quando a capacidade de uma VDU não pode atender a todas as requisições CPRI transmitidas pela VPON associada ao seu LC, VDUs adicionais são ativadas e se comunicam com a VDU original por meio de um switch interno utilizado para comutar para as VDUs adicio- 
nais as requisições CPRI que não serão processadas na VDU original. Entretanto, como já citado anteriormente, esse cenário gera consumo de energia por conta do switch e latências adicionais por conta da comutação entre as VDUs. Em um cenário onde a migração dos dados das vBBUs gere a redistribuição de tráfego em um ou mais VDUs, duas opções de operação surgem. A primeira é a minimização total das VPONs na rede, assim, busca-se redistribuir o tráfego das VDUs migradas em uma única VPON. Nesse caso, diminui-se o consumo proveniente das VPONs, mas surge a latência de comutação entre as VDUs. A segunda opção diz respeito a diminuição dessa latência por meio da utilização de múltiplas VPONs para transmitirem para as VDUs após a redistribuição da carga de trabalho delas. Entretanto, note que um trade off surge nesse cenário. Se após a migração de tráfego as VPONs são minimizadas, o consumo de energia será diminuído mas a latência será aumentada. Por outro lado, se a latência for diminuída pela utilização de mais VPONs em um único nó, o consumo de energia será aumentado. Esse não é um cenário trivial, pois a mitigação de latência em um nó pode exigir uma maior quantidade de VPONs nesse nó, o que pode causar o esgotamento dos comprimentos de onda na rede, impedindo que novos nós de processamento sejam ativados, aumentando assim a probabilidade de bloqueio da rede. Assim, esse trade off deve ser explorado com atenção para que o melhor escalonamento da rede seja alcançado após uma migração de vBBUs e reconfiguração de VPONs.

Assim, nas próximas seções deste Capítulo nós iremos apresentar um mecanismo de migração de carga de trabalho que baseia-se em uma extensão da formulação ILP proposta no Capítulo 5 que incorpora o escalonamento eficiente das VDUs e VPONs no contexto da migração de carga de trabalho.

\subsection{Mecanismo de ativação da migração de carga de trabalho}

De forma geral, o mecanismo utilizado para a migração das cargas de trabalho na rede é baseado em um monitor de carga de trabalho dos nós de processamento que é implementado em uma VDU na nuvem. Esse monitor é responsável por medir a carga de cada nó de processamento sempre que a carga total de trabalho da rede sofre flutuações, seja por conta da saída ou da entrada de um RRH na rede. Para que o procedimento de migração das cargas de trabalho seja iniciado, o monitor considera uma valor de threshold da carga de trabalho de cada nó de processamento que deve ser checado sempre que há mudança na carga de trabalho da rede. Esse valor de threshold representa a quantidade de capacidade computacional livre em cada nó de processamento. Se após uma flutuação na carga da rede algum nó operar acima do valor de threshold, o processo de migração das requisições CPRI é iniciado.

Por sua vez, a migração e a reconfiguração das vBBUs e das VPONs é realizada pela obtenção de um novo escalonamento da rede por uma formulação ILP. Essa formulação será apresentada na seção seguinte.

Note que a migração das cargas de trabalho irá causar a interrupção dos serviços das vBBUs e VPONs participantes em uma migração. Essa interrupção irá causar a interrupção do provisionamento dos recursos da rede aos seus usuários. Mecanismos baseados em Live Migration (LM) $\left[\mathrm{CFH}^{+} 05\right]$ são utilizados para prover migrações de cargas de trabalho buscando-se diminuir o tempo de migração e, por conta disso, assumimos que a migração das cargas de trabalho na arquitetura CF-RAN serão realizadas sob um mecanismo de LM. 
Por fim, é necessário que o impacto da migração na operação da rede seja mensurado. Por conta disso, o modelo de avaliação de desempenho da arquitetura CF-RAN deve considerar a seguinte métrica de avaliação do impacto da migração:

\section{Porcentagem de interrupção dos serviços das vBBUs durante a migração}

Considerando o tempo médio de operação de cada vBBU, ou o tempo médio de serviço de cada RRH, essa métrica busca avaliar a taxa de tempo em que os serviços providos por uma vBBU serão interrompidos em decorrência de uma migração de sua carga de trabalho de um fog node para a nuvem. Essa taxa é expressa como

$$
T_{\text {DownTime }} / T_{\text {ProcTime }}
$$

onde $T_{\text {DownTime }}$ é o tempo médio de interrupção de serviços de uma vBBU e $T_{O p T i m e}$ é o tempo médio de serviço dessa vBBU.

\subsection{Formulação ILP para a migração de vBBUs e reconfiguração das VPONs}

Como a formulação ILP do Capítulo 5, a formulação aqui proposta busca minimizar o consumo de energia dos elementos ativos na rede. Entretanto, essa formulação também considera o escalonamento interno dos recursos nos nós de processamento, podendo também minimizar ou não a latência de comutação entre VDUs. Assim, segue a apresentação da formulação ILP.

\subsubsection{Variáveis de entrada}

$R$ : conjunto das requisições CPRI geradas pelos RRHs $i$

$N$ : conjunto dos nós de processamento $n$

$F_{\text {in }}$ : conjunto de valores binários representando os fog nodes $n$ conectados ao RRH $i$

$V_{w n}$ : conjunto de valores binários que representam a disponibilidade de cada comprimento de onda $w$ de ser alocado ao nó de processamento $n$

$W$ : conjunto de comprimentos de onda e VDUs $w$

$B_{i}$ : demanda de banda da requisição CPRI gerada pelo RRH $i$

$B_{w}$ : capacidade do comprimento de onda $w$

$I_{w}$ : capacidade de processamento da VDU $w$

$B_{e_{n}}$ : largura de banda disponível no switch e no nó $n$

$C_{n}$ : custo energético do nó $n$

$C_{d u}$ : custo energético de uma VDU

$C_{l c}$ : custo energético de um LC

$C_{e}$ : custo energético de um switch

$B$ : um número positivo muito grande

$\alpha, \beta$ and $\rho$ : pesos binários utilizados para priorizar a minimização de elementos específicos

\subsubsection{Variáveis de decisão}

$x_{i w n}:=1$ se a requisição do RRH $i$ é processada no nó $n$ sendo transmitida pela VPON que utiliza o comprimento de onda $w$ 
$u_{i w n}:=1$ se a requisição do RRH $i$ é processada na VDU $w$ no nó $n$

$y_{i n}:=1$ se a vBBU da requisição do RRH $i$ é instanciada no nó $n$

$x_{n}:=1$ se o nó $n$ está ativo

$z_{w n}:=1$ se o comprimento de onda $w$ é alocado ao nó $n$

$k_{i n}:=1$ se a requisição do RRH $i$ é comutada para uma VDU auxiliar $w$ no nó $n$

$r_{w n}:=1$ se a VDU $w$ foi ativado como uma VDU auxiliar para receber requisições CPRI comutadas entre VDUs no nó $n$

$s_{w n}:=1$ se a VDU $w$ está ativa no nó $n$

$e_{n}:=1$ se o switch interno $e$ está ativo no nó $n$ para realizar comutação entre VDUs

$g_{i w n}$ : variável auxiliar que é igual a 1 se a requisição CPRI do RRH $i$ é comutada para a VDU auxiliar $w$ no nó $n$

\subsubsection{Função objetivo}

A função objetivo (8.2) minimiza os nós de processamento ativos, as VPONs e o redirecionamento de tráfego entre VDUs. Os pesos $\beta$ e $\rho$ são usados para priorizar a minimização das VPONs ou do redirecionamento de tráfego, permitindo a avaliação de diferentes cenários. Se $\beta$ é diferente de zero, a minimização de VPONs é priorizada (política minVPON). Caso contrário, se o peso $\rho$ é diferente de zero, a minimização do redirecionamento de tráfego entre VDUs é priorizada (política minRedir). Note que o peso $\alpha$ sempre será igual a 1, já que a minimização de nós ativos é algo que sempre é considerado para reduzir o consumo de energia.

$$
\operatorname{Min.\alpha .}\left(\sum_{n=1}^{N} x_{n} \cdot C_{n}\right)+\beta \cdot\left(\sum_{w=1}^{W} \sum_{n=1}^{N} z_{w n} \cdot C_{l c}\right)+\rho \cdot\left(\sum_{n=1}^{N} e_{n} \cdot C_{e}\right)
$$

\subsubsection{Restrições}

$$
\begin{gathered}
\sum_{w=1}^{W} \sum_{n=1}^{N} x_{i w n}=1, \forall i \in R \\
\sum_{w=1}^{W} \sum_{n=1}^{N} u_{i w n}=1, \forall i \in R \\
\sum_{i=1}^{R} u_{i w n} \geq 0, \forall w, n \in W, N \\
\sum_{n=1}^{N} y_{i n}=1, \forall i \in R \\
\sum_{n=1}^{N} z_{w n} \leq 1, \forall w \in W \\
z_{w n} \leq V_{w n}, \forall w, n \in W, N \\
y_{i n} \leq F_{i n}, \forall i, n \in R, N
\end{gathered}
$$




$$
\begin{aligned}
& \sum_{i=1}^{R} \sum_{n=1}^{N} x_{i w n} . B_{i} \leq B_{w}, \forall w \in W \\
& \sum_{i=1}^{R} \sum_{n=1}^{N} u_{i w n} \leq I_{w}, \forall w \in W \\
& \sum_{i=1}^{R} k_{i n} . B_{i} \leq B_{e_{n}}, \forall n \in N \\
& \text { B. } x_{n} \geq \sum_{i=1}^{R} \sum_{w=1}^{W} x_{i w n}, \forall n \in N \\
& x_{n} \leq \sum_{i=1}^{R} \sum_{w=1}^{W} x_{i w n}, \forall n \in N \\
& B . z_{w n} \geq \sum_{i=1}^{R} \sum_{n=1}^{N} x_{i w n}, \forall w \in W \\
& z_{w n} \leq \sum_{i=1}^{R} \sum_{n=1}^{N} x_{i w n}, \forall w \in W \\
& B . y_{i n} \geq \sum_{w=1}^{W} x_{i w n}, \forall i, n \in R, N \\
& y_{\text {in }} \leq \sum_{w=1}^{W} x_{i w n}, \forall i, n \in R, N \\
& \text { B. } y_{i n} \geq \sum_{w=1}^{W} u_{i w n}, \forall i, n \in R, N \\
& y_{\text {in }} \leq \sum_{w=1}^{W} u_{i w n}, \forall i, n \in R, N \\
& B . s_{w n} \geq \sum_{i=1}^{R} u_{i w n}, \forall w, n \in W, N \\
& s_{w n} \leq \sum_{i=1}^{R} u_{i w n}, \forall w, n \in W, N \\
& B . k_{i n} \geq \sum_{w=1}^{W} g_{i w n}, \forall i, n \in R, N \\
& k_{i n} \leq \sum_{w=1}^{W} g_{i w n}, \forall i, n \in R, N
\end{aligned}
$$




$$
\begin{gathered}
B . r_{w} \geq \sum_{i=1}^{R} \sum_{n=1}^{N} g_{i w n}, \forall w \in W \\
r_{w} \leq \sum_{i=1}^{R} \sum_{n=1}^{N} g_{i w n}, \forall w \in W \\
B . e_{n} \geq \sum_{i=1}^{R} k_{i n}, \forall n \in N \\
e_{n} \leq \sum_{i=1}^{R} k_{i n}, \forall n \in N \\
g_{i w n} \leq x_{i w n}+u_{i w n}, \forall i, w, n \in R, W, N \\
g_{i w n} \geq x_{i w n}-u_{i w n}, \forall i, w, n \in R, W, N \\
g_{i w n} \geq u_{i w n}-x_{i w n}, \forall i, w, n \in R, W, N \\
g_{i w n} \leq 2-x_{i w n}-u_{i w n}, \forall i, w, n \in R, W, N
\end{gathered}
$$

As restrições 8.3 a 8.6 garantem que cada requisição de um RRH $i$ é processada e transmitida em apenas um único nó de processamento, VDU e VPON, respectivamente. A restrição 8.7 impõe que cada comprimento de onda só pode ser alocado para um nó de processamento, garantindo assim que duas VPONs nunca partilhem o mesmo comprimento de onda. A restrição 8.8 impõe que um comprimento de onda só pode ser alocado a um nó ao qual ele nunca foi alocado. A restrição 8.9, por sua vez, garante que cada RRH só irá enviar uma requisição CPRI para ser processada ou na nuvem ou em um fog node ao qual ele esteja conectado. As restrições 8.10, 8.11 e 8.12 limitam a utilização de cada comprimento de onda, nó de processamento e switches internos em função de suas capacidades. As restrições 8.13 a 8.16 ativam um nó de processamento $n$ e uma VPON $w$ quando alguma demanda $i$ os utiliza para processamento e transmissão. O restante das restrições reforça a ativação do switch interno e de VDUs auxiliares em cada nó no caso de comutação de tráfego entre VDUs, além de contabilizar a quantidade de requisições CPRI comutadas entre VDUs. Por fim, a restrição8.33 garante que a função objetivo não pode minimizar conjuntamente as VPONs criadas na rede e a comutação de tráfego entre VDUs.

A formulação ILP proposta é capaz de decidir o escalonamento ótimo de uma única requisição CPRI ou de várias requisições CPRI que são organizadas em um lote, ou batch de requisições, de uma só vez. Assim, para que as migrações de vBBUs e reconfigurações de VPONs sejam feitas na rede quando há a flutuação de tráfego e desbalanceamento da utilização dos recursos, essa formulação ILP é utilizada para tentar encontrar um escalonamento para um batch de requisições CPRI que contém as requisições que estão sendo processadas e transmitidas na rede. 
Para que seja possível utilizar a formulação ILP dessa forma e possa decidir-se quando o escalonamento de um batch seja realizado, nós propomos um algoritmo chamado de nfvILP, que é responsável por executar a formulação ILP para alocar requisições CPRI de forma gulosa e implementar a chamada ao mecanismo de migração de tráfego e reconfiguração de VPONs para buscar um novo escalonamento para um batch de requisições.

O algoritmo nfvILP é descrito formalmente no Algoritmo 3. Para cada requisição CPRI ingressante na rede, é verificado se o valor de threshold de carga de algum nó foi alcançado e se o procedimento de reconfiguração da rede deva ser executado (linhas 2 e 10). Se sim, um batch contendo as requisições já alocadas e a requisição ingressante $i$ é formado (linha 3) e a formulação ILP é executada para a obtenção de um escalonamento ótimo para esse batch (função $I L P($.) na linha 4, que recebe como argumento uma requisição ou um batch de requisições). Se não, o algoritmo busca pela alocação ótima da requisição $i$ apenas (linha 10). Quando uma alocação ótima é encontrada, tanto para uma única requisição ou para um batch, o estado da rede é atualizado pela função nfvUpdate(.) nas linhas 6 e 12, que recebe como argumento o escalonamento ótimo obtido pela formulação ILP, cujos estados das variáveis de decisão são mapeados como a alocação das requisições nos elementos da rede. Se uma alocação não pode ser obtida para uma requisição $i$, sendo ela processada exclusivamente ou dentro de um batch, essa requisição é bloqueada (linhas 8 e 14). Para garantir que a migração das cargas de trabalho também ocorra pela flutuação de tráfego gerada pela saída dos RRHs da rede, o procedimento de verificação do threshold da carga de cada nó é executado (linha 16). Se a migração for acionada, um batch contendo apenas as requisições já alocadas é formado e a formulação ILP busca um novo escalonamento para esse batch, conforme pode ser observado nas linhas 17 e 18. Se um novo escalonamento pode ser encontrado, o estado da rede é atualizado na linha 20 e a migração das cargas de trabalho é realizada. Caso um novo escalonamento ótimo não possa ser encontrado, a migração não é realizada (linha 22). Note que nesse último caso, um novo escalonamento pode ser obtido para o batch, mas ele só será considerado para uma reconfiguração da rede caso ele seja ótimo em relação ao escalonamento corrente da rede. Entretanto, é intuitivo assumir que esse escalonamento sempre será ótimo, pois a flutuação da carga sempre irá causar desbalanceamento nos recursos ativos.

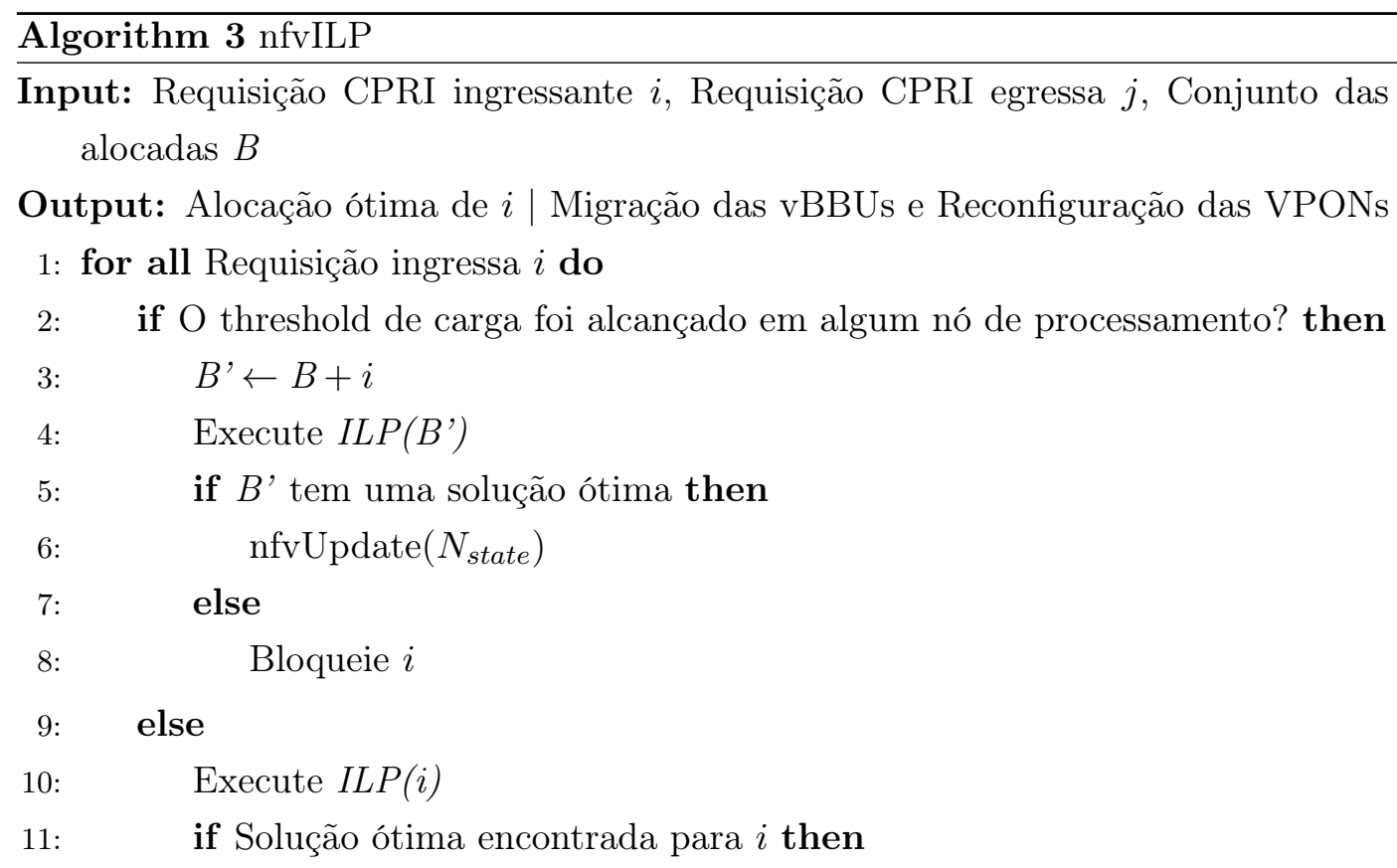




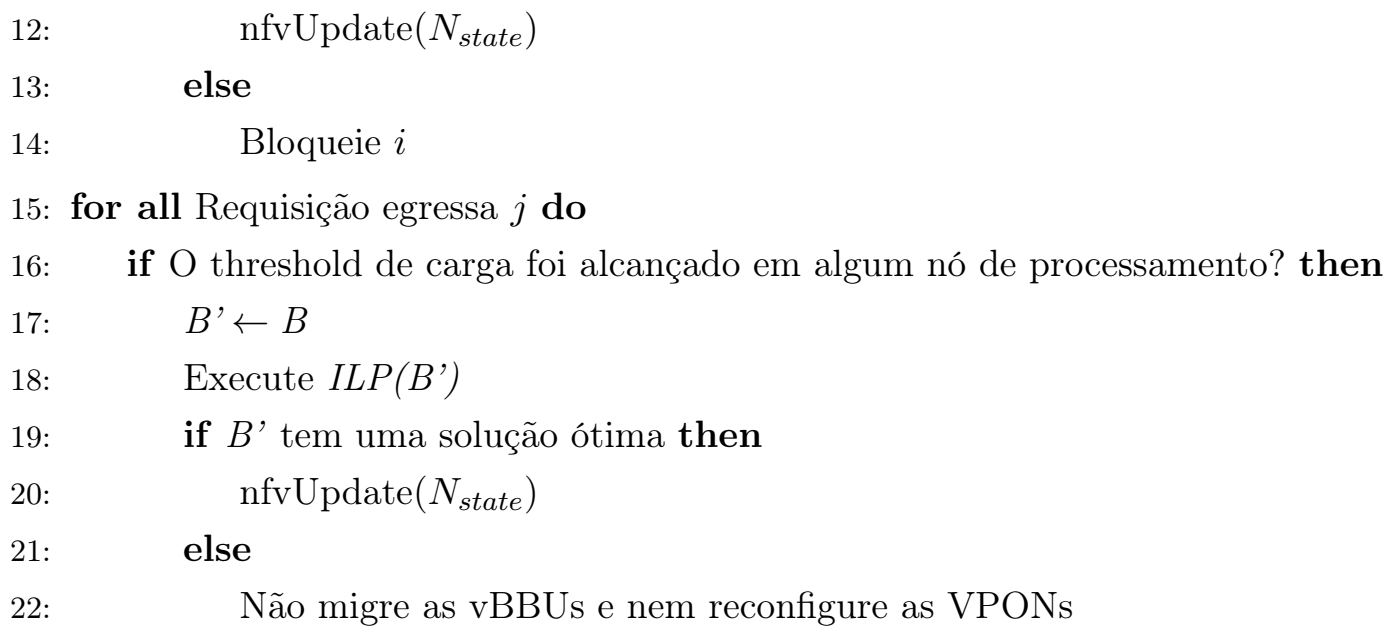

Apesar da formulação ILP ser capaz de retornar soluções ótimas ao problema de escalonamento, seus tempos de execução podem tornar-se proibitivos em cenários de larga escala. Como a migração das cargas de trabalho baseia-se na utilização dessa formulação ILP para a geração de um novo escalonamento ótimo considerando um batch como entrada, faz-se necessário que uma otimização nos tempos de execução da formulação seja proposta. Isso é importante pois, em ambientes reais de uma rede móvel, milhares de antenas podem estar processando dados na rede, como é o caso da cidade de São Paulo, que, somando-se todas as antenas instaladas de todas as operadores, possui uma quantidade de aproximadamente 4 mil antenas. Assim, para que o mecanismo de migração possa ser utilizado em um cenário como esse, nós propomos como otimização uma versão relaxada da formulação ILP, conforme será apresentado na seção seguinte.

\subsection{Relaxação da formulação ILP para migração de cargas de tra- balho}

A relaxação da formulação ILP consiste na retirada das restrições de integridade das variáveis de decisão e das restrições também, fazendo com que o problema possua complexidade polinomial. Assim, uma variável de decisão como a $x_{i w n}$ não possui mais seus possíveis valores retirados do conjunto $\{0,1\}$, mas sim do intervalo $\{0,1\}$. Esse procedimento é repetido para todas as variáveis de decisão da formulação ILP.

Com a retirada das restrições de integridade dessas variáveis, as soluções geradas pela versão relaxada da formulação ILP irá prover valores reais entre 0 e 1 para cada variável de decisão. Isso significa que a alocação da requisição 1 segundo a variável $x_{i w n}$, por exemplo, pode possuir os seguintes resultados: $x_{111}=0,5, x_{112}=0,3$ e $x_{113}$, o que significaria, no contexto de um escalonamento, que a requisição 1 foi alocada tanto nos nós 1, 2 e 3. Entretanto, como isso não faz sentido, pois cada requisição CPRI só deve ser alocada em um único nó de processamento, os resultados da versão relaxada da formulação ILP para uma variável de decisão são considerados como probabilidades. No exemplo citado, o resultado da relaxação para a variável $x_{i w n}$ mostraria as probabilidades da i-nésima requisição CPRI ser transmitida pelo w-ésimo comprimento de onda para ser processada no n-ésimo nó de processamento. Note que por esse comportamento, as soluções relaxadas tendem a produzir soluções de desempenho inferior às formulações ILP, pois como no exemplo dado, foi considerada a ativação de três nós de processamento para o recebimento da requisição 1 que teria que ser dividida entre esses 3 nós. Nesse sentido, existe um trade off entre as duas técnicas, pois 
apesar das soluções da versão relaxada serem inferiores, os tempos de execução são drasticamente reduzidos ao se resolver uma versão relaxada de uma formulação ILP.

Assim, para que se possa obter soluções satisfatórias de uma versão relaxada de uma formulação ILP, faz-se necessário que algoritmos de pós-processamento das soluções relaxadas sejam utilizados. Nesse sentido, é tradicional na literatura propor algoritmos que, como já citado, considerem os valores das variáveis de decisão como probabilidades de uma alocação e, à partir dessas probabilidades, sortear, ou escolher a que possui maior valor como a que possui maior valor probabilístico e arredondá-la para 1, ao passo que as variáveis que não foram escolhidas são descartadas, ou arredondadas para 0 .

Além disso, a associação de valores reais às variáveis de decisão faz com que as restrições de capacidade dos elementos da rede sejam inúteis, pois essas restrições baseavam-se na integralidade das variáveis de decisão para controlar a utilização dos elementos. Da mesma forma, a restrição 8.8, que garantia que cada RRH só poderia utilizar o fog node ao qual estava conectado, também é retirada, pois ela também baseava-se na integralidade das variáveis para definir essa restrição.

Dessa forma, na versão relaxada da formulação, a quantidade de restrições é reduzida, o que contribui ainda mais para uma diminuição da complexidade do problema.

Entretanto, todas essas restrições retiradas da formulação por conta da retirada da integralidade das variáveis devem ser tratadas nos algoritmos de pós-processamento para que a otimalidade da formulação ILP possa ser aproximada pela sua versão relaxada. Assim, retira-se a complexidade da formulação mas acrescenta-se complexidade nos algoritmos de pós-processamento que terão que controlar a utilização das capacidades de cada elemento e a distribuição de processamento dos $\mathrm{RRH}$ em fog nodes de forma que seja garantido que cada RRH só utilize o fog node ao qual esteja conectado.

Por fim, para garantir a não integralidade das variáveis de decisão, a versão relaxada da formulação ILP receberá o acréscimo das seguintes restrições:

$$
\begin{aligned}
& \sum_{i=1}^{|R|} \sum_{w=1}^{|W|} \sum_{n=1}^{|N|} x_{i w n}>=0,1, \forall i \in R, w \in W, n \in N \\
& \sum_{i=1}^{|R|} \sum_{w=1}^{|W|} \sum_{n=1}^{|N|} u_{i w n}>=0,1, \forall i \in R, w \in W, n \in N
\end{aligned}
$$

As restrições 8.34 e 8.35 são necessárias para garantir que, mesmo relaxando-se as variáveis de decisão, elas tenham um valor no mínimo maior que 0 e menor ou igual a 1 . Isso é necessário pois, como a função objetivo busca minimizar os elementos ativos, ao permitir-se que as variáveis de decisão possuam valores no intervalo de $\{0,1\}$, uma função de minimização que pode considerar valores zerados sempre prezará por essa solução para não ativar nenhum nó.

No tocante à função objetivo, ela não é alterada, pois a retirada da integralidade só ocorre nas variáveis de decisão. Entretanto, o comportamento da relaxação pode gerar resultados que não refletem a otimalidade buscada em relação à minimização dos elementos. Como buscamos também investigar a influência da minimização tanto das VPONs ativas quanto da comutação entre VDUs quando a migração de tráfego ocorre, essas minimizações devem ser resolvidas pelo algoritmo de pós-processamento.

Nós propomos três algoritmos de pós-processamento dos resultados da relaxação. A ideia dos 
algoritmos que serão propostos é que eles considerem as variáveis com os valores mais altos retornados pela relaxação como as variáveis com maior probabilidade para a decisão de uma alocação de recursos. Assim, as variáveis com os valores mais altos são arredondadas para 1 pelos algoritmos e todas as outras são arredondadas para 0. Para limitar a complexidade desses algoritmos, eles não realizam o arredondamento de todas as variáveis retornadas pela solução da relaxação, mas apenas de variáveis-chave para determinar a alocação de um recurso. Nesse contexto, apenas as variáveis $x_{i w n}$ e $u_{i w n}$ já são capazes de determinar uma alocação. A variável $x_{i w n}$ é arredondada para determinar a alocação de um nó de processamento e de um comprimento de onda à requisição $i$. A variável $u_{i w n}$, por sua vez, é utilizada para determinar a VDU que será alocada para a requisição $i$.

Para que ambas as minimizações das VPONs criadas e das comutações entre VDUs possam ser contempladas pelas relaxações, três algoritmos de pós-processamento são propostos. O primeiro, chamado de relaxedMin VPON, busca arredondar as variáveis de forma que a quantidade das VPONs criadas seja minimizada. O segundo, chamado de relaxedMinRedir, busca minimizar a ocorrência da ativação de VDUs adicionais para suportar o tráfego excedente de outras VDUs, o que leva à ativação do switch interno e consequentemente à latências adicionais na operação da rede. Por fim, o algoritmo softRelaxMinRedir é uma versão mais sofisticada do algoritmo relaxedMinRedir para ambientes de tráfego estático. Uma limitação do algoritmo relaxedMinRedir é que a minimização da comutação de dados entre VDUs pode vir ao custo de uma maior centralização das VPONs em um único nó. Em cenários de tráfego mais intenso, se todos os comprimentos de onda disponíveis forem centralizados em um único nó, como a nuvem, não existirão comprimentos de onda disponíveis para uso nos outros nós, levando a não ativação desses nós e consequentemente ao bloqueio das requisições que seriam processadas nesses nós. Assim, o algoritmo softRelaxMinRedir busca migrar VPONs de um nó ao outro no caso da escassez de comprimentos de onda para ativação de novos nós. Por fim, a execução desses algoritmos são repetidas mais de uma vez para que o efeito da aleatoriedade nos valores fracionados que são atribuídos às variáveis de decisão seja minimizado.

O algoritmo mostProbability é utilizado para arredondar e descartar as variáveis retornadas pela solução da formulação relaxada. O retorno desse algoritmo é um conjunto das variáveis $x_{i w n}$ e $u_{i w n}$ com seus valores arredondados para 1 e sem os valores arredondados para 0 . Assim, o retorno dessa variável é utilizado pelos algoritmos de pós-processamento para decidir se a alocação de uma requisição $i$ será guiada pela probabilidade de alocação dos comprimentos de onda (relaxedMinVPON) anteriormente à alocação das VDUs ou pela probabilidade de alocação das VDUs (relaxedMinRedir e softRelaxMinRedir) anteriormente à alocação dos comprimentos de onda.

\section{Algorithm 4 mostProbability}

Input: Conjunto vars de listas $i$ de variáveis de decisão providas pela solução da relaxação, onde cada elemento $i$ é uma lista contendo todos os valores contínuos retornados pela formulação relaxada para uma variável de decisão, conjunto vazio dos valores arredondados Higher $_{\text {values }}$

Output: Arredondamento das variáveis $x_{i w n}$ e $u_{i w n}$

1: indexes $\leftarrow$ getIndexes $\left(x_{i w n}\right)$

2: for all $i \in$ vars do

3: $\quad$ Coloque em Higher values apenas a variável com maior valor

4: $\quad$ Higher $_{\text {values }} \leftarrow \max (i)$

5: for all $i \in$ Higher $_{\text {values }}$ do

6: $\quad$ Arredonde as variáveis em Higher $_{\text {values }}$ para 1 
7: $\quad$ i.valor $\leftarrow 1$

8: Retorne Higher $_{\text {values }}$

O algoritmo relaxedMinVPON é formalmente descrito no Algoritmo 5. Nesse algoritmo, o objetivo é escolher o nó de processamento com a maior probabilidade e alocá-lo para recebimento do processamento de banda-base da requisição CPRI $i$ (linhas 4 a 8). Se nem a nuvem ou o fog node possuem capacidade de processamento, a requisição é bloqueada e não se tenta fazer a alocação do comprimento de onda e nem da VDU.

Caso contrário, nas linhas 13 a 37 é feita a alocação de um comprimento de onda. Note que, primeiro busca-se alocar um comprimento de onda que já esteja alocado no nó, para melhor utilização dos recursos. Se há um ou mais comprimentos de onda já alocados no nó, busca-se alocar o primeiro que possua capacidade, caso não se encontre nenhum com capacidade, busca-se alocar qualquer comprimento de onda que não foi alocado a nenhum nó (linhas 30 a 37). Caso não haja comprimentos de onda já alocados no nó, o algoritmo tenta alocar o comprimento de onda que foi retornado com a maior probabilidade pela relaxação, nas linhas 16 e 17. Caso esse comprimento de onda retornado na relaxação já esteja alocado em outro nó ou não possui capacidade livre, o algoritmo busca alocar qualquer comprimento de onda que não foi alocado para nenhum nó (linhas 20 a 23$)$.

Se não foi encontrado nenhum comprimento de onda disponível, a requisição é bloqueada nas linhas 35 e 36. Caso contrário, o algoritmo prossegue com a alocação da VDU. Em relação à VDU, o algoritmo busca alocar a VDU de maior probabilidade retornado na solução relaxada. Se essa VDU possui capacidade, ela é alocada para a requisição nas linhas 39 a 47, e também é verificado se essa VDU acionará a ativação do switch interno caso ela não seja a VDU associada ao comprimento de onda/VPON alocado nos passos anteriores.

Caso o switch deva ser usado, é verificado se o mesmo possui capacidade de transmissão para comutar o tráfego para essa VDU auxiliar (linhas 43 a 45). Note que a função updateSwitch(.) atualiza a utilização de banda do switch no nó $n$, passado como argumento dessa função. Caso a VDU retornado pela solução não possua capacidade de processamento, o algoritmo busca uma VDU aleatória no nó de processamento $n$ para alocar à requisição $i$ (linhas 50 a 55). Finalmente, se foi possível alocar a VDU, o estado do nó de processamento, comprimento de onda e VDU alocados à requisição $i$ é atualizado nas linhas 57 e 58. Se não foi possível alocar a VDU, a requisição $i$ é bloqueada na linha 60 . Por fim, a alocação realizada (a) é guardada em uma lista $A$ na linha 61. Após todas as repetições terem sido realizadas, a melhor alocação, em termos de consumo energético é obtida na linha 62 pela função getBestSolution(.), que recebe como argumento a lista $A$, que contém as alocações realizadas em cada repetição do algoritmo.

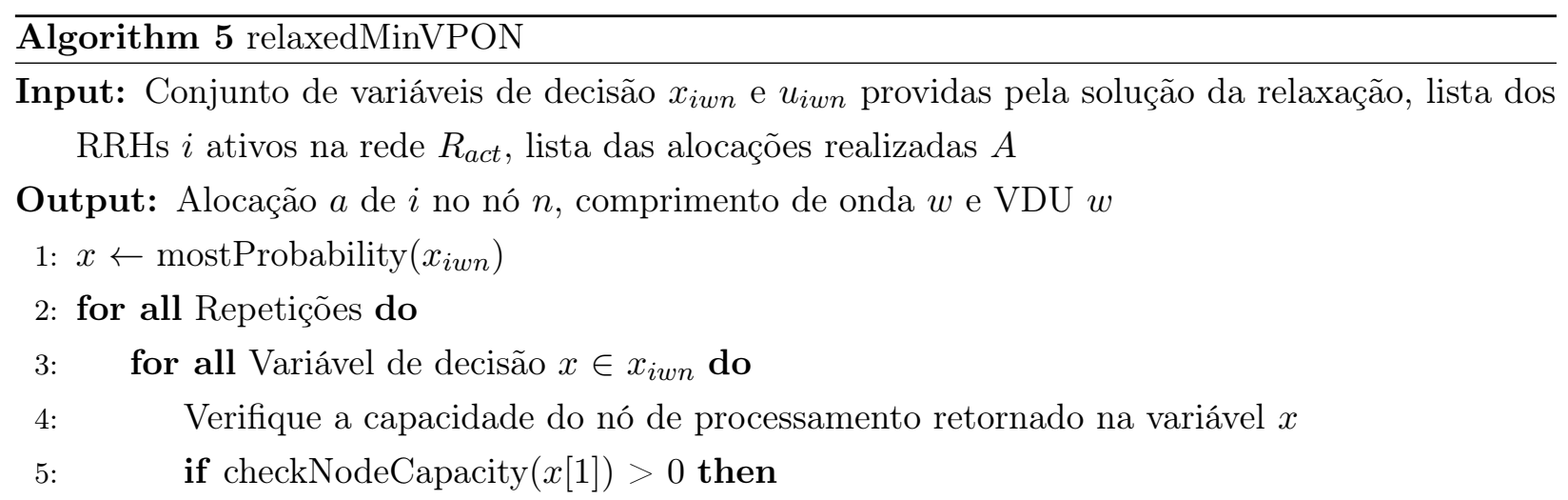


6 :

7: CPRI

17:

18:

19:

20:
21:

22 :

23:

24 :

25: tem capacidade 26:

27:

28:

29:

30:

$$
\text { que esteja livre }
$$

else

$$
\begin{aligned}
& \text { if checkLambdaCapacity }\left(x[2], R_{a c t}[x[i]][1]\right) \text { then } \\
& \qquad R_{a c t}[x[i]][2] \leftarrow x[2] \\
& \text { else }
\end{aligned}
$$

Se não há um comprimento de onda no nó e o retornado na solução não pode ser usado, aloque o primeiro comprimento de onda que não está alocado

$$
\begin{aligned}
& \text { lambda } \leftarrow \text { getFreeLambda }() \\
& \text { if lambda } \neq \emptyset \text { then } \\
& \quad R_{a c t}[x[i]][2] \leftarrow \text { lambda }
\end{aligned}
$$

Há um ou mais comprimentos de onda já alocados no nó $n$, aloque o primeiro que 31 :

$$
\begin{aligned}
& \text { lambda } \leftarrow \text { getFirstFitLambda }() \\
& \text { if lambda } \neq \text { emptyset then } \\
& \qquad R_{a c t}[x[i]][2] \leftarrow \text { lambda } \\
& \text { else }
\end{aligned}
$$

Nenhum comprimento de onda no nó $n$ possui capacidade, tente alocar um

$$
\begin{aligned}
& \text { lambda } \leftarrow \text { getFreeLambda }() \\
& \text { if lambda } \neq \emptyset \text { then } \\
& \qquad R_{a c t}[x[i]][2] \leftarrow \text { lambda }
\end{aligned}
$$

Verifique se foi possível alocar um comprimento de onda if $R_{a c t}[x[i]][2] \neq \emptyset$ then

Bloqueie a requisição $i$ else

Prossiga com a alocação da VDU

Verifique se a VDU retornada na solução possui capacidade de processamento $v d u \leftarrow \operatorname{getVDU}(x)$ if checkVDUCapacity(vdu, $\left.R_{a c t}[x[i]][1]\right)$ then

Verifique se o switch interno deve ser usado 


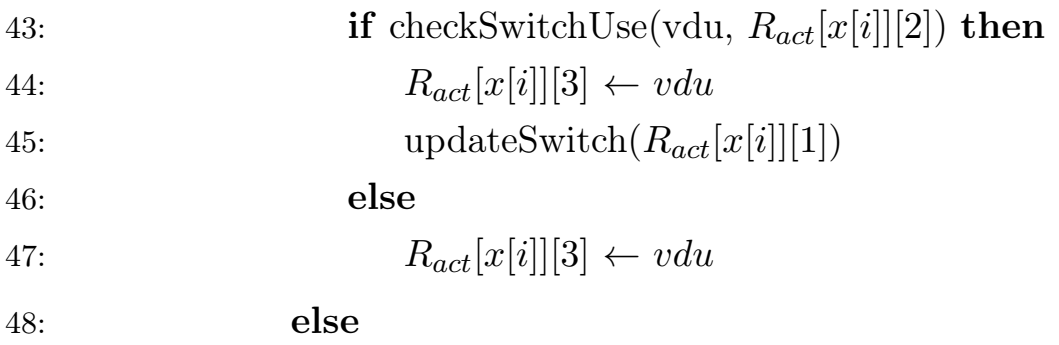

49:

Se a VDU retornada na solução não possui capacidade, aloque uma aleatória que possua capacidade

50:

51 :

52 :

53 :

54:

55:

56: bloqueie $i$

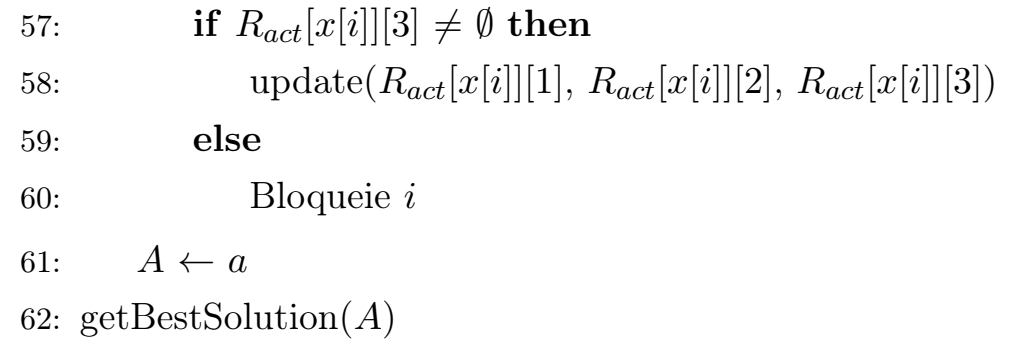

O algoritmo relaxedMinRedir é formalmente descrito no Algoritmo 6. Esse algoritmo, por sua vez, busca por meio das soluções obtidas por meio da relaxação, diminuir a ocorrência de comutação entre VDUs. Para tal, ele busca alocar comprimentos de onda que sejam associados às VDUs das requisições $i$. Em outras palavras, busca-se, para uma dada requisição $i$ alocada no nó $n$, alocar a VDU 1 e o comprimento de onda 1. Semelhantemente ao algoritmo relaxedMinVPON, primeiro realiza-se a alocação do nó de processamento com base na variável de maior probabilidade nas linhas 4 a 8. Após isso, busca-se alocar a VDU retornada na solução da relaxação nas linhas 14 a 17. Caso não seja possível usar a VDU retornada na solução, uma VDU aleatória que possua capacidade de processamento é alocada (linhas 20 e 21). Caso tenha sido possível alocar a VDU, prossegue-se com a alocação do comprimento de onda nas linhas 25 a 38. Nesse ponto, a prioridade é de alocar o comprimento de onda associado à VDU alocada. Isso é feito nas linhas 25 e 26. Caso esse comprimento de onda não esteja disponível no nó ou não possua capacidade, busca-se alocar o primeiro comprimento de onda disponível no nó (linhas 38 a 43). Se não há comprimentos de onda disponíveis no nó, busca-se alocar qualquer um que não foi alocado a nenhum nó (linhas 29 a 35). Por fim, nas linhas 44 a 46, caso o comprimento de onda tenha sido alocado com sucesso, o estado do nó de processamento, comprimento de onda e VDU alocadas é atualizado (note que o estado do switch interno já foi atualizado em passos anteriores). Caso não tenha sido possível alocar qualquer um desses elementos, a requisição é bloqueada na linha 48. Por fim, a alocação realizada (a) é guardada em uma lista $A$ na linha 49. Após todas as repetições terem sido realizadas, a melhor alocação, em termos de consumo energético é obtida na linha 50 pela função getBestSolution(.). 
Algorithm 6 relaxedMinRedir

Input: Conjunto de variáveis de decisão $x_{i w n}$ e $u_{i w n}$ providas pela solução da relaxação, lista dos RRHs $i$ ativos na rede $R_{a c t}$, lista das alocações realizadas $A$

Output: Alocação $a$ de $i$ no nó $n$, comprimento de onda $w$ e VDU $w$

1: $x \leftarrow \operatorname{mostProbability~}\left(x_{i w n}\right)$

2: for all Repetições do onda comutação entre VDUs

else

else

else

$$
\text { else }
$$

for all Variável de decisão $x \in x_{i w n}$ do

Verifique a capacidade do nó de processamento retornado na variável $x$ if $\operatorname{checkNodeCapacity}(x[1])>0$ then

$$
R_{a c t}[x[i]][1] \leftarrow x[1]
$$

$$
R_{a c t}[x[i]][1] \leftarrow R_{f o g}[i]
$$

Verifique se não foi possível alocar um nó de processamento à requisição $i$

$$
\text { if } R_{a c t}[x[i]][1] \text { is } \emptyset \text { then }
$$

Bloqueie a requisição $i$

Prossiga com a alocação da VDU

Verifique se a VDU retornada na solução possui capacidade de processamento livre $v d u \leftarrow \operatorname{getVDU}(x)$

if checkVDUCapacity(vdu, $\left.R_{a c t}[x[i]][1]\right)$ then

$$
R_{a c t}[x[i]][3] \leftarrow v d u
$$

Se a VDU retornada na solução não possui capacidade, aloque uma aleatória que

$$
\begin{aligned}
& \text { Random }_{v d u} \leftarrow \operatorname{getRandomVDU}\left(R_{\text {act }}[x[i]][1]\right) \\
& R_{\text {act }}[x[i]][3] \leftarrow \text { Random }_{v d u}
\end{aligned}
$$

Verifique se um VDU foi alocado, se sim, prossiga com a alocação do comprimento de

$$
\text { if } R_{a c t}[x[i]][3] \neq \emptyset \text { then }
$$

Tente alocar o comprimento de onda $w=\operatorname{VDU} w$, para não existir a necessidade de$$
\text { if checkLambdaCapacity }\left(R_{a c t}[x[i]][3], R_{a c t}[x[i]][1]\right) \text { then }
$$$$
R_{\text {act }}[x[i]][2] \leftarrow R_{\text {act }}[x[i]][3]
$$

O comprimento igual à VDU não está disponível ou não tem capacidade, tente alocar o primeiro disponível no nó, caso não haja, tente alocar qualquer um disponível

$$
\begin{aligned}
& \text { if !checkLambdaInNode }\left(R_{a c t}[x[i]][1]\right) \text { then } \\
& \text { lambda } \leftarrow \text { getFreeLambda }() \\
& \text { if } \operatorname{lambda} \neq \emptyset \text { then } \\
& \text { if checkSwitchUse }\left(\text { Random }_{v d u}, R_{a c t}[x[i]][2]\right) \text { then } \\
& \quad R_{a c t}[x[i]][3] \leftarrow \text { Random }_{v d u} \\
& \text { updateSwitch }\left(R_{a c t}[x[i]][1]\right) \\
& R_{a c t}[x[i]][2] \leftarrow \text { lambda }
\end{aligned}
$$


36: else

37: Há um ou mais comprimentos de onda já alocados no nó $n$, aloque o primeiro que tem capacidade

38:

39:

40:

41:

42:

43:

44: recursos alocados, senão, bloqueie $i$

45:

46:

47:

48:

49: $\quad A \leftarrow a$

50: $\operatorname{getBestSolution}(A)$

O algoritmo softRelaxMinRedir estende o algoritmo relaxedMinRedir com um procedimento de migração de VPONs entre nós quando há a escassez desse recurso (linha 44 do algoritmo relaxedMinRedir. Por conta da similaridade com o restante do algoritmo relaxedMinRedir, nós apresentamos no seguinte algoritmo apenas o mecanismo de migração de VPONs presente no algoritmo softRelaxMinRedir. Após uma requisição $i$ ser bloqueada por escassez de comprimentos de onda, um comprimento de onda alocado na nuvem é escolhido para ser migrado para o fog node a qual o RRH gerador da requisição $i$ está conectado (linhas 1 e 2). Nesse ponto, a heurística escolhe o comprimento de onda menos carregado para garantir que o impacto na comutação de tráfego entre VDUs que será gerado após a realocação dos RRHs que transmitiam na VPON migrada seja minimizado. Após o comprimento de onda a ser migrado ser determinado, essa VPON é desalocada da nuvem e alocada no fog node do RRH gerador de $i$ (linha 3). A capacidade dessa VPON é então zerada e o estado da rede, frente a essa mudança no escalonamento, é atualizado (linha 4). Os RRHs que utilizavam a VPON que foi migrada para o fog node são então movidos para a VPON menos carregada que opera na nuvem (linha 5). Por fim, a VPON migrada para o fog node é alocada para a requisição $i$ (linha 6). 
6: Aloque vpon $_{\text {migrated }}$ para o RRH $i$ 


\section{Capítulo 9}

\section{Avaliação da Migração de vBBUs e Reconfiguração de VPONs}

Neste seção nós iremos apresentar a avaliação do desempenho provido pela formulação ILP para migração das vBBUs e reconfiguração das VPONs. Primeiramente nós apresentaremos resultados de simulações acerca da versão sem relaxação. Em seguida serão apresentados os resultados referentes à versão relaxada da formulação. Os resultados pertinentes à formulação ILP foram publicados em $\left[\mathrm{TBF}^{+} 19 \mathrm{a}\right]$.

\subsection{Resultados acerca da formulação ILP para migração de tráfego}

Nessas simulações nós utilizamos o mesmo simulador utilizado nas simulações das heurísticas baseadas em teoria dos grafos. Entretanto, para integrar a execução das formulação ILP com o simulador, nós utilizamos a API DOCPLEX, escrita em Python. Nossas simulações consideraram uma CF-RAN composta de 1 nuvem e 4 fog nodes. Cada um desses nós de processamento pode implementar até 6 VDUs e cada VDU tem a capacidade de processar até 3 vBBUs na nuvem e apenas 1 vBBU nos fog nodes. O fronthaul TWDM-PON possui 6 comprimentos de onda de capacidade de 10Gbps. Existem $42 \mathrm{RRHs}$ na rede, o que representa a carga de processamento máxima de todos os nós de processamento.

O tráfego é modelado conforme um padrão de 24 horas em uma região comercial de uma cidade, dividido em períodos de 1 hora, conforme mostrado na Figura 7.15 no Capítulo 7. No início da simulação todos os RRHs estão desativados e começam a ser ativados seguindo um processo de Poisson com média igual a (e/60), onde e é a carga (em erlang) em uma dada hora de operação da rede. Após ser alocado, cada RRH permanece sendo processado e transmitido na rede durante um tempo de serviço uniformemente retirado do intervalo (0,25 hora, 1 hora). Nós comparamos o algoritmo nfvILP com um algoritmo incremental chamado incILP, que processa as requisições CPRI incrementalmente a cada RRH que torna-se ativo e não realiza a migração de vBBUs conforme o demanda da rede flutua. Nessas simulações, nós estudamos os efeitos de minimizar tanto a quantidade de VPONs ativas quanto a quantidade de tráfego CPRI comutado entre VDUs para diferentes valores de threshold utilizados para iniciar o processo de migração de vBBUs e reconfiguração de VPONs. Os valores de threhsold correspondem à capacidade de processamento livre de um nó, por exemplo, um threshold de 0,8 em nó de processamento corresponde a esse nó possuir 
$80 \%$ de capacidade de processamento livre.

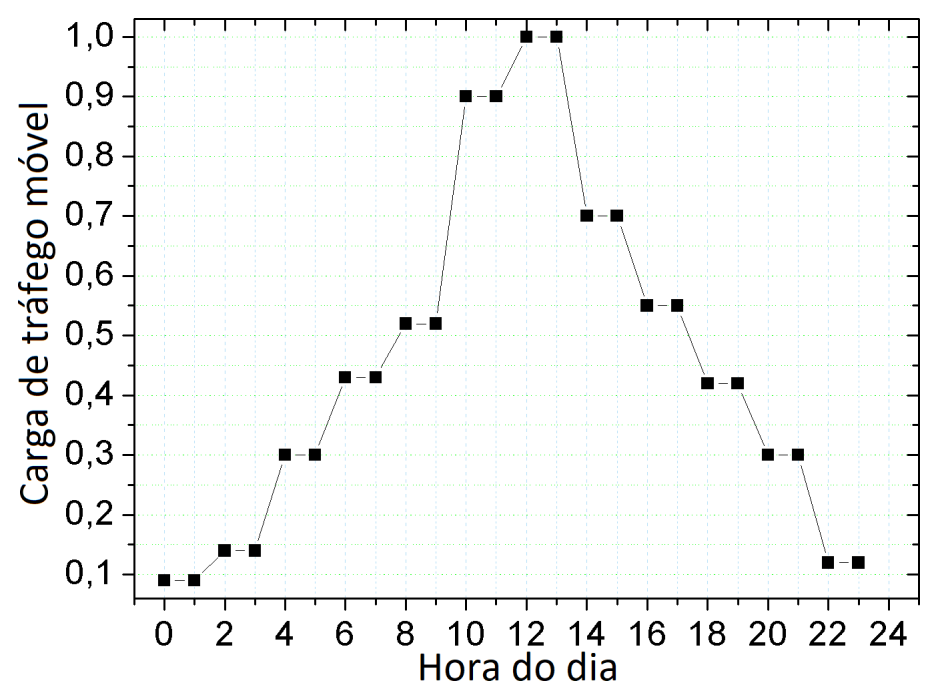

Figura 9.1: Padrão diário de tráfego

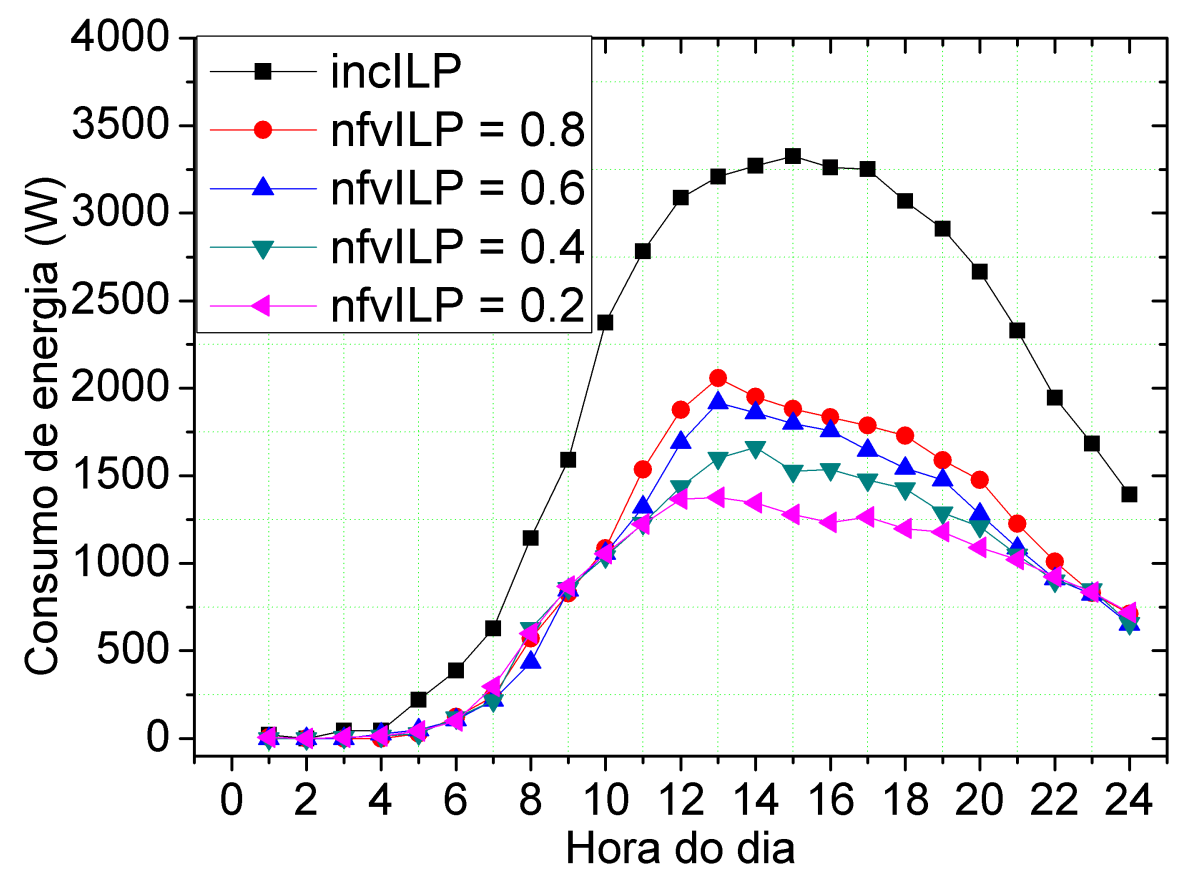

Figura 9.2: Consumo de energia quando a comutação entre VDUs é minimizada

As Figuras. 9.2 e 9.3 mostram o consumo de energia das políticas minRedir e minVPON, respectivamente. Pode ser observado que nossa proposta provê grande economia de energia. Em comparação com o algoritmo incILP, a política minRedir alcança até $62 \%$ de economia de energia e a política min VPON até 38\%. Também é possível observar que o consumo de energia é menor quando a migração das vBBUs e reconfiguração das VPONs são iniciadas mais cedo. Isso ocorre por conta de, tão cedo um novo escalonamento é obtido, mais cedo o tráfego é movido para a nuvem e recursos desbalanceados são desligados. Além disso, a política minRedir reduz o consumo de energia em até $49 \%$ em relação à política min VPON em horários de pico. Isso ocorre porque a política 


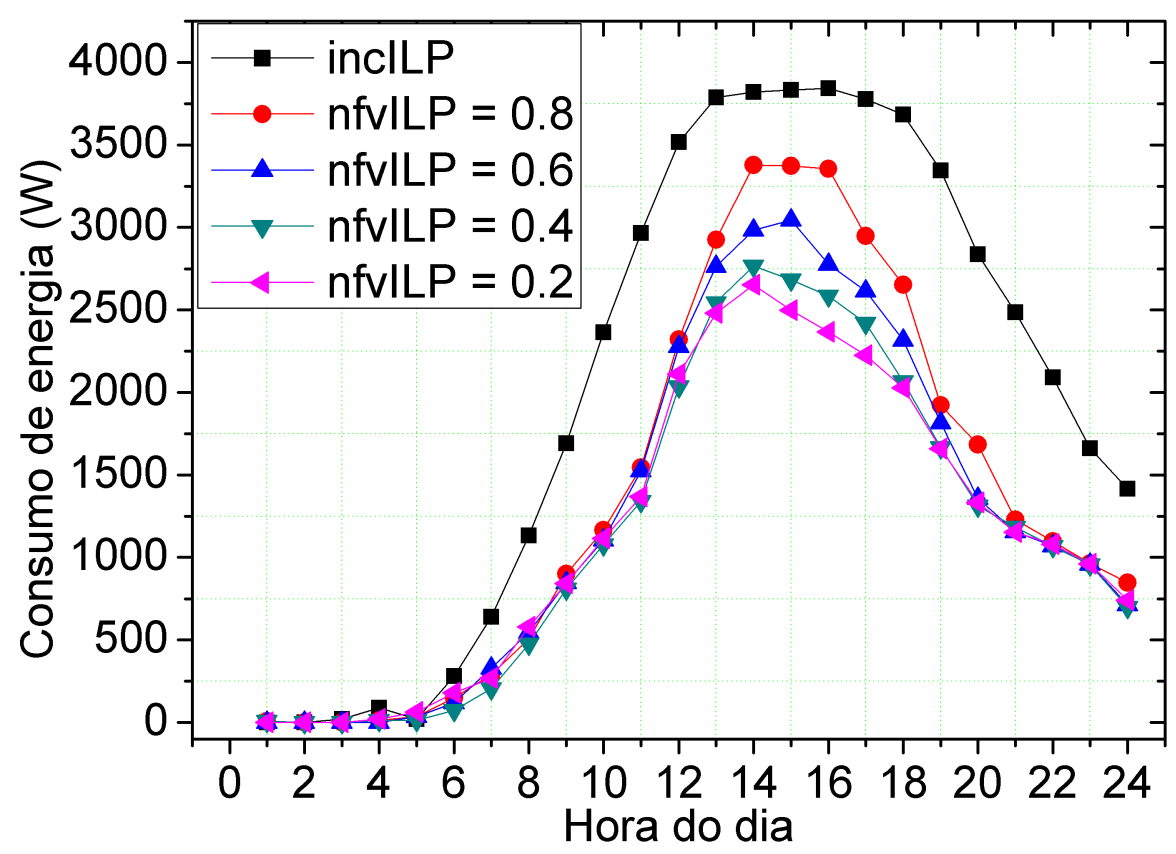

Figura 9.3: Consumo de energia quando a criação de VPONs é minimizada

minRedir busca ativar a maior quantidade possível de VPONs em um único nó de processamento para minimizar a comutação de tráfego entre VDUs e não ativar o switch interno do nó. Entretanto, essa economia de energia causa uma probabilidade de bloqueio maior para a política minRedir, como pode ser observado na Figura 9.4, por conta de ao centralizar-se muitas VPONs em um único nó de processamento, haverá falta de comprimentos de onda para serem alocadas nos outros nós de processamento da rede quando esses forem ativados. $\mathrm{O}$ desperdício de banda (definido como $\left.1-\left(T_{\text {cpri }} / T_{\text {vpons }}\right)\right)$ é muito alto também, como mostrado na Figura 9.6. Esse desperdício vem do fato dos comprimentos de onda serem ativados no nó de processamento apenas para mitigar a comutação entre VDUs diferentes, e não para suportarem a maior quantidade de fluxo CPRI.

Por outro lado, apesar da política minVPON consumir mais energia por ativar o switch interno para reduzir a quantidade de VPONs criadas em um nó, as VPONs são utilizadas de forma mais acurada. Como pode ser observado na Figura 9.5, há uma redução de uma ordem de magnitude na probabilidade de bloqueio e na Figura 9.7 pode ser observado que o desperdício de banda é aproximadamente $33.4 \%$ menor que a política minRedir. Além disso, o consumo de energia adicional da política minRedir se dá pelo fato de mais RRHs serem admitidos na rede, o que causa a ativação de mais nós de processamento e VDUs, algo que é limitado pela centralização de VPONs provida pela política minRedir. Assim, pode ser concluído que é melhor gastar mais energia com a política min VPON para que os melhores desempenhos em termos de probabilidade de bloqueio e consumo de banda sejam obtidos.

Observando a quantidade de migrações de vBBUs para ambas as políticas nas Figuras 9.8 e 9.9, nós observamos que há um aumento no número de migração de vBBUs da política minRedir para a política minVPON, atestando que a migração de vBBUs e reconfiguração de VPONs possuem um papel importante na redução da probabilidade de bloqueio. Entretanto, note que para o valor 


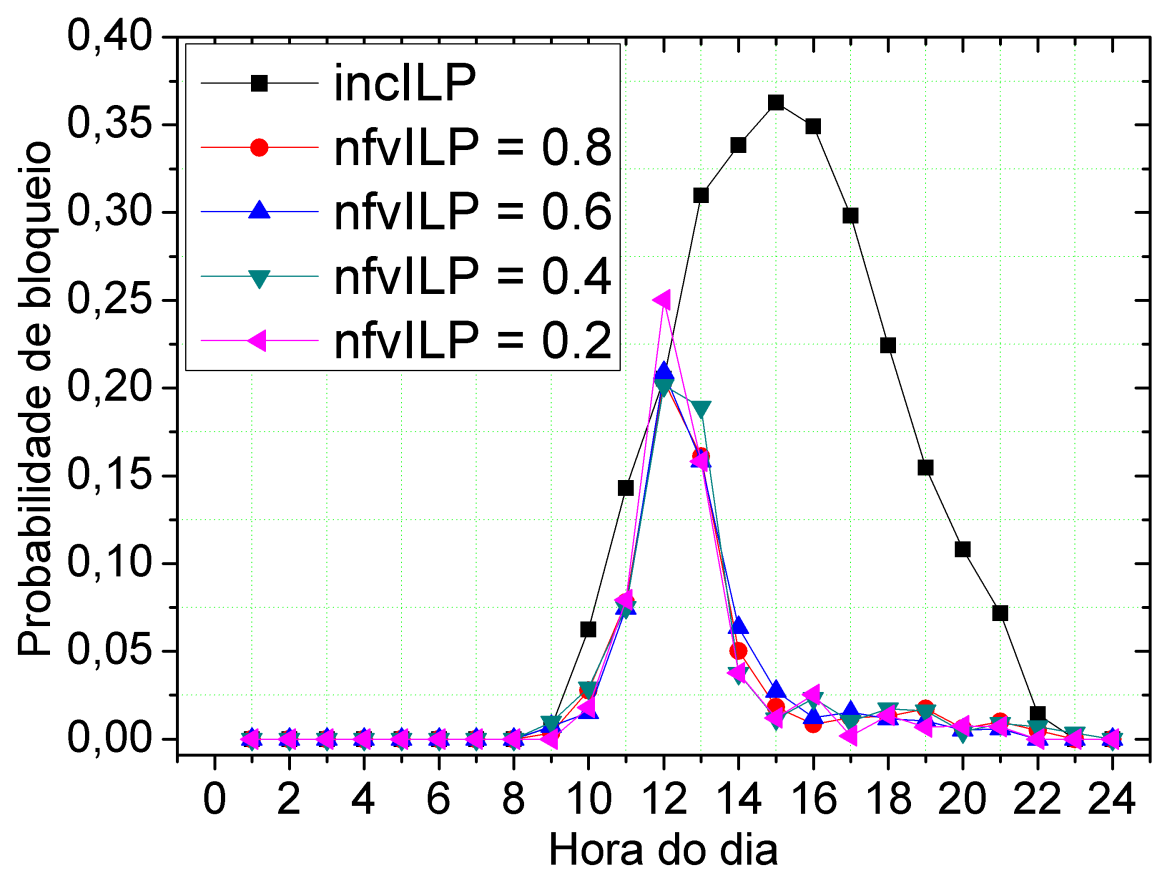

Figura 9.4: Probabilidade de bloqueio quando a comutação entre VDUs é minimizada

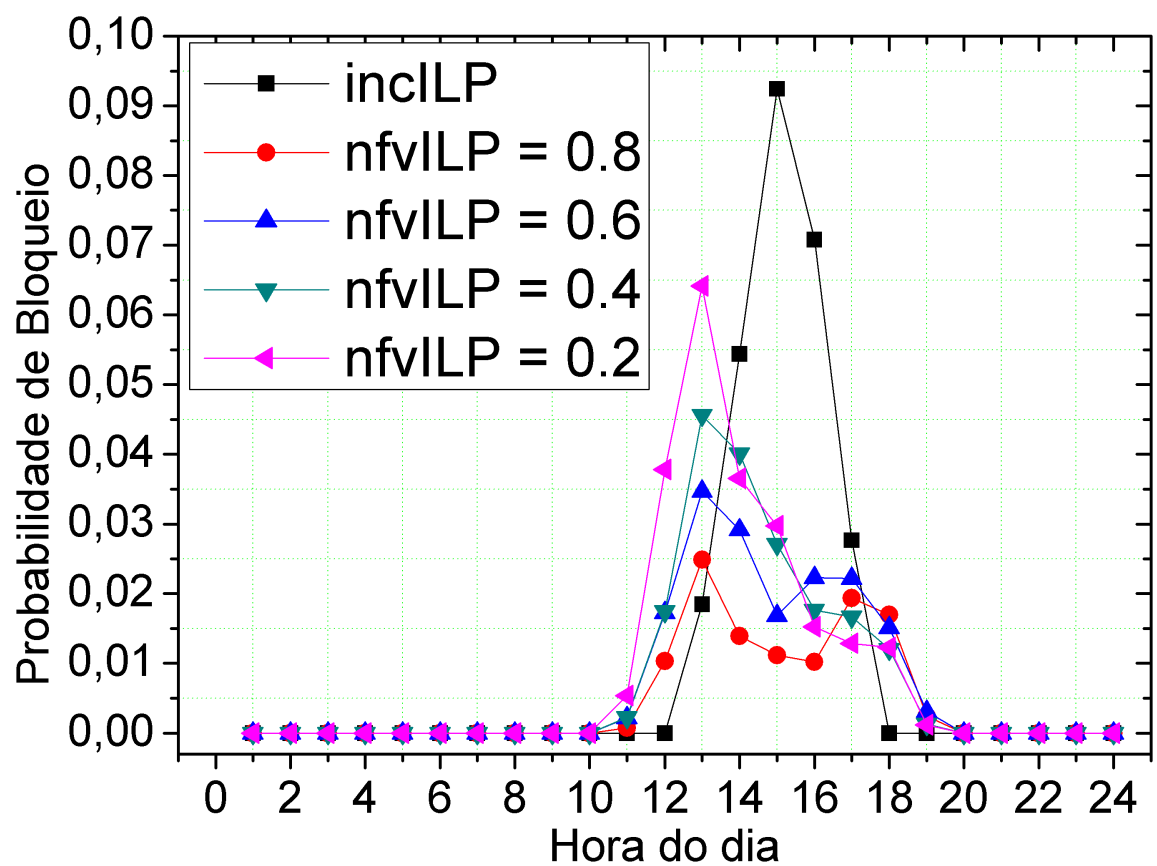

Figura 9.5: Probabilidade de bloqueio quando a criação de VPONs é minimizada

de threshold igual a 0,8 para a política min VPON uma menor quantidade de migrações é realizada. Se as probabilidades de bloqueio forem observadas novamente, nós observamos que a política minVPON com valor de threhsold de 0,8 traz reduções de até $95 \%$ na probabilidade de bloqueio em comparação com a política minRedir. Observando os consumos de energia providos pela política 


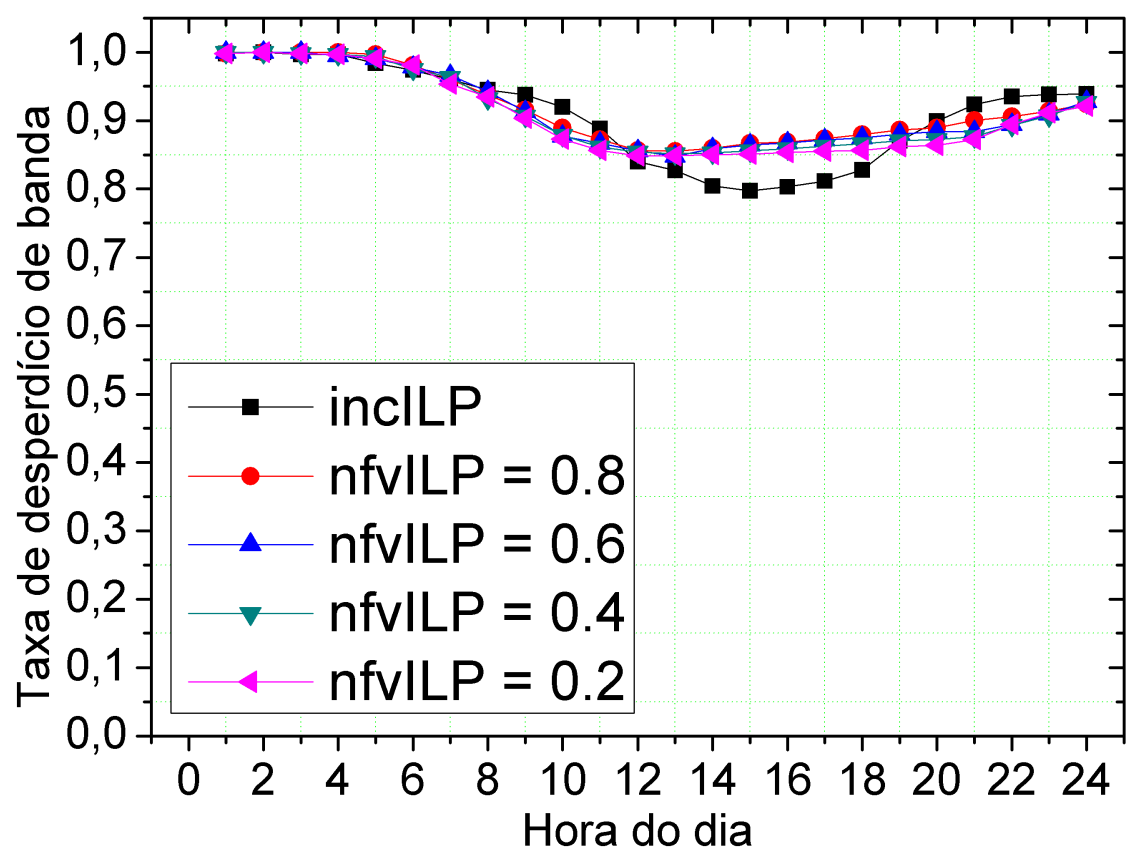

Figura 9.6: Desperdício da largura de banda quando a comutação entre VDUs é minimizada

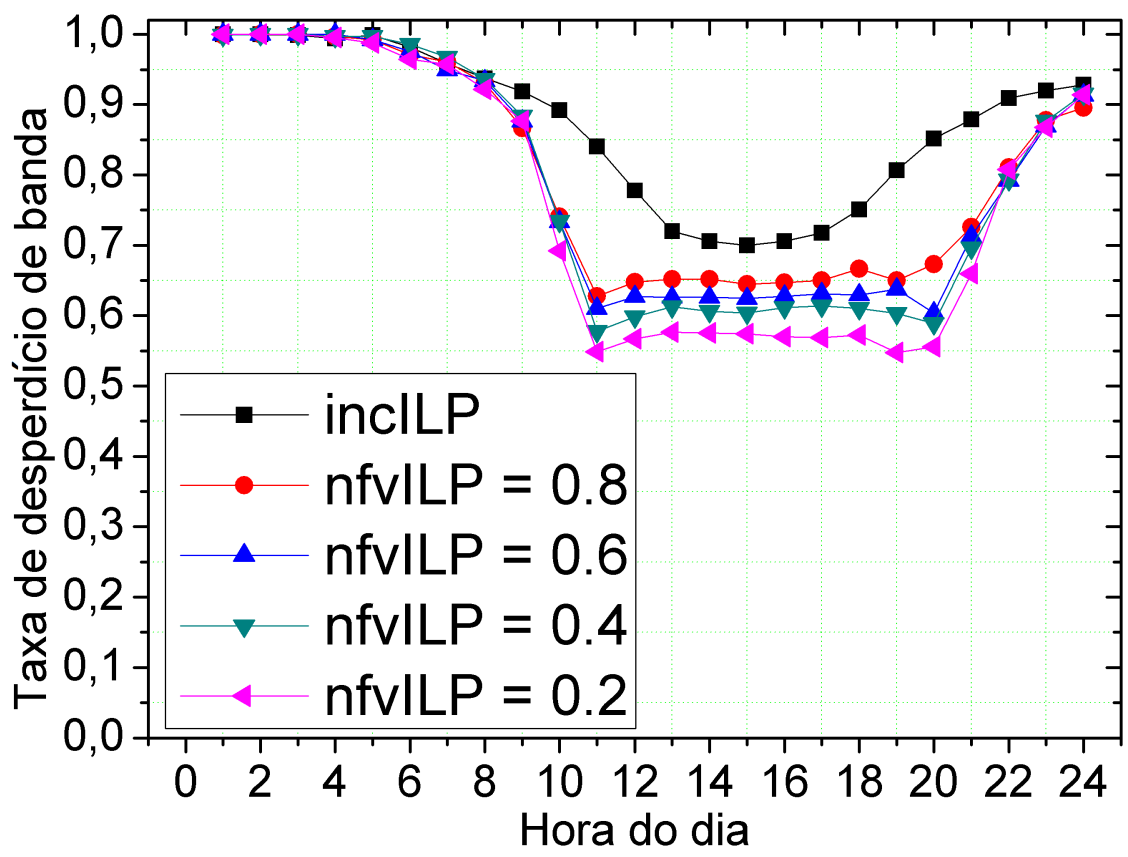

Figura 9.7: Desperdício da largura de banda quando a criação de VPONs é minimizada

min VPON, o menor consumo energético é obtido por meio da maior quantidade de migrações (valor de threhsold $=0,2$ ), quando os fog nodes operam próximos de $100 \%$ de suas capacidades, o que mostra um claro trade off entre o consumo de energia e a quantidade de migrações de vBBUs. Por outro lado, apesar de um alto número de vBBUs esperando ser migrado para a nuvem leva ao 
melhor consumo energético, a migração tardia das vBBUs leva a uma operação ineficiente da rede, produzindo probabilidades de bloqueio muito altas. Assim, concluímos que, mesmo consumindo 49\% mais energia que a política minRedir, é melhor reduzir as VPONs criadas pela política minVPON e realizar a migração de tráfego o quanto antes $($ threshold $=0,8)$ por conta disso trazer altos ganhos na probabilidade de bloqueio, balanço com o consumo de energia e melhor utilização da banda ao custo de menores quantidade de vBBUs migradas.

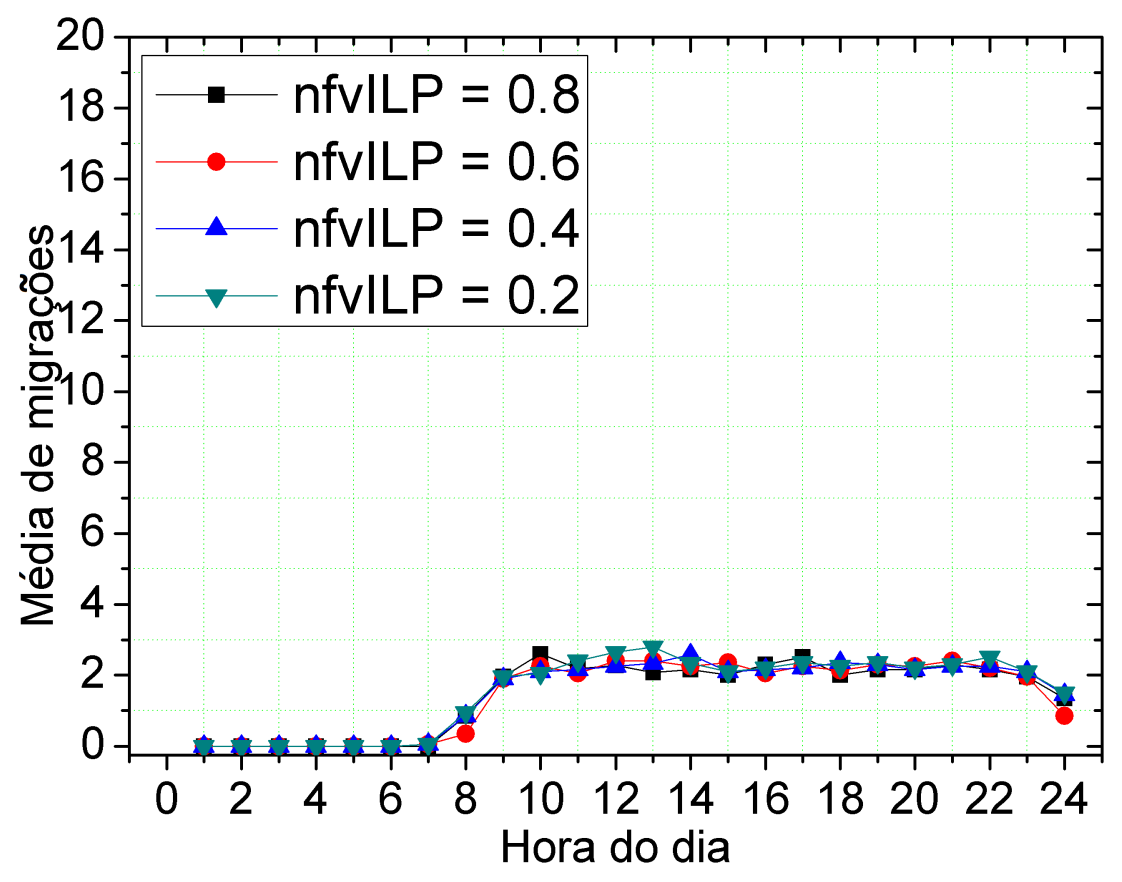

Figura 9.8: Média de migrações de vBBUs para a nuvem quando a comutação entre VDUs é minimizada

O efeito das migrações é mostrado nas Figuras seguintes, onde são mostrados os tempos médios de interrupção de serviço e a probabilidade do serviço das vBBUs ser interrompido por conta da migração de vBBUs e reconfiguração de VPONs.

As Figuras 9.10 e 9.11 apresentam os tempos médios de interrupção dos serviços das vBBUs para as políticas minRedir e min VPON, respectivamente. É possível observar que as duas políticas apresentam tempos semelhantes de interrupção dos serviços, apesar da política minRedir apresentar tempos ligeiramente menores em decorrência da mesma prover uma média menor de migrações de vBBUs. O impacto das migrações e do tempo de interrupção provido por elas é apresentado nas próximas figuras.

A probabilidade do serviço das vBBUs, ou da rede em geral, ser interrompido é mostrado nas Figuras 9.129 .13 para as políticas minRedir e minVPON, respectivamente. É possível notar que, apesar da migração de vBBUs ser necessária para manter uma operação balanceada em termos de consumo de energia, probabilidade de bloqueio e desperdício de largura de banda, a probabilidade dos serviços das vBBUs ser encontrado interrompido é muito pequena e tende a diminuir conforme a carga de trabalho da rede aumenta. Para ambas as políticas minRedir e minVPON, a probabilidade do serviço permanecer interrompido durante a operação da rede é de aproximadamente 0,08\% e 0,04\% nos horários de pico para as políticas minRedir e minVPON, respectivamente, o que é 


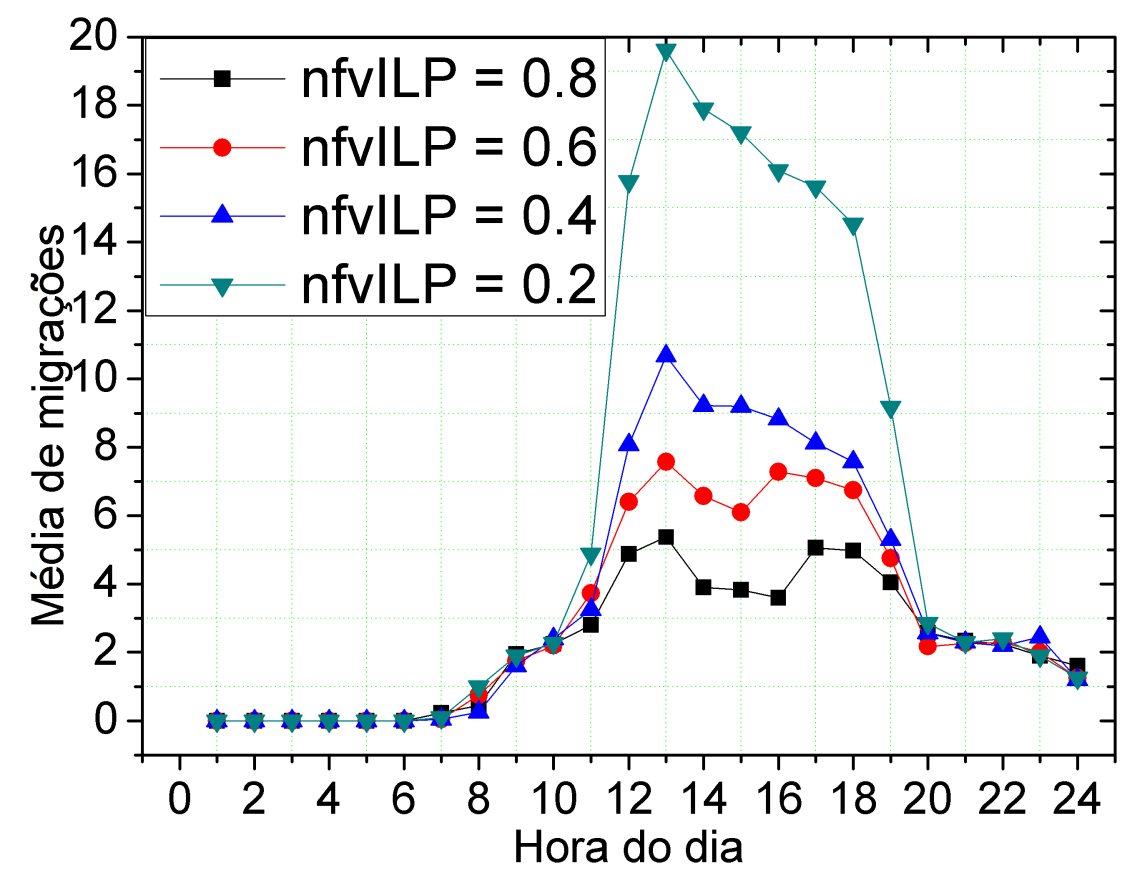

Figura 9.9: Média de migrações de vBBUs para a nuvem quando a criação de VPONs é minimizada

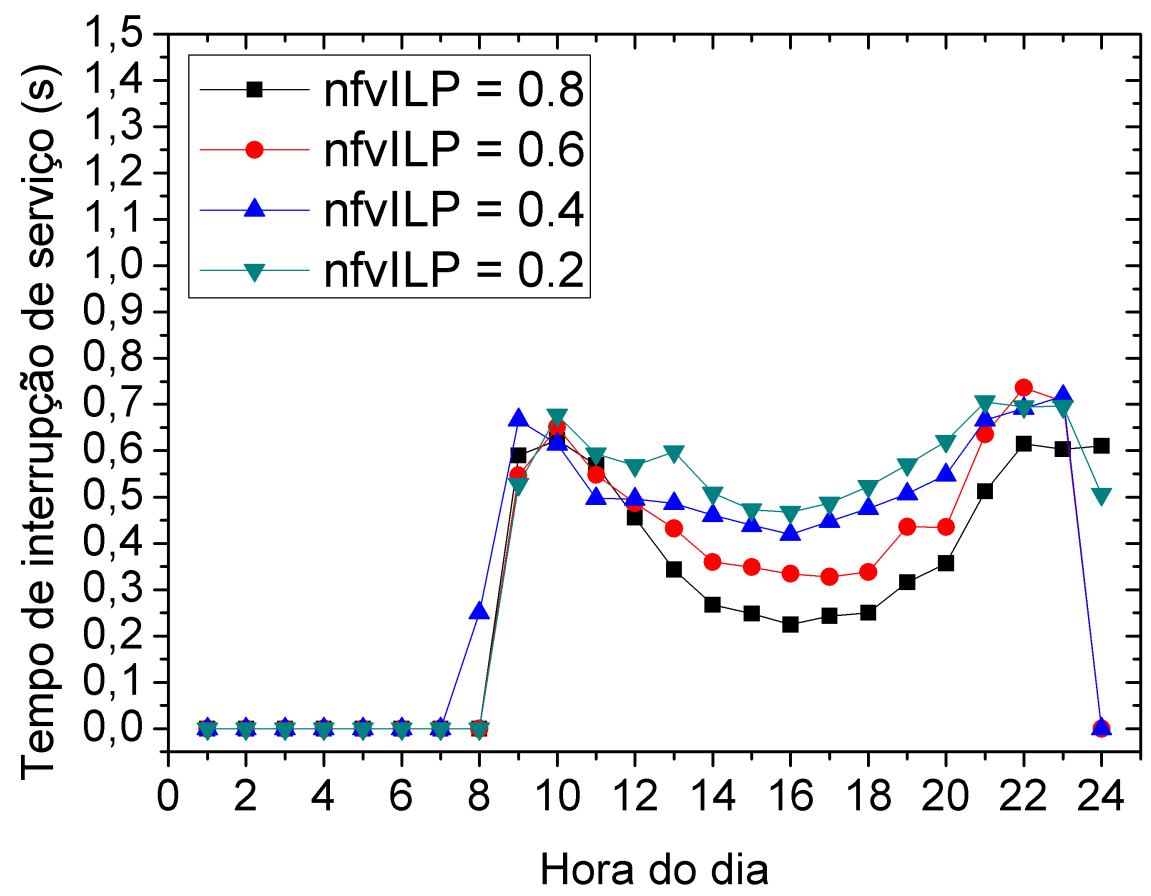

Figura 9.10: Tempo médio de interrupção de serviço quando a comutação entre VDUs é minimizada

uma probabilidade muito baixa. A maior probabilidade de interrupção dos serviços ocorre nos momentos de menor operação da rede, pois nesses momentos de baixa carga é melhor mover as poucas vBBUs instanciadas em fog nodes para a nuvem para economizar energia. Como são poucas vBBUs instanciadas nesse momento, o fato de a maioria delas ser movida para a nuvem causa uma 


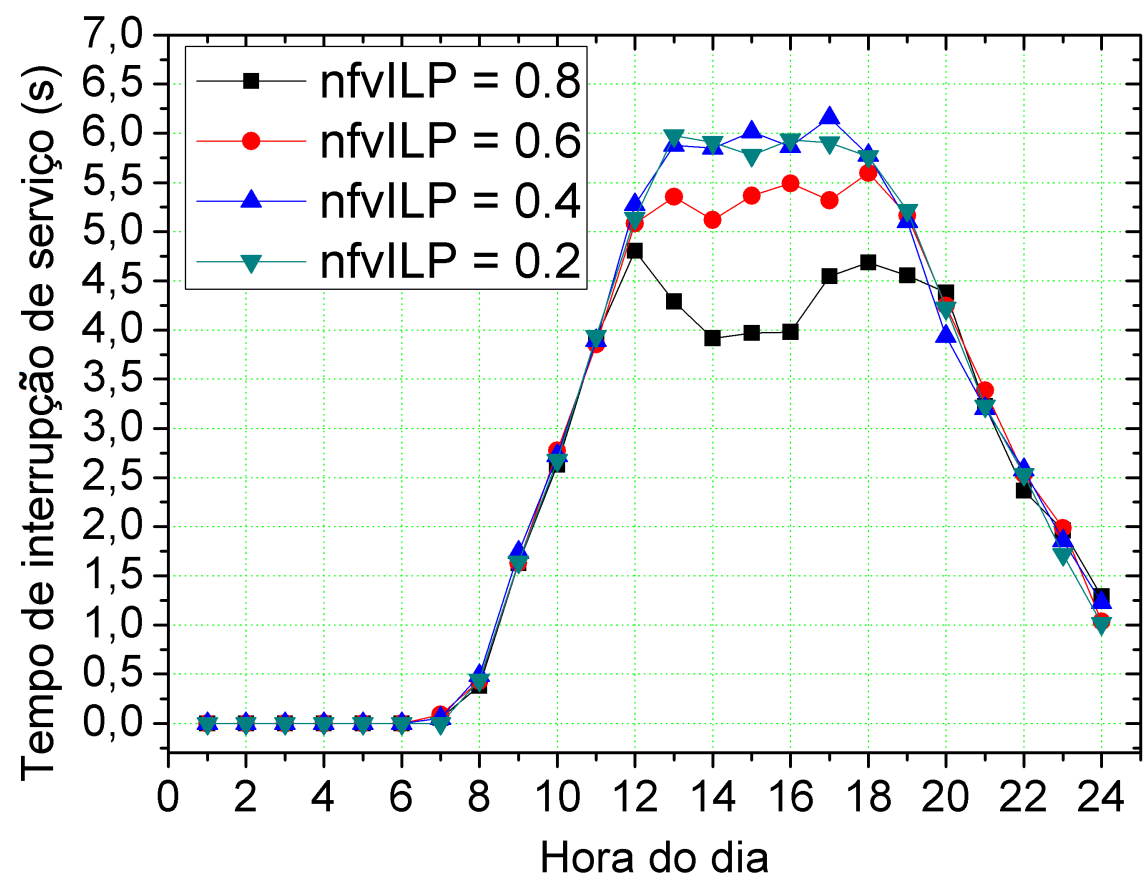

Figura 9.11: Tempo médio de interrupção de serviço quando a criação de VPONs é minimizada

maior interrupção dos serviço. Note que mesmo nesses casos a probabilidade continua sendo muito baixa, atingindo picos de aproximadamente $0,2 \%$ de probabilidade de interrupção de serviços em ambas as políticas.

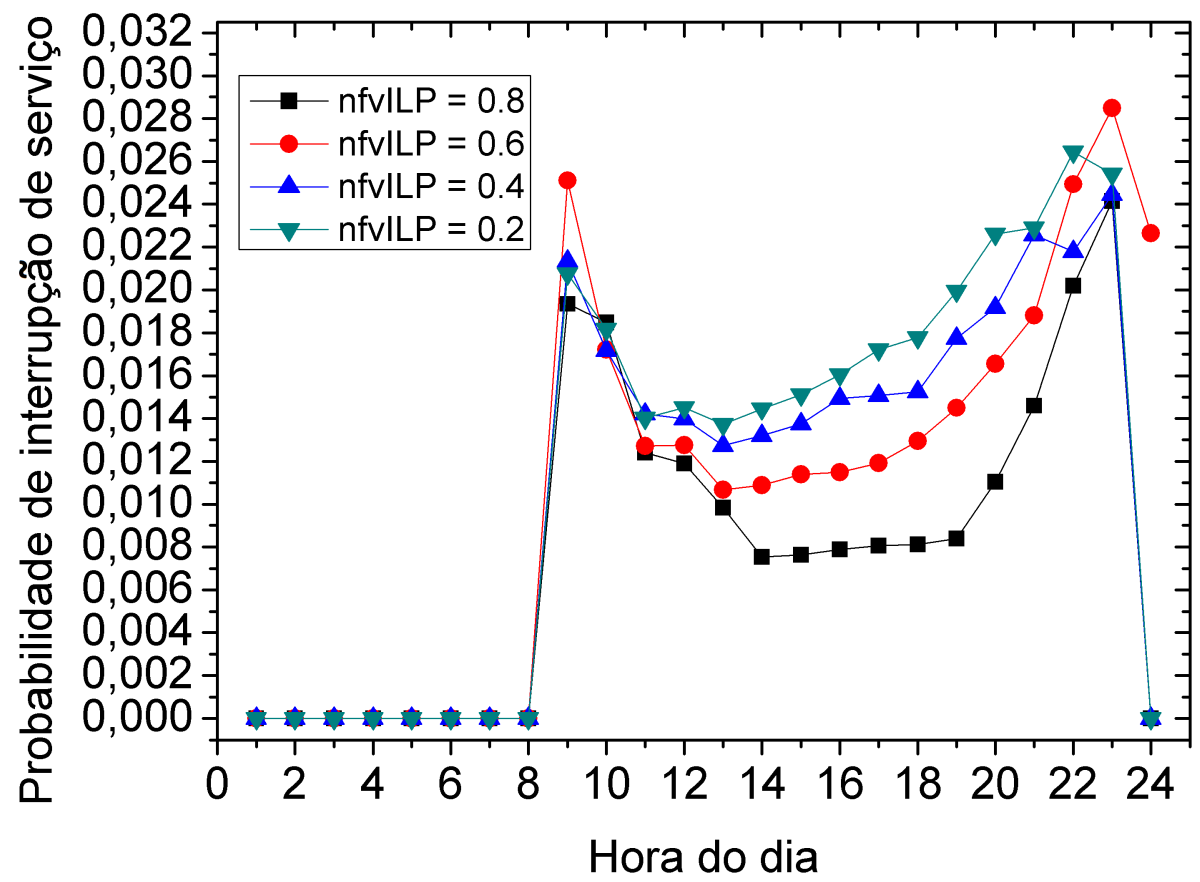

Figura 9.12: Probabilidade do serviço ser interrompido quando a comutação entre VDUs é minimizada 


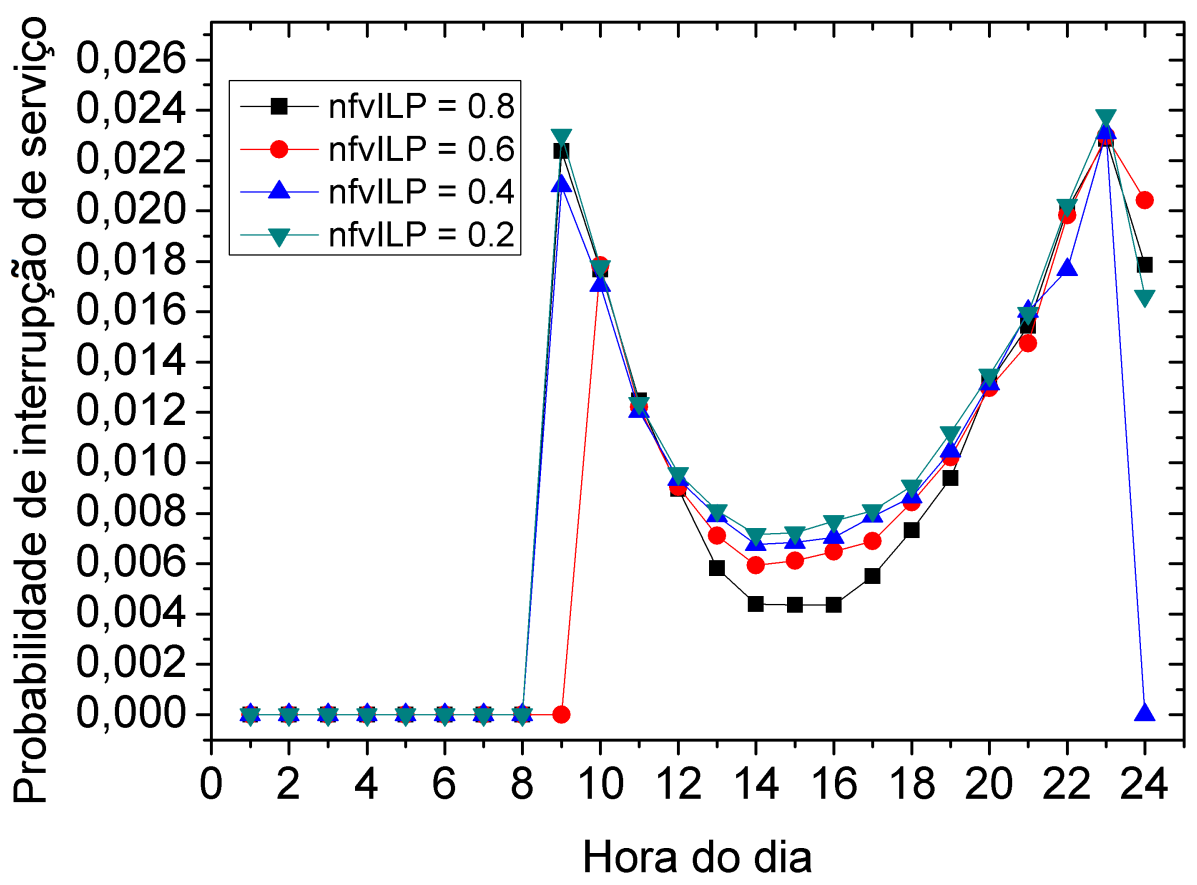

Figura 9.13: Probabilidade do serviço ser interrompido quando a criação de VPONs é minimizada

\subsubsection{Discussão}

Nesta seção foi avaliado qual é o impacto da migração de vBBUs e reconfiguração das VPONs no consumo de energia, na probabilidade de bloqueio e no desperdício da largura de banda durante a criação de VPONs para o suporte da transmissão de tráfego CPRI. Duas políticas de minimização de recursos foram avaliadas, a política minRedir, que realiza a alocação de vBBUs e criação de VPONs minimizando a comutação de fluxos CPRI entre VDUs e a política minVPON, que busca minimizar a quantidade de VPONs criadas na rede. Conforme os resultados apresentados, a migração de carga de trabalho entre fog nodes e nuvem possui um papel importante no desempenho da rede, provendo melhora de desempenho tanto em relação ao consumo de energia da rede quanto às probabilidade de bloqueio e desperdício de largura de banda. A minimização da comutação entre VDUs é capaz de prover menor consumo energético em comparação com a minimização das VPONs criadas, entretanto, a minimização da comutação vêm ao custo de uma maior centralização das VPONs em um único nó de processamento, o que impede que comprimentos de onda sejam alocados para a criação de VPONs em outros nós da rede, o que resultou em altas probabilidades de bloqueio e maior desperdício de largura de banda. Nesse sentido, a política min VPON provê uma operação mais balanceada pois, apesar de consumir mais energia, é capaz de diminuir significantemente a probabilidade de bloqueio e aumentar a eficiência na utilização da banda disponível. Por fim, também foi observado que o impacto da migração das cargas de trabalho é muito baixo, e a probabilidade do serviço das vBBUs ser encontrado indisponível tende a diminuir conforme a carga de trabalho da rede aumenta. Nas próximas seções nós iremos apresentar os resultados acerca da relaxação do modelo ILP aqui avaliado para que tempos menores de execução sejam encontrados para instâncias maiores do problema. 


\section{Capítulo 10}

\section{Avaliação da Relaxação da Formulação ILP}

Nesta seção a eficiência das heurísticas baseadas na relaxação da formulação ILP será avaliada. Primeiramente, a eficácia das relaxações será testada em um cenário de tráfego estático, onde a carga de fluxo CPRI a ser processada e transmitida é conhecida de antemão. Após isso, os resultados da aplicação das heurísticas relaxadas em um cenário de tráfego dinâmico serão apresentados.

\subsection{Cenário de tráfego estático}

No cenário estático, em cada execução da formulação ILP o tamanho da rede foi incrementado, com os valores sendo apresentados na tabela a seguir:

Tabela 10.1: Quantidade de RRHs, nós de processamento e comprimentos de onda

\begin{tabular}{|r|lll|}
\hline Execução & RRHs & Nós & Comprimentos de Onda \\
\hline 1 & 12 & 2 & 3 \\
2 & 20 & 3 & 4 \\
3 & 30 & 4 & 5 \\
4 & 42 & 5 & 6 \\
5 & 56 & 6 & 7 \\
6 & 72 & 7 & 8 \\
\hline
\end{tabular}

As métricas de performance avaliadas foram as seguintes: Consumo de energia, a quantidade de tráfego redirecionado, o desperdício de largura de banda, a quantidade de nós, comprimentos de onda, VDUs e switches ativados e os tempos de execução. Os resultados apresentados são a média de 10 execuções de cada cenário. Note que a quantidade de execuções limitou-se a 6 por conta do tempo de execução da formulação ILP.

A Figura 10.1 mostra que as heurísticas baseadas na relaxação da formulação do modelo ILP são capazes de prover resultados muito próximos que as soluções ótimas providas pela formulação ILP. A heurística relaxedMin VPON apresenta um pequeno crescimento em relação à formulação ILP (políticas minRedir e minVPON) e a heurística softRelaxMinRedir é capaz de obter o mesmo desempenho energético que a formulação ILP. A heurística relaxedMinRedir apresenta uma queda significativa no consumo de energia conforme o tamanho do problema cresce, entretanto, isso se 
deve ao fato de ela apresentar altas probabilidades de bloqueio em decorrência da centralização das VPONs em um único nó de processamento.

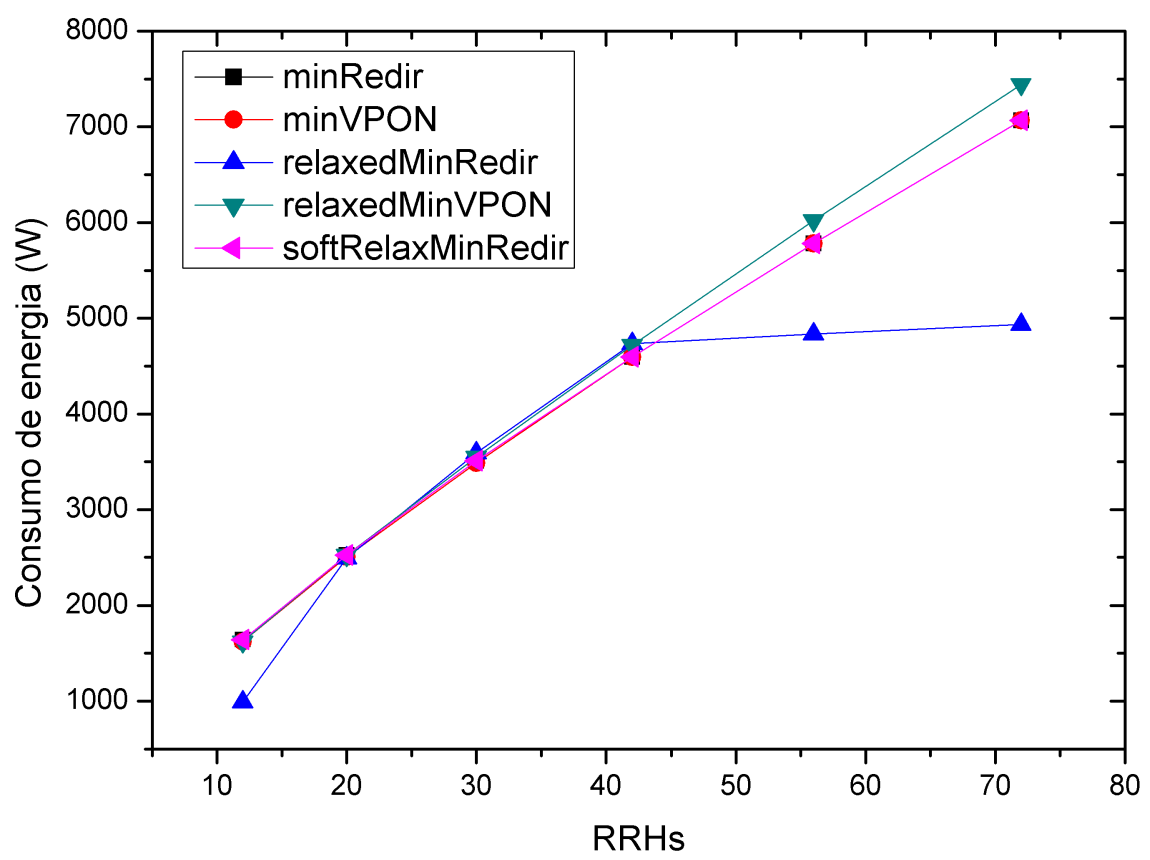

Figura 10.1: Consumo de energia

As probabilidades de bloqueio são apresentadas na Figura 10.2. Note que a qualidade das soluções providas pela heurística softRelaxMinRedir possui o custo de pequenas probabilidades de bloqueio em cenários maiores. Note que até a quantidade de 42 RRHs o desempenho da rede pode ser mantido sem a ocorrência de bloqueio de requisições CPRI. Entretanto, a partir da quantidade de 56 RRHs pequenas taxas de bloqueios são experimentadas na rede. A heurística relaxedMinRedir possui o pior desempenho em cenários maiores e não é uma opção viável nesses casos, principalmente quando os fog nodes devem ser ativados mas não há comprimentos de onda disponíveis por conta de todos eles terem sido centralizados na nuvem para a minimização da comutação de tráfego entre VDUs.

A quantidade de tráfego comutado entre VDUs é mostrada na Figura 10.3. Note que por conta de priorizar a minimização da quantidade de VPONs criadas, a heurística relaxedMin VPON apresenta uma maior quantidade de redirecionamento de tráfego para todos os cenários executados. Note que a heurística softRelaxMinRedir é capaz de diminuir o redirecionamento de tráfego em todos os cenários, provendo dessa forma uma minimização também nos atrasos gerados pelos redirecionamentos entre VDUs.

A taxa de desperdício de largura de banda é apresentada na Figura 10.4. Note que as heurísticas relaxadas são capazes de prover uma melhor utilização da banda disponível. Em especial, a capacidade da heurística softRelaxMinRedir de realizar migrações de VPONs da nuvem para os fog nodes contribui positivamente no aproveitamento da banda disponível, e, conforme o tamanho da rede aumenta, faz-se necessário que mais migrações de VPONs para os fog nodes sejam realizadas, o que leva a um melhor aproveitamento da banda disponível e, conforme mostrado na Figura 10.3, 


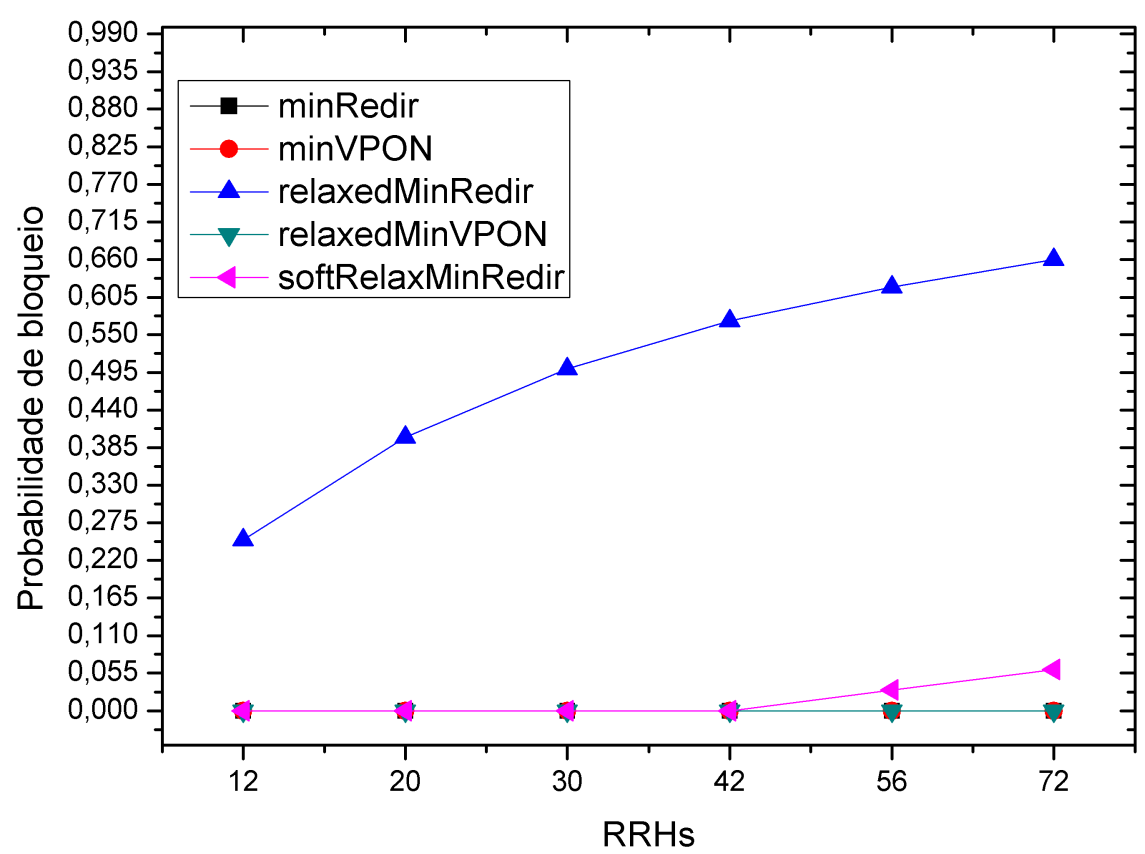

Figura 10.2: Probabilidade de bloqueio

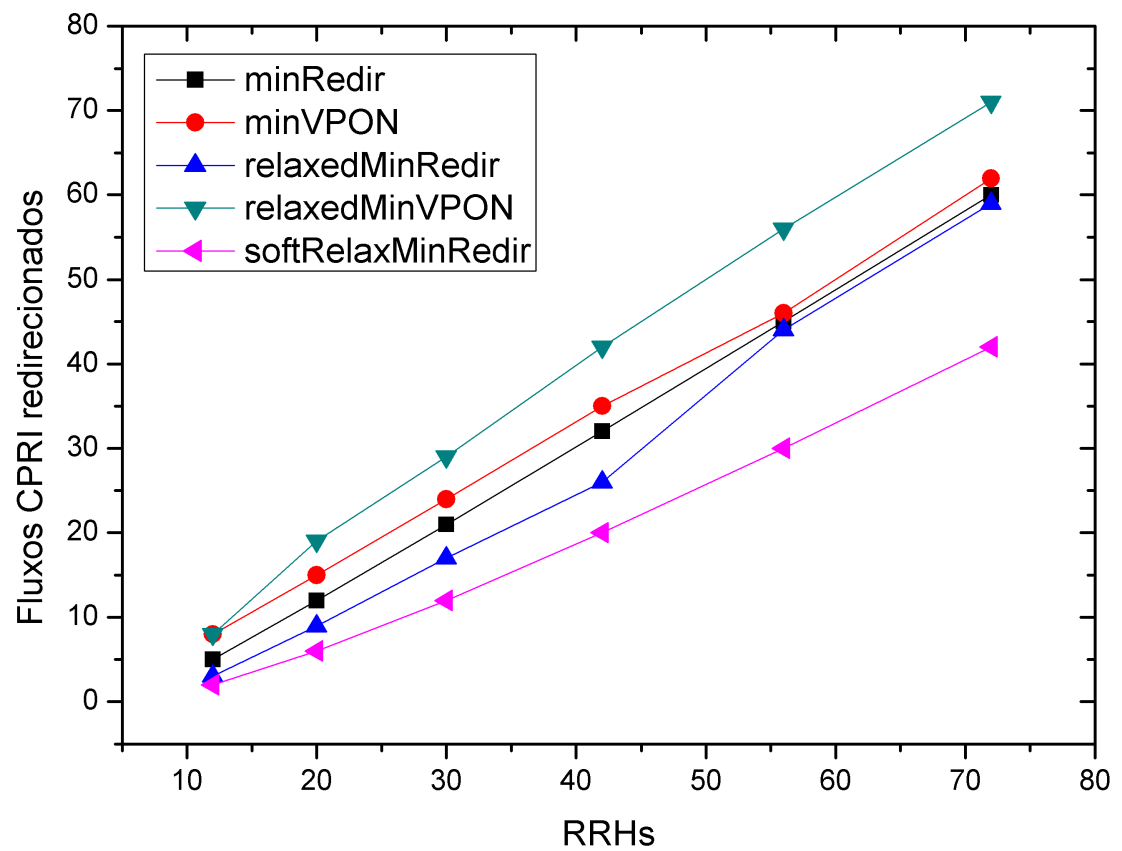

Figura 10.3: Quantidade de fluxos CPRI redirecionados entre VDUs

ao custo da menor quantidade de comutações entre VDUs.

Entretanto, como as formulações ILP são capazes de obter soluções ótimas para as diferentes instâncias do problema e, como visto até aqui, as heurísticas relaxadas vêm apresentando soluções por vezes melhores que a formulação ILP em relação a algumas métricas de desempenho, existe um 


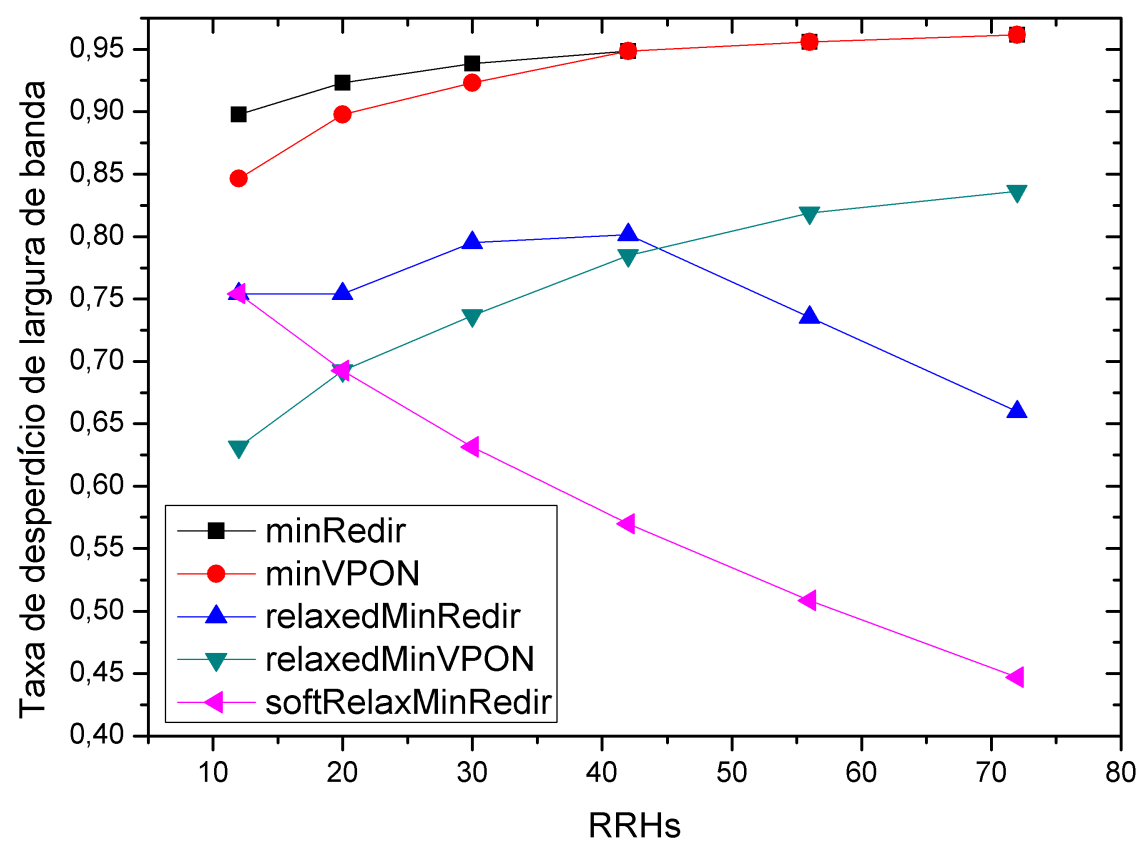

Figura 10.4: Taxa de desperdício de largura de banda

ponto em que as heurísticas devem apresentar uma queda no desempenho em relação às soluções da formulação ILP. Esse ponto de queda de desempenho, ou até mesmo de balanceamento com os resultados da formulação ILP encontra-se na taxa de desperdício da utilização da capacidade de processamento, ou das VDUs, disponíveis na rede. Conforme mostrado na Figura 10.5, os recursos de processamento são melhores utilizados nas soluções providas pela formulação ILP. Nesse ponto, as heurísticas baseadas na relaxação apresentam um desempenho 2 vezes pior que a formulação ILP. Isso pode ser explicado pela aleatoriedade provida pelas relaxações na alocação dos recursos, mas principalmente das VDUs.

Em relação a quantidade de recursos ativados pelos algoritmos, a Figura 10.6 mostra as heurísticas ativam a mesma quantidade de nós, com a exceção da heurística relaxedMinRedir, que não é capaz de ativar mais nós nas instâncias maiores do problema por conta da escassez de comprimentos de onda que ela mesmo acaba causando. Os resultados desse gráfico mostram que a performance dos algoritmos não está ligada com a quantidade de nós ativados, mas sim com o gerenciamento dos outros recursos, tais como as VPONs e VDUs.

A quantidade de VPONs criadas por cada uma das heurísticas é mostrada na Figura 10.7. Note que ambas as políticas minRedir e minVPON e a heurística softRelaxMinRedir provêm a menor quantidade de VPONs criadas. Em instâncias menores do problema, a política minVPON possui o melhor desempenho, entretanto, conforme o tamanho da rede cresce, os desempenhos das duas políticas da formulação ILP e da heurística softRelaxMinRedir é igualado. O pior desempenho é apresentado pela heurística relaxada relaxedMin VPON, que ativa uma quantidade significantemente maior de VPONs nas instâncias maiores do problema.

A quantidade de VDUs ativadas é apresentada na Figura 10.8. Note que todos os algoritmos, com exceção novamente da heurística relaxedMinRedir, ativam a mesma quantidade de VDUs. 


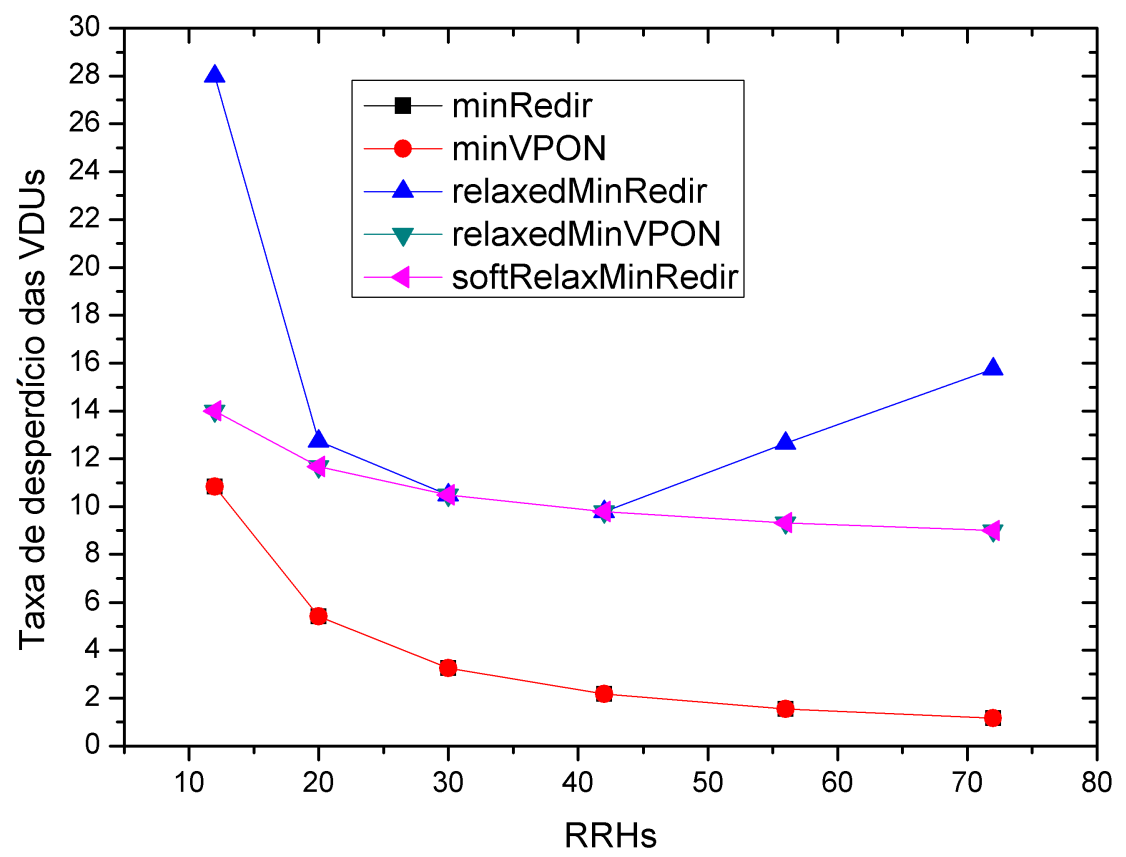

Figura 10.5: Taxa de desperdício da capacidade de processamento

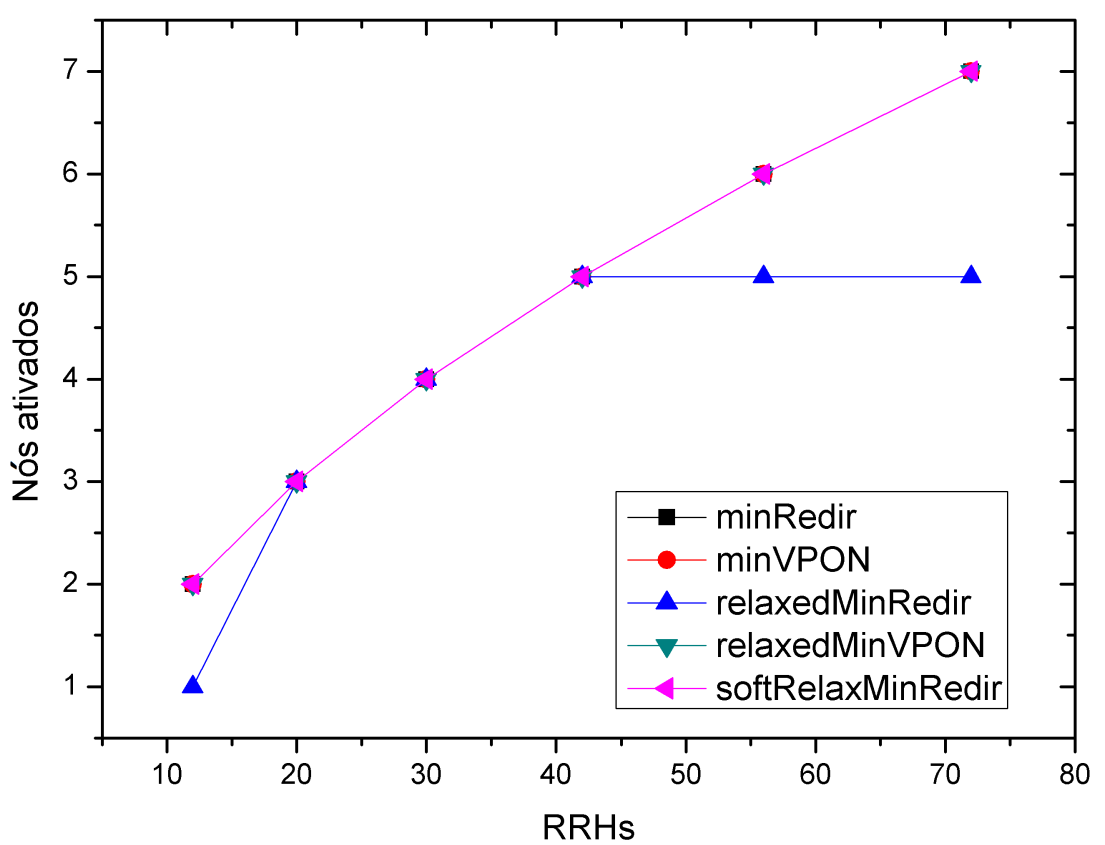

Figura 10.6: Quantidade de nós de processamento ativados

Entretanto, conforme foi mostrado na Figura 10.5, a formulação ILP é capaz de alocar vBBUs de forma mais eficiente nas VDUs ativadas.

Por fim, os tempos de execução dos algoritmos são mostrados nas Figuras 10.9, 10.10 e 10.11. A Figura 10.9 apresenta os tempos de execução de todos os algoritmos. A política minRedir apresenta 


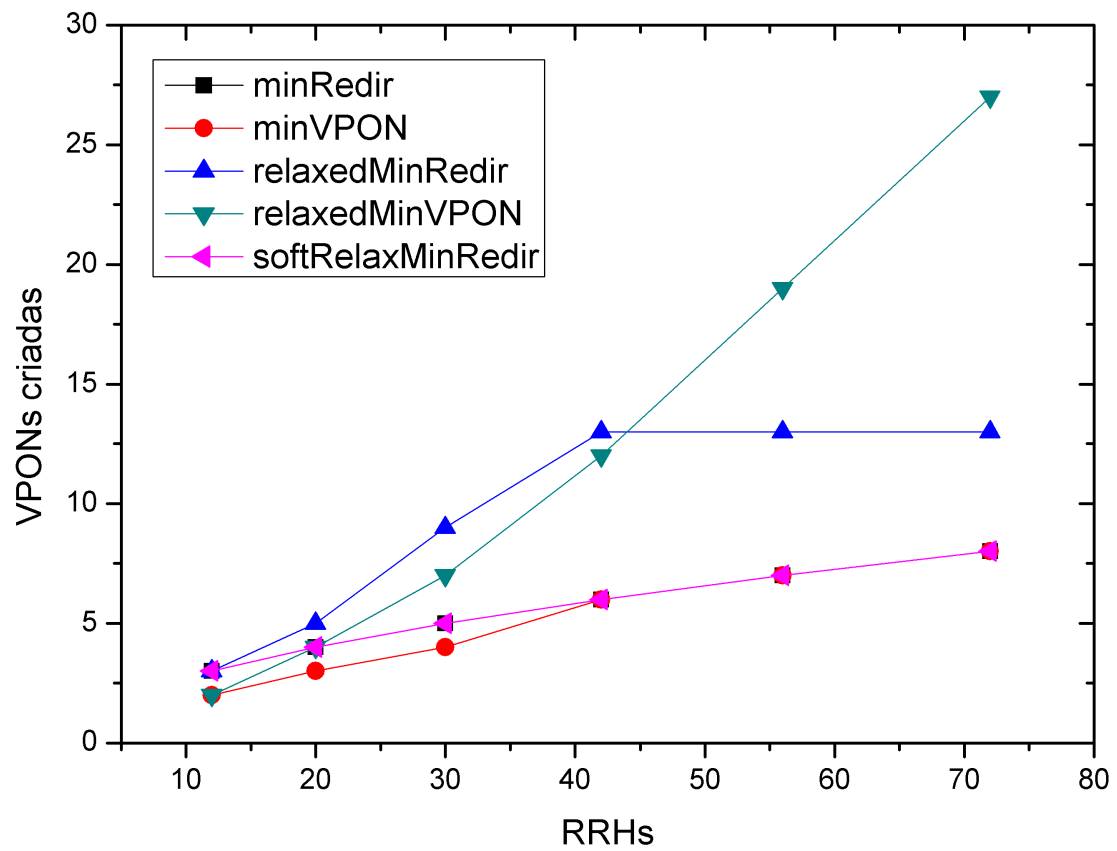

Figura 10.7: Quantidade de VPONs ativadas

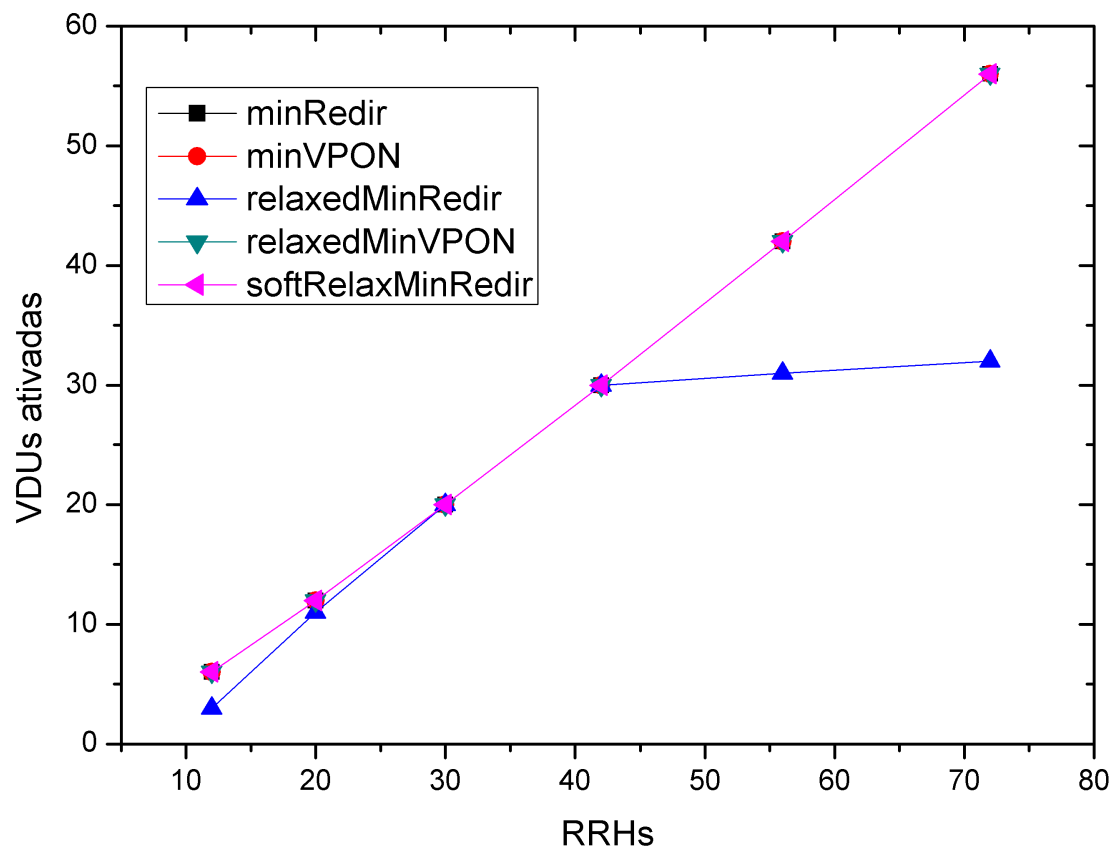

Figura 10.8: Quantidade de VDUs ativados

tempos de execuções muitos longos nas instâncias maiores do problema. Isso se deve ao fato de que, para minimizar efetivamente a quantidade de tráfego comutado entre VDUs, a formulação ILP deve otimizar a alocação de um número maior de variáveis em relação à política min VPON, que é capaz de prover tempos de execuções até $60 \mathrm{X}$ menores. Em relação às relaxações, as reduções 
nos tempos de execução em relação à política minRedir são de, aproximadamente, até 3000X para as heurísticas relaxedMinRedir e softRelaxMinRedir e de, aproximadamente, até 3200X para a heurística relaxedMin VPON.

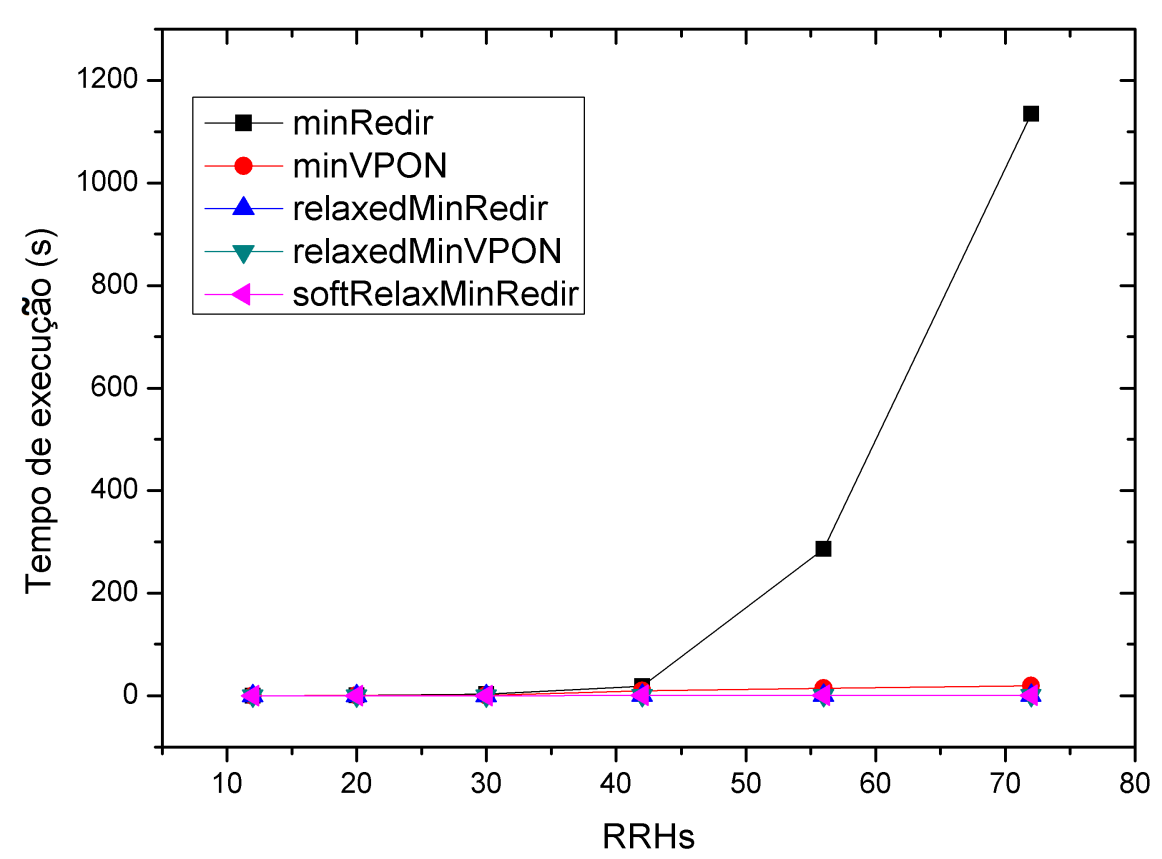

Figura 10.9: Tempo de execução

Para uma melhor visualização dos resultados, a Figura 10.10 exclui a política minRedir dos resultados. Note que os ganhos em relação à política minVPON também são significativos, sendo de, aproximadamente, até 50X pelas heurísticas relaxedMinRedir e softRelaxMinRedir e de, aproximadamente, até 53X para a heurística relaxedMin VPON.

Por fim, a Figura 10.11 apresenta um comparativo dos tempos de execução das relaxações. Os tempos, além de serem muito baixos, são muito próximos e com poucas variações, com exceção da heurística softRelaxMinRedir que apresenta um pequeno pico na segunda execução das instâncias do problema.

\subsubsection{Discussão}

Nesta seção foi avaliada a eficácia das heurísticas baseadas na relaxação da formulação ILP apresentada no Capítulo 8. Por meio de simulações, foi possível observar que as relaxações são capazes de alcançar soluções sub-ótimas muito próximas das soluções ótimas providas pela formulação ILP original. Entretanto, as heurísticas relaxadas oferecem reduções imensas no tempo de obtenção das soluções, sendo possível obter reduções de até 3200X em relação à formulação original com a política minRedir. Na próxima seção será avaliada a eficácia das relaxações no tratamento de tráfego dinâmico. 


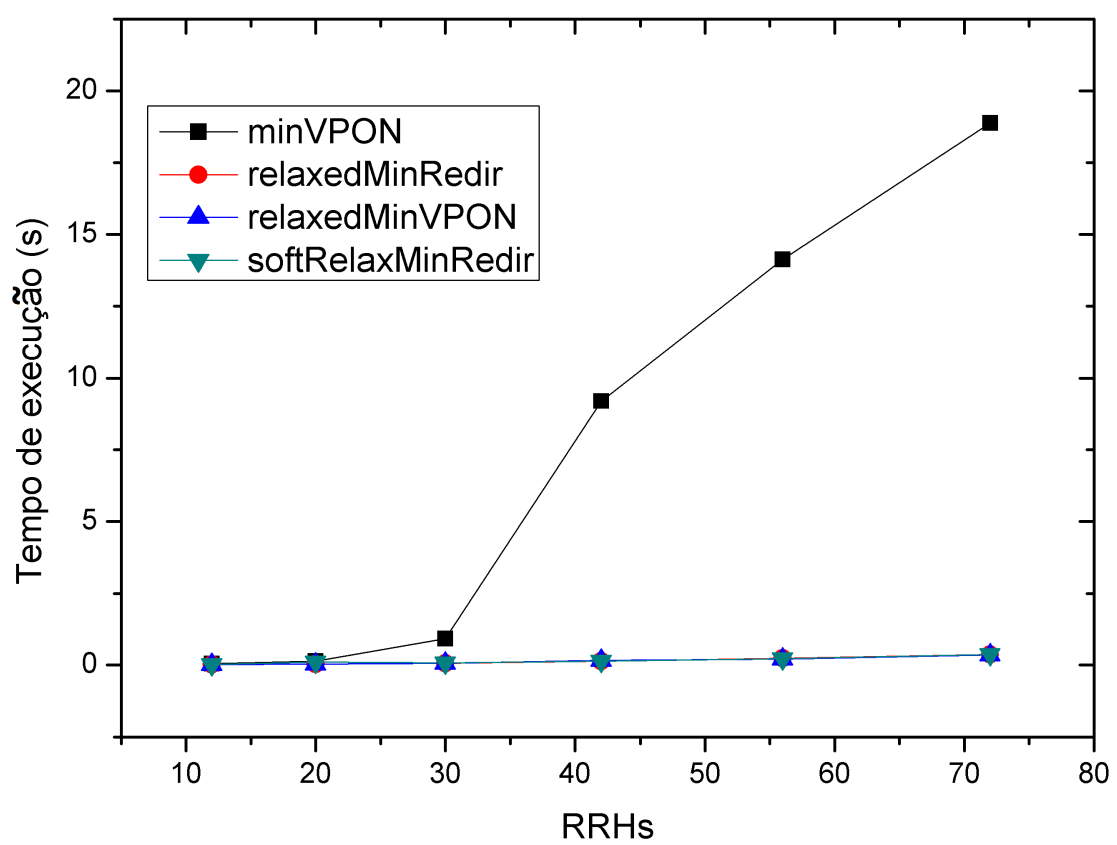

Figura 10.10: Tempo de execução da política min VPON e relaxações

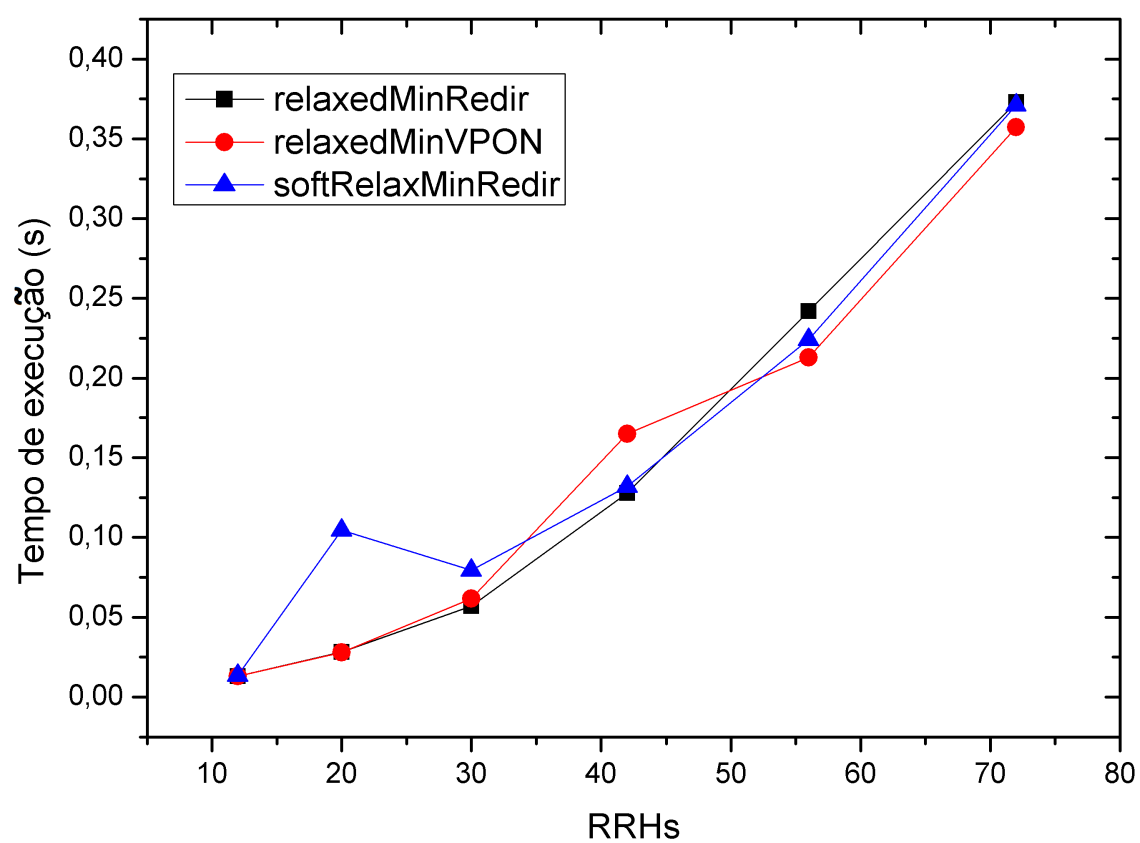

Figura 10.11: Tempo de execução das relaxações

\subsection{Cenário de tráfego dinâmico}

Nesta seção a eficácia das soluções obtidas pelas relaxações é atestada em um cenário de tráfego dinâmico. A rede simulada nestas simulações é a mesma rede simulada no Capítulo 9. Os 
resultados apresentados são referentes a execuções das heurísticas relaxadas relaxedMinRedir e relaxedMin VPON e as métricas avaliadas foram o consumo de energia, probabilidade de bloqueio, migrações, desperdício de largura de banda e tempo de execução. A heurística softRelaxMinRedir não foi executada para o caso dinâmico por conta da heurística relaxedMinRedir apresentar um bom desempenho nesse tipo de cenário.

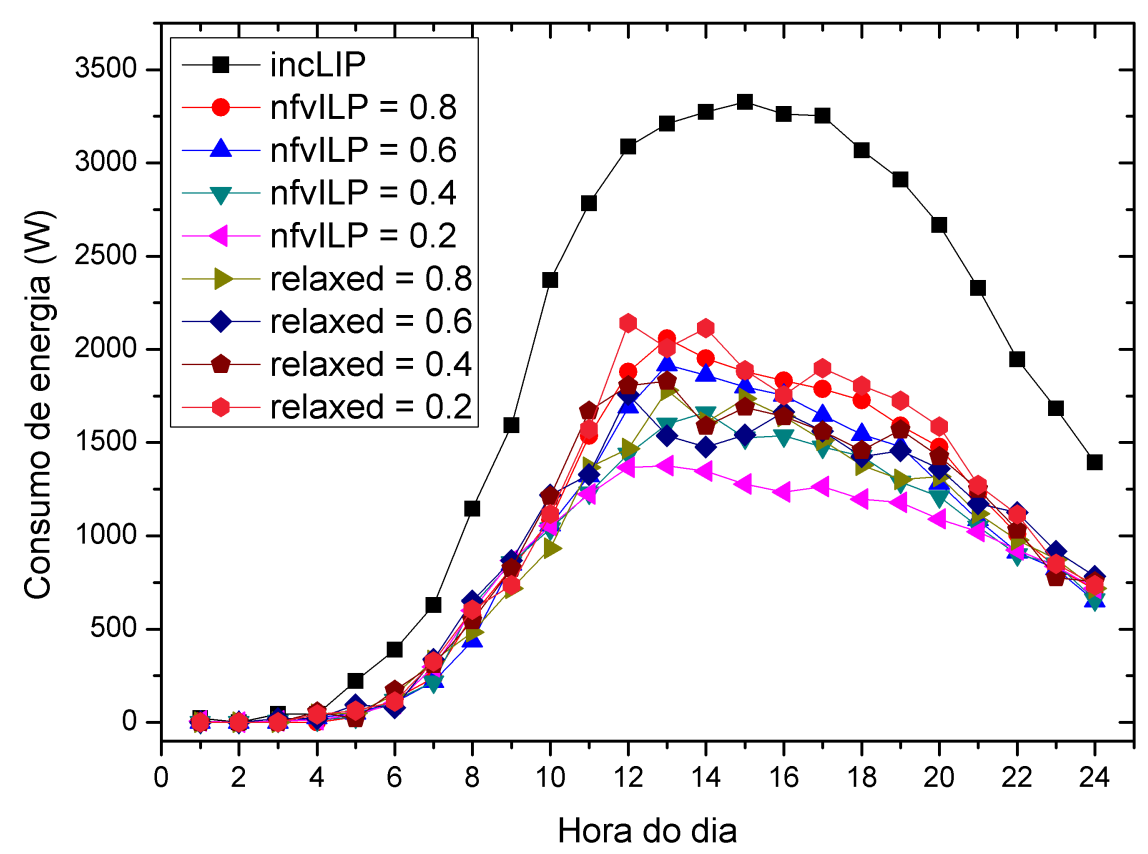

Figura 10.12: Consumo de energia das relaxações e ILP no cenário dinâmico, política minRedir e heurística relaxada relaxedMinRedir

A Figura 10.12 apresenta as curvas do consumo de energia para a formulação ILP com a política minRedir e a heurística relaxada relaxedMinRedir. É possível notar que as soluções obtidas pelas relaxações são superiores às curvas obtidas pelo algoritmo incILP e, além disso, são muito próximas das soluções obtidas pela formulação ILP sem relaxação. Em alguns valores de threshold os resultados obtidos pela relaxação são até mesmo superiores aos da formulação ILP. Isso se dá pelo fato das heurísticas relaxadas sempre priorizarem a utilização da nuvem em todos os valores de carga de trabalho, ao passo que em alguns casos de cargas mais baixas a formulação ILP opta pela ativação de fog nodes por conta do consumo deles ser inferior ao da nuvem. Em longo prazo, essa priorização pode levar a notáveis diferenças no consumo de energia.

O consumo energético obtido pela formulação ILP com a política minVPON e a heurística relaxedMin VPON é mostrado na Figura 10.13. De forma geral, as relaxações apresentam o mesmo comportamento em relação à formulação ILP, entretanto, como já mostrado nas análises do Capítulo 9, tanto a política minVPON quanto a heurística relaxedMinVPON apresentam consumo mais elevado que a política minRedir pelo fato de essa prover maior probabilidade de bloqueio e assim impedir a ativação de novos recursos na rede. As probabilidades de bloqueio obtidas pelas relaxações são mostradas nas Figuras 10.14 e 10.15.

Conforme mostrado na Figura 10.14, as relaxações provêm probabilidades de bloqueio prati- 


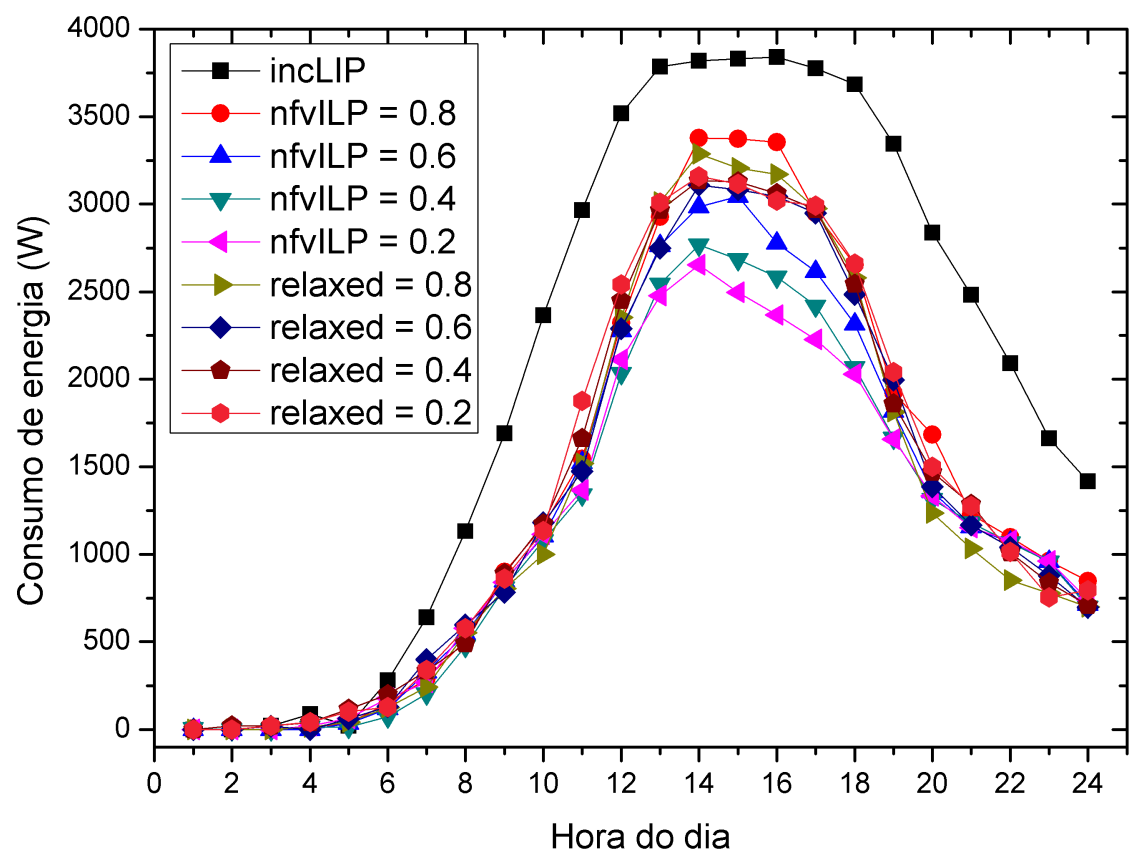

Figura 10.13: Consumo de energia das relaxações e ILP no cenário dinâmico, política minVPON e heurística relaxada relaxedMin $V P O N$

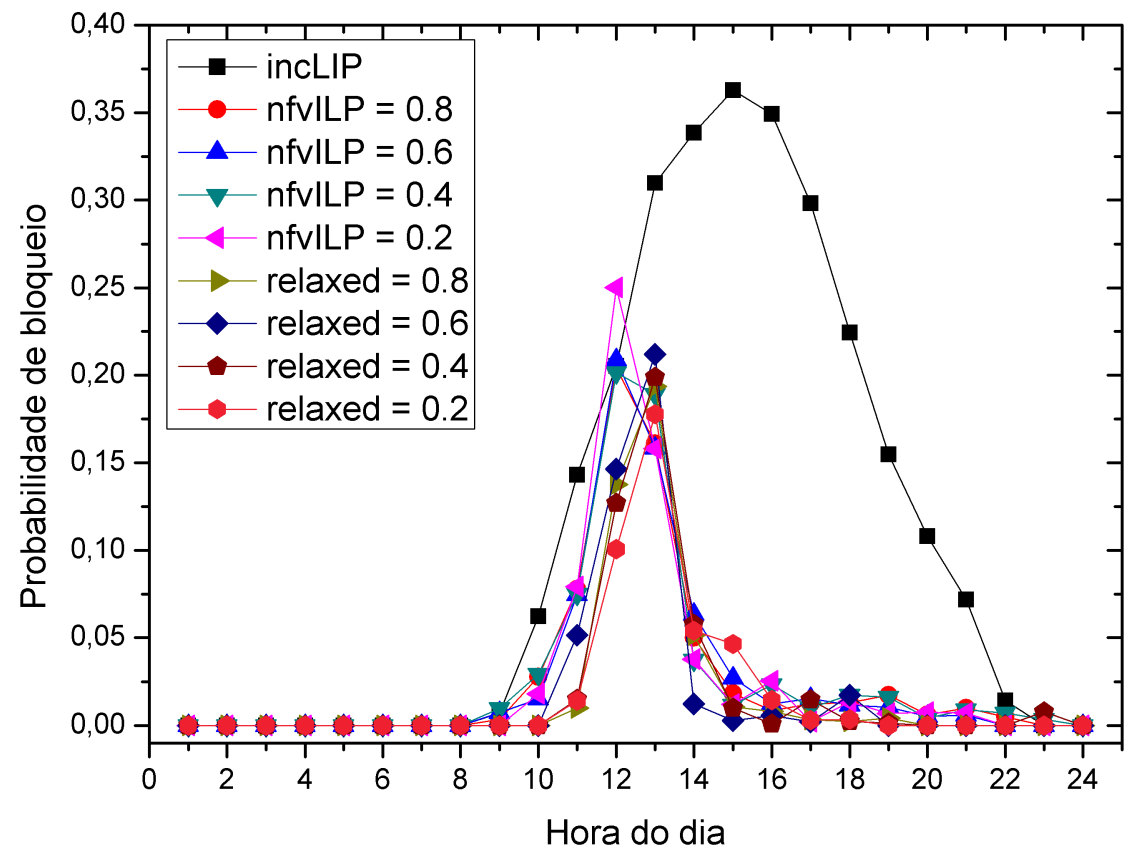

Figura 10.14: Probabilidade de bloqueio das relaxações e ILP no cenário dinâmico, política minRedir

camente iguais às providas pela formulação ILP com a política minRedir, o que garante a aproximação das soluções obtidas pela relaxação à otimalidade provida pela formulação ILP. Em relação à minimização das VPONs, a Figura 10.15 apresenta as probabilidades de bloqueio obtidas pelas 
relaxações. É possível observar que, de forma geral, a heurística relaxedMin VPON se aproxima da formulação ILP com pequenas variações na qualidade das soluções obtidas. Conforme esperado, as probabilidades de bloqueio na minimização das VPONs são significantemente menores que as providas pela minimização da comutação de dados entre VDUs na Figura 10.14, até mesmo nas horas de pico da rede.

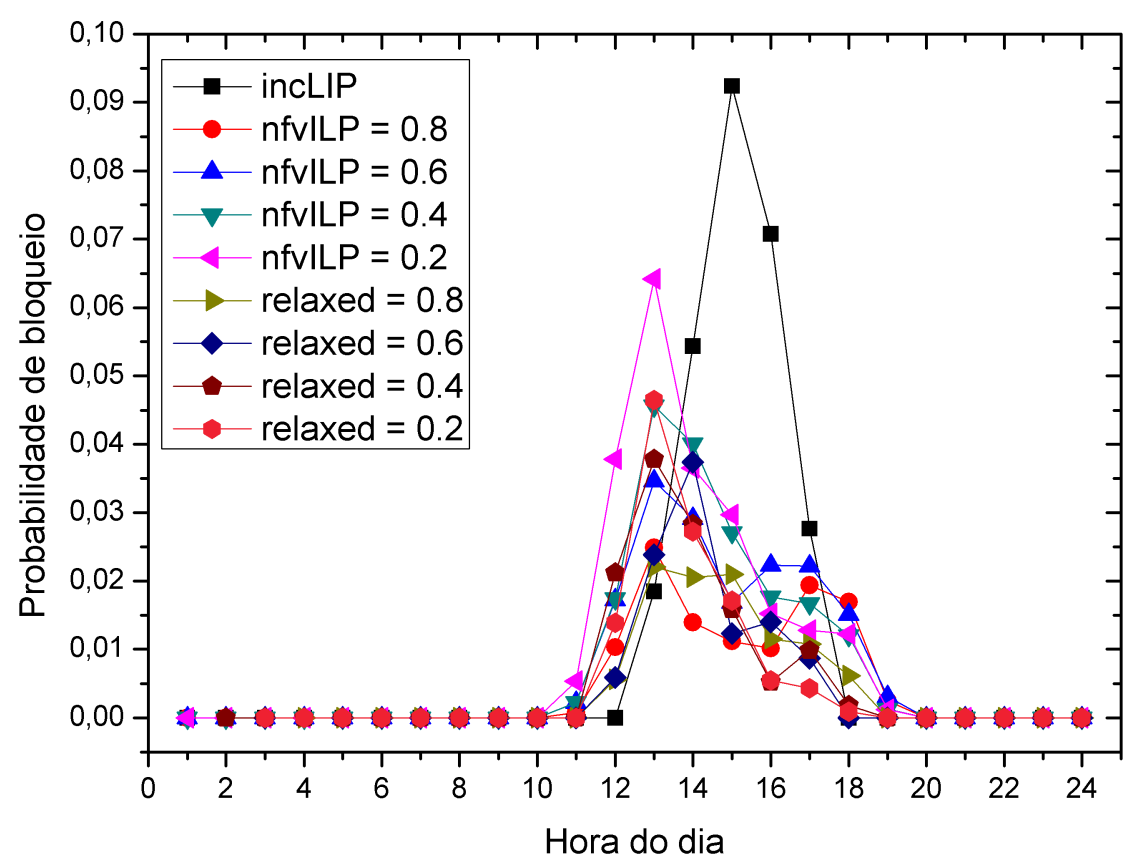

Figura 10.15: Probabilidade de bloqueio das relaxações e ILP no cenário dinâmico, política minVPON

A quantidade de migrações providas pelas relaxações são apresentadas nas Figuras 10.16 e 10.17. Note que com exceção do valor de threshold de 0,8 em ambas heurísticas relaxadas, as relaxações provêm um aumento significativo na quantidade de tráfego que é migrado de fog nodes para a nuvem, o que pode ser explicado pela característica das relaxações de sempre priorizarem a utilização da nuvem, o que acaba aumentando a quantidade de tráfego movido para ela quando o procedimento de migração é ativado.

Os tempos médios de interrupção dos serviços das vBBUs provido pelas relaxações relaxedMinRedir e relaxedMin VPON são apresentados nas Figuras 10.18 e 10.19, respectivamente. Em relação à heurística relaxedMinRedir, um aumento de aproximadamente $4 \mathrm{X}$ pode ser notado no tempo médio de interrupção dos serviços em relação à formulação ILP. Em relação à heurística relaxedMin VPON, o tempo médio de interrupção de serviços das vBBUs é reduzido em aproximadamente 2,6X em relação à formulação ILP. De acordo com as Figuras 10.16 e 10.17, é possível observar que a heurística relaxedMinVPON produz uma quantidade de migrações significativamente maior que a heurística relaxedMinRedir, o que reflete em tempos médios de interrupção de serviços das vBBUs relativamente maiores.

A probabilidade de interrupção dos serviços das vBBUs é apresentada em escala logarítmica na Figura 10.20 para a heurística relaxedMinRedir. É possível observar que a priorização da utilização da nuvem pelas heurísticas é capaz de diminuir a probabilidade de interrupção do serviço em até 3 


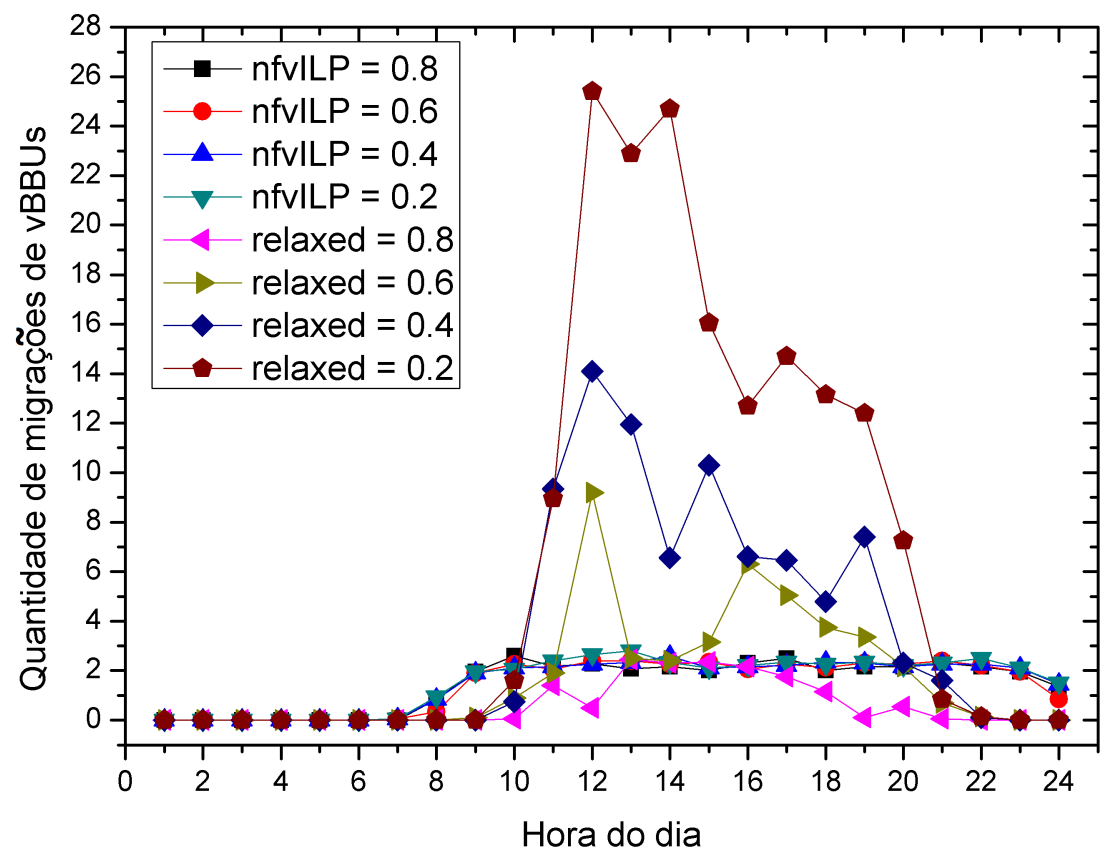

Figura 10.16: Quantidade de migrações das relaxações e ILP no cenário dinâmico, política minRedir

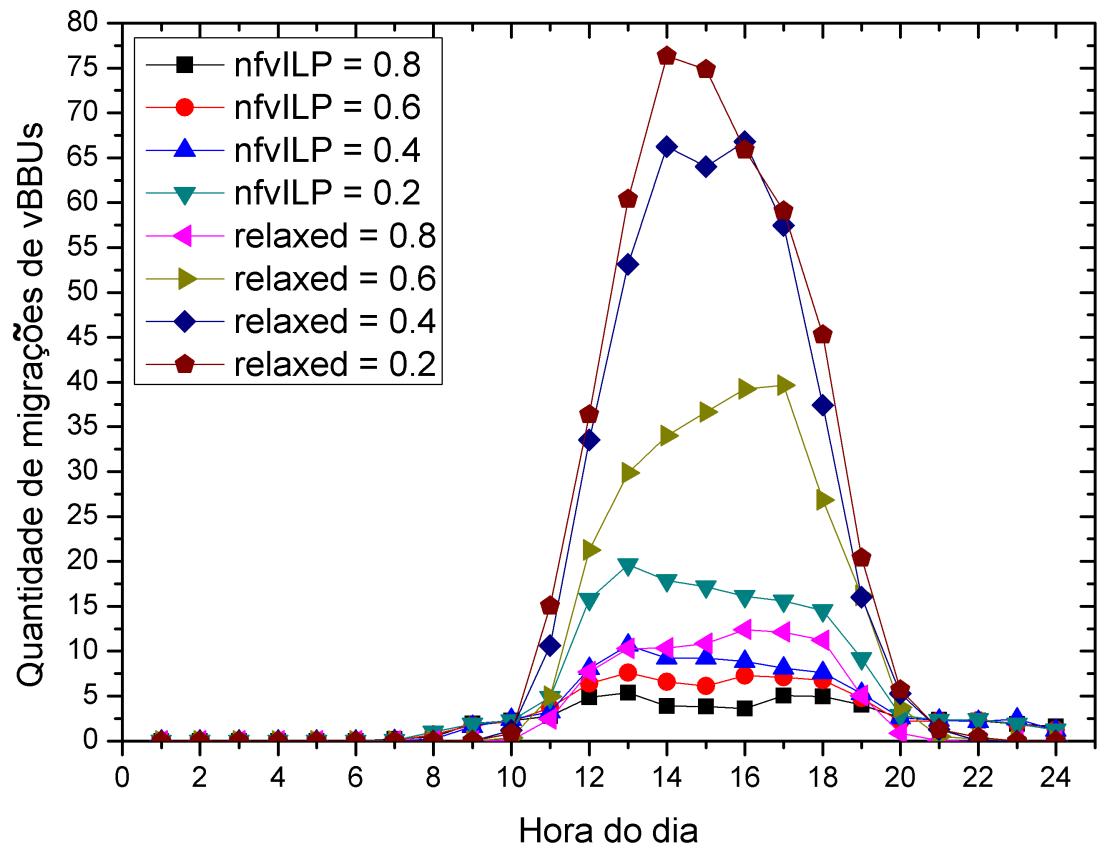

Figura 10.17: Quantidade de migrações das relaxações e ILP no cenário dinâmico, política minVPON

ordens de magnitude.

Comportamento semelhante pode ser observado nas probabilidades de interrupção de serviços providas pela heurística relaxedMin VPON na Figura 10.21, também em escala logarítmica. No caso dessa heurística, a redução em comparação à formulação ILP é ligeiramente menor que a heurística 


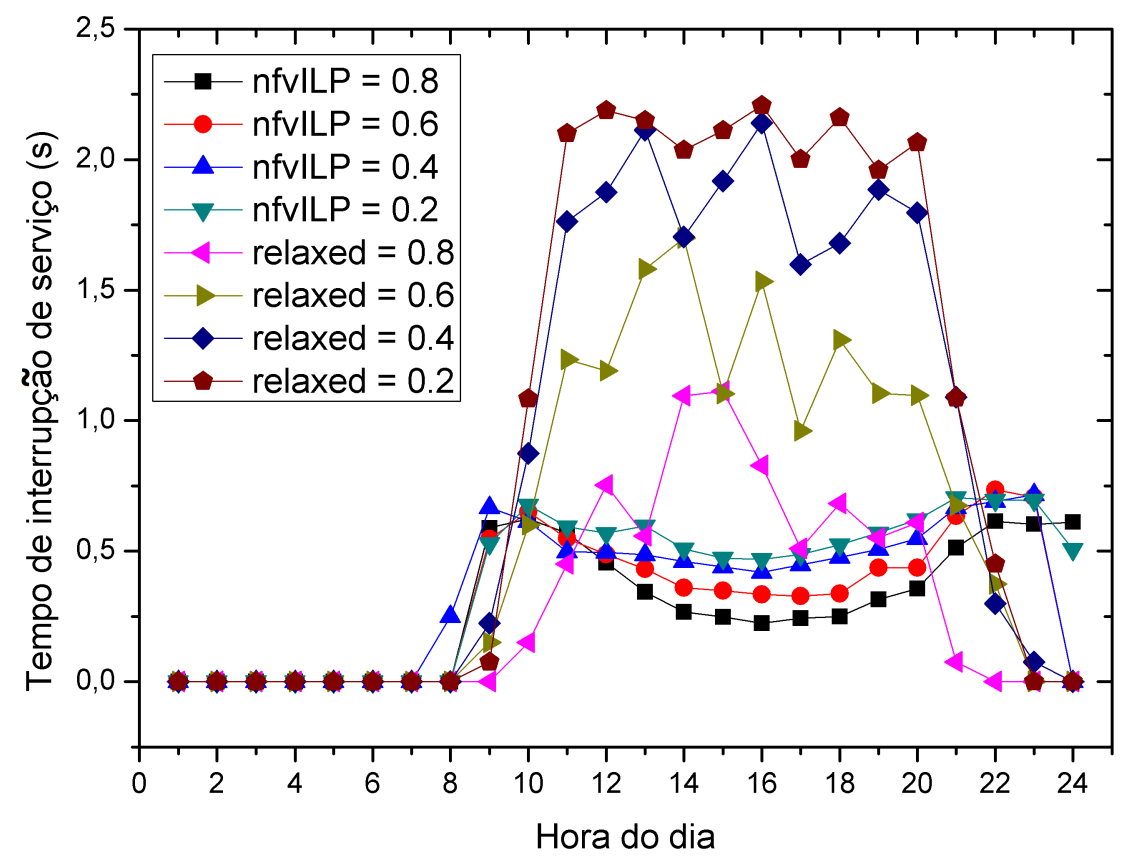

Figura 10.18: Tempo médio de interrupção de serviços das vBBUs das relaxações e ILP no cenário dinâamico, política minRedir

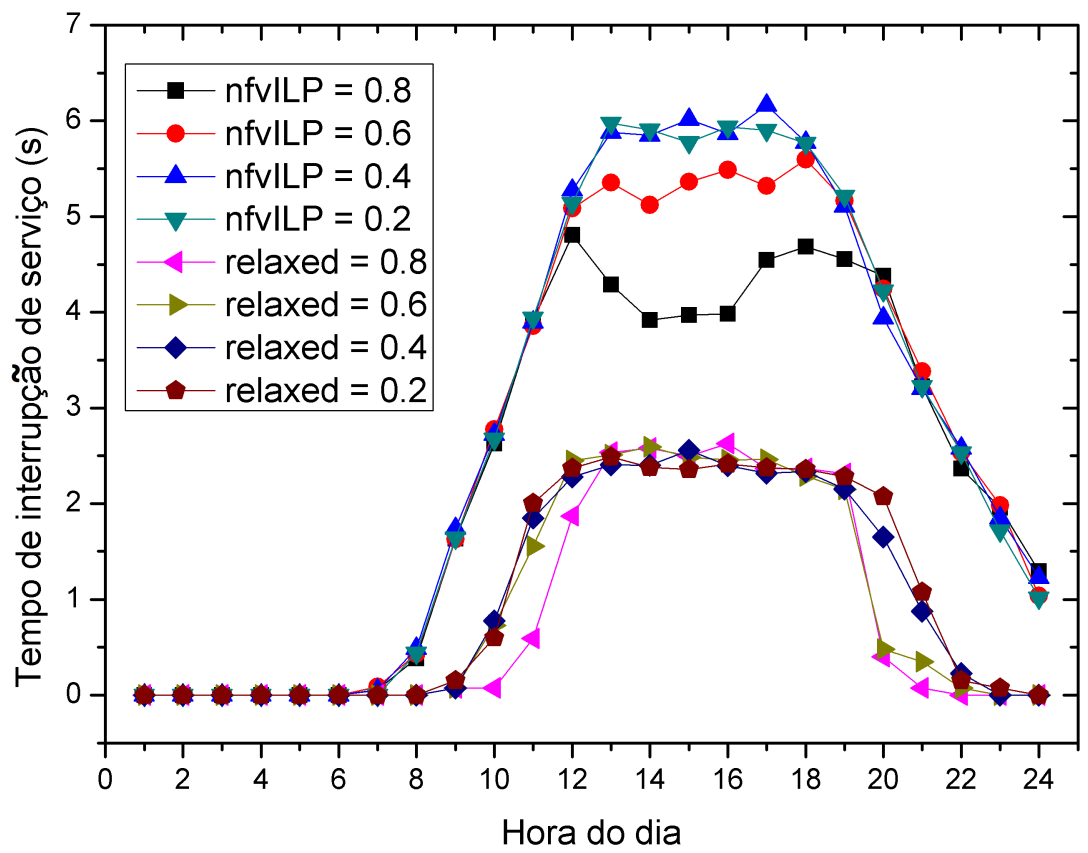

Figura 10.19: Tempo médio de interrupção de serviços das vBBUs das relaxações e ILP no cenário dinâmico, política min VPON

relaxedMinRedir, mas mesmo assim reduções entre 2 e 3 ordens de magnitude podem ser observadas.

A taxa de desperdício de largura de banda é apresentada nas Figuras 10.22 e 10.23, para as 


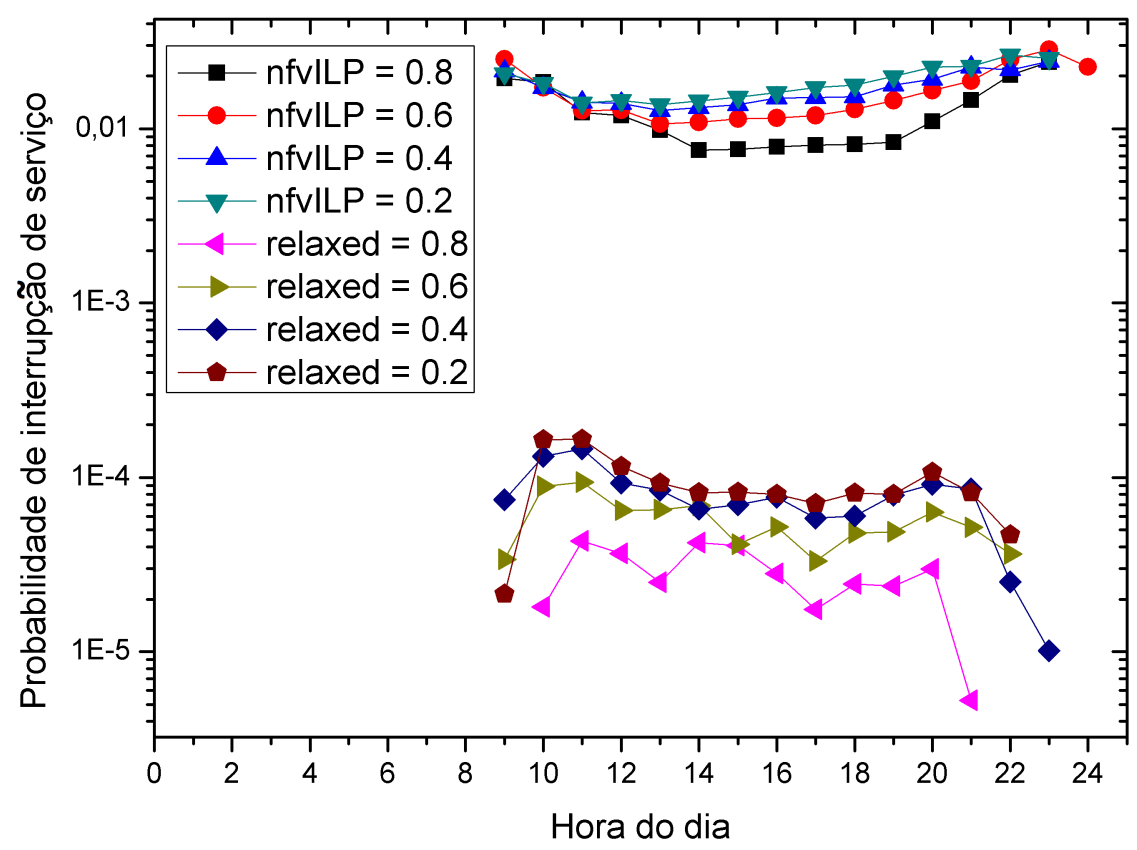

Figura 10.20: Probabilidade de interrupção de serviços das vBBUs das relaxações e ILP no cenário dinâmico, política minRedir, em escala logarítmica

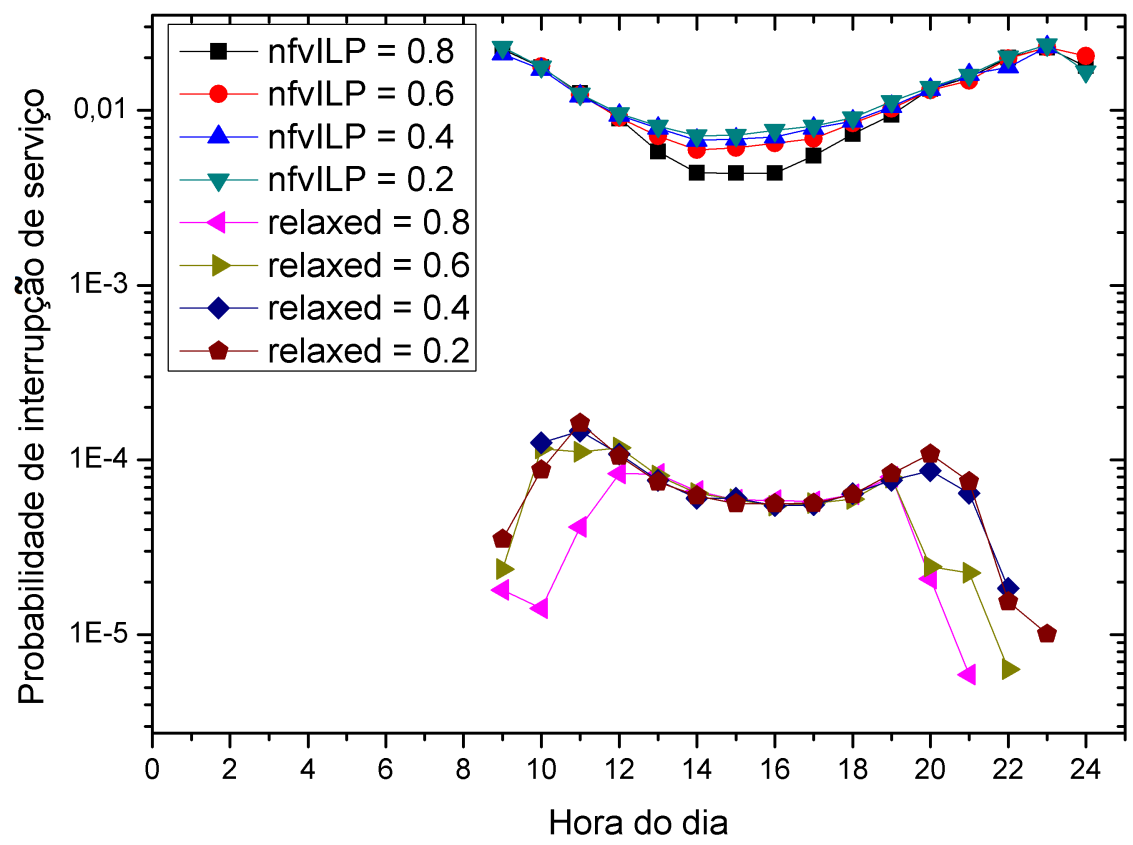

Figura 10.21: Probabilidade de interrupção de serviços das vBBUs das relaxações e ILP no cenário dinâmico, política min VPON, em escala logarítmica

heurísticas relaxedMinRedir e relaxedMinVPON, respectivamente. Comparando as duas heurísticas, a superioridade da heurística relaxedMin $V P O N$ é notável, provendo diminuições significativas 


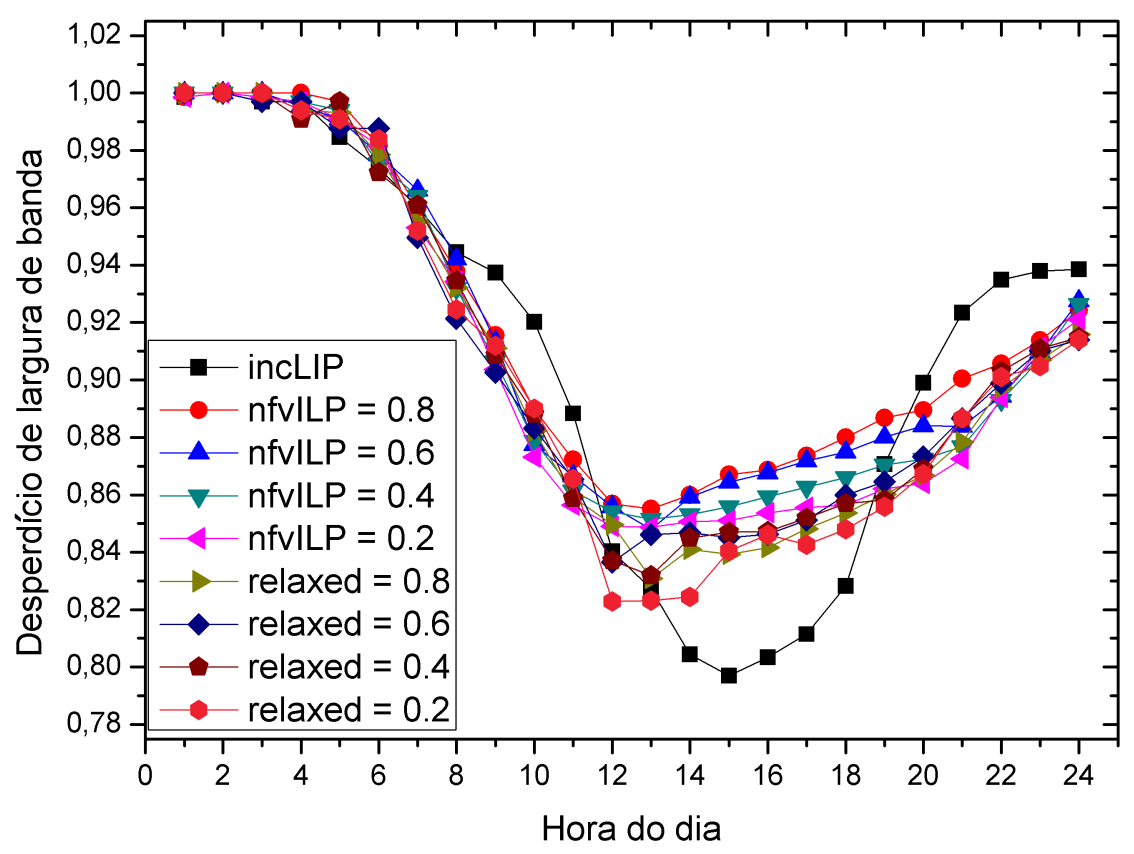

Figura 10.22: Desperdício de largura de banda das relaxaçôes e ILP no cenário dinâmico, política minRedir

no desperdício da banda em relação à heurística relaxedMinRedir. Isso ocorre pelo fato de, naturalmente, a heurística relaxedMin VPON buscar a minimização das VPONs alocadas. Em relação à aproximação das soluções providas pela formulação ILP, a heurística relaxedMinRedir é capaz de ligeiramente prover melhor utilização da banda. Em relação à heurística relaxedMinVPON, a formulação ILP provê uma melhor utilização da banda para todos os valores de threshold em relação à heurística relaxedMin VPON. Isso pode ser explicado pela característica da aleatoriedade na alocação dos recursos pela heurística relaxada, que considera a alocação de comprimentos de onda pelos valores reais que foram retornados nas variáveis de decisão pela execução da versão relaxada da formulação ILP.

Os tempos de execução são comparados nas Figuras 10.24 e 10.25. Para a política minRedir e a heurística relaxedMinRedir, há um grande ganho nos tempos de execução em comparação com os valores mais baixos de threshold, onde espera-se que mais vBBUs sejam migradas, aumentando assim o tamanho da instância do problema a ser resolvida. É possível observar que nos valores de threshold iguais a 0,8 e 0,6 a relaxação obteve desempenho inferior que a formulação ILP. Isso se deve ao fato de no cenário dinâmico existir grande variação do tamanho da entrada do problema. Em relação política min VPON e a heurística relaxedMin VPON, de forma geral as relaxações apresentam reduções significantes nos tempos de execução, especialmente uma redução de até $13 \mathrm{X}$ em relação à formulação ILP para o valor de threshold de 0,2 .

Entretanto, como em um cenário dinâmico há muita variação no tamanho da instância do problema durante a execução das simulações, muitas vezes os tempos comparados podem se referir a diferentes tamanhos de entrada do problema, fazendo com que análises dos tempos de execuções nesses cenários dinâmicos não sejam completamente confiáveis. Dessa forma, a análise dos tempos de execução realizada no cenário de tráfego estático é muito mais acurada em mostrar os ganhos pro- 


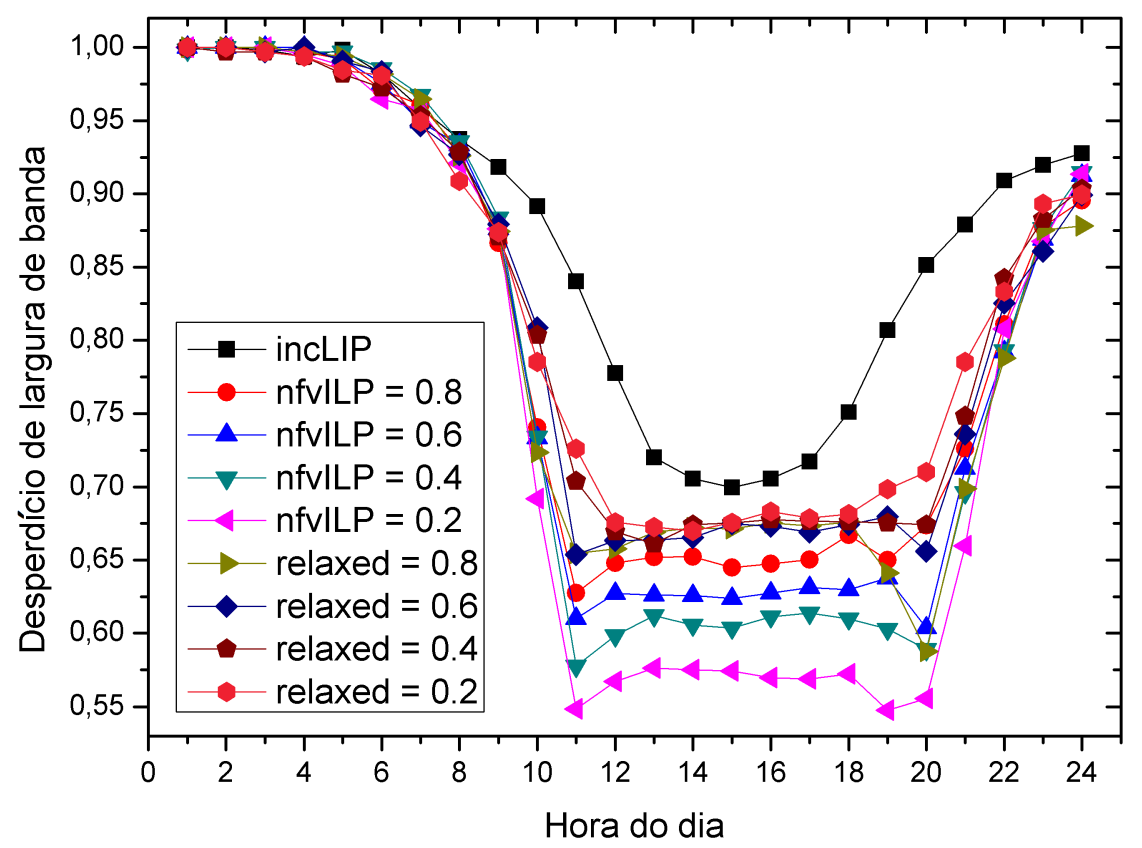

Figura 10.23: Desperdício de largura de banda das relaxações e ILP no cenário dinâmico, política min VPON

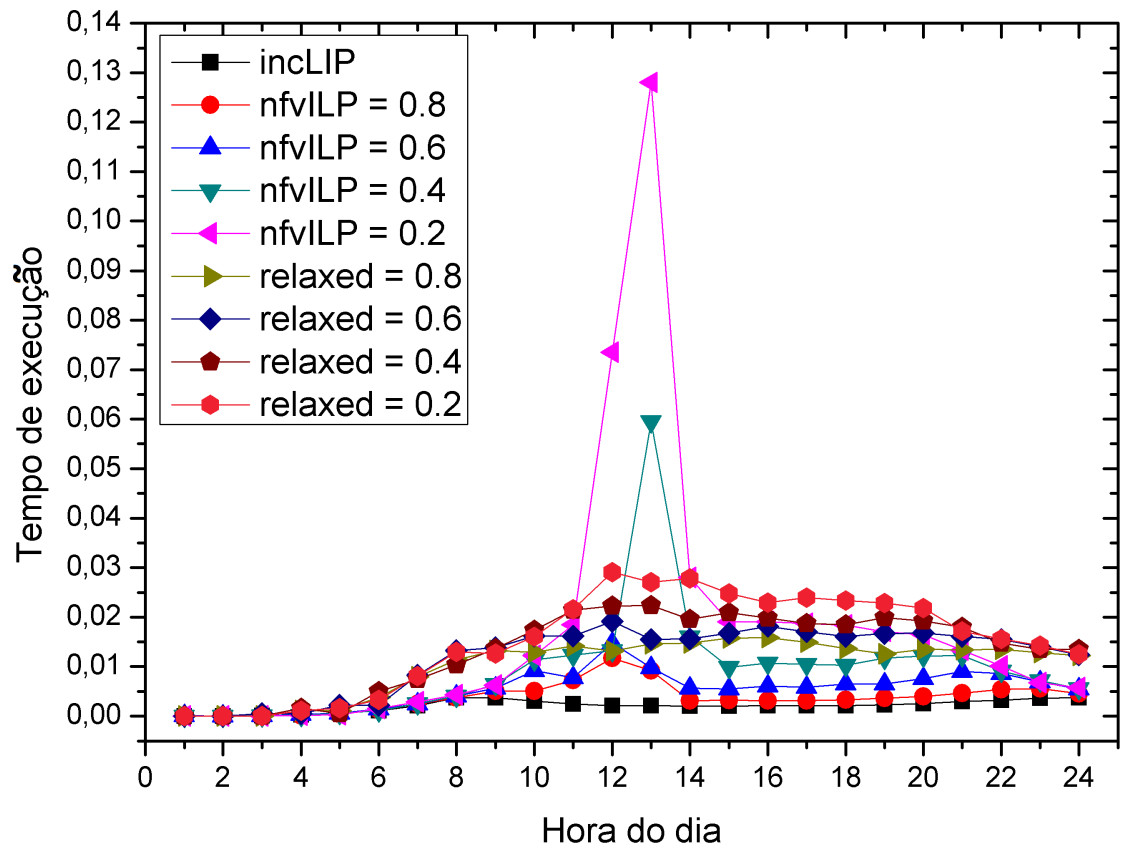

Figura 10.24: Tempos de execução das relaxações e ILP no cenário dinâmico, política minRedir

vidos pela utilização das relaxações e como sua complexidade computacional cresce com o tamanho da entrada do problema a ser resolvido. 


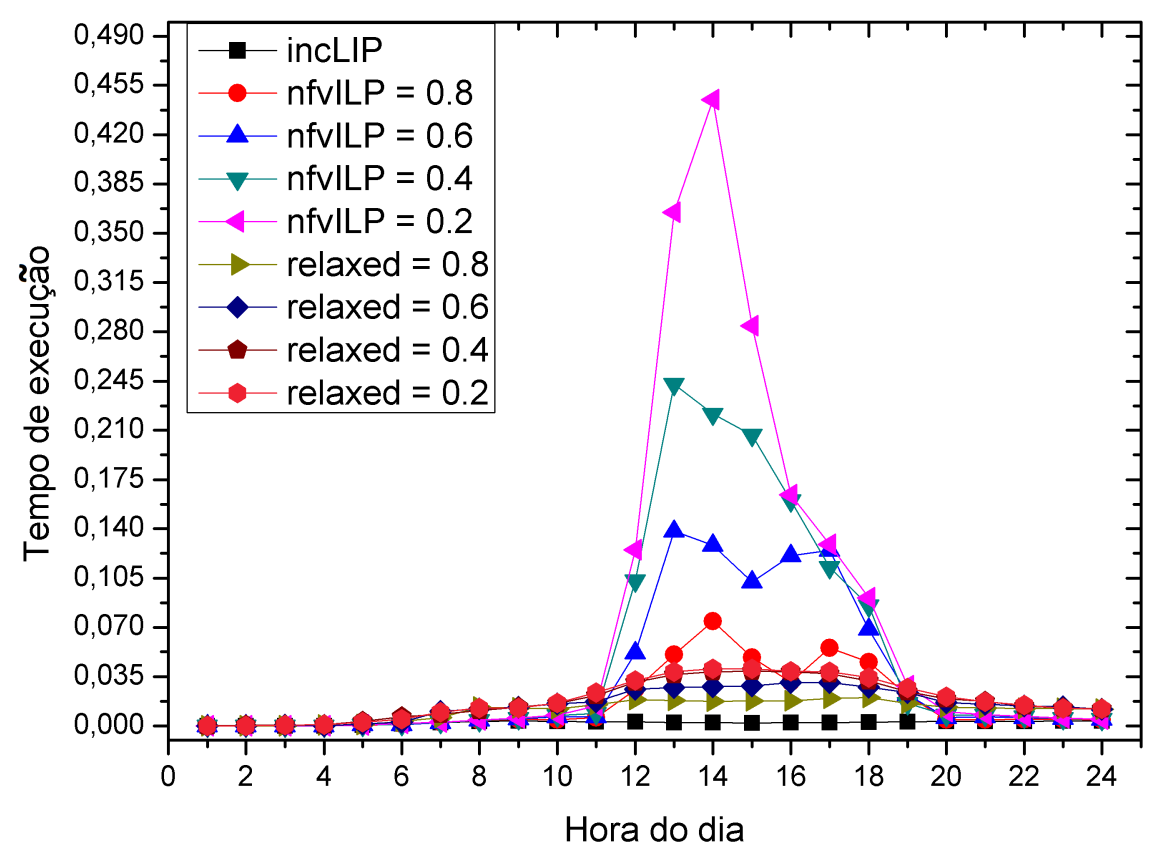

Figura 10.25: Tempos de execução das relaxações e ILP no cenário dinâmico, política minVPON

\subsubsection{Discussão}

Nesta seção o desempenho das heurísticas baseadas na relaxação da formulação ILP foi avaliado em um cenário de tráfego dinâmico. Foi observado que, semelhantemente ao cenário de tráfego estático, as heurísticas baseadas em relaxação são capazes de prover soluções muito próximas daquelas providas pela formulação ILP sob ambas políticas minRedir e minVPON. Entretanto, o tempo de execução das heurísticas relaxadas é drasticamente menor em comparação com os tempos de execução da formulação ILP, especialmente em cenários com um tamanho de entrada consideravelmente grande e principalmente em comparação com a política minRedir, que é a política da formulação ILP com maior tempo de execução por conta de ter que otimizar mais variáveis de decisão para que o redirecionamento de tráfego entre VDUs seja minimizado. Em resumo, a utilização das relaxações pode diminuir o tempo para obtenção de uma solução em até $13 \mathrm{X}$. 


\section{Capítulo 11}

\section{Conclusões}

Esta Tese introduziu uma nova arquitetura de rede de acesso a rádio baseada em computação em nuvem e névoa chamada de CF-RAN. A arquitetura CF-RAN é uma arquitetura eficiente em termos de consumo de energia, disponibilidade de banda e latência. Nossos resultados mostraram que, por meio da utilização de um fronthaul suportado por uma rede TWDM-PON, é possível prover a banda necessária para a transmissão de requisições CPRI em redes de pequena e grande escala ao mesmo tempo em que as restrições de latência são atendidas. Além disso, a proposta da arquitetura CF-RAN baseou-se fortemente na virtualização tanto dos recursos computacionais (vBBUs) quanto dos canais de transmissão ópticos (VPONs).

O problema de alocação de vBBUs e de dimensionamento dos comprimentos de onda foi introduzido nesta Tese para que os recursos de rede e de processamento da CF-RAN pudessem ser eficientemente utilizados. Por meio de uma formulação ILP e da heurística CF-FL, foi possível atestar o desempenho energético superior da CF-RAN em comparação com a arquitetura DRAN em cenários de tráfego estático. Além disso, a heurística CF-FL foi capaz de obter soluções ótimas e sub-ótimas em comparação com a formulação ILP, porém com grandes reduções no tempo de execução em cenários de larga escala.

Quanto à operação dinâmica da rede, as heurísticas ML, LL e FgF foram propostas para avaliar o desempenho da CF-RAN frente à dinamicidade da chegada e saída de requisições CPRI. Os resultados mostraram que, apesar da arquitetura CRAN sempre prover o menor consumo energético, sua cobertura de rede é limitada em cenários de maior carga de trabalho e, nesse contexto, a arquitetura CF-RAN provê as menores probabilidades de bloqueio das requisições CPRI. Foi observado também que a utilização prioritária dos fog nodes provê a melhor cobertura aos usuários móveis, provendo as menores probabilidades de bloqueio em relação à utilização prioritária da nuvem. Entretanto, tal vantagem demanda o maior custo energético da rede, podendo tornar a operação da rede proibitiva em termos dos custos energéticos. Por meio da avaliação dos trade offs entre o consumo de energia, probabilidade de bloqueio e latência, pode-se concluir que a priorização da nuvem sobre os fog nodes provê a operação mais balanceada da rede em relação às métricas citadas.

O impacto da migração das cargas de trabalho entre os fog nodes e a nuvem e da reconfiguração dos nós destino das VPONs também foi avaliado. Por meio da proposta de uma nova formulação ILP e heurísticas baseadas na relaxação linear dessa formulação, foi observado que, quando a migração das cargas de trabalho é realizada, o consumo energético, a probabilidade de bloqueio e a utilização da banda disponível podem ser otimizados. Nesse contexto, existe um trade off entre a minimização da criação de VPONs e da comutação entre VDU de um nó de processamento. A minimização das 
VPONs durante a migração das cargas de trabalho provê um consumo energético um pouco superior ao provido pela minimização da comutação entre VDUs, entretanto, para que essa comutação seja minimizada, faz-se necessário que mais banda, ou VPONs, sejam alocados em um mesmo nó de processamento, o que em longo prazo aumenta a probabilidade de bloqueio da rede por conta da centralização de VPONs em poucos nós de processamento. Além disso, a minimização das VPONs também provê uma utilização mais eficiente da banda disponível, provendo assim uma operação mais balanceada do que a minimização da comutação entre VDUs. Os algoritmos de migração propostos também foram capazes de prover baixa probabilidade de interrupção dos serviços das vBBUs, fazendo com que a interrupção dos serviços diminuísse conforme a carga da rede aumentasse. Em relação às relaxações, elas foram capazes de prover soluções muito próximas àquelas providas pela formulação ILP, porém com reduções muito grandes nos tempos de execução.

\subsection{Trabalhos futuros}

Muitas oportunidades de pesquisa surgem a partir dos resultados obtidos nesta Tese de doutorado.

Do ponto de vista algorítmico, novas heurísticas podem ser propostas para reduzir ainda mais os tempos de execução e a qualidade das soluções apresentadas nesta Tese. Em relação ao esgotamento da capacidade da nuvem e do fronthaul, há uma nova tendência que busca realizar o particionamento do processamento dos sinais de banda-base. Diferentemente da utilização dos fog nodes proposta nesta Tese, onde os mesmos só são ativados quando há esgotamento da nuvem ou do fronthaul, o particionamento do processamento pode ser investigado para propor uma operação de rede mais balanceada entre o consumo dos recursos da nuvem, do fronthaul e o consumo energético da rede. O particionamento pode ser utilizado para deixar a nuvem com maior capacidade para receber requisições que demandam maior poder computacional, ou até mesmo para reservar o uso dos fog nodes para o processamento da porção de processamento de banda-base mais sensível à latência das requisições CPRI. De toda forma, faz-se necessário que este tema seja investigado com maior cautela e novas formulações ILP e heurísticas sejam propostas para o tratamento desse problema.

Outro problema importante que envolve o escalonamento dos recursos da rede diz respeito ao escalonamento de recursos para processamento de técnicas baseadas em CoMP. Como já citado no Capítulo 2, esse escalonamento já vem sendo tratado na arquitetura CRAN, entretanto, faz-se necessário que esta técnica seja explorada em arquiteturas híbridas como a própria CF-RAN.

Em relação ao estudo da utilização de redes ópticas no suporte a redes $5 \mathrm{G}$, a emergente tecnologia de redes ópticas elásticas é uma nova tendência que demanda a atenção dos pesquisadores em relação ao seus benefícios no suporte a uma arquitetura CRAN ou CF-RAN. Como foi observado nos nossos resultados, o desperdício da banda utilizada pode ser diminuído por meio de nossos algoritmos, entretanto, notou-se que ainda existe um desperdício considerável da banda utilizada. Esse desperdício poderia ser ainda mais diminuído, ou até mesmo mitigado pela utilização de redes ópticas elásticas, onde o tamanho da frequência dos canais de transmissão é decidido de forma dinâmica em função da largura de banda demandada pelas requisições CPRI. Como a largura de banda demandada pelas requisições CPRI pode variar entre 614, 4Mbps e 24, 3Gbps em decorrência das configurações MIMO dos RRHs, a criação de VPONs de tamanhos dinâmicos pode ser benéfica para a utilização geral da banda disponível. 
Por fim, outra direção futura do trabalho realizado é o estudo da implantação do backhaul na CF-RAN. Nesse contexto, a implantação do backhaul torna-se mais complicada em termos arquiteturais do que a sua utilização em uma arquitetura CRAN, onde os enlaces que levam a ele podem sair da nuvem. Como na CF-RAN há a presença dos fog nodes, uma forma de interligar todos os nós de processamento ao backhaul por uma única rede de transporte óptica deve ser investigada. Nesse contexto, seria interessante propor a interconexão dos fog nodes por uma rede óptica ativa que pudesse ser ligada ao backhaul. Além dessa proposta arquitetural, novos algoritmos também seriam necessários para alocar os recursos que seriam utilizados para transmitir ao backhaul. 
118 CONCLUSÕES 


\section{Referências Bibliográficas}

[AIM10] Luigi Atzori, Antonio Iera e Giacomo Morabito. The internet of things: A survey. Computer networks, 54(15):2787-2805, 2010. 1

[All18] NGMN Alliance. Ngmn overview on 5g ran functional decomposition. Next Generation Mobile Networks Ltd., Feb, 24, 2018. 11

[ATM17] Isiaka Ajewale Alimi, António Luís Teixeira e Paulo Pereira Monteiro. Toward an efficient c-ran optical fronthaul for the future networks: a tutorial on technologies, requirements, challenges, and solutions. IEEE Communications Surveys $\&$ Tutorials, 20(1):708-769, 2017. 2

[BdFMG08] Daniel M Batista, Nelson LS da Fonseca, Flavio K Miyazawa e Fabrizio Granelli. Self-adjustment of resource allocation for grid applications. Computer Networks, 52(9):1762-1781, 2008. 6

[Ber14] David Bernstein. Containers and cloud: From lxc to docker to kubernetes. IEEE Cloud Computing, 1(3):81-84, 2014. 5

[BMZA12] Flavio Bonomi, Rodolfo Milito, Jiang Zhu e Sateesh Addepalli. Fog computing and its role in the internet of things. Em Proceedings of the first edition of the MCC workshop on Mobile cloud computing, páginas 13-16. ACM, 2012. 4

$\left[\mathrm{CFH}^{+}\right.$05] Christopher Clark, Keir Fraser, Steven Hand, Jacob Gorm Hansen, Eric Jul, Christian Limpach, Ian Pratt e Andrew Warfield. Live migration of virtual machines. Em Proceedings of the 2nd conference on Symposium on Networked Systems Design 8 Implementation-Volume 2, páginas 273-286. USENIX Association, 2005. 72

[Cis] Cisco - Complete Visual Networking Index (VNI) Forecast. http://www.cisco. $\mathrm{com} / \mathrm{c} / \mathrm{en} / \mathrm{us} /$ solutions/collateral/service-provider/visual-networking-index-vni/ vni-hyperconnectivity-wp.html. Último acesso: 17/11/2016. 1

$\left[\mathrm{CJC}^{+} 18\right]$ Xiaoting Cui, Yanxiang Jiang, Xuan Chen, Fuchun Zhengy e Xiaohu You. Graphbased cooperative caching in fog-ran. Em 2018 International Conference on Computing, Networking and Communications (ICNC), páginas 166-171. IEEE, 2018. 12

[CLRS09] Thomas H Cormen, Charles E Leiserson, Ronald L Rivest e Clifford Stein. Introduction to algorithms. MIT press, 2009. 43

$\left[\mathrm{CNW}^{+} 12\right]$ Hafedh Chourabi, Taewoo Nam, Shawn Walker, J Ramon Gil-Garcia, Sehl Mellouli, Karine Nahon, Theresa A Pardo e Hans Jochen Scholl. Understanding smart cities: An integrative framework. Em 2012 45th Hawaii international conference on system sciences, páginas 2289-2297. IEEE, 2012. 1

[CPR] CPRI - Common Public Radio Interface. http://www.cpri.info/. Last Access: 02/02/2017. 3

[CSI07] Ivica Cale, Aida Salihovic e Matija Ivekovic. Gigabit passive optical network-gpon. 
Em 2007 29th International Conference on Information Technology Interfaces, páginas 679-684. IEEE, 2007. 18

[CSK16] Di Chen, Stephan Schedler e Volker Kuehn. Backhaul traffic balancing and dynamic content-centric clustering for the downlink of fog radio access network. Em IEEE 17th SPAWC, páginas 1-5, 2016. 12

[CTP14] Nicola Carapellese, Massimo Tornatore e Achille Pattavina. Energy-efficient baseband unit placement in a fixed/mobile converged wdm aggregation network. IEEE Journal on Selected Areas in Communications, 32(8):1542-1551, 2014. 9

[DC02] JM Valério De Carvalho. Lp models for bin packing and cutting stock problems. European Journal of Operational Research, 141(2):253-273, 2002. 5, 39

[DlOHLA16] Antonio De la Oliva, José Alberto Hernández, David Larrabeiti e Arturo Azcorra. An overview of the cpri specification and its application to c-ran-based lte scenarios. IEEE Communications Magazine, 54(2):152-159, 2016. 3

[dSTFB19] Matias R P dos Santos, Rodrigo I Tinini, Gustavo B Figueiredo e Daniel M Batista. Data analysis and energy consumption prediction in a cloud-fog ran environment. Em 2019 11th IEEE Latin-American Conference on Communications (LATINCOM), páginas 1-6. IEEE, 2019. 8

[EIY01] Frank J Effenberger, Hiroshi Ichibangase e Haruo Yamashita. Advances in broadband passive optical networking technologies. IEEE Communications Magazine, 39(12):118-124, 2001. 18

[EM00] Jaafar MH Elmirghani e Hussein T Mouftah. All-optical wavelength conversion: technologies and applications in dwdm networks. IEEE Communications Magazine, 38(3):86-92, 2000. 15

[EMPP09] Frank J Effenberger, Hiroaki Mukai, Soojin Park e Thomas Pfeiffer. Next-generation pon-part ii: candidate systems for next-generation pon. IEEE Communications $M a-$ gazine, 47(11):50-57, 2009. 19

[FB05] Adrian Farrel e Igor Bryskin. GMPLS: architecture and applications. Elsevier, 2005. 16

[FT07] Yijia Fan e John Thompson. Mimo configurations for relay channels: Theory and practice. IEEE Transactions on Wireless Communications, 6(5):1774-1786, 2007. 4

[FWM $\left.{ }^{+} 16\right]$ G. B. Figueiredo, X. Wang, C. C. Meixner, M. Tornatore e B. Mukherjee. Load balancing and latency reduction in multi-user CoMP over TWDM-VPONs. Em 2016 IEEE International Conference on Communications (ICC), páginas 1-6, May 2016. $4,5,9,10,39$

[FXDF12] Gustavo B Figueiredo, Eduardo Candido Xavier e Nelson LS Da Fonseca. Optimal algorithms for the batch scheduling problem in obs networks. Computer Networks, 56(14):3274-3286, 2012. 6

[Gor00] Walter J Goralski. ADSL and DSL technologies. McGraw-Hill, Inc., 2000. 16

[GPC02] Nasir Ghani, Jin-Yi Pan e Xin Cheng. Metropolitan optical networks. Em Optical Fiber Telecommunications IV-B, páginas 329-403. Elsevier, 2002. 16

[HRTA14] Ekram Hossain, Mehdi Rasti, Hina Tabassum e Amr Abdelnasser. Evolution toward $5 \mathrm{~g}$ multi-tier cellular wireless networks: An interference management perspective. IEEE Wireless Communications, 21(3):118-127, 2014. 1 
[HSMA14] Hassan Hawilo, Abdallah Shami, Maysam Mirahmadi e Rasool Asal. NFV: state of the art, challenges, and implementation in next generation mobile networks (vepc). IEEE Network, 28(6):18-26, 2014. 5

[IDM $\left.{ }^{+} 11\right]$ Ralf Irmer, Heinz Droste, Patrick Marsch, Michael Grieger, Gerhard Fettweis, Stefan Brueck, Hans-Peter Mayer, Lars Thiele e Volker Jungnickel. Coordinated multipoint: Concepts, performance, and field trial results. IEEE Communications Magazine, 49(2):102-111, 2011. 1, 3

[JMT07] Brigitte Jaumard, Christophe Meyer e Babacar Thiongane. Comparison of ilp formulations for the rwa problem. Optical Switching and Networking, 4(3-4):157-172, 2007. 5

[Kal02] Charles Kalmanek. A retrospective view of atm. ACM SIGCOMM Computer Communication Review, 32(5):13-19, 2002. 18

$\left[\mathrm{KBC}^{+}\right.$09] Jun-ichi Kani, Fabrice Bourgart, Anna Cui, Albert Rafel, Malcolm Campbell, Russell Davey e Silvana Rodrigues. Next-generation pon-part i: Technology roadmap and general requirements. IEEE Communications Magazine, 47(11):43-49, 2009. 19

[Kei06] Gerd Keiser. Fttx concepts and applications. 2006. 16

[KP02] Glen Kramer e Gerry Pesavento. Ethernet passive optical network (epon): building a next-generation optical access network. IEEE Communications magazine, 40(2):6673, 2002. 18

[Kra05] Glen Kramer. What is Passive Optical Network? McGraw-Hill, 2005. 17

[KSG+ $\left.{ }^{+} 7\right]$ Leonid G Kazovsky, Wei-Tao Shaw, David Gutierrez, Ning Cheng e Shing-Wa Wong. Next-generation optical access networks. Journal of lightwave technology, 25(11):34283442, 2007. 16

[LBG08] Christoph Lange, Mario Braune e Nikolaus Gieschen. On the energy consumption of $\mathrm{fttb}$ and ftth access networks. Em National Fiber Optic Engineers Conference, página JWA105. Optical Society of America, 2008. 17

[LHS03] David J Love, Robert W Heath e Thomas Strohmer. Grassmannian beamforming for multiple-input multiple-output wireless systems. IEEE transactions on information theory, 49(10):2735-2747, 2003. 3

[LSPS09] Joachim Lohr, Eiko Seidel, Dragan Petrovic e Hidetoshi Suzuki. Harq protocol with synchronous retransmissions, Março 24 2009. US Patent 7,509,554. 3, 25

$\left[\mathrm{LZE}^{+} 12\right]$ Yuanqiu Luo, Xiaoping Zhou, Frank Effenberger, Xuejin Yan, Guikai Peng, Yinbo Qian e Yiran Ma. Time-and wavelength-division multiplexed passive optical network (twdm-pon) for next-generation pon stage 2 (ng-pon2). Journal of lightwave technology, 31(4):587-593, 2012. 3, 19

$\left[\mathrm{LZG}^{+} 15\right]$ J. Liu, S. Zhou, J. Gong, Z. Niu e S. Xu. Graph-based framework for flexible baseband function splitting and placement in C-RAN. Em 2015 IEEE International Conference on Communications (ICC), páginas 1958-1963, June 2015. 11

$\left[\mathrm{MBC}^{+} 16\right]$ Francesco Musumeci, Camilla Bellanzon, Nicola Carapellese, Massimo Tornatore, Achille Pattavina e Stéphane Gosselin. Optimal bbu placement for 5g c-ran deployment over wdm aggregation networks. Journal of Lightwave Technology, 34(8):19631970, 2016. 2 
$\left[\mathrm{MBT}^{+}\right.$17] Francesco Musumeci, Camilla Bellanzon, Massimo Tornatore, Achille Pattavina e Jose Torrijos Gijon. Enhancing ran throughput by optimizec controller placement in optical metro networks. Em 2017 IEEE International Conference on Communications (ICC), páginas 1-6. IEEE, 2017. 4

[mJGJ96] EG Co man Jr, MR Garey e DS Johnson. Approximation algorithms for bin packing: A survey. Approximation algorithms for NP-hard problems, páginas 46-93, 1996. 36

[MTM07] E Mehdizadeh e Reza Tavakkoli-Moghaddam. A new ilp model for identical parallelmachine scheduling with family setup times minimizing the total weighted flow time by a genetic algorithm. International Journal of Engineering, 20(2):183-194, 2007. 5

[Muk97] Biswanath Mukherjee. Optical communication networks. McGraw-Hill Companies, 1997. 15

[Muk00] Biswanath Mukherjee. Wdm optical communication networks: progress and challenges. IEEE Journal on Selected Areas in communications, 18(10):1810-1824, 2000. 15

[Net15] NGMN Next Generation Mobile Networks. Project ran evolution: Backhaul and fronthaul evolution, 2015. 26

[NYW15] Huaning Niu, Hujun Yin e Geng Wu. Remote radio unit (rru) and base band unit (bbu), Agosto 18 2015. US Patent 9,112,758. 1

$\left[\mathrm{P}^{+} 08\right]$ Josep Prat et al. Next-generation ftth passive optical networks. Springer Science+ Business Media B., 5, 2008. 16

[PJ93] Roy P Pargas e Rajat Jain. A parallel stochastic optimization algorithm for solving $2 \mathrm{~d}$ bin packing problems. Em Proceedings of 9th IEEE Conference on Artificial Intelligence for Applications, páginas 18-25. IEEE, 1993. 36

$\left[\mathrm{PLJ}^{+}\right.$14a] Mugen Peng, Yuan Li, Jiamo Jiang, Jian Li e Chonggang Wang. Heterogeneous cloud radio access networks: A new perspective for enhancing spectral and energy efficiencies. IEEE Wireless Communications, 21(6):126-135, 2014. 1

$\left[\mathrm{PLJ}^{+}\right.$14b] Mugen Peng, Yuan Li, Jiamo Jiang, Jian Li e Chonggang Wang. Heterogeneous cloud radio access networks: a new perspective for enhancing spectral and energy efficiencies. IEEE Wireless Communications, 21(6):126-135, 2014. 11

$\left[\mathrm{PLL}^{+} 11\right]$ Chunyi Peng, Suk-Bok Lee, Songwu Lu, Haiyun Luo e Hewu Li. Traffic-driven power saving in operational $3 \mathrm{~g}$ cellular networks. Em Proceedings of the 17th annual international conference on Mobile computing and networking, páginas 121-132. ACM, 2011. 5, 60, 69

$\left[\mathrm{PLW}^{+} 11\right]$ Mugen Peng, Yang Liu, Dongyan Wei, Wenbo Wang e Hsiao-Hwa Chen. Hierarchical cooperative relay based heterogeneous networks. IEEE Wireless Communications, 18(3), 2011. 2

[RDA $\left.{ }^{+} 18\right]$ Mateus Riva, Henrique Donâncio, Felipe R Almeida, Gustavo B Figueiredo, Rodrigo I Tinini, Roberto M Cesar Jr e Daniel M Batista. An elastic optical network-based architecture for the 5g fronthaul. Em Anais do XXXVI Simpósio Brasileiro de Redes de Computadores e Sistemas Distribuídos. SBC, 2018. 8

[rGPPG13] 3GPP The 3rd Generation Partnership Project (3GPP). Lte-advanced, 2013. 1

[rGPPG19] 3GPP The 3rd Generation Partnership Project (3GPP). 3gpp specification set: 5g, 2019. 1 
[RSS09] Rajiv Ramaswami, Kumar Sivarajan e Galen Sasaki. Optical networks: a practical perspective. Morgan Kaufmann, 2009. 3, 15

[SM07] Darren P Shea e John E Mitchell. Long-reach optical access technologies. IEEE Network, 21(5):5-11, 2007. 16

[SS91] Paul W Shumate e Richard K Snelling. Evolution of fiber in the residential loop plant. IEEE Communications Magazine, 29(3):68-74, 1991. 17

[TA15] Keiji Tanaka e Akira Agata. Next-generation optical access networks for c-ran. Em Optical Fiber Communication Conference, páginas Tu2E-1. Optical Society of America, 2015. 2

[TBF18] R. I. Tinini, D. M. Batista e G. B. Figueiredo. Energy-efficient VPON formation and wavelength dimensioning in Cloud-Fog RAN over TWDM-PON. Em 2018 IEEE Symposium on Computers and Communications (ISCC), páginas 521-526, June 2018. $8,23,35$

$\left[\mathrm{TBF}^{+}\right.$19a] Rodrigo Izidoro Tinini, Daniel M. Batista, Gustavo Bittencourt Figueiredo, Massimo Tornatore e Biswanath Mukherjee. Energy-Efficient BaseBand processing via vBBU migration in virtualized Cloud-Fog RAN. Em 2019 IEEE Global Communications Conference: Optical Networks and Systems (Globecom2019 ONS), Waikoloa, USA, Dezembro 2019. 7, 69, 87

$\left[\mathrm{TBF}^{+}\right.$19b] Rodrigo Izidoro Tinini, Daniel Macêdo Batista, Gustavo Bittencourt Figueiredo, Massimo Tornatore e Biswanath Mukherjee. Low-latency and energy-efficient bbu placement and vpon formation in virtualized cloud-fog ran. IEEE/OSA Journal of Optical Communications and Networking, 11(4):B37-B48, 2019. 7, 23, 41

[TEK88] Rodney S Tucker, Gadi Eisenstein e Steven K Korotky. Optical time-division multiplexing for very high bit-rate transmission. Journal of lightwave technology, 6(11):17371749, 1988. 20

[TFB19] Rodrigo Izidoro Tinini, Gustavo Bittencourt Figueiredo e Daniel M. Batista. A Batch Scheduling Algorithm for VPON Reconfiguration and BBU Migration in Hybrid Cloud-Fog RAN. Em The 18th IEEE International Symposium on Network Computing and Applications (NCA 2019), Cambridge, USA, Setembro 2019. 7, 69

[TJ91] Sirin Tekinay e Bijan Jabbari. Handover and channel assignment in mobile cellular networks. IEEE Communications magazine, 29(11):42-46, 1991. 1

[TM17] Chin Tsai e Melody Moh. Load balancing in 5g cloud radio access networks supporting iot communications for smart communities. Em IEEE ISSPIT, páginas 259-264, 2017. 12

[TRB ${ }^{+}$17] R. I. Tinini, L. C. M. Reis, D. M. Batista, G. B. Figueiredo, M. Tornatore e B. Mukherjee. Optimal placement of virtualized BBU processing in hybrid Cloud-Fog RAN over TWDM-PON. Em GLOBECOM 2017 - 2017 IEEE Global Communications Conference, páginas 1-6, Dec 2017. 8, 23, 35

$\left[\mathrm{VCA}^{+} 17\right]$ L. Velasco, A. Castro, A. Asensio, M. Ruiz, G. Liu, C. Qin, R. Proietti e S. J. B. Yoo. Meeting the requirements to deploy cloud ran over optical networks. IEEE/OSA Journal of Optical Communications and Networking, 9(3):B22-B32, March 2017. 10

[WAC17] Xinbo Wang, Abdulrahman Alabbasi e Cicek Cavdar. Interplay of energy and bandwidth consumption in CRAN with optimal function split. Em Communications (ICC), 2017 IEEE International Conference on, 21-25 May 2017, Paris, France. IEEE conference proceedings, 2017. 11, 32 
[Way98] Winston I Way. Broadband Hybrid Fiber Coax Access System Technologies. Academic Press, Inc., 1998. 16

[WLLM14] Rui Wang, Han Hyub Lee, Sang Soo Lee e Biswanath Mukherjee. Energy saving via dynamic wavelength sharing in twdm-pon. IEEE Journal on Selected Areas in Communications, 32(8):1566-1574, 2014. 12

[Woo05] Robert Wood. Next-generation network services. Cisco Press, 2005. 15

$\left[\mathrm{WTT}^{+}\right.$16] Xinbo Wang, Saigopal Thota, Massimo Tornatore, Hwan Seok Chung, Han Hyub Lee, Soomyung Park e Biswanath Mukherjee. Energy-efficient virtual base station formation in optical-access-enabled Cloud-RAN. IEEE Journal on Selected Areas in Communications, 34(5):1130-1139, 2016. 5, 25, 32, 60

[WWC $\left.{ }^{+} 16\right]$ Xinbo Wang, Lin Wang, Cicek Cavdar, Massimo Tornatore, Gustavo B Figueiredo, Hwan Seok Chung, Han Hyub Lee, Soomyung Park e Biswanath Mukherjee. Handover reduction in virtualized cloud radio access networks using TWDM-PON Fronthaul. Journal of Optical Communications and Networking, 8(12):B124-B134, 2016. 10

[WZHW15] Jun Wu, Zhifeng Zhang, Yu Hong e Yonggang Wen. Cloud radio access network (C-RAN): a primer. IEEE Network, 29(1):35-41, 2015. 1, 2

[XLA13] Ping Xia, Chun-Hung Liu e Jeffrey G Andrews. Downlink coordinated multi-point with overhead modeling in heterogeneous cellular networks. IEEE Transactions on Wireless Communications, 12(8):4025-4037, 2013. 3

[XYH02] Dexiang Xu, Wei Yen e Elton Ho. Apparatus and method for protection of an asynchronous transfer mode passive optical network interface, Junho 13 2002. US Patent App. 09/864,671. 18

[ZQC $\left.{ }^{+} 17\right]$ Haijun Zhang, Yu Qiu, Xiaoli Chu, Keping Long e Victor CM Leung. Fog radio access networks: Mobility management, interference mitigation, and resource optimization. IEEE Wireless Communications, 24(6):120-127, 2017. 12 